\title{
Funktionelle Untersuchungen zum PTPN11-Genprodukt SHP2 und zu PTPN11 Mutanten, die dem Noonan-Syndrom zugrunde liegen
}

\author{
Dissertation \\ zur Erlangung des Doktorgrades \\ der Mathematisch-Naturwissenschaftlichen Fakultäten \\ der Georg-August-Universität zu Göttingen
}

vorgelegt von

Roser Ufartes Mas

aus Barcelona, Spanien

Göttingen, 2005 
D7

Referent: $\quad$ Prof. Dr. W. Engel

Korreferent: $\quad$ Frau PD Dr. Hoyer-Fender

Tag der mündlichen Prüfung: 19.01.2006 


\title{
Inhaltsverzeichnis
}

\author{
ABKÜRZUNGSVERZEICHNIS
}

FACHWORTVERZEICHNIS

1 EINLEITUNG

1.1 Das Noonan-Syndrom im klinischen Überblick

1.2 Das Noonan-Syndrom im genetischen Überblick

1.2.1 PTPN11-Mutationen bei Patienten mit verwandten Syndromen

1.3 Molekulare Ursachen für den NS-Phänotyp

1.3.1 Charakteristika von SHP2

1.4 Mausmodell für NS 6

$\begin{array}{lll}1.5 & \text { Ziele der Arbeit } & 7\end{array}$

2 MATERIAL UND METHODEN 8

2.1 Material $\quad 8$

$\begin{array}{ll}\text { 2.1.1 Chemikalien und Reagenzien } & 8\end{array}$

$\begin{array}{ll}\text { 2.1.2 Biochemikalien und Enzyme } & 10\end{array}$

2.1.3 Gebrauchswaren $\quad 11$

$\begin{array}{ll}\text { 2.1.4 Sterilisationsverfahren } & 11\end{array}$

2.1.5 Gebrauchsfertige Reaktionssysteme 12

2.1.6 Lösungen 12

$\begin{array}{ll}\text { 2.1.7 Längenstandards } & 18\end{array}$

2.1.8 Medien, Antibiotika, Agarplatten 19 
2.1.8.1 Medien für Bakterien $\quad 19$

$\begin{array}{ll}\text { 2.1.8.2 Medien für eukaryontische Zellkulturen } & 19\end{array}$

2.1.9 Biologisches Material 20

2.1.9.1 Bakterienstamm 20

$\begin{array}{ll}2.1 .9 .2 & \text { Eukaryontische Zelllinien } \\ & 20\end{array}$

2.1.10 Verwendete Vektoren, Gensonden und Antikörper 21

$\begin{array}{lll}2.1 .10 .1 & \text { Vektoren } & 21\end{array}$

$\begin{array}{ll}\text { 2.1.10.2 Konstrukte } & 21\end{array}$

2.1.10.3 cDNA-Fragmente für Southern Blot-Analysen 21

2.1.10.4 Antikörper 22

2.1.11 Synthetische Oligonukleotide 22

2.1.11.1 Oligonukleotide zur Analyse des PTPN11-Promoters 22

2.1.11.2 Oligonukleotide für die EMSA-Analyse 23

2.1.11.3 Oligonukleotide für die Mutationsanalyse 24

2.1.11.4 Oligonukleotide für die PCR-Mutagenese 25

2.1.11.5 Oligonukleotide zur Herstellung von shRNA-Kontrukten 26

2.1.11.6 Oligonukleotide zur Herstellung des transgenen Mäuse 26

2.1.11.7 Oligonukleotide für die Taqman-Analyse 28

$\begin{array}{ll}2.1 .12 \text { Mausstämme } & 29\end{array}$

2.1.13 Herkunft des Patientenmaterials 29

2.1.14 Datenbanken und Analyse-Software $\quad 29$

$\begin{array}{ll}2.2 \text { Methoden } & 31\end{array}$

2.2.1 Isolierung und Aufreinigung von Nukleinsäuren 31

2.2.1.1 Isolierung von genomischer DNA aus Gewebe 31

2.2.1.2 Minipräparation von Plasmid-DNA 31

2.2.1.3 Herstellung von Bakterien-Glycerin-Stocks 32

2.2.1.4 Midipräparation von Plasmid-DNA 32

2.2.1.5 Ethanolfällung von DNA aus wässrigen Lösungen 32

2.2.1.6 Isolierung von Gesamt-RNA aus Gewebe 33

2.2.1.7 Isolierung von Gesamt-RNA aus EDTA-Blut 33

2.2.1.8 Isolierung von DNA-Fragmenten aus Agarosegelen 33

2.2.1.9 Konzentrationsbestimmung von Nukleinsäuren 34

2.2.2 Enzymatische Modifikation von DNA 34 
2.2.2.1 Spaltung von DNA mit Restriktionsendonukleasen 34

2.2.2.2 Auffüllreaktion von DNA-Fragmenten 35

2.2.2.3 Dephosphorylierung von Plasmid-DNA 35

2.2.2.4 Ligation von DNA-Fragmenten 35

2.2.2.5 Subklonierung von PCR- und RT-PCR-Produkten 36

2.2.2.6 Transformation kompetenter Zellen mit Plasmid-DNA 37

2.2.2.7 Radioaktive Random prime-Markierung von Nukleinsäuren 37

2.2.2.8 Radioaktive Endmarkierung von Oligonukleotiden 37

$\begin{array}{ll}\text { 2.2.2.9 DNaseI-Behandlung } 38 & 38\end{array}$

2.2.3 Gelelektrophorese $\quad 39$

2.2.3.1 Gelelektrophorese von DNA 39

2.2.3.2 Native Polyacrylamid-Gelelekrophorese 39

2.2.4 Transfertechniken von Nukleinsäuren $\quad 40$

2.2.4.1 Southern Blot-Analyse $\quad 40$

2.2.4.2 Hybridisierung mit radioaktiv markierten DNA-Sonden $\quad 40$

2.2.5 Polymerase-Kettenreaktion (PCR) 41

2.2.5.1 DNA-Amplifikation mittels Polymerase-Kettenreaktion 41

2.2.5.2 PCR-Mutagenese 42

2.2.5.3 Reverse Transkription 43

2.2.5.4 Quantitative real time-PCR 43

$\begin{array}{ll}\text { 2.2.5.5 DNA-Sequenzanalyse } & 47\end{array}$

2.2.6 Proteinchemische Techniken 48

2.2.6.1 Isolierung von Gesamtprotein aus Zellkulturen 48

2.2.6.2 Isolierung von Kernproteinen aus kultivierten Zellen 48

2.2.6.3 Isolierung von Gesamtprotein aus Organen der Maus 49

2.2.6.4 Transkription und Translation in vitro 49

2.2.6.5 Konzentrationsbestimung von Proteinen 50

2.2.6.6 Acetonfällung von Proteinen 51

2.2.6.7 SDS-Polyacrylamidgelelektrophorese (SDS-PAGE) 51

2.2.6.8 Western Blot-Analyse von Proteinen auf Nitrocellulose-Membranen 52

2.2.6.9 Färbung von Proteingelen 52

2.2.6.10 Inkubation von membrangebundenen Proteinen mit Antikörpern 52

2.2.6.11 Enzyme-Linked Immuno-absorbant Assay (ELISA): 53

2.2.6.11.1 Indirekter ELISA 53

2.2.6.11.2 Enzym-Antigen-Assay: DiFMUP -Nachweis 54 
2.2.6.12 Malachit-Grün Phosphatase-Assay

2.2.7 Elektrophoretischer Mobilitäts-Shift-Assay (EMSA) 56

2.2.8 Zellbiologische Methoden 58

2.2.8.1 Zellkultur eukaryontischer Zellen $\quad 58$

2.2.8.2 Kryokonservierung und Revitalisierung eukaryontischer Zellen 58

2.2.8.3 Transfektion eukaryontischer Zellen 58

2.2.8.4 Transformation von humanen Lymphozyten durch EBV 59

2.2.8.5 Herstellung von Interleukin-Medium aus der Milz der Ratte 60

2.2.9 Quantitativer Nachweis von Reporter-Enzymen 60

2.2.9.1 Messung der Luciferase-Aktivität $\quad 61$

2.2.9.2 Messung der $\beta$-Galaktosidase-Aktivität 61

2.2.10 Herunterregulierung der Genexpression mittels RNA-Interferenz 62

2.2.10.1 Überblick über den Mechanismus von RNAi 62

2.2.10.2 Entwicklung der Hairpin-Oligonukleotide 64

2.2.11 Erzeugung transgener Mäuse 64

2.2.11.1 Vorbereiten der DNA zur Mikroinjektion 64

3 ERGEBNISSE $\quad 66$

3.1 Untersuchung des PTPN11-Promotors 66

$\begin{array}{ll}\text { 3.1.1 Bioinformatik } & 66\end{array}$

3.1.1.1 Analyse der Homologie zwischen murinem, humanem und Ratten-Promotor von $\begin{array}{ll}\text { PTPN11 } & 66\end{array}$

3.1.1.2 Putative Bindungsstellen von Transkriptionsfaktoren 68

3.1.2 Experimentelle Bestätigung des Minimalpromotors von PTPN11 70

3.1.3 Identifizierung von Bindungsstellen für die Transkriptionsfaktoren SP1, CREB und $\begin{array}{ll}\text { STAT im PTPN11-Promotor } & 73\end{array}$

$\begin{array}{ll}\text { 3.1.3.1 Supershift-Experimente } & 76\end{array}$

$\begin{array}{ll}\text { 3.1.3.2 Mutationsanalyse } & 76\end{array}$

3.1.3.3 Mutationssuche im PTPN11-Promotor bei Noonan-Patienten 78

3.2 Identifizierung von großen Deletionen im PTPN11-Gen 79

$\begin{array}{ll}\text { 3.2.1 Taqman-Analyse } & 80\end{array}$ 
3.2.2 Verifizierung der Ergebnisse der quantitativen real time-PCR-Analysen bei den Patienten 24633, 24640 und 24653

3.2.2.1 Longrange PCR-Analyse 81

3.2.2.2 Southern Blot-Analysen

\subsection{Bestimmung der Phosphatase-Aktivität von SHP2}

3.3.2 Allelspezifische Inhibition von PTPN11-Mutanten durch siRNA

3.3.3 Messung der SHP2 Phospatase-Aktivität mittels Malachit-Grün-Assay 90

3.3.3.1 Expression von rekombinanten SHP2-Proteinen

3.3.3.2 Messung der SHP2-Phosphatase-Aktivität von Patienten-Material

3.3.3.3 ELISA zur Bestimmung der Phosphatase-Aktivität von SHP2 in Patienten-Material 94

3.4 Herstellung eines transgenen Mausmodells für das Noonan-Syndrom

3.4.2 PCR zur Genotypisierung der F0-(Founder) und F1-Generation der transgenen PTPN11-Mäuse

3.4.3 Nachweis der Expression des transgenen NS1-Konstruktes in NIH/3T3-Zellen

3.4.4 Nachweis der Funktionalität der transgenen NS1-, NS2- und NS3-Fusionsproteine über einen SOCS-1-Luciferase-Assay

3.4.5 Relative Kopienzahlbestimmung an genomischer DNA der verschiedenen Founder

(F0) und ausgewählter Verpaarungen

3.4.6 Bestimmung der Zahl der Integrationen der NS1-, NS2- und NS3-Konstrukte im

Genom durch Taqman- und Southern Blot-Analyse

3.4.7 Expressionsanalysen in NS1-, NS2- und NS3-transgenen Mäusen

3.4.7.1 Analyse der Expression der transgenen PTPN11-Varianten auf RNA-Ebene

3.4.7.2 Untersuchung der Expression der transgenen SHP2-Varianten auf Proteinebene 
4.2 SHP2: Signalwege und biologische Funktionen

4.2.1 Gruppe der IL-6-Typ-Zytokine

4.4 Große Deletionen im PTPN11-Gen als Ursache für das Noonan-Syndrom?

4.5 Wirkung der Überaktivität des mutierten SHP2 


\section{Abkürzungsverzeichnis}

A

Abb.

Amp

APS

AS

ATP

BLAST

BLAT

bp

BSA

bzw.

${ }^{\circ} \mathrm{C}$

ca.

cDNA

$\mathrm{Ci}$

$\mathrm{cm}$

CpG

Da

CREB

dATP

dCTP

ddNTP

del

DEPC

dest

dGTP

d.h.

DHPLC

DMSO

DNA

DNAse
Ampere

Abbildung

Ampicillin

Ammoniumperoxodisulfat

Aminosäure

Adenosintriphosphat

basic local alignment search tool

BLAST-like alignment tool

Basenpaar

Rinderserumalbumin

beziehungsweise

Grad Celsius

circa (ungefähr)

komplementäre DNA

Curie

Zentimeter

Cytidin-Phosphat-Guanosin-Dinukleotide

Dalton

Cyclic AMP (cAMP) response element binding

Desoxyadenosintriphosphat

Desoxycytosintriphosphat

Didesoxy-Nukleotidtriphosphat

Deletion

Diethylpyrocarbonat

Destilliert

Desoxyguanosintriphosphat

Das heisst

denaturierende Hochleistungs-Flüssigkeitschromatographie

Dimethylsulfoxid

Desoxyribonukleinsäure

Desoxyribonuklease 


\begin{tabular}{|c|c|}
\hline dNTPs & Desoxynukleotidtriphosphate \\
\hline ds & doppelsträngig \\
\hline DTT & 1,4-Dithiothreitol \\
\hline dTTP & Desoxythymidintriphosphat \\
\hline EBV & Epstein-Barr-Virus \\
\hline E.coli & Escherichia coli \\
\hline ECR & Evolunationary Conserved Regions \\
\hline EDTA & Ethylendiamintetraessigsäure \\
\hline EGTA & Ethylenglycol-bis (ß-Aminoethylether)-Tetraace \\
\hline ELISA & Enzyme linked immuno-absorbant-assay \\
\hline EMBL & European Molecular Biology Laboratory \\
\hline EMSA & Elektrophoretisxcher-Mobilitäts-Shift-Assay \\
\hline EST & expressed sequence tag \\
\hline et al. & et alteri (und andere) \\
\hline Etbr & Ethidiumbromid \\
\hline $\mathrm{EtOH}$ & Ethanol \\
\hline Fa. & Firma \\
\hline FKS & Fötales Kälberserum \\
\hline g & Gramm, Erdbeschleunigungskonstante \\
\hline h & Stunde \\
\hline IPTG & Isopropyl- $\beta$-thiogalactopyranosid \\
\hline $\mathrm{K}$ & Kilo \\
\hline $\mathrm{kb}$ & Kilobasenpaare \\
\hline $\mathrm{KDa}$ & Kilodalton \\
\hline 1 & Liter \\
\hline LB & Luria-Bertani \\
\hline Luc & Luciferase \\
\hline $\mathrm{m}$ & milli $=10^{-3}$ \\
\hline M & Molar \\
\hline $\mathrm{mA}$ & Milliampere \\
\hline MCS & multiple cloning site \\
\hline$\mu$ & Mikro $=10^{-6}$ \\
\hline $\min$ & Minute \\
\hline MOPS & Morpholinopropansulfonsäure \\
\hline
\end{tabular}




\begin{tabular}{|c|c|}
\hline mRNA & messenger RNA = Boten-RNA \\
\hline $\mathrm{n}$ & nano $=10^{-9}$ \\
\hline $\mathrm{NaAc}$ & Natriumacetat \\
\hline NCBI & The National Center for Biotechnology Information \\
\hline Nr. & Nummer \\
\hline $\mathrm{nt}$ & Nukleotide \\
\hline OD & Optische Dichte \\
\hline OMIM & Online Mendelian Inheritance in Man \\
\hline $\mathrm{p}$ & pico $=10^{-12}$ \\
\hline PAGE & Polyacrylamidgelelektrophorese \\
\hline PAA & Polyacrylamid \\
\hline PBS & Phosphat-gepufferte Kochsalzlösung \\
\hline PCR & Polymerase-Kettenreaktion \\
\hline $\mathrm{pH}$ & Negativer dekadischer Logarithmus der Protonenkonzentration \\
\hline pSU6 & pSIlencer $^{\mathrm{TM}}$ 1.0-U6 siRNA Expressionsvektor \\
\hline RNA & Ribonukleinsäure \\
\hline RNase & Ribonuklease \\
\hline rpm & revolutions per minute, Umdrehungen pro Minute \\
\hline $\mathrm{RT}$ & Raumtemperatur; reverse Transkription \\
\hline $\mathrm{s}$ & Sekunde \\
\hline SDS & Natriumdodecylsulfat \\
\hline siRNA & small interfering RNA \\
\hline sog. & sogenannt \\
\hline SS & einzelsträngig \\
\hline SSC & Standard saline citrat (-Puffer) \\
\hline Tab. & Tabelle \\
\hline Taq & Thermus aquaticus \\
\hline TBE & Tris-Borat-EDTA (-Puffer) \\
\hline TBS & Tris-gepufferte Kochsalzlösung \\
\hline $\mathrm{TE}$ & Tris-EDTA (-Puffer) \\
\hline TEMED & Tetramethylethylendiamin \\
\hline Tris & Tris-hydroxymethyl-aminomethan \\
\hline Twenn 20 & Polyoxyethylensorbitanmonooleat \\
\hline $\mathrm{U}$ & Unit $=$ definierte Enzymeinheit \\
\hline
\end{tabular}


u.a.

ÜN

UTR

UV

V

$\mathrm{v} / \mathrm{v}$

Vol

$\mathrm{w} / \mathrm{V}$

WT

X-GAL

z.B.

z.T. unter anderem

über Nacht

nicht translatierte Region

ultraviolettes Licht

Volt

Volumen pro Volumen

Volumen

Gewicht pro Volumen

Wildtyp

5-Brom-4-Chlor-3-Indolyl- $\beta$-D-Galactopyranosid

zum Beispiel

zum Teil 


\section{Fachwortverzeichnis}

Englische Fachbegriffe der Molekularbiologie werden, soweit sinnvoll, auch als solche verwendet und nicht ins Deutsche übersetzt, da deutsche Ersatzwörter oftmals unwissenschaftlich klingen und nur eine Umschreibung dessen sind, was im Englischen mit einem Wort ausgedrückt werden kann. Die Bedeutung dieser Fachbegriffe wird hier nochmals aufgeführt, sofern dies nicht im Text geschieht.

Alignment

Annealing

Antisense

Assay

Downstream

Elongation

Full length

Housekeeping
Wörtlich übersetzt: anordnen, abgleichen

Zwei oder mehrere Sequenzen werden so angeordnet, dass sie bestmöglich übereinstimmen. Auf diese Weise können gleiche oder komplementäre Sequenzen oder Sequenzbereiche ermittelt werden.

Wörtlich übersetzt: ausglühen, härten

Primer-Anlagerung während der PCR

Komplementär zum kodierenden Nukleinsäurestrang

Wörtlich übersetzt: untersuchen, Untersuchung

Test, Versuchsreihe

Wörtlich übersetzt: stromabwärts

In einer Kaskade: unterhalb, als nachgeschalteter Faktor

Bei einem Gen: weiter 3’ gelegen

Wörtlich übersetzt: Verlängerung

Hier: DNA-Strang-Verlängerung während der PCR

Wörtlich übersetzt: Volle Länge

Hier: das gesamte Protein oder kompletten kodierenden

Bereich einer cDNA betreffend

Wörtlich übersetzt: Haushalt

Ein housekeeping-Gen ist ein konstitutiv exprimiertes Gen, das in allen Zellen essentiell ist. 
In frame

Primer

Proofreading

Real time

Sandwich

Screening

Second messenger

Sense

Silencing
Wörtlich übersetzt: im Rahmen

Bei der Herstellung eines Fusionsproteins muss darauf geachtet werden, dass bei der Klonierung der nachgeschalteten cDNA der Leserahmen der vorgeschalteten cDNA eingehalten wird.

Oligonukleotid von 20-35 Basenpaaren, welches von Polymerasen als Starthilfe zum Ansynthetisieren weiterer Nukleotide genutzt wird.

Wörtlich übersetzt: Korrekturlesen

Polymerasen mit einer Proofreading-Aktivität sind in der Lage, falsch eingebaute Nukleotide über ihre $3^{\prime}-5^{\prime}$ Exonuklease-Aktivität zu entfernen.

Wörtlich übersetzt: Echtzeit

Während der PCR kann die Zunahme der Amplifikate auf einem Monitor in Echtzeit verfolgt werden

Wörtlich übersetzt: belegtes Brot

Hier: Art des Aufbaus beim Western und Northern BlotTransfer. Die Membran wird zwischen Whatman-Papier + Gel und Whatman-Papier gelegt.

Wörtlich übersetzt: (durch)sieben, untersuchen

Hier: Durchsuchen einer Bibliothek nach bestimmten

Proteinen und Genen

Botenstoff, der in Reaktion auf extrazelluläre Signale in der Zelle gebildet wird und die Signalkaskade verstärkt fortsetzt

Entspricht dem kodierenden Nukleinsäurestrang

Wörtlich übersetzt: zum Schweigen bringen

Bei der Transkription: Umstände, die die Transkription eines Gens unterdrücken 
Template

Upstream

Yeast-two-hybrid-screening
Wörtlich übersetzt: Schablone, Vorlage, Matrize

Hier: RNA oder DNA, die während einer PCR amplifiziert werden soll

Wörtlich übersetzt: stromaufwärts

In einer Kaskade: oberhalb, als vorgeschalteter Faktor

Bei einem Gen: weiter 5'-gelegen

Hefesystem, um Proteine nachzuweisen, die an ein bestimmtes Protein, das untersucht werden soll, binden. 


\section{Einleitung}

\subsection{Das Noonan-Syndrom im klinischen Überblick}

Das Noonan-Syndrom (NS) ist ein komplexes Fehlbildungssyndrom, das durch ein charakteristisches Gesicht mit Hypertelorismus und Ptosis, großen und tief sitzenden Ohren, Kleinwuchs, leichter geistiger Behinderung, Kryptorchismus und verschiedene Herzfehlbildungen (vor allem Pulmonalstenosen und hypertrophische Kardiomyopathie) gekennzeichnet ist (Abb. 1.1). In der Tabelle 1.1 sind die klinischen Eigenschaften des NS dargestellt. Aufgrund der Ähnlichkeit mit dem Ullrich-Turner-Syndrom (45,X-Syndrom), bezeichnet man das NS auch als Pseudo-Turner-Syndrom. Im Gegensatz zum Ullrich-TurnerSyndrom sind die Chromosomen jedoch unauffällig. Das NS betrifft beide Geschlechter gleich häufig. Die Bezeichnung geht auf die Kinderkardiologin Jacqueline Noonan zurück, die der Erkrankung im Jahr 1963 ihren Namen gab [Noonan et al., 1963].

A.

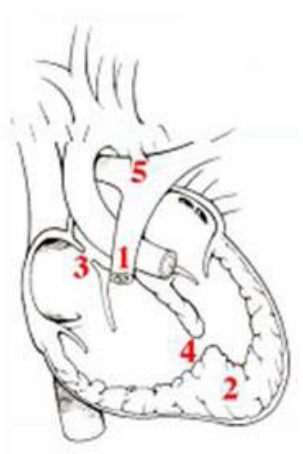

B.

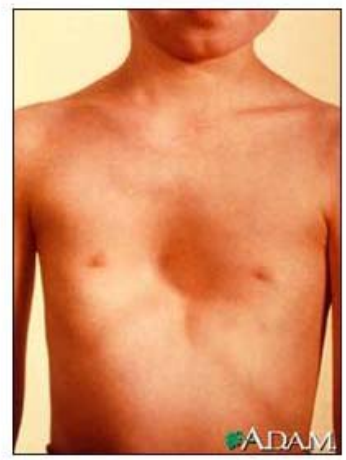

C.

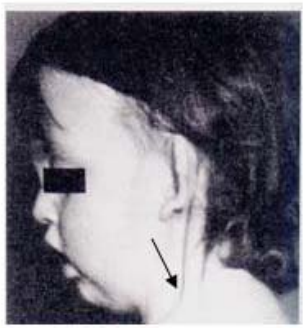

D.

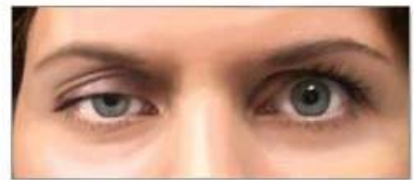

Abb. 1.1: Darstellung der klinischen Zeichen des NS: A. Häufigste Herzfehlbildungen (G.Kampino, MD, Università Cattolica del Sacro Cuore, Rome, Italien). 1. Pulmonalstenose; 2. HypertrophischeKardiomyopathie; 3. Atriumseptumdefekt (ASD); 4. Ventrikelseptumdefekt (VSD); 5. Persistierender Ductus arteriosus (PDA). B. Trichterbrust (www.nlm.nih.gov/medlineplus). C. Flügelhals (Klinisches Wörterbuch). D. Ptosis (www.nlm.nih.gov/medlineplus). 


\section{Klinische Eigenschaften}

$\begin{array}{ll}\text { Dysmorphien } & \text { Epicanthus } \\ & \text { Ptose } \\ & \text { nach lateral abfallende Lidachsen } \\ & \text { dreieckige Gesichtsform } \\ & \text { große, tief sitzende Ohren } \\ & \text { helle Augenfarbe } \\ & \text { lockiges, dickes Haar } \\ & \text { Kongenitale Herzfehler }\end{array}$

Pulmonalstenose

Atriumseptumdefekt (ASD)

Mitralklappendefekt

Fallot'sche Tetralogie

Ventrikelseptumdefekt (VSD)

Persistierender Ductus arteriosus (PDA)

Minderwuchs

rtrophische

Kardiomyopathie (HCM)

Hals

Flügelhals

Tiefer Haaransatz

Skelett

Pectus excavatum

Cubitus valgus

Skoliose

Kryptorchidismus

Wirbelkörperanomalien

Fütterungsprobleme

Neurologie

Mentale Retardierung

Aufmerksamkeits-Defizit-

/Hyperaktivitäts-Syndrom

Gerinnungsstörungen Thrombozytopenien

Isolierte oder kombinierte

Defizienz an Faktor VIII, XI oder

XII

Leukämie

Ophthalmologie

Strabismus

Myopie

Hörstörungen

Tab. 1.1: Mögliche Symptome beim Noonan-Syndrom [Tartaglia et al., 2005] 


\subsection{Das Noonan-Syndrom im genetischen Überblick}

In großen holländischen und belgischen Noonan-Familien mit dominanter Vererbung wurde durch Kopplungsanalysen ein Locus für das NS verursachendes Gen auf Chromosom 12 identifiziert und weiter auf 12q24 eingegrenzt [Jamieson et al.,1994; Legius et al., 1998]. Im November 2001 wurde von Tartaglia et al. [2001] gezeigt, dass Mutationen im PTPN11-Gen bei ca. 40-50\% der Patienten mit NS zu finden sind. Da einerseits in einigen Familien mit dominanter Vererbung des NS keine PTPN11-Mutationen gefunden wurden und andererseits in einigen Familien ein rezessiver Erbgang wahrscheinlich ist [van der Brugt et al., 2000], müssen weitere Loci und eine genetische Heterogenität für das NS angenommen werden [Schlüter et al., 2003].

Bislang wurden 39 verschiedene PTPN11 missense-Mutationen und zwei TrinukleotidDeletionen gefunden. Die meistens Mutationen treten in Exon 3, 7, 8 und 13 auf, wobei N308D als häufigste Mutation bei ca. 25\% der Patienten zu finden ist. In Abbildung 1.2 [Tartaglia et al., 2005] sind die Mutationen in PTPN11 bei NS und verwandten Syndromen zusammengefaßt (1.2.1).

\section{PTPN11}

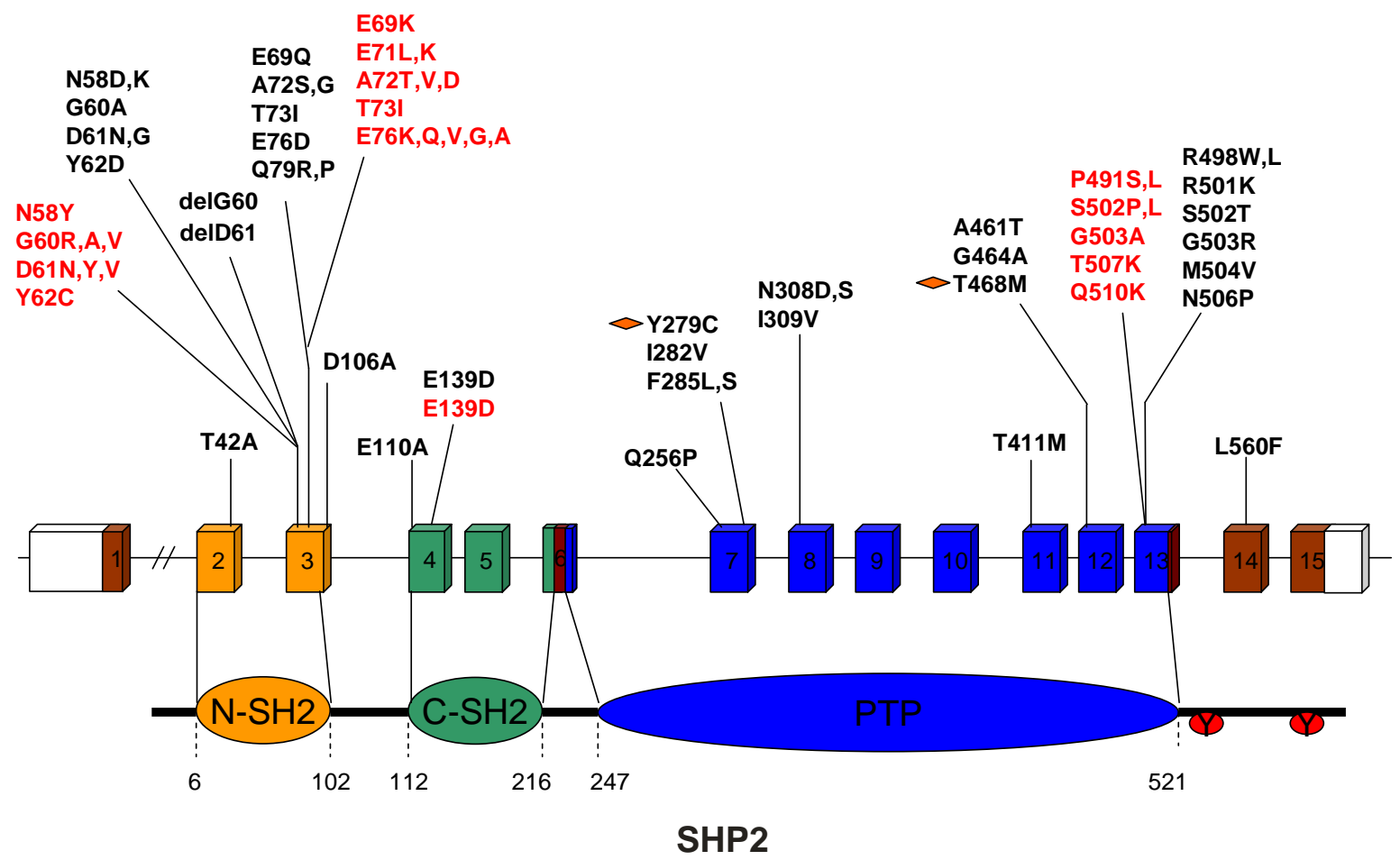

Abb. 1.2: Übersichtsdarstellung des PTPN11-Gens und des zugehörigen SHP2-Proteins. Gezeigt sind die Mutationen im NS, verwandten Syndromen und Formen der Leukämien [Tartaglia et al., 2005]. Schwarze Schrift: NS, LS $(\diamond)$; Rote Schrift: Somatische Mutationen bei Leukämien. Abkürzungen: N-SH2: N-terminale SH2-Domäne; C-SH2: C-terminale SH2-Domäne; PTP: Tyrosin-Phosphatase-Domäne 


\subsubsection{PTPN11-Mutationen bei Patienten mit verwandten Syndromen}

Mutationen in PTPN11 sind bei zwei verschiedenen Phänotypen ähnlich dem NS entdeckt worden: Noonan syndrome with multiple giant cell lesions in bone (NL/MGCLS; OMIM 163955) und LEOPARD-Syndrom (LS; OMIM 151100).

Zum ersten Mal wurde von Tartaglia et al. [2002] die Mutation N308S in einer Familie mit NL/MGCLS und bei zwei Patienten mit sporadischem NS gefunden. Später wurden von dieser Arbeitsgruppe drei weitere Familien mit diesem Phänotyp analysiert und bei zwei dieser Familien ebenfalls die Mutation N308S gefunden. Lee et al. [2005]. untersuchten drei Patienten mit NL/MGCLS und fanden bei zwei Patienten die Mutationen D106A und F285L. Beim LEOPARD-Syndrom (lentigenes, electrocardiografic conduction abnormalities, ocular hypertelorism, pulmonary stenosis, abnormal genitalia, retardation of growth, sensorineural deafness) zeigen sich neben den Symptomen des NS zusätzlich multiple Lentigenes, café-aulait-Flecken der Haut, HCM (hypertrophe Kardiomyopathie), Atrioventrikuläre Überleitungsstörungen und Taubheit. Die Untersuchung von acht Patienten mit LS zeigte in sieben Patienten eine missense-Mutation in PTPN11. Weiterhin wurden NS-Patienten mit café-au-lait-Flecken analysiert. Drei von diesen neun Patienten besaßen die Mutation Y279C und die anderen sechs zeigten T468M [Digilio et al., 2002]. Die Mutationen Y279C und T468M sind die typischen Mutationen, die bei LS-Patienten gefunden werden. Die molekulargenetischen Befunde haben den bereits aufgrund klinischer Ähnlichkeiten bestehenden Verdacht bestätigt, dass das LS und das NS allelische Syndrome sind.

Aufgrund gewisser phänotypischer Ähnlichkeiten mit NS wurden Patienten mit dem CardioFacial-Cutane-Syndrom (CFC) [Kavamura et al., 2002; Ion et al., 2003] auf Mutationen in PTPN11 hin analysiert, jedoch konnte keine Mutation nachgewiesen werden [Fryer et al., 1991; Ward et al., 1994; Leichtman, 1996; Neri et al., 1996; Wieczorek et al., 1997]. Auf die gleiche Weise wurde das Costello-Syndrom für PTPN11 analysiert, aber auch hier wurde keine Mutation entdeckt [Tartaglia et al., 2003; Troger et al., 2003].

Kinder mit NS sind für juvenile myelomonocytäre Leukämie (JMML) und möglicherweise auch für andere Formen der Leukämien (akute lymphoblastische Leukämie (ALL), akute myeloische Leukämie (AML), myelodysplastisches Syndrom (MDS)) empfänglich [Tartaglia et al., 2005]. Bei JMML-Patienten und AML-Patienten mit oder ohne NS wurde daher das PTPN11-Gen analysiert und missense-Mutationen gefunden. 34\% der JMML-Patienten zeigten eine Mutation in PTPN11. Auch 10\% bzw. 4\% der Patienten mit MDS und AML weisen solche Mutationen auf. Bei NS/JMML wurden die Mutationen auch in nicht 
hämatopoetischen Geweben gefunden, d.h. die Mutationen stellen Keimbahn-Mutationen dar. Im Gegensatz dazu wurden bei JMML-Patienten ohne Zeichen eines NS die Mutationen lediglich in den malignen hämatopoetischen Zellen gefunden, d.h. die Mutationen sind somatische Mutationen [Tartaglia et al., 2003; Loh et al., 2004 und 2005].

\subsection{Molekulare Ursachen für den NS-Phänotyp}

\subsubsection{Charakteristika von SHP2}

Mutationen im PTPN11-Gen finden sich bei $40-50 \%$ der Noonan-Patienten. Das PTPN11Gen (OMIM 176876) erstreckt sich über $90 \mathrm{~kb}$ und besteht aus 16 Exons. Die humane PTPN11-mRNA hat einen offenen Leserahmen von 1782 bp, der für ein Protein (SHP2) mit 593 Aminosäuren kodiert. SHP2 wird ubiquitär exprimiert und wirkt in der Signalvermittlung zwischen Rezeptoren für Wachstumsfaktoren, Hormonen und Zytokinen und dem Zellkern. SHP2 besteht aus zwei Src-homology-2 (SH2)-Domänen (N-SH2 und C-SH2), einer Phosphatase-Domäne (PTP) und einem carboxyterminalen Bereich, der zwei TyrosinPhosphorylierungsstellen (AS-Position 542 und 580) enthält. Die Bindung der N-SH2Domäne an ein Phosphotyrosin-Motiv fördert die Interaktion mit anderen Proteinen (Tyrosinkinase-Rezeptoren, Zytokinrezeptoren, transmembrane regulatorische Proteine, Zelladhäsionsmoleküle, inhibitorische Rezeptoren und scaffolding adapters (insulin receptor substrate (IRS), Grb2-associated binder (Gab) und Proteinen der fibroblast growth factor receptor substrate (FRS)-Familie). Zudem findet eine Relokalisierung von SHP2 an die Zellmembran statt. Die Analyse der Kristallstruktur von SHP2 zeigt, dass die N-SH2-Domäne wechselseitig mit zwei verschiedenen Liganden interagieren kann: eine intermolekulare Interaktion mit Phosphotyrosin-Motiven anderer Proteine und eine intramolekulare Interaktion mit der PTP-Domäne des eigenen Moleküls [Hof et al., 1998]. N-SH2 stellt daher einen konformativen Schalter dar: entweder interagiert N-SH2 mit der PTP-Domäne und hemmt diese, oder verbindet sich mit einem Phosphotyrosin-Motiv von Signalpartnern (z.B. Gab1) und lässt die Phosphatase-Domäne frei und aktiv. Die C-SH2-Domäne hat keine direkte Rolle in der Aktivierung der Phosphatase-Domäne. Sie stellt Bindungsenergie bereit, damit die N-SH2-Domäne eine zweite Stelle binden kann. 


\subsubsection{Einfluß der Mutationen in PTPN11 auf die Funktion von SHP2}

Die meisten PTPN11-Mutationen liegen im Interaktionsbereich zwischen den Domänen NSH2 und PTP. Diese Mutationen verhindern die Bindung zwischen N-SH2 und PTP, was zu einer permanenten Aktivierung von SHP2 führt. Diese SHP2-Überaktivität (gain of function) soll zur Pathogenese von NS beitragen [Tartaglia et al., 2001 und 2002]. Bislang wurden keine non-sense-, framshift- oder splicing-Defekte in PTPN11 entdeckt, auch keine Mutationen in für die Phosphatase-Aktivität von SHP2 notwendigen Aminosäuren. Eine Haploinsuffizienz als Ursache für NS und für verwandte Syndrome kann daher weitgehend ausgeschlossen werden.

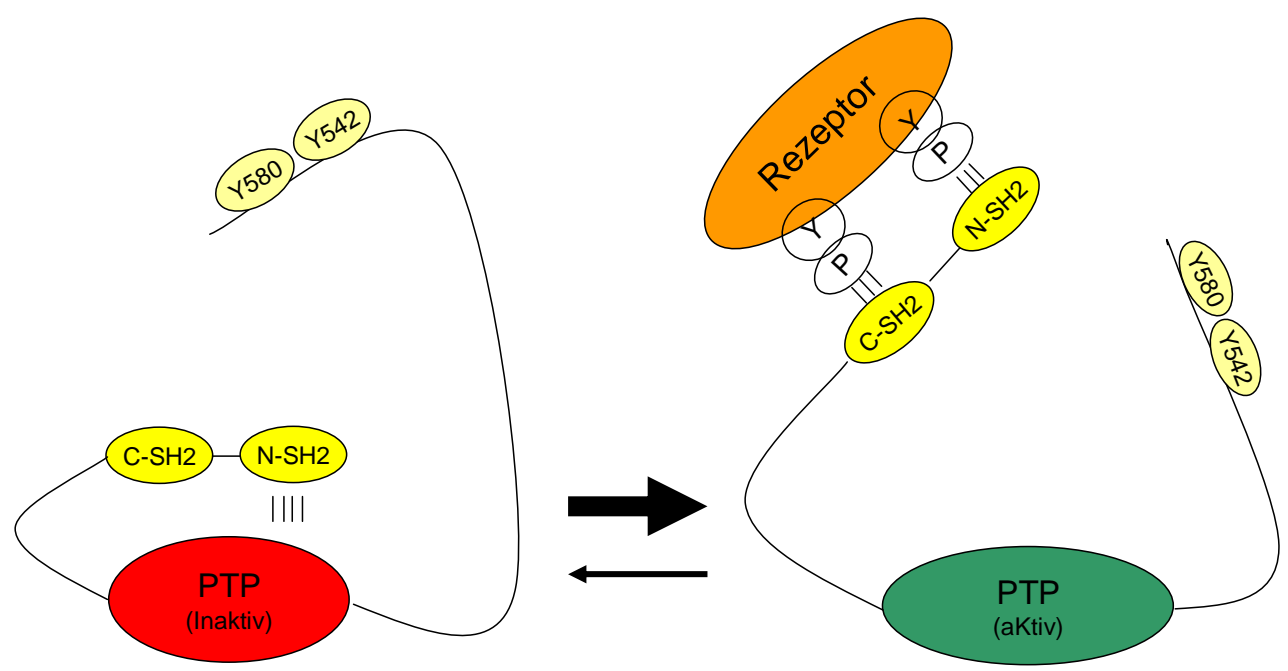

Abb. 1.3: Übersichtsdarstellung der biochemischen Mechanismen von SHP2. Gezeigt sind die Proteindomänen von SHP2 mit den zwei möglichen Konformationen: aktiv oder inaktiv. SHP2 schaltet zwischen einer inaktiven Form, N-SH2 interagiert mit der katalytischen PTP-Domäne und inhibiert diese, oder einer aktiven Form, N-SH2 bindet das Phosphotyrosin-Motiv von Signalpartnern und die Phosphatase-Domäne ist frei und aktiv. Bei Mutationen in PTPN11 befindet sich SHP2 in einer permanenten aktiven Form. Gelb: N-SH2 und C-SH2; rot/grün: inaktive oder aktive PTP-Domäne; Ockergelb: Tyrosin-Phosphorylierungsstellen (AS-Position 542 und 580).

\subsection{Mausmodell für NS}

Araki et al. [2004] beschrieben eine knock-in-Maus mit der D61G-Mutation. Sowohl PTPN11 ${ }^{\text {D61G/D61G }}$-Mäuse als auch PTPN11 ${ }^{\text {D61G/+}}$-Mäuse zeigen einen auffälligen Phänotyp. PTPN11 ${ }^{\text {D61G/D61G }}$-Tiere sind embryonal letal. Es zeigen sich ödematöse, bluthaltige und Leber-Nekrosen am Tag E13, 5. Es wurden verschiedene kardiovaskuläre Anomalien wie z.B. 
Septumdefekte und ein dünneres Myokard beobachtet. Bei PTPN11 ${ }^{\mathrm{D} 1 \mathrm{G} /{ }^{+}}$-Tieren wurden Minderwuchs und Gesichtsdysmorphien gefunden. Die Tiere zeigen eine ausgeprägte Variabilität im Phänotyp, was auf die Wirkung von modifizierenden Genen hindeutet.

\subsection{Ziele der Arbeit}

Im Rahmen der vorliegenden Arbeit sollten drei Aspekte untersucht werden. Im ersten Teil der Arbeit stand die Untersuchung unbekannter Ursachen des NS im Vordergrund. Sowohl die Mutationen im PTPN11-Promotor als auch große Deletionen wurden als fragliche Ursachen für das NS in Betracht gezogen. Der zweite Teil der Arbeit konzentrierte sich auf die Bestimmung der Phosphatase-Aktivität von SHP2-Varianten in vitro mit Hilfe eines SOCS1-Luciferase-Assays und eines Malachit-Grün-Assays. Bei gain of function bot sich der Versuch der allelspezifischen Inhibition von PTPN11-Mutanten mit Hilfe der RNAi-Technik an. Schließlich sollte ein Mausmodell für das NS und das LS etabliert werden, da es zu Beginn dieser Arbeit noch kein Mausmodell gab. Da bisher unklar ist, ob nur mutiertes PTPN11 NS auslöst oder auch eine Überexpression von WT-PTPN11 Symptome auslösen kann, sollte auch eine transgene Maus mit Überexpression von WT-PTPN11 generiert werden. 


\section{Material und Methoden}

\subsection{Material}

\subsubsection{Chemikalien und Reagenzien}

Alle Substanzen, die nicht aufgeführt sind, wurden von den Firmen Roth (Karlsruhe) und Sigma-Aldrich (Deisenhofen) bezogen.

Chemikalien

ABTS

Acrylamid-Bis 40\% (29:1)

Acrylamid/bis-Lösung 40\% (19:1)

Acetonitril HPLC Qualität

Agar

Agarose

Ampicillin

Ampuwa

Bacto-Trypton

1-Bromo-3-chloropropan (BCP)

Bromphenolblau

Chloroform

Coomassie-Brilliant Blau R250

Cyclosporin-A

Diethylpyrocarbonat (DEPC)

Dimethylsulfoxid (DMSO)

DPBS

Dithiothreitol (DTT)

dNTPs (100 mM)

EDTA

EGTA

Entwickler

\section{Hersteller}

Sigma-Aldrich, Deisenhofen

Roth, Karlsruhe

Roth, Karlsruhe

Tansgenomics, Berlin

Roth, Karlsruhe

Invitrogen, Karlsruhe

Roth, Karlsruhe

Fresenius AG, Bad Homburg

Roth, Karlsruhe

Fluka, Neu-Ulm

Fluka, Neu-Ulm

Baker, Deventer (NL)

Fluka, Neu-Ulm

Sigma-Aldrich, Deisenhofen

Sigma-Aldrich, Deisenhofen

Merck, Darmstadt

PAN Biotech, Aidenbach

Biomol, Hamburg

Invitrogen, Karlsruhe

ICN, Aurora, USA

Sigma-Aldrich, Deisenhofen

Kodak, Darmstadt 


\begin{tabular}{|c|c|}
\hline Chemikalien & Hersteller \\
\hline Essigsäure & Roth, Karlsruhe \\
\hline Ethanol & Baker, Deventer (NL) \\
\hline Ethidiumbromid & Eurobio, Les Ulis (F) \\
\hline Ficoll 400 & Amersham Biosciences, Freiburg \\
\hline Fixierer & Kodak, Darmstadt \\
\hline Fötales Kälberserumalbumin (FKS) & PAN Biotech, Aidenbach \\
\hline Glukose (Dextrose) & Becton Dickinson, Cockeysville (USA) \\
\hline Glycerol & Merck, Darmstadt \\
\hline Glycin & Roth, Karlsruhe \\
\hline Glycylglycin & Biomol, Hamburg \\
\hline Hefeextrakt & Roth, Karlsruhe \\
\hline HEPES & Sigma-Aldrich, Deisenhofen \\
\hline Isopropyl- $\beta$-D-thiogalactopyranosid & Biomol, Hamburg \\
\hline Isopropanol & Merck, Darmstadt \\
\hline Kanamycin & Sigma-Aldrich, Deisenhofen \\
\hline D-Luciferin (freie Säure, synthetisch) & PJK, Kleinbittersdorf \\
\hline ß-Mercaptoethanol & Serva, Heidelberg \\
\hline MOPS Puffersubstanz & Roth, Karlsruhe \\
\hline Natriumhydroxid & Merck, Darmstadt \\
\hline Natriumcarbonat & Merck, Darmstadt \\
\hline Natriumhydrogencarbonat & Roth, Karlsruhe \\
\hline NuPAGE TM MES Running buffer (20x) & Invitrogen, Karlsruhe \\
\hline NuPAGE тм LDS Sample buffer (4x) & Invitrogen, Karlsruhe \\
\hline Natriumdodecylsulfat (SDS) & Serva, Heidelberg \\
\hline Orange-G & Sigma-Aldrich, Deisenhofen \\
\hline Penicillin/Streptavidin & Biochrom, Berlin \\
\hline Phenol & Invitrogen, Karlsruhe \\
\hline PMSF & Sigma-Aldrich, Deisenhofen \\
\hline Poly (dI-dC) & Amersham Bioscuences, Freiburg \\
\hline Radioaktiv markiertes [ $\left.\alpha^{32} \mathrm{P}\right]$-dCTP & Amersham Biosciences, Freiburg \\
\hline Rapid-Hyb Hybridisierungspuffer & Amersham Biosciences, Freiburg \\
\hline Rediprime $^{\mathrm{TM} I I}$ & Amersham Biosciences, Freiburg \\
\hline
\end{tabular}




\begin{tabular}{ll}
\hline Chemikalien & Hersteller \\
\hline RNase freies Wasser & QIAGEN, Hilden \\
Roti®Fect & Roth, Karlsruhe \\
Roti ${ }^{\circledR}-N a n o q u a n t$ & Roth, Karlsruhe \\
Salzsäure & Roth, Karlsruhe \\
TEMED & ICN Biomendicals \\
Triethylammoniumacetat & Tansgenomics, Berlin \\
Trinatriumcitrat-Dihydrat & Roth, Karlsruhe \\
Tris & Roth, Karlsruhe \\
Tween 20 & Merck, Darmstadt \\
X-Gal & Biomol, Hamburg \\
Zellkulturmedien & PAN, Nürnberg \\
\hline
\end{tabular}

\subsubsection{Biochemikalien und Enzyme}

\begin{tabular}{ll}
\hline Enzym & Hersteller \\
\hline Antarctic Phosphatase & NEB, Schwalbach/Taunus \\
DNAse RNase-frei & Boehringer Mannheim \\
Klenow-Fragment & Invitrogen, Karlsruhe \\
Lachsspermien-DNA & Sigma-Aldrich, Deisenhofen \\
Pfu-Ultra-HF-DNA Polymerase & Stratagene, La Jolla (USA) \\
Proteinase Inhibitor Cocktail & Roche, Mannheim \\
Platinum-Taq-DNA Polymerase & Invitrogen, Karlsruhe \\
Reverse Transkriptase SuperScript II & Invitrogen, Karlsruhe \\
TaKaRa-LA Taq-Polymerase & TaKaRa BIO INC., Shiga (Japan) \\
T4-DNA-Ligase & Promega, Mannheim \\
\hline
\end{tabular}




\subsubsection{Gebrauchswaren}

Nicht aufgeführte Gebrauchswaren wurden von den Firmen Omnilab (Göttingen), sowie Sarstedt (Nümbrecht) und Greiner (Frickenhausen) bezogen.

\begin{tabular}{ll}
\hline Gebrauchsware & Hersteller \\
\hline 12-Well cell culture cluster & Corning Inc., New York, (USA) \\
96-Well-PCR-Platten & ABgene, Hamburg \\
Blottingpapier GB 003 & Schleicher \& Schüll, Dassel \\
flachbödige 96-Well-Mikrotiterplatten & Greiner, Nürtingen \\
384-Well-Platten, weiß & ABgene, Hamburg \\
Hybond ${ }^{\text {TM }}$ XL-Membran & Amersham Biosciences, Freiburg \\
Hyperfilm ${ }^{\text {TM }}$ Autoradiographie Film & Amersham Biosciences, Freiburg \\
Pipettenspitzen & Sarstedt, Nümbrecht \\
Quarz-Küvette & Hellma, Mühlheim \\
Reaktionsgefäße & Eppendorf, Hamburg \\
Sterilfilter & Sartorius, Göttingen \\
Turbo-Blot-Apparatur & Schleicher \& Schüll, Dassel \\
Zellkulturflaschen & Greiner Bio-One, Frickenhausen \\
\hline
\end{tabular}

\subsubsection{Sterilisationsverfahren}

Gebrauchswaren, Lösungen und Kulturmedien wurden bei $121^{\circ} \mathrm{C}$ und 1,5 Bar autoklaviert oder über Nacht bei $220^{\circ} \mathrm{C}$ hitzesterilisiert. Hitzeempfindliche Lösungen wurden sterilfiltriert. Wässrige Lösungen für RNA-Präparationen und RNA-Analysen wurden mit 0,1\% (v/v) Diethylpyrocarbonat (DEPC) versetzt, für 12 bis 24 h bei RT inkubiert und anschließend autoklaviert. 


\subsubsection{Gebrauchsfertige Reaktionssysteme}

\begin{tabular}{|c|c|}
\hline Reaktionssystem & Hersteller \\
\hline Easy Pure Gelextraktions-Kit & Biozym, Oldendorf \\
\hline Galacto-Light ${ }^{\mathrm{TM}}$ & Applied Biosystems, Lincoln (USA) \\
\hline Micro Spin ${ }^{\mathrm{TM}}$-S200 HR Säulen & Amersham Biosciences, Freiburg \\
\hline Montage $^{\mathrm{TM}}$ PCR Centrifugal Filter Devices & Millipore, Schwalbach \\
\hline MultiScreen-HV Platten & Millipore, Schwalbach \\
\hline Plasmid Midi Kit Nucleobond AX100 & Macherey \& Nagel, Düren \\
\hline Proteinase $\mathrm{K}$ & Amersham Biosciences, Freiburg \\
\hline PTP Assay kit 2 & Biomol, Hamburg \\
\hline Purescript ${ }^{\mathrm{TM}}$ RBC-Lysis-Solution & Gentra Systems, Minneapolis (USA) \\
\hline QuantiTect ${ }^{\mathrm{TM}}$ SYBR®-Green PCR Master & Qiagen, Hilden \\
\hline \multicolumn{2}{|l|}{ Mix } \\
\hline Quick change ${ }^{\circledR}$ II XL Mutagenesis Kit & Stratagene, La Jolla (USA) \\
\hline Rediprime $^{\mathrm{TM}} \mathrm{II}$ Random Prime-labelling & Amersham Biosciences, Freiburg \\
\hline \multicolumn{2}{|l|}{ System } \\
\hline SuperSignal ${ }^{\circledR}$ West Pico Chemiluminescent & Pierce, Rockford, USA \\
\hline \multicolumn{2}{|l|}{ Substrate } \\
\hline Tri-Reagent ${ }^{\mathrm{TM}}$ & Sigma-Aldrich, Deisenhofen \\
\hline
\end{tabular}

\subsubsection{Lösungen}

Lösungen für den routinemäßigen Gebrauch wurden nach Sambrook et al. [1989] angesetzt.

Die benötigten Chemikalien wurden den Erfordernissen gemäß in bidestilliertem oder DEPCbehandeltem Wasser gelöst und nach Bedarf autoklaviert oder sterilfiltriert.

\begin{tabular}{ll}
\hline Lösung / Puffer & Zusammensetzung \\
\hline Ampicillin-Stammlösung & $\begin{array}{l}50 \mathrm{mg} \text { Ampicillin/ml fertige Stammlösung } \\
\left(\mathrm{in} \mathrm{H}_{2} \mathrm{O}\right)\end{array}$ \\
Blockpuffer I & $\begin{array}{l}\text { 1x PBS } \\
3-5 \% \text { Milchpulver (Antikörper-abhängig) }\end{array}$ \\
\hline
\end{tabular}




\begin{tabular}{|c|c|}
\hline Lösung / Puffer & Zusammensetzung \\
\hline \multirow[t]{3}{*}{ Carbonat-bicarbonat Puffer } & $15 \mathrm{mM} \mathrm{Na}_{2} \mathrm{CO}_{3}$ \\
\hline & $35 \mathrm{mM} \mathrm{NaHCO} 3$ \\
\hline & $\mathrm{pH} 9,6$ \\
\hline \multirow[t]{3}{*}{ Coomassie-Lösung } & 30\% (v/v) Methanol \\
\hline & 10\% (v/v) Essigsäure \\
\hline & 0,05\% (w/v) Coomassie-Brilliant Blau R250 \\
\hline \multirow[t]{2}{*}{ Denaturierungslösung } & $1,5 \mathrm{M} \mathrm{NaCl}$ \\
\hline & $0,5 \mathrm{M} \mathrm{NaOH}$ \\
\hline \multirow[t]{3}{*}{ DEPC- $\mathrm{H}_{2} \mathrm{O}$} & 0,1\% (v/v) Diethylpyrocarbonat \\
\hline & Inkubation für 24 h unter Rühren und \\
\hline & anschließend Dampfdrucksterilisation \\
\hline \multirow[t]{4}{*}{ dNTP-Mix ( je 10 mM) } & 10 mM dATP \\
\hline & 10 mM dGTP \\
\hline & 10 mM dCTP \\
\hline & $10 \mathrm{mM}$ dTTP \\
\hline \multirow[t]{5}{*}{ DiFMUP-Lösung } & 25 mM MOPS pH 7 \\
\hline & $50 \mathrm{mM} \mathrm{NaCl}$ \\
\hline & $1 \mathrm{mM}$ DTT \\
\hline & 0,05\% Tween20 \\
\hline & 50 M DiFMUP (10 mM in DMSO) \\
\hline \multirow[t]{4}{*}{ Erythorzytenlysepuffer } & $155 \mathrm{mM} \mathrm{NH}_{4} \mathrm{Cl}$ \\
\hline & $10 \mathrm{mM} \mathrm{KHCO}_{3}$ \\
\hline & $0,1 \mathrm{mM}$ EDTA \\
\hline & Eingestellt auf pH 7,5 und autoklaviert \\
\hline
\end{tabular}


Lösung / Puffer

Gel Loading 10x Buffer (EMSA)

Gel shift Binding 5x Buffer

Glycylglycinpuffer

IPTG

Kaliumphosphat (1M):

Kernproteinpuffer NE (Zellen)

Kernproteinpuffer NESG (Zellen)

\section{Zusammensetzung}

250 mM Tris-HCl pH 7,5

0,2\% Bromphenolblau

40\% Glycerol

20\% Glycerol

$5 \mathrm{mM} \mathrm{MgCl}_{2}$

2,5 mM EDTA

2,5 mM DTT

$250 \mathrm{mM} \mathrm{NaCl}$

Tris-HCl pH 7,5

0,25 $\mu \mathrm{g} / \mu \mathrm{l}$ Poly (dI-dC)-poly (dI-dC)

25 mM Glycylglycin (pH 7,8)

15 mM MgSO4

4 mM EGTA

$100 \mathrm{mM}$ in $\mathrm{H}_{2} \mathrm{O}$

$0,17 \mathrm{M} \mathrm{KH}_{2} \mathrm{PO}_{4}$

$0,72 \mathrm{M} \mathrm{K}_{2} \mathrm{HPO}_{4}$

10 mM HEPES (pH 7,9)

$10 \mathrm{mM} \mathrm{KCl}$

0,2 mM EDTA

0,2 mM EGTA

25\% (v/v) Glycerol

20 mM HEPES (pH 7,9)

0,2 mM EDTA

0,2 mM EGTA 
Lösung / Puffer

Zu den Kernproteinpuffern wurde vor Gebrauch zugefügt:

1 mM DTT

$1 \mathrm{mM}$ PMSF

Proteinase Inhibitor Cocktail

Lachs-Spermien-DNA

Luciferin-Assay-Buffer (LAB)

(pro Ansatz)

Luciferin-Stammlösung

Luciferin-Injektionslösung

Lysispuffer I für Luciferase Assay

Lysispuffer II für Proteine (Zellkultur)
$100 \mu \mathrm{g} / \mathrm{ml}$ (Scherung durch Sonifikation)

20 mM Glycylglycinpuffer (pH 7,8)

17,5 mM Kaliumphosphat (pH 7,8)

1,2 mM DTT

2,4 mM ATP

10 mM Luciferin

$10 \mathrm{mM}$ DTT

in Glycylglycinpuffer (pH 7,8)

$1 \mathrm{ml}$ Luciferin-Stocklösung

4 ml 25 mM Glycylglycinpuffer (pH 7,8)

$80 \mu$ l 0,5 M DTT

100 mM Kaliumphosphat (pH 7,8)

0,2\% Triton ${ }^{\circledR} \mathrm{X}-100$

0,5 mM DTT

25 mM HEPES pH 7,4

$150 \mathrm{mM} \mathrm{NaCl}$

2 mM EDTA

0,5\% Triton ${ }^{\circledR} \mathrm{X}-100$

$1 \mathrm{mM}$ DTT

1:100 Proteinase Inhibitor Cocktail 


\section{Lösung / Puffer}

Lysispuffer III für Proteine (Organe)

Lysispuffer IV für Proteine

(Frische Lymphozyten)

10x MOPS Puffer

Neutralisationslösung

10x Oligonucleotid Annealing Buffer

P1 Puffer (Plasmid-Minipräparation)

\section{Zusammensetzung}

$0,5 \%$ SDS

$50 \mathrm{mM}$ Tris $\mathrm{pH} 8$

0,1 mM EDTA

$150 \mathrm{mM} \mathrm{NaCl}$

$50 \mathrm{mM}$ Hepes pH 7,4

1 mM EDTA

0,1 mM DTT

1\% Triton ${ }^{\circledR} \mathrm{X}-100$

1:100 Proteinase Inhibitor Cocktail

$50 \mathrm{mM} \mathrm{NaAc}$

10 mM EDTA

200 mM MOPS (pH 7,0)

$1,5 \mathrm{M} \mathrm{NaCl}$

0,5 M Tris-HCl (pH 7,2)

1 mM EDTA (pH 8,0)

100 mM Tris/HCl pH 7,5

$1 \mathrm{M} \mathrm{NaCl}$

10 mM EDTA

50 mM Tris-HCl $(\mathrm{pH} \mathrm{8,0)}$

10 mM EDTA

$100 \mu \mathrm{g} / \mathrm{ml}$ RNase A

$200 \mathrm{mM} \mathrm{NaOH}$

$1 \%$ SDS

10 mM EDTA

200 mM MOPS (pH 7,0) 
Lösung / Puffer

P3 Puffer (Plasmid-Minipräparation)

10x PBS

PBS-T

SDS-PAGE Sammelgelpuffer (2x)

SDS-PAGE Trenngelpuffer (4x)

SDS PAGE Laufpuffer (10x)

Stopp-Mix

Substrat-Puffer (pH 4)

50x TAE-Puffer ( $\mathrm{pH} \mathrm{8,3)}$

5x TBE-Puffer

\section{Zusammensetzung}

3,0 M Natriumacetat (pH 5,5)

$1,37 \mathrm{M} \mathrm{NaCl}$

$81 \mathrm{mM} \mathrm{Na} 2 \mathrm{HPO} 4$

$27 \mathrm{mM} \mathrm{KCl}$

$14,7 \mathrm{mM} \mathrm{KH}_{2} \mathrm{PO} 4$

PBS

0,05\% Tween 20

0,25 M Tris/HCl (pH 6,8)

$0,2 \%$ SDS

1,5 M Tris/HCl (pH 8,8)

$0,4 \%$ SDS

250 mM Tris/HCl

15\% Ficoll 400

200 mM EDTA

$0,1 \%$ Orange G

0,1 $\mathrm{M} \mathrm{NaPO}_{4}$

0,08 M Natriumcitrat

2 M Tris-Acetat

0,05 M EDTA

445 mM Tris/HCl (pH 8,0)

445 mM Borsäure

10 mM EDTA 


\begin{tabular}{ll}
\hline Lösung / Puffer & Zusammensetzung \\
\hline 10x TBS & $1,37 \mathrm{M} \mathrm{NaCl}$ \\
& $100 \mathrm{mM}$ Tris/HCl, pH 7.3 \\
& $10 \mathrm{mM}$ Tris-HCl (pH 8,0) \\
1x TE-Puffer & $1 \mathrm{mM}$ EDTA \\
& in PBS \\
& \\
20x Turbo-Puffer & $0,2 \mathrm{M} \mathrm{NaOH}$ \\
& mit festem $\mathrm{H}_{3} \mathrm{BO}_{3}$ auf pH 8,0 \\
& \\
\hline
\end{tabular}

\subsubsection{Längenstandards}

Um die Größe von DNA- bzw. RNA-Fragmenten auf Agarosegelen zu bestimmen, wurden folgende Längenstandards parallel mitgeführt:

\begin{tabular}{ll}
\hline Längenstandard & Hersteller \\
\hline 1 kb DNA Ladder & Invitrogen, Karlsruhe \\
$\lambda$ DNA EcoRI/HindIII geschnitten & MBI Fermentas, St. Leon-Rot \\
100 bp DNA Ladder & Invitrogen, Karlsruhe \\
50 bp DNA Ladder & MBI Fermentas, St. Leon-Rot \\
\hline
\end{tabular}




\title{
2.1.8 Medien, Antibiotika, Agarplatten
}

\subsubsection{Medien für Bakterien}

\begin{tabular}{ll}
\hline Medium & Zusammensetzung /Hersteller \\
\hline LB (Luria-Bertani)-Medium: & $10 \mathrm{~g} / \mathrm{l} \mathrm{Trypton}$ \\
& $5 \mathrm{~g} / \mathrm{l} \mathrm{Hefeextrakt}$ \\
& $10 \mathrm{~g} / \mathrm{l} \mathrm{NaCl}$ \\
& $15 \mathrm{~g} / \mathrm{l} \mathrm{Agar} \mathrm{(} \mathrm{bei} \mathrm{festem} \mathrm{Nährmedium)}$ \\
& $\mathrm{pH} 7,0$ \\
& \\
S.O.C. Medium & Invitrogen, Karlsruhe \\
\hline
\end{tabular}

Die Medien wurden mit bidestilliertem Wasser angesetzt, autoklaviert und bei $4^{\circ} \mathrm{C}$ aufbewahrt. Für die Selektion wurden der jeweiligen Resistenz entsprechend Ampicillin (Endkonzentration $100 \mu \mathrm{g} / \mathrm{ml}$ ) bzw. Kanamycin (Endkonzentration $50 \mu \mathrm{g} / \mathrm{ml}$ ) zugegeben.

\subsubsection{Medien für eukaryontische Zellkulturen}

Das zur Kultur eukaryontischer Zellen verwendete Medium (DMEM) wurde als sterile Lösung bezogen (PAN, Nürnberg) und vor Gebrauch mit folgenden Komponenten versetzt:

DMEM (Dulbecco`s modified Eagle medium) (PAN) für NIH/3T3

\author{
$10 \%(\mathrm{v} / \mathrm{v}) \mathrm{FKS}$ \\ 2 mM Glutamin \\ $100 \mu \mathrm{g} / \mathrm{ml}$ Streptomycin \\ 100 U/ml Penicillin
}




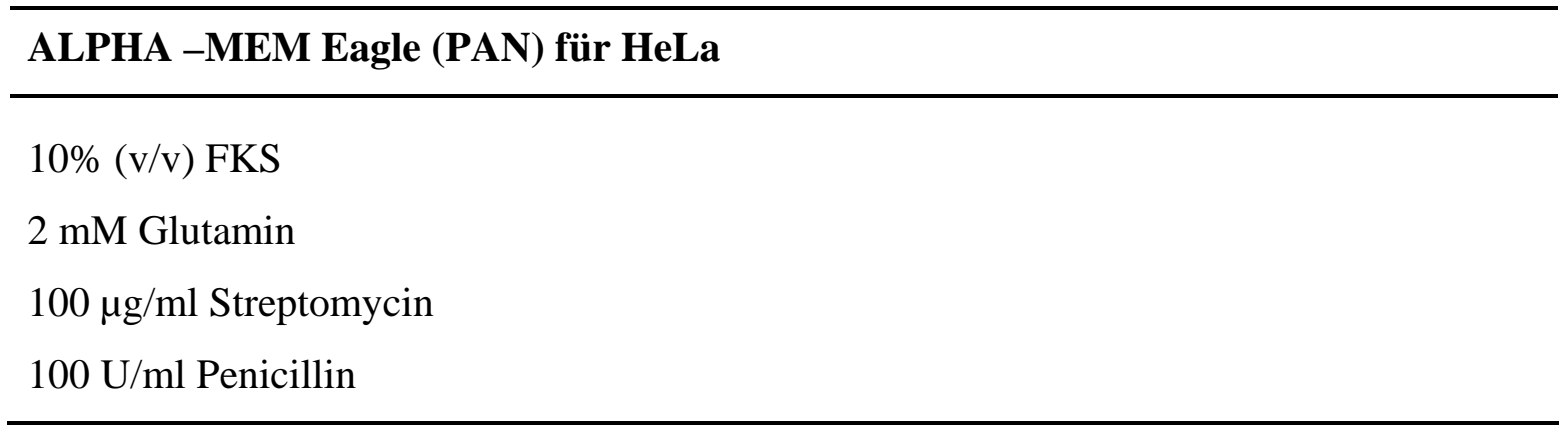

\title{
RPMI 1640 (PAN) für EBV-Lymphozyten
}

\author{
$10 \%(\mathrm{v} / \mathrm{v}) \mathrm{FKS}$ \\ 2 mM Glutamin \\ $100 \mu \mathrm{g} / \mathrm{ml}$ Streptomycin \\ 100 U/ml Penicillin \\ $10 \mu \mathrm{M} ß$-Mercaptoethanol
}

Medienzusätze zur Lagerung in $\mathrm{N}_{2}: 20 \%$ (v/v) FKS, 10\% (v/v) DMSO

\subsubsection{Biologisches Material}

\subsubsection{Bakterienstamm}

Bakterienstamm

Escherichia coli DH5 $\alpha$ [Hanahan, 1983]

\section{Hersteller}

Invitrogen, Karlsruhe

\subsubsection{Eukaryontische Zelllinien}

Zellinie Hersteller

NIH/3T3 (Embryonale Maus-Fibroblasten

„NIH Swiss Mouse“, kontaktinhibiert)

B 95-8 EBV Linie
ATCC, Rockville, USA

(Kulturbedingungen: DMEM, $37^{\circ} \mathrm{C}, 5 \% \mathrm{CO}_{2}$ )

Humangenetik, Berlin 


Zellinie Hersteller

EBV-transformierte Lymphozyten

Humangenetik, Göttingen

\subsubsection{Verwendete Vektoren, Gensonden und Antikörper}

\subsubsection{Vektoren}

\begin{tabular}{ll}
\hline Plasmid & Hersteller \\
\hline pBluescript ${ }^{\circledR} \mathrm{KS}(+/-)$ & Stratagene, La Jolla (USA) \\
pCR®II TOPO & Invitrogen, Karlsruhe \\
pGEM $^{\circledR}$-T-easy & Promega, Mannheim \\
pGL3 $^{\circledR}$-basic & Promega, Mannheim \\
pGL3 $^{\circledR}$-control & Promega, Mannheim \\
pSU6 & Ambion, Cambridgeshire, GB \\
\hline
\end{tabular}

\subsubsection{Konstrukte}

\begin{tabular}{ll}
\hline Konstrukt & Urheber \\
\hline pCMV- $\beta-G a l$ & G. C. Shevelev, Moskau \\
pEXP1-GWlac & Invitrogen, Karlsruhe \\
\hline
\end{tabular}

\subsubsection{3 cDNA-Fragmente für Southern Blot-Analysen}

\begin{tabular}{lll}
\hline Konstrukt & Eigenschaften & Herkunft \\
\hline NS & $\begin{array}{l}\text { 1,2 kb der WT-PTPN11-cDNA; } \\
\text { Nachweis der Integration auf DNA-Blot }\end{array}$ & $\begin{array}{l}\text { Ausgeschnitten mit BglI und PstI } \\
\text { aus WT-SHP2- pCR }{ }^{\circledR I I} \text { TOPO. }\end{array}$ \\
\hline
\end{tabular}




\subsubsection{Antikörper}

\begin{tabular}{ll}
\hline Antikörper & Bezugsquelle \\
\hline Anti-SH-PTP2 & Sigma-Aldrich, Deisenhofen \\
Anti-cmyc Tag, clone 4A6 & Biomol, Hamburg \\
$\begin{array}{l}\text { Ziege Anti-Kaninchen IgG HRP } \\
\text { (horseradish peroxidase) konjugiert }\end{array}$ & Dianova, Hamburg \\
$\begin{array}{l}\text { Kaninchen Anti-Maus IgG HRP } \\
\text { (horseradish peroxidase) konjugiert }\end{array}$ & Dianova, Hamburg \\
\hline
\end{tabular}

\subsubsection{Synthetische Oligonukleotide}

Die verwendeten Oligonukleotide wurden von der Firma Qiagen (Hilden) bezogen, mit 0,5x TE auf eine Konzentration von $100 \mu \mathrm{M}(100 \mathrm{pmol} / \mu \mathrm{l})$ eingestellt und als Stocklösung bei $-20^{\circ} \mathrm{C}$ gelagert.

\subsubsection{Oligonukleotide zur Analyse des PTPN11-Promoters}

\begin{tabular}{ll}
\hline Name & Sequenz \\
\hline pro-M-c1 & 5'-CTT AAA ATG GTC ATA TGA GGG CAA C-3' \\
pro-M-c2 & 5'-ACC TGA AAG GGT CCT GTG TGA AG-3' \\
pro-M-c3 & 5'-TCT AAA GGT GTT CCC TGA CTT CCA CA-3 \\
pro-M-Nco3 & 5'-TCA CCT CCG CGA TGC CAT GGT CCT CCC GTC TCC-3' \\
pro-M-BglII & 5'-AAA CTC CCT AGA TCT GCT CAG GGC CCC GCA A-3' \\
pro-M-Kpn1 & 5'-GGC GCG GGC GAG GGG GTA CCG AGC CGG GCG GCG G-3' \\
NS-pro-F1 & 5'-CCC CGA GTG ACC CGC CTA GTT TTG T-3' \\
NS-pro-R1 & 5'-TCT AGC TGG CCA GGA TTT AGG GAG A-3' \\
NS-pro-F2 & 5'-TCA TGA GGC AAT GGG TCA GGA ATG C-3' \\
\hline
\end{tabular}




\begin{tabular}{ll}
\hline Name & Sequenz \\
\hline NS-pro-R2 & 5'-CTC CCC AAG TGA GCA GGG TTA TTT C-3' \\
NS-hsSstI & 5'-GCA GTG GCG TGA GCT CGA CTC ACT GCA GCC-3' \\
NS-hsSstII & 5'-GCG CGG GAG CTC ACA CCT GGC GGC CGC GGT T-3' \\
NS-hsNcoI & 5'-GCG ATG CCA TGG TCC TCC CGC CCT CCG CGT-3' \\
ProHF3 & 5'-CGG AGA CAG TAG GTA ATT TCC CCA AG-3' \\
ProHR3 & 5'-CTT CCG GAC GGG GCT AAC CGA AC-3' \\
NS-pro-R2 & 5'-CTC CCC AAG TGA GCA GGG TTA TTT C-3' \\
NS-hsSstI & 5'-GCA GTG GCG TGA GCT CGA CTC ACT GCA GCC-3' \\
NS-hsSstII & 5'-GCG CGG GAG CTC ACA CCT GGC GGC CGC GGT T-3' \\
NS-hsNcoI & 5'-GCG ATG CCA TGG TCC TCC CGC CCT CCG CGT-3' \\
ProHF3 & 5'-CGG AGA CAG TAG GTA ATT TCC CCA AG-3' \\
ProHR3 & 5'-CTT CCG GAC GGG GCT AAC CGA AC-3' \\
\hline
\end{tabular}

\subsubsection{Oligonukleotide für die EMSA-Analyse}

\begin{tabular}{|c|c|}
\hline Name & Sequenz \\
\hline $25 /+13 \mathrm{~F}$ & $\begin{array}{l}\text { 5'-GGT GCG GAG CCG GAG ACG GGA GGA ACA TGA CAT CGC } \\
\text { GGA G-3' }\end{array}$ \\
\hline 25/+13 R & $\begin{array}{l}\text { 5'-GGC TCC GCG ATG TCA TGT TCC TCC CGT CTC CGG CTC } \\
\text { CGC A-3' }\end{array}$ \\
\hline$-56 /-18 F$ & $\begin{array}{l}\text { 5'-GGA CCC CGC GGA GCC TGA GCG AGC AGC GGG TCC GTG } \\
\text { CGG A-3' }\end{array}$ \\
\hline$-56 /-18 \mathrm{R}$ & $\begin{array}{l}\text { 5'-GGT CCG CAC GGA CCC GCT GCT CGC TCA GGC TCC GCG } \\
\text { GGG T-3' }\end{array}$ \\
\hline$-85 /-47 \mathrm{~F}$ & $\begin{array}{l}\text { 5'-GGC CTC GCT CGG GCC CCC TCC ATG TGA CGG TAC CCC } \\
\text { GCG G-3' }\end{array}$ \\
\hline$-85 /-47 \mathrm{R}$ & $\begin{array}{l}\text { 5'-GGC CGC GGG GTA CCG TCA CAT GGA GGG GGC CCG AGC } \\
\text { GAG G-3' }\end{array}$ \\
\hline$-116 /-79 \mathrm{~F}$ & $\begin{array}{l}\text { 5'-GGT GCC CGC ACC CGT GTC GGC TCC GGA GCG GGG CCT } \\
\text { CGC T-3' }\end{array}$ \\
\hline$-116 /-79 R$ & $\begin{array}{l}\text { 5'-GGA GCG AGG CCC CGC TCC GGA GCC GAC ACG GGT GCG } \\
\text { GGC A-3' }\end{array}$ \\
\hline$-147 /-109 \mathrm{~F}$ & $\begin{array}{l}\text { 5'-GGA GGG GGT TGT GCG CGC GCG GCC GGC CGG CTC TGC } \\
\text { CCG C-3' }\end{array}$ \\
\hline
\end{tabular}




\begin{tabular}{ll}
\hline Name & Sequenz \\
\hline -147/-109 R & 5'-GGG CGG GCA GAG CCG GCC GGC CGC GCG CGC ACA ACC \\
CCC T-3' & 5'-GGG GCC GCG CAG TGT CCG GGA TCC AGG CCT GGC AGG \\
-179/-140 F & GGG T-3' \\
-179/-140 R & GGA CCC CCT GCC AGG CCT GGA TCC CGG ACA CTG CGC \\
-206/-168 F & 5'-GGG AGG GCG GAG CGA GCC GGG CGG CGG GGC GGC CGC \\
-206/-168 R & 5'-GGC TGC GCG GCC GCC CCG CCG CCC GGC TCG CTC CGC \\
-229/-191 F & C'-GGC GG' \\
-229/-191 R & 5'-GGG C-3' CAG GGG CGG GGG CGC GGG CGA GGG CGG AGC \\
SP1 F & GCC G-3' \\
5'-GGA TTC GAT CGG GGC GGG GCG AGC-3' \\
CREB F & 5'-GGG CTC GCC CCG CCC CGA TCG AAT-3' \\
CREB R & 5'-GGC TAG CTC TCT GAC GTC AGG CAA TCT CT-3' \\
AP2 F & 5'-GGG ATC GAA CTG ACC GCC CGC GGC CCG T-3' \\
AP2 R & 5'-GGA CGG GCC GCG GGC GGT CAG TTC GAT C-3' \\
\hline
\end{tabular}

\subsubsection{Oligonukleotide für die Mutationsanalyse}

\begin{tabular}{lc}
\hline Name & sequenz \\
\hline$-229 /-191$ & 5'-GGC GGC CAG GTT CGG GGG CGC GGG CGA GGG CGG AGC \\
mut1F & GAG C-3' \\
$-229 /-191$ & 5'-GGG CTC GCT CCG CCC TCG CCC GCG CCC CCG AAC CTG \\
mut1R & GCC G-3' \\
$-229 /-191$ & 5'-GGC GGC CAG GGG CGG GGG CGC GGG CGA GTT CGG AGC \\
mut2F & GAG C-3' \\
$-229 /-191$ & 5'-GGG CTC GCT CCG AAC TCG CCC GCG CCC CCG CCC CTG \\
mut2R & GCC G-3' \\
$-229 /-191$ & 5'-GGC GGC CAG GTT CGG GGG CGC GGG CGA GTT CGG AGC \\
mut12F & GAG C-3' \\
$-229 /-191$ & 5'-GGG CTC GCT CCG AAC TCG CCC GCG CCC CCG AAC CTG \\
mut12R & GCC G-3' \\
$-260 /-222 F$ & 5'-GGG CGG CGC GCG ATG ACG TCA CGC AGG CGC CGG CGG \\
$-260 /-222 R$ & CCA G-3' \\
$-260 /-222$ & C'-GGG TGG CCG CCG GCG CCT GCG TGA CGT CAT CGC GCG \\
mutF & CCA G-3' \\
\hline
\end{tabular}




\begin{tabular}{ll}
\hline Name & sequenz \\
\hline$-260 /-222$ & 5'-GGC TGG CCG CCG GCG CCT GCG TGA CAA CAT CGC GCG \\
mutR & CCG C-3' \\
$-291 /-253$ F & 5'-GGC GCA AAC CGG AAG CAG ATA GTG GCC GTG GCG GCG \\
-291/-253 R & 5'-GGG C-3' \\
$-291 /-253$ & T'-GGC G-3' \\
mutF & GCG C-3' \\
$-291 /-253$ & 5'-GGG CGC CGC CGC CAC GGC CAC CCC TGC TTC CGG TTT \\
mutR & GCG-3' \\
$-291 /-253$ & 5'-GGC GCA AAA AGG AAG CAA GAA GTG GCC GTG GCG GCG \\
mutF1 & GCG C-3' \\
$-291 /-253$ & 5'-GGG CGC CGC CGC CAC GGC CAC TTC TTG CTT CCG GTT \\
mutR1 & TGC G-3' \\
SP1mutF & 5'-GGA TTC GAT CGG TTC GGG GCG AGC-3' \\
SP1mutR & 5'-GGG CTC GCC CCG AAC CGA TCG AAT-3' \\
CREBmut F & 5'-GGA GAG ATT GCC TGT TGT CAG AGA GCT AG-3' \\
CREBmut R & 5'-GGC TAG CTC TCT GAC AAC AGG CAA TCT CT-3' \\
\hline
\end{tabular}

\subsubsection{Oligonukleotide für die PCR-Mutagenese}

\begin{tabular}{ll}
\hline Name & Sequenz \\
\hline \multirow{2}{*}{ NS52mutF } & 5'-CGT TAG AAG AAA TGG AGC TGT CAC TCA CAT CAA GAT \\
NS52mutR & TCA G-3' \\
5'-CTG AAT CTT GAT GTG AGT GAC AGC TCC ATT TCT TCT \\
AAC G-3' \\
NS279mutF & 5'-CAA AAA TAG ATG TAA AAA CAT CCT GCC CTT TGA TCA \\
NS279mutR & TAC C-3' \\
& TTT GTG ATC AAA GGG CAG GAT GTT TTT ACA TCT ATT \\
NS285mutF & 5'-GAT ATA AAA ACA TCC TGC CCT CTG ATC ATA CCA GGG \\
& TTG TCC-3' \\
NS285mutR & 5'-GGA CAA CCC TGG TAT GAT CAG AGG GCA GGA TGT TTT \\
NS308mutF & TAT ATC-3' \\
& CCT GTT TCA GAT TAC ATC AAT GCA GAT ATC ATC ATG \\
NS308mutR & 5'-CAA ATT CAG GCA TGA TGA TAT CTG CAT TGA TGT AAT \\
& CTG AAA CAG G-3' \\
NS468mutF & 5'-GAA TTG GCC GGA CAG GGA CGT TCA TTG TGA TTG ATA \\
& TTC-3' \\
NS468mutR & 5'-GAA TAT CAA TCA CAA TGA ACG TCC CTG TCC GGC CAA \\
& TTC-3' \\
NS491mutF & C'-GGT GTT GAC TGC GAT ATT GAC GTT CTC AAA ACC ATC \\
\hline
\end{tabular}




\begin{tabular}{ll}
\hline Name & Sequenz \\
\hline NS491mutR & 5'-GCA CCA TCT GGA TGG TTT TGA GAA CGT CAA TAT CGC \\
pTriEx F & 5'-ACT ATA GGG GAA TTG TGA GCG GAT A-3' \\
pTriEx R & 5'-CAA TAT GGT GGA AAA TAA CCG GAA T-3' \\
\hline
\end{tabular}

\subsubsection{Oligonukleotide zur Herstellung von shRNA-Kontrukten}

\begin{tabular}{lc}
\hline Name & sequenz \\
\hline \multirow{2}{*}{ NS308-I-R } & 5'-AAT TAA AAA ATG CAA ATA TCA TCA TGC CTT CTC TTG \\
& AAA GGC ATG ATG ATA TTT GCA GGC C-3' \\
NS308-I-F & 5'-TGC AAA TAT CAT CAT GCC TTT CAA GAG AAG GCA TGA \\
& TGA TAT TTG CAT TTT TT-3' \\
NS308-mut-R & 5'-AAT TAA AAA ATG CAG ATA TCA TCA TGC CTT CTC TTG \\
NS308-mut-F & 5AA GGC ATG ATG ATA TCT GCA GGC C-3' \\
& TGA TAT CTG CAT TTT TT-3' \\
\hline
\end{tabular}

\subsubsection{Oligonukleotide zur Herstellung des transgenen Mäuse}

\begin{tabular}{ll}
\hline Name & Sequenz \\
\hline NS 300 F & 5'-GTT GAC AAG AGG AGT TGA TGG CAG T-3' \\
NS 300 R & 5'-AGG TGG TTT CAT GGA CAT CTC TCT G-3' \\
NS 600 F & 5'-GAA CTG AAA TAC GAC GTT GGT GGA G-3' \\
NS 600 R & 5'-CTC TAA AAG AAT ATG GCG TCA TGC G-3' \\
491SeqF & 5'-ACC ATA AGC AGG AGA GCA TCA TGG-3' \\
491seqR & 5'-TAT TCT CTA GCG GAC CAG ACG AGT G-3' \\
500F & 5'-TCA AAG GCA AGA AAA CAA AAA CAA A-3' \\
mGAPDH-F & 5'-CAT CAC CAT CTT CCA GGA GC-3' \\
mGAPDH-R & 5'-ATG ACC TTG CCC ACA GCC TT-3' \\
\hline
\end{tabular}




\begin{tabular}{|c|c|}
\hline Name & Sequenz \\
\hline NS-NcoI-F & 5’-AGG ACC ATG GGG ACA TCG CGG AGA TGG-3' \\
\hline NS-Ba-R & 5’-AGC GGA TCC TCT GAA ACT TTT CTG TTG CAT C-3’ \\
\hline Cmyc-Ba-F & $\begin{array}{l}\text { 5'-ATC GGA TCC GAA CAA AAC TCA TCT CAG AGA GGA TCT } \\
\text { GAA-3' }\end{array}$ \\
\hline Cmyc-Bc-R & $\begin{array}{l}\text { 5'-AGA TTG ATC AAT TCG ATC CTC TTC TGA GTG AGT TTT } \\
\text { TGT-3' }\end{array}$ \\
\hline NS4-genF & 5'-TTT CAT GGA CAT CTC TCT GGG AAA G-3' \\
\hline NS4-genR & 5'-CAG CGA ATC ATA ACA TGG GTC ACT T-3' \\
\hline 3U-Bc-F & $\begin{array}{l}\text { 5'-CTT ATC AGA TGA TCA GAA AAC CTG CCA AAA CTT CAG } \\
\text { CAC AG-3' }\end{array}$ \\
\hline 3U-H3-R & 5'-GCA CTG GCA TTA AAG AGT CAT AGA AAA GCT TAT C-3' \\
\hline $3 \mathrm{U}-\mathrm{F}^{\prime}$ & 5'-CAG TGC TAG AGT CTA TGA AAA CGT G-3' \\
\hline 3U-R' & 5'-ATG AAT TAA GGT AAG AGG TGT GGC T-3' \\
\hline cmyc-F3 & 5'-AGA GGA TCC GAA CAA AAA CTC ATC T-3' \\
\hline 3'UTR R3 & 5'-CAC TCT ACC ACC AGT ATC AGC CAT T-3' \\
\hline Transgen & 5'-ACA TTG GGT ACA GTA CTA CAA CTC-3' \\
\hline NS-P1 F & 5'-AGG CAT GAT AGC CAA CAC CTT TAA T-3' \\
\hline NS-P1 R & 5'-AGT TCC AGG ACA GTC AGG GCT ATA C-3' \\
\hline NS-P2 F & 5'-CTG GGA ATT GAA ACC TAG TCC TCT G-3' \\
\hline NS-P2 R & 5'-CTA TGT ACC ACG GCC ATA CGT TTA C-3' \\
\hline NS-P3 F & 5'-TGG ACA TTT GGA AGG AGA AGT TAT G-3' \\
\hline NS-P3 R & 5'-GTA GGG AGA CCC TGT CAA AAA GAA A-3' \\
\hline NS-P4 F & 5'-ATA TAT ATT TCT AGC CGG GCG TGG T-3' \\
\hline NS-P4 R & 5'-AGC AGA TCT AGG GAG TTT GGT GTG-3' \\
\hline NS-P5 F & 5'-GAT GCA TAT TGT GTA TTG TGT CCT C-3' \\
\hline NS-P5 R & 5'-GTC TCC AGG GTT ACT TTT ACT AGG C-3' \\
\hline NS-U1 F & 5'-AAT TAG AAA CTT ATC TGG GCA TGG T-3' \\
\hline NS-U1 R & 5'-GGA AGC AGG TAT TGT TGA GTT AAA A-3' \\
\hline NS-U2 F & 5'-CCC TGT ACT TCT TTT TCC AAG ATG G-3' \\
\hline
\end{tabular}




\begin{tabular}{ll}
\hline Name & Sequenz \\
\hline NS-U2 R & 5'-CAA AGT GCT GGG ATT ACA GGT ATG A-3' \\
NS-U3 F & 5'-CAC CCT CTC CCT AAA AAG ATC AAG A-3' \\
\hline
\end{tabular}

\subsubsection{Oligonukleotide für die Taqman-Analyse}

\begin{tabular}{|c|c|}
\hline Name & Sequenz \\
\hline NS 2Taq F & 5'-GGT TTC ACC CAA ATA TCA CTG GTG T-3' \\
\hline NS 2Taq $\mathrm{R}$ & 5'-CTA ACG GAA AGT GTG AAG TCT CCA G-3' \\
\hline NS 3Taq F2 & 5'-TGG CTG AGT TGG TCC AGT ATT ACA T-3' \\
\hline NS 3Taq R2 & 5'-CTT TCA GAG GTA GGA TCT GCA CAG T-3' \\
\hline NS 4Taq F & 5'-AGT TTT CTT GTA CGA GAG AGC CAG A-3' \\
\hline NS 4Taq $\mathrm{R}$ & 5'-GCG AAT CAT AAC ATG GGT CAC TTT A-3' \\
\hline $3 \mathrm{p} 2 \mathrm{~F}$ & 5'-AAC TAC CTG TCC CAG CCC GGC CCC A-3' \\
\hline 3p2R & 5'-CAT CCA AGA GCC CGA AGC CTG CCT GC-3' \\
\hline PeloF11 & 5'-TGA GCC CAG ACT GTA CGT GAC-3' \\
\hline PeloR12 & 5'-TCT GCA CCT TAG CGT GAA GCC-3' \\
\hline NS3del F & 5'-CCC TCC AGT GCT TGA GAC TTG T-3' \\
\hline NS3del R & 5'-CAG GTG GTG TTA AGG GCT CAT C-3' \\
\hline RNS3taqF & 5'-GCC TCC CTT TCC AAT GGA CTA T-3' \\
\hline RNS3taqR & 5'-CCG TCA TGC ATT TCT GAC ACT C-3' \\
\hline NS4taqdelF & 5'-TGT GAA AGA ACA ACA TGA ACC CAT A-3' \\
\hline NS4taqdelR & 5'-CTT GCC AGA CCC ATT TTT CAA C-3' \\
\hline NS2taqf & 5'-GGG ACA GGG AAG GTC TTG ATT T-3' \\
\hline NS2taqR & 5'-GCT ATC CAA GCA TGG TTT TAC CAC-3' \\
\hline NS15delF & 5'-TCC CTT GTA GGG TTC AGA TCC A-3' \\
\hline NS15delR & 5'-GCC AGT GCA AAG GTC AAC TTC T-3' \\
\hline
\end{tabular}




\begin{tabular}{ll}
\hline Name & Sequenz \\
\hline Sonde Del3F & 5'-TTG CAT TTT TAA AAG AGG AGG GAT T-3' \\
Sonde Del3R & 5'-ATG TAA TGG TGT TTG TCC TCT TCC A-3' \\
\hline
\end{tabular}

\subsubsection{Mausstämme}

Die verwendeten Mäuse der Stämme FVB und NMRI stammten aus institutseigenen Beständen, dem Max-Planck Institut für experimentelle Medizin (Göttingen) oder wurden von der Firma Charles River (Hannover) bezogen. Die Haltungsbedingungen bestanden aus einem zwölfstündigen Hell-Dunkel-Rhythmus bei $22^{\circ} \mathrm{C}$ und $55 \pm 5 \%$ relativer Luftfeuchtigkeit. Tierfutter wurde von der Firma ssniff-Spezialdiäten (Soest) bezogen.

\subsubsection{Herkunft des Patientenmaterials}

Im Rahmen dieser Arbeit fanden molekulargenetische Untersuchungen an der DNA von Patienten mit der klinischen Diagnose eines Noonan-Syndrom statt. Die Blut-Proben der Patienten wurden zum Zwecke einer molekulargenetischen Noonan-Syndrom-Diagnostik von der Pädriatrichen Kardiologie des Universitätsklinikums Göttingen und von auswärtigen Kliniken zugesandt. Als Untersuchungsmaterial wurde aus einer EDTA-Blutprobe DNA aus peripheren Blutlymphozyten isoliert.

\subsubsection{Datenbanken und Analyse-Software}

Folgende Programme wurden zur Bearbeitung von Daten verwendet:

\begin{tabular}{ll}
\hline Programm & Verwendung \\
\hline $\begin{array}{l}\text { BLAST-Programm [Altschul et al., 1990] } \\
\text { http://www.ncbi.nlm.nih.gov }\end{array}$ & Analyse von DNA-Sequenzen \\
BLAT-Search [Kent, 2002] & \\
http://genome.ucsc.edu/cgi-bin/hgBlat & Überprüfung der Spezifität von \\
\hline
\end{tabular}




\section{Programm}

BCM Search Launcher

http://searchlauncher.bcm.tmc.edu/

Ensembl v32

http://www.ensembl.org/

National Center for Biotechnology Information :

http://ncbi.nlm.nih.gov/

DCODE.org Comparative Genomics Center

http://www.dcode.ord

Blast two sequences [Altschul et al., 1990]

http://www.ncbi.nlm.nih.gov/blast/

ClustalW und Boxshade

http://ch.embnet.org

DCODE.org Comparative Genomics Center

http://www.dcode.ord

Genomatix

http://www.genomatix.de

Transcriptional Factor search

http://www.cbrc.jp/research/db/TFSEARCH.htm

Transcriptional Element Search Systemm (TESS)

http://www.cbil.upenn.edu/tess

Human Protein Reference Database

http://www.hrpd.org

NEB Cutter 2.0

http://tools.neb.com/NEBcutter2/index.php

\section{Verwendung}

Bioinformatik

Alignment

Regulatorische Elemente des Genom

Regulatorische Elemente des Genom

Analyse von humanen Proteinen

Restriktions-Schnittstellen-Kartierung 


\begin{tabular}{ll}
\hline Programm & Verwendung \\
\hline $\begin{array}{l}\text { Primer3 } \\
\text { http://frofo.wi.mit.edu/chi- } \\
\text { bin/primer3/primer3_www.cgi }\end{array}$ & Auswahl von Oligonukleotiden für PCR \\
SDS Version 2.1 & Auswertung der real time-PCR \\
Repeatmasker & Maskierung von repetitiven Sequenzen \\
http://repeatmasker.genome.washington.edu/ & \\
http://genome.ucsc.edu/ & \\
\hline
\end{tabular}

\subsection{Methoden}

\subsubsection{Isolierung und Aufreinigung von Nukleinsäuren}

\subsubsection{Isolierung von genomischer DNA aus Gewebe}

[Laird et al., 1991]

Frisches oder tiefgefrorenes Gewebe (0,1-1 g) wurde über Nacht in $750 \mu$ l GewebeLysispuffer und $45 \mu \mathrm{l}$ Proteinase $\mathrm{K}(10 \mathrm{mg} / \mathrm{ml})$ bei $56^{\circ} \mathrm{C}$ unter Schütteln inkubiert. Die Proteine wurden einmal mit 1 Vol Phenol und einmal mit 1 Vol Phenol/Chloroform (1:1) extrahiert, und die DNA würde mit 1 Vol Isopropanol aus der wässrigen Phase gefällt. Die DNA wurde abzentrifugiert, das DNA-Pellet einmal mit 70\%igem Ethanol gewaschen und in Wasser $(80-200 \mu \mathrm{l})$ bei $56^{\circ} \mathrm{C}$ gelöst.

\subsubsection{Minipräparation von Plasmid-DNA}

Diese Methode wurde zur schnellen Isolierung rekombinanter Plasmide im analytischen Maßstab verwendet. Hierzu wurden 3 ml einer Übernachtkultur bei 16000 x g abzentrifugiert und das Pellet in $200 \mu \mathrm{l}$ P1-Lösung resuspendiert. Nach Zugabe von $200 \mu \mathrm{l}$ P2 (modifizierte alkalische Lyse [Birnboim und Doly, 1979]) und $200 \mu \mathrm{l}$ P3 (Neutralisierung) wurde die Probe 
5 min auf Eis inkubiert und für 20 min bei 16000 x g $\left(4^{\circ} \mathrm{C}\right)$ zentrifugiert. Um die PlasmidDNA durch eine $30 \mathrm{~min}$ Zentrifugation bei $16000 \mathrm{x} \mathrm{g}\left(4^{\circ} \mathrm{C}\right) \mathrm{zu}$ fällen, wurde der Überstand in ein neues Gefäß überführt und mit 0,7 Vol Isopropanol versetzt. Anschließend wurde das DNA-Pellet mit $500 \mu \mathrm{l}$ 70\%igem Ethanol gewaschen und nach dem Trocknen in 50-70 $\mu \mathrm{l}$ $\mathrm{H}_{2} \mathrm{O}$ aufgenommen. Die Qualität dieser DNA ist hinreichend gut, um sie in Restriktionsanalysen und für die Isolierung von DNA-Fragmenten einzusetzen.

\subsubsection{Herstellung von Bakterien-Glycerin-Stocks}

$700 \mu \mathrm{l}$ einer Bakteriensuspension wurden mit $300 \mu \mathrm{l}$ sterilem Glycerin 50\% versetzt, gut gemischt und bei $-80^{\circ} \mathrm{C}$ aufbewahrt.

\subsubsection{Midipräparation von Plasmid-DNA}

Zur Isolierung größerer Mengen hochreiner Plasmid-DNA wurde das Plasmid-Midi Kit der Firma Macherey \& Nagel (Düren) verwendet. Die DNA wird dabei über Säulen aus dem Kit affinitätschromatographisch aufgereinigt. Die Aufarbeitung erfolgte nach dem Protokoll des Herstellers. Die mit dieser Methode isolierte Plasmid-DNA kann u.a. für die Transfektion von Zelllinien, für Restriktionsanalysen, Subklonierung oder Sequenzierung eingesetzt werden.

\subsubsection{Ethanolfällung von DNA aus wässrigen Lösungen}

Die Ethanolfällung wurde eingesetzt, um DNA zu konzentrieren und sie von Salzverunreinigungen zu befreien. Zur Fällung von Plasmid-DNA oder PCR-Produkten wurde der Ansatz mit 1/10 Vol 3 M Natriumacetat-Lösung ( $\mathrm{pH} \mathrm{5,2)} \mathrm{und} 3$ Vol kaltem 96\%igem Ethanol versetzt. Die Präzipitation erfolgte durch Inkubation für 15 min bei $80^{\circ} \mathrm{C}$ oder für $2 \mathrm{~h}$ bei $-20^{\circ} \mathrm{C}$. Der Ansatz wurde für $30 \mathrm{~min}$ bei $16000 \mathrm{x}$ g zentrifugiert und das Pellet mit 70\%igem Ethanol gewaschen. Anschließend wurde das Pellet getrocknet und in einem entsprechenden Volumen $\mathrm{H}_{2} \mathrm{O}$ aufgenommen. 


\subsubsection{Isolierung von Gesamt-RNA aus Gewebe}

[modifiziert nach Chomczynski und Sacchi, 1987]

RNA wurde mit Hilfe des sog. Tri-Reagent (Sigma, Deisenhofen) isoliert. Zum schnellen Zellaufschluß wird hierbei eine Mischung aus Phenol und Guanidinthiocyanat benutzt. Zum Schutz vor RNasen wurden RNase-freie Kunststoff Einweg-Gefäße und Filterspitzen verwendet. Frische oder bei $-70^{\circ} \mathrm{C}$ gelagerte Gewebe wurden in einem Glas/Glas-Potter in 5-10 Vol Tri-Reagent bei Raumtemperatur aufgeschlossen, mit 0,1 Vol 1-Brom-3chlorpropan gemischt (15 s Vortex) und nach einer Inkubationszeit von 10 min zentrifugiert (15 min, $16000 \times \mathrm{g}, 4^{\circ} \mathrm{C}$ ). Dadurch bildet sich eine untere organische Phase, welche die Proteine enthält, eine durch DNA gebildete Interphase und eine wässrige obere Phase, in der die RNA gelöst ist. Die RNA wird in ein neues Gefäß überführt und durch Zugabe von 0,5 Vol (bezogen auf das Tri-Reagent Volumen) Isopropanol gefällt, zentrifugiert (15-30 min, $15000 \mathrm{x} \mathrm{g}, 4^{\circ} \mathrm{C}$ ), zweimal mit $800 \mu \mathrm{l}$ 70\%igem Ethanol gewaschen und in $\mathrm{H}_{2} \mathrm{O}$ gelöst.

\subsubsection{Isolierung von Gesamt-RNA aus EDTA-Blut}

Für die RNA-Isolierung aus Blut wurde $1 \mathrm{ml}$ EDTA-Blut mit 2 ml Purescript ${ }^{\mathrm{TM}}$ RBC-LysisSolution versetzt und nach $10 \mathrm{~min}$ Inkubation bei RT bei $16000 \mathrm{x}$ g für $5 \mathrm{~min}\left(4^{\circ} \mathrm{C}\right)$ abzentrifugiert. Die pelletierten Lymphozyten wurden in $600 \mu \mathrm{l}$ Tri-Reagent resuspendiert und $5 \mathrm{~min}$ auf Eis inkubiert. Das weitere Vorgehen entsprach der RNA-Isolierung aus Gewebe (2.2.1.6).

\subsubsection{Isolierung von DNA-Fragmenten aus Agarosegelen}

Die Isolierung von DNA-Restriktionsfragmenten aus Agarosegelen erfolgte mit Hilfe des Easy Pure ${ }^{\circledR}$ DNA Purification Kit von Biozym (Oldendorf). Diese Methode beruht auf dem von Vogelstein und Gillespie [1979] beschriebenen Prinzip der reversiblen Bindung von Nukleinsäuren an Partikel einer Anionenaustauschersilikat-Suspension (Glasmilch), abhängig von der Ionenstärke des Lösungsmittels. Die gewünschte Bande wurde nach gelelektrophoretischer Auftrennung unter UV-Licht (354 nm) aus dem Agarosegel ausgeschnitten und die DNA den Herstellerangaben folgend extrahiert. 


\subsubsection{Konzentrationsbestimmung von Nukleinsäuren}

Die Konzentration der aus Gelextraktionen erhaltenen Mengen an DNA wurden im Vergleich mit Proben bekannter Konzentration auf Agarosegelen abgeschätzt. Dazu wurden verschiedene Volumina aus den Elutionslösungen neben einem DNA-Standard aufgetragen, der definierte Mengen an DNA/Bande enthielt (Massruler, MBI). Die der Größe nach entsprechende Bande wurde mit Hilfe der Ethidiumbromidfärbung mit den eluierten DNAs verglichen. Die Konzentration von Midi-Präparation und isolierter Gesamt-RNA wurde mit einem Spektralphotometer (BioPhotometer, Eppendorf) bestimmt. Nach Abgleichen des Nullwertes konnten die Absorption der gemessenen Nukleinsäurelösung (bei $260 \mathrm{~nm}$ ) bestimmt und gleichzeitig Verunreinigungen durch Proteine (bei $280 \mathrm{~nm}$ ) bzw. Salze (bei $320 \mathrm{~nm}$ ) festgelegt werden. Die Berechnung der Nukleinsäurekonzentration wurde nach folgender Formel durchgeführt:

$\mathrm{C}[\mu \mathrm{g} / \mu \mathrm{l}]=(\mathrm{E} 260-\mathrm{E} 320) \times \mathrm{f} \times \mathrm{C}$

$\mathrm{C}=$ Nukleinsäurekonzentration der gemessenen Probe

$\mathrm{E} \quad=$ Extinktion

$\mathrm{f} \quad=\quad$ Verdünnungsfaktor

c $=$ nukleinsäurespezifischer Koeffizient in $\mu \mathrm{g} / \mu \mathrm{l}$

für doppelsträngige DNA: $\quad c=0,05 \mu \mathrm{g} / \mu \mathrm{l}$

für einzelsträngige DNA: $\quad c=0,025 \mu \mathrm{g} / \mu \mathrm{l}$

für RNA: $\quad \mathrm{c}=0,04 \mu \mathrm{g} / \mu \mathrm{l}$

\subsubsection{Enzymatische Modifikation von DNA}

\subsubsection{Spaltung von DNA mit Restriktionsendonukleasen}

Zur enzymatischen Spaltung von DNA wurde der Restriktionsansatz in einem Volumen von mindestens $20 \mu \mathrm{l}$ bei der für das Enzym optimalen Temperatur für 1-2 h oder über Nacht inkubiert, wobei pro $\mu \mathrm{g}$ DNA 2-3 U des jeweiligen Enzyms eingesetzt wurden. Für den simultanen Verdau mit zwei Restriktionsendonukleasen wurde ein Puffer eingesetzt, der beiden Enzymen eine ausreichende Aktivität erlaubt. Die Vollständigkeit der Spaltung wurde mittels Agarose-Gelelektrophorese überprüft. Die Restriktionsendonukleasen wurden vor der Durchführung weiterer enzymatischer Modifikationen hitzeinaktiviert (15 min, 65 $\mathrm{C}$ ). 


\subsubsection{Auffüllreaktion von DNA-Fragmenten}

Durch die Behandlung mit Klenow-Fragment oder Taq-Polymerase mit proof-reading Aktivität wurden 5'-überhängende Enden von DNA-Fragmenten zu stumpfen (blunt ends) aufgefüllt. Die Reaktionen wurden in Volumina von $20 \mu$ l durchgeführt, wobei jeweils ca. 1 $\mu g$ DNA modifiziert werden konnte. Die genauen Bedingungen der Reaktion richteten sich nach den Angaben des Herstellers des verwendeten Enzyms. Wegen der hohen Stabilität des Enzyms mußte die so behandelte DNA mit einer Phenol/Chloroform Extraktion mit anschließender Ethanolfällung oder über Agarosegelelektrophorese mit anschließender Glasmilchelution (2.2.1.8) aufgereinigt werden.

\subsubsection{Dephosphorylierung von Plasmid-DNA}

Um eine Religation linearisierter Plasmid-DNA zu verhindern, wurde, eine Dephosphorylierung durchgeführt. Die endständigen 5'-Phosphatgruppen des Vektors wurden mit hilfe des Enzyms Antartic Phosphatase entfernt. Dazu wurde die DNA mit 2 U Antarctic Phosphatase für $1 \mathrm{~h}$ bei $37^{\circ} \mathrm{C}$ und anschließend zur Hitzeinaktivierung des Enzyms für 15 min bei $65^{\circ} \mathrm{C}$ inkubiert.

\subsubsection{Ligation von DNA-Fragmenten}

Die Ligation von Vektor-DNA (geschnitten und dephosphoryliert) mit DNA-Fragmenten wurde in dem vom Hersteller angegebenen Puffersystem der T4-Ligase in $10 \mu$ l-Ansätzen durchgeführt. Das Enzym T4-DNA-Ligase katalysiert dabei die Bildung von Phosphodiesterbindungen zwischen 3'-Hydroxyl- und 5'-Phosphatenden der linearisierten DNA, so dass rekombinante DNA-Moleküle entstehen. In der Regel wurden folgende Mengen für einen Ligationsansatz eingesetzt:

$\begin{array}{rl}25-50 \mathrm{ng} & \text { Vektor-DNA } \\ 30-120 \mathrm{ng} & \text { Insert-DNA } \\ 1 \mu \mathrm{l} & \text { T4-DNA-Ligase }(5 \mathrm{U} / \mu \mathrm{l}) \\ 1 \mu \mathrm{l} & 10 \mathrm{x} \text { Ligationspuffer } \\ \text { ad } 10 \mu \mathrm{l} & \mathrm{H}_{2} \mathrm{O}\end{array}$


Der Ansatz wurde über Nacht bei $4^{\circ} \mathrm{C}$ inkubiert.

\subsubsection{Subklonierung von PCR- und RT-PCR-Produkten}

Taq- und andere Polymerasen besitzen eine terminale Transferase-Aktivität, die zu einer Addition von einem Nukleotid an das 3'-Ende von PCR-Produkten führt. In Anwesenheit aller vier Nukleotide wird hauptsächlich dA angehängt. Diese terminale Transferase-Aktivität ist die Grundlage für die TA-Klonierungsstrategie. Für die Subklonierung von PCR- und RTPCR-Produkten wurde das pGEM-T-easy Vektor-System verwendet, bei welchem die Enden des linearisierten Vektors am 5'-Ende T-Überhänge besitzen. Folgende Komponenten wurden für den Ligationsansatz verwendet:

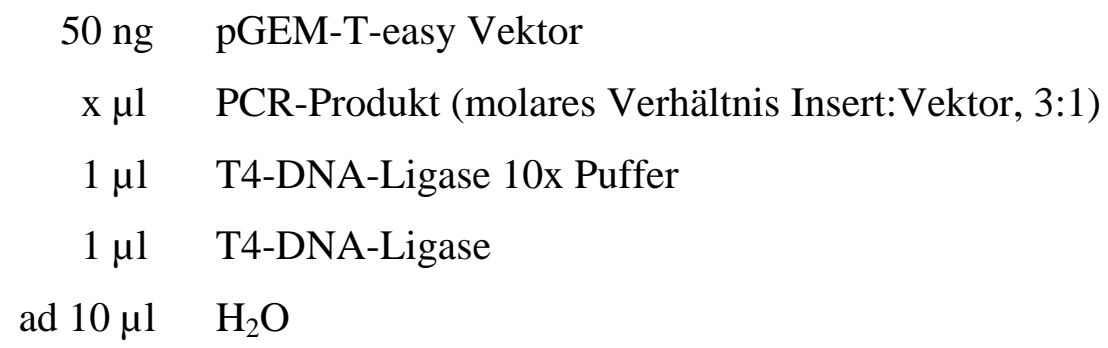

Die Bestandteile wurden gemischt und über Nacht bei $4^{\circ} \mathrm{C}$ inkubiert. Die Produkte einer Ligation wurden anschließend in kompetente E. coli Bakterien transformiert (2.2.2.6).

Die PfuUltra-high-fidelity-Polymerase besitzt keine terminale Transferase-Aktivität, so dass zur Subklonierung der PCR-Produkte in einen pGEM-Teasy Vektor an das 3'-Ende ein dA angehängt werden muss. Folgende Komponenten wurden dabei gemischt und bei $70^{\circ} \mathrm{C}$ für 30 min inkubiert:

$$
\begin{array}{ll}
7 \mu \mathrm{l} & \text { aufgereinigtes PCR-Produkt } \\
1 \mu \mathrm{l} & \text { Platinum-Taq } \\
1 \mu \mathrm{l} & \text { 10x Platinum-Puffer }+\mathrm{MgCl}_{2} \\
1 \mu \mathrm{l} & \text { dATPs (2mM) }
\end{array}
$$

Anschließend konnte eine Ligation wie oben beschrieben durchgeführt werden. 


\subsubsection{Transformation kompetenter Zellen mit Plasmid-DNA}

[Hanahan, 1983]

Für die Transformation wurde zunächst ein $50 \mu$ l-Aliquot kompetenter Zellen auf Eis aufgetaut, 5-10 $\mu \mathrm{l}$ des Ligationsansatzes hinzugefügt und für $30 \mathrm{~min}$ auf Eis inkubiert. Anschließend wurden die Zellen einem Hitzeschock bei $42^{\circ} \mathrm{C}$ für 1 min ausgesetzt und umgehend für 2 min auf Eis gestellt. Nach Zugabe von $500 \mu$ l SOC-Medium erfolgte eine einstündige Inkubation des Transformationsansatzes bei $37^{\circ} \mathrm{C}$ unter Schütteln. Zuletzt wurden 50-500 $\mu \mathrm{l}$ der transformierten Zellen auf Agarplatten ausgestrichen, die der Resistenz des transformierten Plasmids entsprechende selektive Agenzien enthielten. Einzelkolonien zeigten sich nach einer Inkubation über Nacht bei $37^{\circ} \mathrm{C}$.

\subsubsection{Radioaktive Random prime-Markierung von Nukleinsäuren}

[Feinberg und Vogelstein, 1983]

Für die radioaktive Markierung von Sonden zur Hybridisierung von Southern Blot-Analyse wurden doppelsträngige DNA-Fragmente (50-150 ng in $46 \mu \mathrm{H}_{2} \mathrm{O}$ ) für 5 min in einem kochenden Wasserbad denaturiert und anschließend auf Eis abgekühlt. $\mathrm{Zu}$ diesen einzelsträngigen Templates wurden $40 \mu \mathrm{Ci}(4 \mu \mathrm{l})\left[\alpha^{32} \mathrm{P}\right] \mathrm{dCTP}$ (Amersham) gegeben. Mit diesem Ansatz wurden die an eine Glasmatrix gebundenen Komponenten des Rediprime ${ }^{\mathrm{TM}}$ Random labelling Kit II (Amersham Biosciences, Freiburg) gelöst. Der getrocknete Rediprime $^{\mathrm{TM}}$ Reaktionsansatz enthält Oligo(dN)9-Primer, Reaktionspuffer, Klenow-DNA Polymerase und nichtmarkierte Nukleotide (dATP, dGTP und dTTP). Anschließend wurde die markierte DNA mit Hilfe einer MicroSpin S-200HR Säule (Amersham), den Herstellerangaben folgend, von nicht eingebautem [ $\left.\alpha^{32} \mathrm{P}\right] \mathrm{dCTP}$ befreit.

\subsubsection{Radioaktive Endmarkierung von Oligonukleotiden}

Für den Elektrophoretischen Mobilitäts-Shift-Assay (EMSA) wurden Oligonukleotide in Sense- und Antisense-Orientierung hergestellt (Invitrogen, Karlsruhe). Nach der Anlagerung der einzelsträngigen Oligonukleotide werden doppelsträngige Fragmente mit überhängenden 
Enden (Guanin) erhalten. Für das Anlagern wurden die komplementären Oligonukleotide zusammengegeben und 5 min im kochenden Wasserbad denaturiert. Der Ansatz wurde langsam bis auf RT abgekühlt.

$$
\begin{array}{rl}
12,5 \mu \mathrm{l} & 100 \mu \mathrm{M} \text { Oligonukleotid in Sense } \\
12,5 \mu \mathrm{l} & 100 \mu \mathrm{M} \text { Oligonukleotidin Antisense } \\
5 \mu \mathrm{l} & 10 \mathrm{x} \text { Oligonucleotid Annealing Buffer } \\
20 \mu \mathrm{l} & \text { DEPC- } \mathrm{H}_{2} \mathrm{O}
\end{array}
$$

Das Markieren erfolgte mit Klenow-Polymerase unter Verwendung von $\left[\alpha^{32} \mathrm{P}\right] \mathrm{dCTP}$. Folgende Komponenten wurden dabei gemischt und bei $37^{\circ} \mathrm{C}$ für $1 \mathrm{~h}$ inkubiert:

$$
\begin{array}{rl}
1,6 \mu \mathrm{l} & \text { dopplesträngige Oligonukleotide }(2,5 \mu \mathrm{M}) \\
2 \mu \mathrm{l} & 10 \mathrm{x} \text { Klenow Puffer } \\
5 \mu \mathrm{l} & \text { dNTP ohne dCTP (je 0,5 mM) } \\
1 \mu \mathrm{l} & {\left[\alpha^{32} \mathrm{P}\right] \text { dCTP }} \\
1 \mu \mathrm{l} & \text { Klenow- Ploymerase } \\
\text { ad } 20 \mu \mathrm{l} & \text { Nuklease- freies } \mathrm{H}_{2} \mathrm{O}
\end{array}
$$

Die Reaktion wurde unter Zugabe von $1 \mu$ 0,5 mM EDTA gestoppt. Anschließend wurde die Probe mit Nuklease-freiem $\mathrm{H}_{2} \mathrm{O}$ auf $100 \mu \mathrm{l}$ aufgefüllt und durch Auftragen auf eine MicroSpin S-200HR Säule (Amersham), den Herstellerangaben folgend, von nicht eingebautem [ $\left.\alpha^{32} \mathrm{P}\right]$ dCTP befreit. Die Aktivität in 1-5 $\mu$ l der gelösten Sonde wurde im Szintillationszähler (Canberra/Packard, Dreieich) gemessen. Das ca. 105 Zerfallsereignisse/min entsprechende Volumen wurde in einem Polyacrylamidgel auf seine Integrität geprüft, indem eine einzelne Bande auf einem geschwärzten Röntgenfilm nachgewiesen wurde.

\subsubsection{DNaseI-Behandlung}

Nach der Isolierung von Gesamt-RNA aus Gewebe wurde diese einer DNAseI- Behandlung (1U/1 $\mu$ g-RNA) unterzogen, um die Gefahr von DNA-Kontamination in einer folgenden RTPCR zu vermeiden. Die Komponenten wurden $1 \mathrm{~h}$ bei $37^{\circ} \mathrm{C}$ inkubiert und danach wurde die DNAse I für 15 min bei $70^{\circ} \mathrm{C}$ inaktiviert. 


\subsubsection{Gelelektrophorese}

\subsubsection{Gelelektrophorese von DNA}

Testgele zur Kontrolle von Restriktionsanalysen, Gele für Restriktionskartierungen oder für Insertisolierungen wurden in Gelkammern gegossen. Je nach Größe der zu trennenden Fragmente wurde 0,5 bis 3\% (w/v) Agarose zugesetzt. Je nach Anwendung wurde 1x Turbooder 1x TAE- (für Insertisolierungen) Puffer eingesetzt. Nach dem Lösen der Agarose durch mehrmaliges kurzes Aufkochen des Ansatzes wurde die Lösung auf RT abgekühlt. Kurz vor dem Gießen des Gels wurde Ethidiumbromid in einer Endkonzentration von 0,1 $\mu \mathrm{g} / \mathrm{ml}$ zugesetzt. Die Größenbestimmung der DNA-Fragmente erfolgte über den Vergleich mit einem geeigneten Längenstandard. Die Proben wurden vor dem Einfüllen in die Taschen des Gels mit ca. 20\% Stop-Mix beschwert. Die Elektrophorese erfolgte anschließend bei konstanter Spannung von 50-150 V.

\subsubsection{Native Polyacrylamid-Gelelekrophorese}

Die Native Polyacrylamid-Gelelektrophorese (PAGE) wurde zur Darstellung von Elektrophoretischen Mobilitäts-Shift-Assays (2.2.7) verwendet. Es wurden 6\%ige Gele in den folgenden Komponenten zwischen zwei Glasplatten ( 20 x 20 x 0,15 mm) einer vorbereiteten Gelapparatur (Fa. PHASE, Lübeck) gegossen:

$\begin{array}{rl}7,5 \mathrm{ml} & \text { Acrylamid/Bisacrylamid-Lösung 40\% (19:1) } \\ 10 \mathrm{ml} & 5 \times \text { TBE } \\ 50 \mu \mathrm{l} & 10 \% \text { APS } \\ 50 \mu \mathrm{l} & \text { TEMED } \\ \text { ad } 50 \mathrm{ml} & \mathrm{H}_{2} \mathrm{O}\end{array}$




\subsubsection{Transfertechniken von Nukleinsäuren}

\subsubsection{Southern Blot-Analyse}

[Southern, 1975]

Für die Southern Blot-Analyse wurden je 15-20 $\mu \mathrm{g}$ genomische DNA einer Restriktionsspaltung unterzogen und gelelektrophoretisch aufgetrennt. Die DNA wurde im Gel mit Ethidiumbromid angefärbt, fotografiert und anschließend bei RT unter Schütteln für 15 min in 0,25 M HCl inkubiert. Dadurch kommt es zur partiellen Depurinierung und infolgedessen zur Fragmentierung der DNA, wodurch der spätere Transfer großer Fragmente verbessert wird. Anschließend erfolgte eine 30 minütige Inkubation in Denaturierungslösung und eine 45 minütige Inkubation in Neutralisierungslösung. Die so behandelte einzelsträngige DNA wurde durch ein modifiziertes Kapillarblotting-Verfahren mit einem Turbo-Blotter ${ }^{\mathrm{TM}}$ der Firma Schleicher \& Schüll (Dassel) auf eine Hybond XL-Nylonmembran mit nukleinsäurebindenden Eigenschaften übertragen und durch crosslinking mit UV-Licht (UV Stratalinker ${ }^{\mathrm{TM}}$ 1800, Stratagene, Heidelberg, 254 nm, 120 mJ) fixiert. Die Southern BlotAnalyse wurde den Herstellerangaben folgend mit 20x SSC als Transferpuffer durchgeführt und erfolgte für 6-16 h bei RT.

\subsubsection{Hybridisierung mit radioaktiv markierten DNA-Sonden}

Die Nitrocellulosefilter wurden in 2x SSC äquilibriert und mit der nicht beladenen Fläche luftblasenfrei an die Wandung des mit 2x SSC gefüllten Hybridisierungsröhrchens gedrückt. Der Puffer wurde durch $8 \mathrm{ml}$ Rapid Hyb Puffer (Amersham) ersetzt, der $150 \mu \mathrm{l}$ denaturierte Lachspermien-DNA (10 mg/ml, 5 min im kochenden Wasserbad erhitzt und auf Eis abgekühlt) enthielt. Die Prähybridisierung erfolgte zur Absättigung unspezifischer Bindungen für 1-4 h bei $65^{\circ} \mathrm{C}$ im Rollofen (Bachhofer, Reutlingen). Zur spezifischen Hybridisierung wurde dann die Sonde mit weiteren $150 \mu$ l Lachsspermien-DNA wie oben beschrieben denaturiert und nach dem schnellen Abkühlen direkt in die Prähybridisierungslösung gegeben. Die Hybridisierung erfolgte über Nacht unter denselben Bedingungen wie die Prähybridisierung. 
Zur weiteren Behandlung der Membranen wurde die Hybridisierungslösung mit Sonde abgegossen (gegebenenfalls zur erneuten Verwendung verwahrt). Die Filter wurden je nach gewünschter Stringenz in den Hybridisierungsröhrchen mehrfach mit jeweils $50 \mathrm{ml}$ Waschlösung II bei $65^{\circ} \mathrm{C}$ im Rollerofen solange gewaschen, bis keine deutliche Abnahme der Radioaktivität mehr zu messen war. Die getrockneten Membranen wurden in Folie eingeschweißt und zur Auswertung mit einem Röntgenfilm bei $-70^{\circ} \mathrm{C}$ (Autoradiographiekassette mit Verstärkermembran) oder mit einer Phosphor-Imagermembran (Kodak, Rochester, NY) bei RT exponiert.

\subsubsection{Polymerase-Kettenreaktion (PCR)}

[Saiki et al., 1985]

\subsubsection{DNA-Amplifikation mittels Polymerase-Kettenreaktion}

Die Polymerase-Kettenreaktion (PCR) wurde mit folgendem Reaktionsansatz durchgeführt:

$$
\begin{array}{cl}
\mathrm{x} \mu \mathrm{l} & \text { Template-DNA }(10-200 \mathrm{ng} \text { DNA }) \\
1 \mu \mathrm{l} & \text { forward Primer }(10 \mathrm{pmol} / \mu \mathrm{l}) \\
1 \mu \mathrm{l} & \text { reverse Primer }(10 \mathrm{pmol} / \mu \mathrm{l}) \\
1 \mu \mathrm{l} & \mathrm{dNTPs}(10 \mathrm{mM}) \\
5 \mu \mathrm{l} & \text { Taq-Polymerase Puffer }(10 \mathrm{x}) \\
0,4 \mu \mathrm{l} & \text { Platinum Taq-Polymerase }(2,5 \mathrm{U} / \mu \mathrm{l}) \\
\text { ad } 50 \mu \mathrm{l} & \mathrm{dH}_{2} \mathrm{O}
\end{array}
$$

Die DNA-Amplifikation erfolgte mittels 30-40 Zyklen in einem PTC-200 Thermocycler der Firma MJ Research. Die Anzahl der Zyklen, die einzelnen Temperaturschritte und die jeweilige Dauer der Zyklen mussten für jedes DNA-Fragment und die dafür eingesetzten Primer neu gewählt werden. Ein Zyklus bestand aus folgenden Einzelschritten: 


\begin{tabular}{|c|c|c|c|}
\hline $95^{\circ} \mathrm{C}$ & $3 \mathrm{~min}$ & & Vordenaturierung \\
\hline $94^{\circ} \mathrm{C}$ & $30 \mathrm{~s}$ & & Denaturierung \\
\hline $58-65^{\circ} \mathrm{C}$ & $30 \mathrm{~s}$ & > 30-35 Zyklen & Annealing \\
\hline $72^{\circ} \mathrm{C}$ & $1 \mathrm{~min} / \mathrm{kb}$ & & Elongation \\
\hline $72^{\circ} \mathrm{C}$ & $5 \mathrm{~min}$ & & Endelongation \\
\hline $4^{\circ} \mathrm{C}$ & $\infty$ & & Aufbewahrung \\
\hline
\end{tabular}

Für eine Erhöhung der Spezifität unspezifisch bindender Primer wurde eine sog. touchdown PCR durchgeführt. Dabei wurde die Anlagerungstemperatur über sieben Zyklen hinweg sukzessive um $1^{\circ} \mathrm{C}$ pro Zyklus herabgesetzt und im Anschluss erfolgten weitere 30 Zyklen bei konstanter Anlagerungstemperatur. 1/10 Vol des Ansatzes wurde mit Stop-Mix gemischt und je nach Größe des PCR-Produkts auf ein 1-1,5\%iges Agarosegel aufgetragen und elektrophoretisch aufgetrennt.

\subsubsection{PCR-Mutagenese}

Die PCR-Mutagenese oder auch quick-change Mutagenese eignet sich zur Einführung definierter Basensubstitutionen in Sequenzen. Verwendet wurde das Quick-Change II XL Site-Directed Mutagenesis Kit der Firma Stratagene und die Mutagenese wurde den Herstellerangaben folgend durchgeführt. Das Prinzip dieser Methode ist die Verwendung zweier Oligonukleotid-Primer, die jeweils komplementär zu einem der beiden Stränge des Template-Plasmids sind und welche die Basensubstitution tragen. In einer PCR-Reaktion fand die Verlängerung der an das Template angelagerten Primer durch die PfuUltra high-fidelityDNA-Polymerase statt. Dadurch entstanden mutierte Plasmide, die sog. staggerd nicks (verschobene Einzelstrangbrüche) besitzen. Es folgte eine Endonuklease-Spaltung der DNA des Mutagenese-Ansatzes durch das Enzym DpnI. DpnI ist spezifisch für methylierte und hemimethylierte DNA und spaltet daher die nicht mutierte Template-DNA. Die nicht methylierten, neusynthetisierten Plasmide, die die Mutation tragen, bleiben dagegen intakt. Zuletzt wurden ultrakompetente XL10-Gold-Zellen mit einem Aliquot des EndonukleaseAnsatzes transformiert. In den transformierten XL10-Gold-Zellen findet schließlich die Reparatur der Einzelstrangbrüche der mutierten Plasmide statt. 


\subsubsection{Reverse Transkription}

[Loh et al., 1989]

Bei der Erststrang-Synthese dient die mRNA als Matrize für das Enzym Reverse Transkriptase, welches eine der mRNA komplementäre cDNA synthetisiert. Hierbei können entweder ein Oligo(dT)-Primer, der mit dem Poly(A)-Schwanz der mRNA hybridisiert, oder ein genspezifischer Primer verwendet werden. Im Falle des Oligo(dT) -Primers werden alle vorhandenen mRNAs revers transkribiert, während bei der Verwendung eines genspezifischen Primers Transkripte umgeschrieben werden, an die der Primer binden kann. Im Idealfall sind dies nur die Transkripte eines Gens. In einer anschließenden PCR wird mit Hilfe von sequenzspezifischen Primern ein DNA-Fragment amplifiziert. Die RT-PCR wurde mit Hilfe der SuperScript ${ }^{\mathrm{TM}}$ II Reversen Transkriptase von Invitrogen (Karlsruhe) durchgeführt.

Für die Erststrang-Synthese wurden $1 \mathrm{ng}$ - $5 \mu \mathrm{g}$ RNA zusammen mit $1 \mu$ l Oligo(dT)-Primer (500 $\mu \mathrm{g} / \mathrm{ml})$ und $1 \mu \mathrm{dNTP}-\mathrm{Mix}(10 \mathrm{mM})$ eingesetzt. Mit RNase-freiem Wasser wurde der Ansatz auf ein Gesamtvolumen von $12 \mu \mathrm{l}$ aufgefüllt. Zunächst erfolgte die Denaturierung der RNA bei $65^{\circ} \mathrm{C}$ für 10 min. Nach dem Abkühlen auf Eis wurden $4 \mu \mathrm{l} 5$ First-Strand Puffer und $2 \mu \mathrm{l}$ 0,1 M DTT zugegeben und für 2 min auf $42^{\circ} \mathrm{C}$ temperiert. Anschließend folgten die Zugabe von $1 \mu$ l SuperScript ${ }^{\mathrm{TM}}$ II RT (Invitrogen, Karlsruhe) und eine 50 minütige Inkubation bei $42^{\circ} \mathrm{C}$. Zuletzt wurde das Enzym für 15 min bei $70^{\circ} \mathrm{C}$ inaktiviert.

\subsubsection{Quantitative real time-PCR}

Real time-PCR bezeichnet ein PCR-Verfahren, bei dem während der PCR die Menge der entstandenen Produkte in Echtzeit gemessen wird. Die Messung der Produktzunahme geschieht anhand von Fluoreszenzlicht, welches in Abhängigkeit von der Produktmenge emittiert wird. Eine Möglichkeit zur Generierung produktabhängiger Fluoreszenz bieten dsDNA bindende Fluoreszenzfarbstoffe. Hier wurde der Cyaninfarbstoff SYBR-Green I [Jin et al., 1994; Singer et al., 1994], welcher als QuantiTect SYBR-Green PCR Master Mix von der Firma Qiagen (Hilden) vertrieben wird, verwendet. Der Farbstoff bindet weitgehend sequenzunspezifisch in der kleinen Furche doppelsträngiger DNA, mit einer etwa 100fach höheren Affinität als Ethidiumbromid. Das derart gebundene SYBR-Green fluoresziert nach 
Anregung etwa 1000x stärker als der freie Farbstoff, weshalb SYBR-Green sehr gut geeignet ist, die Akkumulation doppelsträngiger PCR-Produkte sichtbar zu machen [Morrison et al., 1998]. SYBR-Green lässt sich in Gegenwart von doppelsträngiger DNA mit Blaulicht (480 nm) anregen und zeigt ein Emissionsspektrum mit einem Maximum bei $520 \mathrm{~nm}$ (Abb.2.1).

A)

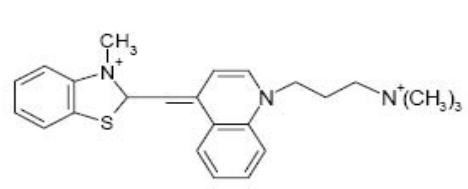

B)

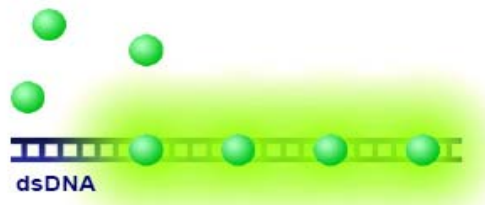

C)

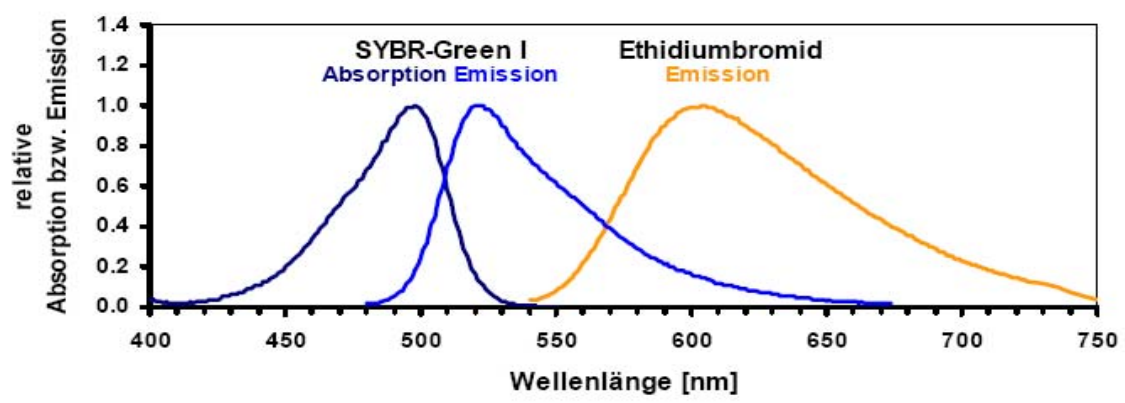

Abb. 2.1: Struktur und Eigenschaften von SYBR-Green I [Wilhelm, 2003].

A. Struktur von SYBR-Green I. B. Generierung von Fluoreszenzsignalen während der PCR durch SYBR-Green. Das Anregungslicht wird von frei in Lösung befindlichem SYBR-Green nicht absorbiert. Nur der in der kleinen Furche der dsDNA gebundene Farbstoff fluoresziert nach Anregung. C. Absorptions-/Emissionsspektren von SYBR-Green I. Zum Vergleich ist das Emissionsspektrum von Ethidiumbromid nach Anregung mit Licht einer Wellenlänge von $320 \mathrm{~nm}$ unter sonst gleichen Bedingungen gezeigt.

Die Analyse wurde im 384-Well Maßstab mit dem „ABI Prism 7900T Sequence Detection System" durchgeführt. Dieses System arbeitet mit einem Temperatur-Cycler und einem Laser, der zu jedem der 384 Reaktionsansätze gelenkt wird und diese anregt. Über ein ladungsempfindliches Detektionssystem erfolgte die Messung der Fluoreszenz jeder Probe, die durch an dsDNA gebundenes SYBR-Green emittiert wird. Die Daten wurden mithilfe der Sequenz-Detektionssystem-Software (SDS Version 2.1, PE Applied Biosystems) quantifiziert, exportiert und in Excel (Microsoft) ausgewertet. Die Reaktions-Ansätze enthielten je 0,25 $\mu \mathrm{M}$ der Oligonukleotide und $5 \mu$ l 2x QuantiTect ${ }^{\mathrm{TM}}$ SYBR $^{\circledR}$-Green PCRMaster-Mix (Qiagen, Hilden). Letzterer enthält die HotStarTaq ${ }^{\mathrm{TM}}$ DNA-Polymerase in einem optimierten Puffer, dNTP-Mix (mit dUTP-Additiv), den SYBR ${ }^{\circledR}$-Green I FluoreszenzFarbstoff und ROX-Farbstoff als passive Referenz. Der ROX-Farbstoff soll die Korrektur 
minimaler Abweichungen erlauben, die durch Pipettierungenauigkeiten oder FluoreszenzSchwankungen entstehen können.

Jedem Ansatz wurden 25 ng genomische DNA zugefügt (Endkonzentration 2,5 ng/ $\mu$ ). Für die Erstellung einer Standardkurve wurden Ansätze mitgeführt, die entweder genomische DNA einer klinisch unauffälligen Kontroll-Person oder einer transgenen Maus der F1-Generation in den Endkonzentrationen 5,0 ng/ $\mu \mathrm{l}, 2,5 \mathrm{ng} / \mu \mathrm{l}, 1,25 \mathrm{ng} / \mu \mathrm{l}$ und 0,625 ng/ $\mu \mathrm{l}$ enthielten. Um das Auftreten von unspezifischen Produkten auszuschließen, wurde nach Abschluss der Amplifikation eine Schmelzkurvenanalyse durchgeführt. Dabei wurde kontinuierlich die Fluoreszenz (F) bei steigender Temperatur (T) gemessen und die Steigung $\mathrm{dF} / \mathrm{dT}$ (1. Ableitung) errechnet. Diese wurde gegen die Temperatur aufgetragen und damit die Maxima bei den primerspezifischen Schmelztemperaturen aufgezeigt. Zusätzliche Maxima verrieten unspezifische Produkte, z.B. Primer-Dimere. Folgendes Programm wurde für alle Primer verwendet:

\begin{tabular}{|c|c|c|c|}
\hline $50^{\circ} \mathrm{C}$ & $2 \min$ & & \\
\hline $95^{\circ} \mathrm{C}$ & $15 \min$ & & Vordenaturierung \\
\hline $94^{\circ} \mathrm{C}$ & $15 \mathrm{~s}$ & & Denaturierung \\
\hline $58^{\circ} \mathrm{C}$ & $30 \mathrm{~s}$ & 35 Zyklen & Annealing \\
\hline $72^{\circ} \mathrm{C}$ & $1 \mathrm{~min}$ & & Elongation \\
\hline $95^{\circ} \mathrm{C}$ & $15 \mathrm{~s}$ & & \\
\hline $60^{\circ} \mathrm{C}$ & $15 \mathrm{~s}$ & & \\
\hline $60^{\circ} \mathrm{C}-95^{\circ} \mathrm{C}$ & $2^{\circ} \mathrm{C} / \mathrm{min}$ & & Schmelzkurve \\
\hline
\end{tabular}

Die relative Quantifizierung der initialen Kopienzahl erfolgt bei der real time-PCR anhand des Verhältnisses der Kopienzahl des zu untersuchenden Zielamplikons und eines Referenzamplikons, das unter identischen Bedingungen amplifiziert wird. Bei der Auswertung wird ein Signal-Schwellenwert definiert, bei welchem sich jede Einzelreaktion in der exponentiellen Phase befinden sollte. Der Zeitpunkt (in Zyklen), zu dem das Signal diesen Schwellenwert erreicht, wird als Schwellenwertzyklus oder $\mathrm{C}_{\mathrm{T}}$-Wert (threshold cycle) genannt. Dieser $\mathrm{C}_{\mathrm{T}}$-Wert korreliert mit der Anzahl der Kopien, die für die Reaktion eingesetzt wurden. Wie in Abbildung 2.2 gezeigt, resultiert eine höhere oder niedrigere Start-Kopienzahl in einem signifikant früheren oder späteren Anstieg der Fluoreszenz-Emission. 


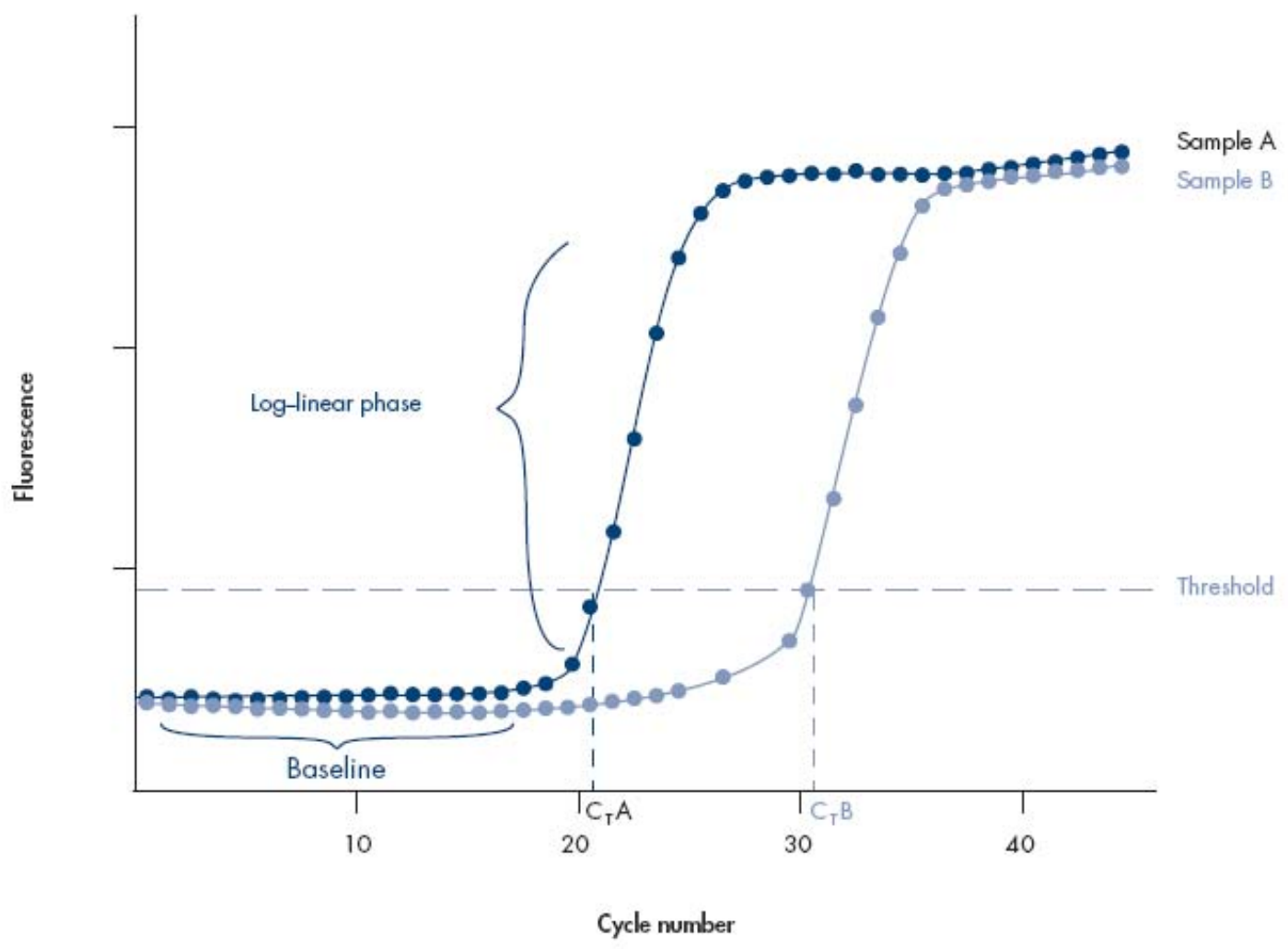

Abb. 2.2: Zunahme der Fluoreszenz zweier Proben (A und B) in Abhängigkeit von der PCR-ZyklusAnzahl. Probe A enthält eine größere Menge an Start-Kopien als Probe B und überschreitet den Schwellenwert daher bei einem früheren Zyklus als Probe A. $\mathrm{C}_{\mathrm{T}}$ : Schwellenwertzyklus. Quelle: QuantiTect SYBR-Green PCR Handbook, Qiagen (2003).

Aus den Daten der Standardkurven für jedes Amplikon interpoliert das Programm SDS 2.1 die theoretisch eingesetzte DNA-Menge für Referenzamplikon und Testamplikon jeder Probe (entweder Patienten-DNA oder Maus-DNA). Da man für das Testamplikon und das Referenzamplikon einer Probe exakt gleiche DNA-Mengen für die Taqman-Analyse einsetzt, sollte das Verhältnis der durch das Programm interpolierten DNA-Menge von Testamplikon zu Referenzamplikon den Wert 1 ergeben. Im Falle einer Deletion des Bereiches, in dem das Testamplikon liegt, befindet sich nur halbsoviel Template-DNA für das Testamplikon wie für das Referenzamplikon in den Taqman-Ansätzen. Bei der Berechnung des Verhältnisses Testamplikon zu Referenzamplikon erhält man in diesem Fall einen Wert von ca. 0,5. Diese Berechnung wurde zur Auswertung der Ergebnisse für alle Amplikons jedes Patienten in Excel durchgeführt. Um zu bestimmen, wie viele Kopien/Integrationen des transgenen Konstruktes nach der Mikroinjektion in den Pronukleus tatsächlich in das Genom der transgenen Mäuse eingebaut wurden, wurde eine real time-PCR mit einem etablierten Standard und der genomischen DNA der transgenen Mäuse durchgeführt. Da die 
Integrationszahl des Standards (genomische DNA von 129/Sv-Mäusen) bekannt ist (1 Kopie), kann man von den dabei erhaltenen Ergebnissen Rückschlüsse auf die noch unbekannte Integrationszahl der transgenen Mäuse ziehen. Die Genotypisierung der transgenen Mäuse wurde mittels relativer Quantifizierung durchgeführt. Für die Erstellung einer Standardkurve wurde eine transgene Maus der F1-Generation verwendet. Im Falle einer homozygoten transgenen Maus befindet sich doppelt soviel Template-DNA für das Testamplikon wie im Vergleich für das Referenzamplikon in den Taqman-Ansätzen. Bei der Berechnung des Verhältnisses von Testamplikon zu Referenzamplikon erhält man in diesem Fall einen Wert von ca. 2. Diese Berechnung wurde zur Auswertung der Ergebnisse für alle Amplikons jeder transgenen Maus in Excel durchgeführt.

\subsubsection{DNA-Sequenzanalyse}

[Sanger et al., 1977]

Die nichtradioaktive Sequenzierung basiert auf dem Prinzip des Kettenabbruchverfahrens [Sanger et al., 1977], wobei vier Didesoxynukleotide zum Einsatz kommen, die jeweils mit verschiedenen Fluoreszenzfarbstoffen markiert sind, welche wiederum während der gelelektrophoretischen Analyse über Laserabtastung automatisch detektiert werden. Die Sequenzreaktion wurde mit 200 ng/kb Plasmid-DNA, 10 pmol sequenzspezifischem Primer und $4 \mu \mathrm{l}$ ET-Mix (DYEnamic ET terminator Cycle sequencing Kit der Firma Amersham, Freiburg) in einem Gesamtansatz von $10 \mu$ l aufgefüllt. Falls PCR-Produkte für die Sequenzierung eingesetzt wurden, erfolgte zuvor eine Aufreinigung über „Montage ${ }^{\mathrm{TM}}$ PCR Centrifugal“-Filter-Säulen (Millipore), die den Herstellerangaben folgend durchgeführt wurde. Die Kettenabbruchreaktion wurde als PCR in einem Thermocycler mit dem folgenden PCR-Programm betrieben:

$\left.\begin{array}{ll}95^{\circ} \mathrm{C} & 1 \mathrm{~min} \\ 95^{\circ} \mathrm{C} & 20 \mathrm{~s} \\ 60^{\circ} \mathrm{C} & 30 \mathrm{~s} \\ 60^{\circ} \mathrm{C} & 3 \mathrm{~min} \\ 60^{\circ} \mathrm{C} & 5 \mathrm{~min}\end{array}\right\} \quad \begin{array}{ll}\text { Denaturierung } \\ \text { Denaturierung } \\ \end{array}$


Anschließend wurde der Ansatz mit $10 \mu \mathrm{l} \mathrm{H}_{2} \mathrm{O}$ aufgefüllt und über eine Sephadex MultiScreen-HV Platte (Millipore) aufgereingt. Die gelelektrophoretische Analyse erfolgte mit der automatischen Sequenzieranlage MegaBACE ${ }^{\mathrm{TM}} 1000$ der Firma Amersham.

\subsubsection{Proteinchemische Techniken}

\subsubsection{Isolierung von Gesamtprotein aus Zellkulturen}

Gesamtproteine aus kultivierten Zellen und Geweben wurden zum immunologischen Nachweis nach SDS-PAGE und Transfer der Proteine auf Nitrocellulose und zur Verwendung in Reportergen-Assays und Phosphatase-Assays isoliert. Der einzige Unterschied bei der Proteinisolierung betrifft die Zusammensetzung des Lysispuffers (2.1.6). Die bei Transfektionsexperimenten verwendeten adhärenten Zellen wurden 24-48 h nach der Transfektion einmal mit PBS gewaschen. Anschließend wurde der PBS-Puffer sorgfältig entfernt und die Zellen mit $200 \mu$ l Lysispuffer, z.B. je Schale einer 12-Well Platte (Costar®, Fa. Corning, New York), lysiert. Anschließend wurden die Zellextrakte in $1,5 \mathrm{ml}$ Reaktionsgefäße überführt, Zelltrümmer durch Zentrifugation pelletiert (5 min, 12000 x g, $4^{\circ} \mathrm{C}$ ) und ein Aliquot des Überstandes im entsprechenden Test auf Luciferase- oder $\beta$ - Galactosidaseaktivität untersucht.

Die Isolierung des Gesamtproteins aus frischen Lymphozyten wurde aus 0,5 ml Blut durchgeführt. Das Blut wurde mit 4,5 ml Erythrozytenlysepuffer gemischt und nach $10 \mathrm{~min}$ Inkubation wurden die Lymphozyten pelletiert (10 min, $1000 \mathrm{x}$ g, RT) und dreimal mit TBS gewaschen. Die Proteine wurden in $150 \mu$ l Lysispuffer IV resuspendiert und in Aliquots eingefroren.

\subsubsection{Isolierung von Kernproteinen aus kultivierten Zellen}

Die zur Isolierung von Kernproteinen verwendeten adhärend wachsenden HeLa-Zellen wurden vor der Proteinextraktion nach zweimaligem Waschen mit PBS noch in der Kulturschale mit NE-Puffer (1 ml NE-Puffer /100 mm Kulturschale) überschichtet, mit einem Schaber abgekratzt und in $2 \mathrm{ml}$ Reaktionsgefäße überführt. Die Zellen wurden 15 min auf Eis inkubiert und anschließend zum Aufbrechen der Zellwände 10x durch eine 25 gauge Kanüle aufgezogen. Die Kerne wurden anschließend in einem kurzen Zentrifugationsschritt (30 s, 
$10000 \mathrm{x} \mathrm{g}, 4^{\circ} \mathrm{C}$ ) von den Zellresten getrennt und die pelletierten Kerne in $100 \mu \mathrm{l} \mathrm{NESG-}$ Puffer resuspendiert. Der Aufschluß der Kerne erfolgte dann während einer 30 minütigen Inkubation auf Eis, wobei die Proben häufig aufgeschüttelt wurden. Die Kernproteine blieben nach der folgenden Zentrifugation (20 min, 20000 x g, $4^{\circ} \mathrm{C}$ ) im Überstand und wurden bei $70^{\circ} \mathrm{C}$ gelagert oder bis zur Verwendung auf Eis aufbewahrt.

\subsubsection{Isolierung von Gesamtprotein aus Organen der Maus}

Die direkt nach dem Abtöten der Mäuse entnommenen Organe wurden mit eiskaltem PBS gewaschen und zunächst in flüssigem Stickstoff eingefroren. Zur Isolierung der Proteine wurde zu den Organen $1 \mathrm{ml}$ Lysispuffer III gegeben, zu dem vorher frischer Proteaseschutz und 3,5 mM DTT hinzugefügt wurde. Mit Hilfe eines speziell für 1,5 ml Eppendorf-Gefäße angefertigten Mörsers wurde das Gewebe zerstoßen. Die nicht löslichen Bestandteile wurden 10 min bei 16000 x g abzentrifugiert. Der die Proteine enthaltende Überstand wurde in ein sauberes Eppendorf-Gefäß überführt und bis zur weiteren Verwendung als Aliquots bei $-80^{\circ} \mathrm{C}$ eingefroren.

\subsubsection{Transkription und Translation in vitro}

Die in vitro Transkription/Translation (T/T) stellt eine einfache und schnelle Möglichkeit dar, Gensequenzen in ihre Aminosäuresequenz $\mathrm{zu}$ übersetzen und $\mathrm{zu}$ analysieren. Das hier verwendete TNT ${ }^{\circledR}$ T7 Expressway Plus Expression System von Invitrogen ist geeignet für die in vitro Translation eukaryontischer DNA-Sequenzen. Für die Transkription benötigt man zirkuläre Plasmid-DNA oder ein PCR-Fragment, welche den Promotor für die T7 RNAPolymerase vor der Gensequenz, die transkribiert bzw. translatiert werden soll, enthalten. Zur Durchführung einer Transkription/Translation in vitro wurden folgende Komponenten verwendet: 


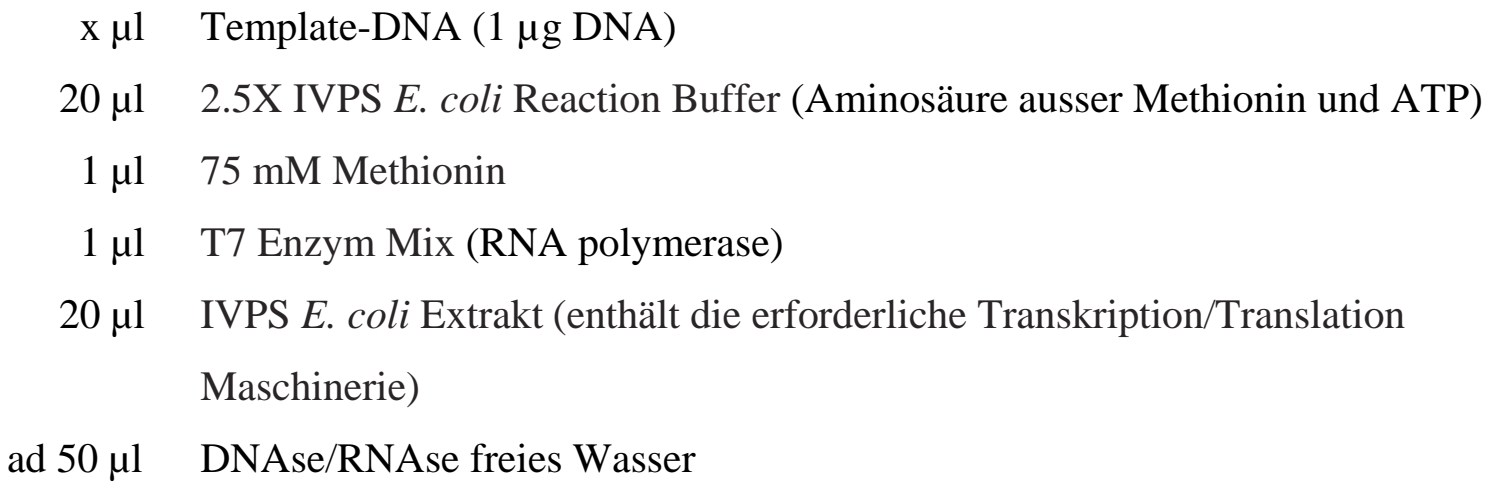

Die Reaktion erfolgte in einem $2 \mathrm{ml}$ Reaktionsgefäß und wurde $4 \mathrm{~h}$ bei $37^{\circ} \mathrm{C}$ und $1200 \mathrm{x} \mathrm{g}$ inkubiert. Danach wurde $5 \mu \mathrm{l}$ RNaseA hinzugegeben und bei $37^{\circ} \mathrm{C}$ inkubiert. Nach der folgenden Zentrifugation ( $1 \mathrm{~min}, 20000 \mathrm{x} \mathrm{g}, 4^{\circ} \mathrm{C}$ ) wurden die Proteine bei $-70^{\circ} \mathrm{C}$ gelagert oder bis zur Verwendung innerhalb einiger Minuten auf Eis aufbewahrt. Die Analyse der Reaktionsprodukte erfolgte mittels SDS-PAGE. Als Postivkontrolle wurde die in vitro Transkription/Translation mit dem Vektor pEXP1-GW/lacZ durchgeführt, so dass durch Messung der ß-Galaktosidase die Effizienz der Methoden bestätigt werden konnte. Als Negativkontrolle wurde $\mathrm{H}_{2} \mathrm{O}$ verwendet.

\subsubsection{Konzentrationsbestimung von Proteinen}

[Bradford et al., 1976]

Coomassie Brilliant Blue G250 wird durch die Bindung an Proteine vom kationischen in den anionischen Zustand überführt und absorbiert in diesem Zustand Licht mit einer Wellenlänge von $595 \mathrm{~nm}$ (der kationische Zustand absorbiert bei $470 \mathrm{~nm}$ ). Das vorgefertigte BradfordReagenz (Roti®-Nanoquant, Fa. Roth) enthält den Farbstoff Coomassie Brilliant Blue G250, welcher unter Zusatz von Ethanol und $\mathrm{H}_{3} \mathrm{PO}_{4}$ gelöst in $\mathrm{H}_{2} \mathrm{O}$ vorliegt. Für die Verwendung in Mikrotiterplatten wurde wie vom Hersteller angegeben 1 Vol des Reagenz mit $4 \mathrm{Vol}_{2} \mathrm{O}$ verdünnt. Pro Messung wurden dann $200 \mu$ l verdünntes Reagenz zu $50 \mu l$ der vorgelegten Standards und verdünnten Proben gegeben. Alle Absorptionsmessungen wurden immer auf eine Eichgerade mit BSA (BSA gelöst in $\mathrm{H}_{2} \mathrm{O}: 0 ; 10 ; 20 ; 40 ; 60 ; 80 ; 100 \mu \mathrm{g} / \mathrm{ml}$ ) bezogen. Nach 5 minütiger Inkubation bei RT wurde die $\mathrm{OD}_{595}$ und nachfolgend die $\mathrm{OD}_{450}$ in einer flachbödigen 96-Well-Mikrotiterplatte (Greiner, Nürtingen) in einem „EL 800 Universal Microplate Reader“ (Bio-Tek Instruments Inc., Winooski, Vt.) gemessen. Alle Messungen 
wurden in Doppelbestimmungen durchgeführt. Zur Auswertung wurde die $\mathrm{OD}_{595} / \mathrm{OD}_{450}$ für jede Probe gegen die eingesetzte Proteinmenge aufgetragen. Bei der Messung von Proben, die mit Hilfe von Glycerin, Triton ${ }^{\circledR X}$-100 oder SDS enthaltenden Lysispuffern erhalten wurden, mußte beachtet werden, das diese Reagenzien ab einer bestimmten Konzentration das Anfärbeverhalten von Coomassie Blue beeinflussen (siehe Produktprotokoll).

\subsubsection{Acetonfällung von Proteinen}

Proteinproben konnten, wenn eine Volumenreduzierung nötig war, über Acetonfällung aufkonzentriert werden. Hierzu wurden $4 \mathrm{Vol}$ Aceton (vorgekühlt auf $-20^{\circ} \mathrm{C}$ ) zugegeben. Nach 1 h bei $-20^{\circ} \mathrm{C}$ wurden die ausgefallenen Proteine 30 min bei 10000 x g zentrifugiert und die erhaltenen Pellets einmal mit 80\%igem Aceton gewaschen.

\subsubsection{SDS-Polyacrylamidgelelektrophorese (SDS-PAGE)}

Proteine werden in Anwesenheit von reduzierenden Agenzien (DTT und $\beta$-Mercaptoethanol) und SDS aufgekocht, wobei die natürlichen Ladungen der Probe durch die negativen Ladungen des SDS maskiert werden und so eine Auftrennung der nun gleich geladenen Proteine nach ihrer Größe gewährleistet wird. Die große Trennleistung der Diskelektrophorese wird über Diskontinuitäten im pH-Wert und in der Porengröße erreicht, die aus der Kombination eines großporigen Sammelgels (4\% Polyacrylamid) zur Konzentrierung der Probe auf eine schmale Startzone und eines feinporigen Trenngels (1015\% Polyacrylamid) resultieren. Es wurden diskontinuierliche Gele in PHASE Minigelkammern mit Trennlängen von ca. $70 \mathrm{~mm}$ gegossen oder vorgefertigte Gele des NuPAGE $^{\mathrm{TM}}$ Elektrophorese Systems (NOVEX, San Diego) benutzt. In der Regel wurden Trenngele mit 10\% Polyacrylamid (29:1) gegossen (1x Trenngelpuffer, 0,1\% APS und 0,1\% TEMED zur Polymerisierung). Um bei selbst gegossenen Gelen eine glatte Oberfläche des Trenngels zu erhalten, wurden diese direkt nach dem Gießen mit Butanol überschichtet. Das Butanol wurde nach dem vollständigen Polymerisieren des Trenngels mit Wasser abgespült, danach das 4\%ige Sammelgel gegossen und der Kamm luftblasenfrei eingesetzt. Die Proteinproben wurden mit 0,25 Vol Probenpuffer (LDS Sample Buffer (4x), NuPAGE ${ }^{\mathrm{TM}}$, Invitrogen, Karlsruhe) versetzt, $10 \mathrm{~min}$ bei $70^{\circ} \mathrm{C}$ inkubiert, auf Eis abgekühlt und danach auf das Gel aufgetragen. Die Elektrophorese erfolgte bei 40-100 V, und zwar solange bis der 
mitlaufende gefärbte Proteinstandard (NuPAGETM See Blue Plus2, Invitrogen) eine genügende Auftrennung der Proben anzeigte.

\subsubsection{Western Blot-Analyse von Proteinen auf Nitrocellulose-Membranen}

[Gershoni et al., 1982, 1983]

Eine auf die Größe des zu blottenden Polyacrylamidgels zugeschnittene NitrocelluloseMembran (Macherey \& Nagel) wurde kurz (5-10 s) in 100\% Methanol getaucht und anschließend in Transferpuffer für 10 min äquilibriert. Fünf zurechtgeschnittene Whatman GB003 Filter (Schleicher \& Schüll, Dassel) wurden in Transferpuffer getränkt. Darauf wurden die Nitrocellulose-Membran und sofort das nach der elektrophoretischen Auftrennung der Proteine mit Wasser abgespülte Polyacrylamidgel gelegt. Fünf weitere mit Transferpuffer getränkte Filterpapiere wurden nach dem sandwich-Model oben aufgesetzt. Der Transfer wurde in einem Elektroblotter (Biometra, Göttingen) bei $50 \mathrm{~V}$ und $100 \mathrm{~mA}$ für 1,5-2 h durchgeführt.

\subsubsection{Färbung von Proteingelen}

SDS-PAGE Gele wurden zwecks Proteinfärbung über Nacht in Coomassie Brilliant BlauFärbelösung geschwenkt. Anschließend wurden die Gele bis zur Entfärbung in Wasser geschwenkt. Zur Lagerung wurden die gefärbten Gele in Folie eingeschweißt.

\subsubsection{Inkubation von membrangebundenen Proteinen mit Antikörpern}

Um unspezifische Bindungsstellen abzublocken, wurde die Membran zunächst in 1x PBS mit 3-5\% Milchpulver (Blockpuffer I) für 1 h bei RT inkubiert. Danach erfolgte die Inkubation mit dem Primärantikörper bei einer für den jeweiligen Antikörper entsprechenden Verdünnung in Blockpuffer I bei RT 2 h oder bei $4^{\circ} \mathrm{C}$ über Nacht. Anschließend wurde die Membran 2x 5 min in 1,5-2,5\% Milchpulver/0,1\% Tween 20 (Waschlösung) gewaschen und mit einem entsprechenden Sekundärantikörper in einer Verdünnung von 1:2000 bis 1:10000 in Blockpuffer I für $2 \mathrm{~h}$ bei RT inkubiert. Sollten die Proteine über Chemilumineszenz 
nachgewiesen werden, wurde die Membran nach Waschen mit Waschlösung mindestens 2x 5 min in 1x PBS gewaschen, um Milchpulverrückstände zu entfernen. Anschließend wurde etwa $1 \mathrm{ml}$ der SuperSignal ${ }^{\circledR} \quad$ West $\quad$ Substrate-Arbeitslösung hergestellt, indem Luminol/Enhancer-Lösung und die stabile Peroxid-Lösung der Firma Pierce (Rockford, USA) 1:1 gemischt wurden. Die HRP setzt das Substrat der Arbeitslösung um. Die Produkte bilden ein sichtbares Präzipitat um den Antigen-Antikörperkomplex. Die Lösung wurde auf die Membran gegeben und 5 min inkubiert. Anschließend wurde die abgetropfte Membran in Plastik eingeschweißt und in eine Filmkammer gelegt. Der Film wurde in der Dunkelkammer aufgelegt und nach 60 s entwickelt. Je nach Intensität der Banden konnte die Entwicklungszeit verlängert oder verkürzt werden.

\subsubsection{Enzyme-Linked Immuno-absorbant Assay (ELISA):}

Die Methode des Enzyme-linked immuno-absorbant Assay (ELISA) ermöglicht eine quantitative Bestimmung eines Antigens (Indirekter ELISA) oder der Enzym-Aktivität des Antigens (Enzym-Antigen-Assay) mit Antikörpern bekannter Spezifität.

\subsection{Indirekter ELISA}

Im indirekten ELISA wird hierzu das Antigen (Rekombinante Proteine, EBV transformierte Lymphozyten) über elektrostatische Wechselwirkung an der Kunststoffoberfläche der Mikrotiterplatte immobilisiert Das Antigen wurde mit $100 \mu \mathrm{l}$ Bicarbonat-Carbonat-Puffer gelöst und in die flachbödigen 96-Well-Mikrotiterplatten (Greiner, Nürtingen) gegeben und $2 \mathrm{~h}$ bis über Nacht inkubiert. Die Antigenlösung wurde ausgeschlagen und die Platten dreimal mit $200 \mu$ PBS-T gewaschen. Anschließend wurde 1 h mit $200 \mu \mathrm{l}$ 2\% Milchpulver inkubiert. Nach Ausschlagen der Milchpulverlösung und dreimaligem Waschen mit PBS-T wurden $200 \mu \mathrm{l}$ des anti-SHP2 Antikörpers (1:200 mit PBS-T verdünnt) dazugegeben. Nach einer Inkubationszeit von $2 \mathrm{~h}$ bei RT und dreimaligem Waschen wurden $200 \mu \mathrm{l}$ anti-KaninchenPeroxidase-Konjugat 1:8000 verdünnt in PBS-T zupipettiert. Nach 2 h bei RT und 3 Waschschritten erfolgte die Detektion mit $200 \mu$ l des Enzymsubstrats, das frisch angesetzt wurde. Die Komponenten des Enzymsubstrats sind die folgenden Reagenzien: 
$10 \mathrm{ml}$ Substrat-Puffer

0,5 ml $22 \mathrm{mg} / \mathrm{ml}$ ABTS (2,2'-Azino-di-[3-ethylbenzthiazolin-Sulfonsäure])

$10 \mu \mathrm{l} \quad 30 \% \mathrm{H}_{2} \mathrm{O}_{2}$

Die Extinktion der Färbung wurde nach kurzem Warten im ELISA-Reader (MR580

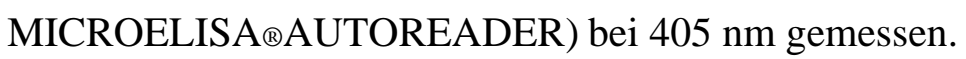

\subsection{Enzym-Antigen-Assay: DiFMUP -Nachweis}

In einem Enzym-Antigen-Assay wird der erste Antikörper (anti-SHP2 oder anti-c-myc) über elektrostatische Wechselwirkung an der Kunststoffoberfläche der Mikrotiterplatte gekoppelt. Der erste Antikörper wurde mit PBS-T verdünnt und jeweils $100 \mu \mathrm{l}$ in die flachbödigen 96Well-Mikrotiterplatten (Greiner, Nürtingen) pipettiert. Nach einer 2 stündigen Inkubation des Antikörpers wurde die Reaktionslösung ausgeschlagen und die Platten dreimal mit $200 \mu \mathrm{l}$ PBS-T gewaschen. Nicht-besetzte Bindungsstellen in der Polysterolplatte wurden mit $200 \mu \mathrm{l}$ Blockpuffer I (2\% Milchpulver) 2 h bei RT abgesättigt, und die Platte wurde dann viermal für 3 min mit $200 \mu$ PBS-T gewaschen. Anschließend wurden $200 \mu$ l des Antigens (Proteine von EBV-transformierten Lymphozyten) in PBS-T 2 h bei RT inkubiert. Nach dreimaligem Waschen mit PBS-T wurde der ELISA mit $200 \mu$ l DiFMUP-Lösung inkubiert. DiFMU wurde als Produkt der Reaktion der Phosphatase bei $\mathrm{OD}_{358} / \mathrm{OD}_{452}$ in einem „FLx800 Microplate Fluorescence Reader“ (Bio-Tek Instruments Inc., Winooski, Vt.) gemessen.

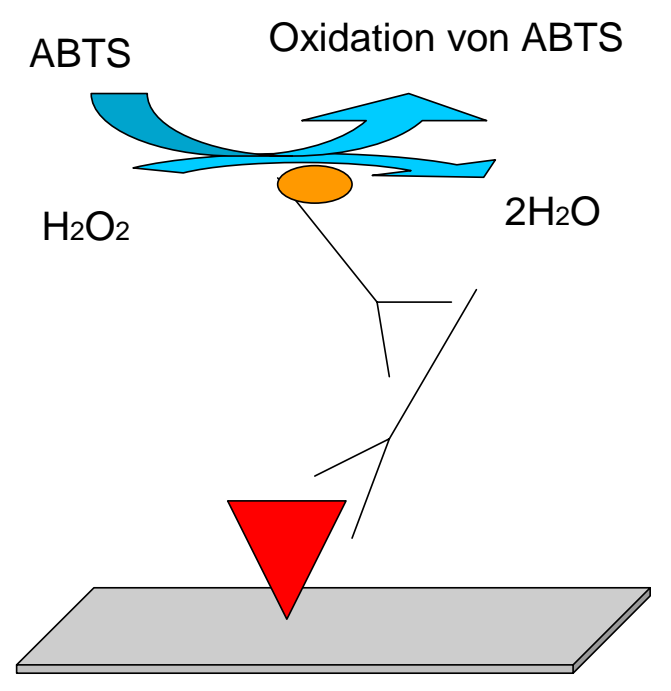

A. Indirekter ELISA

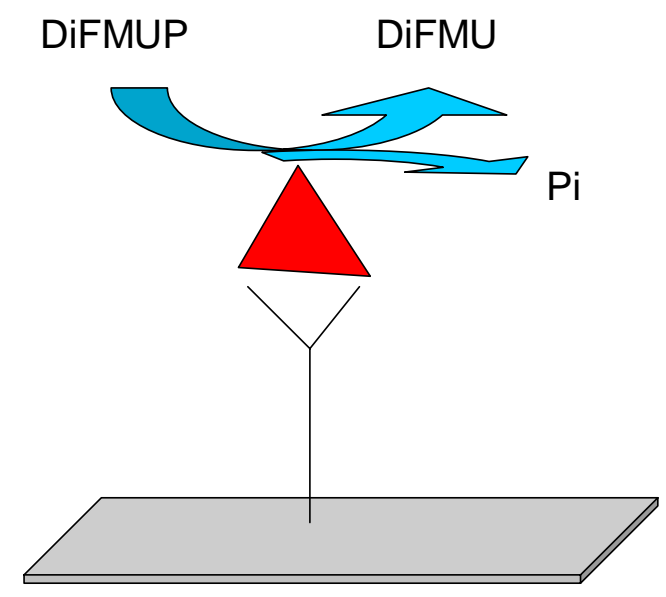

B. Enzym-Antigen-Assay 
Abb. 2.3: Indirekter ELISA und Enzym-Antigen-Assay: A. Indirekter ELISA: Quantitative Bestimmung des auf einer Kunststoffoberfläche immobilisierten Antigens und Nachweis durch Detektion des Enzymsubstrats des zweiten Antikörpers. Abkürzungen: ABTS: 2,2'-Azino-di-[3-ethylbenzthiazolin-Sulfonsäure] B. EnzymAntigen-Assay: Quantitative Bestimmung der Enzym-Aktivität des Antigens. Der erste Antikörper wird auf einer Kunstoffoberfläche immobilisiert. Das interessierende Antigen wird durch den spezifischen Antikörper gekoppelt. Nach der Inkubation des Phosphatase-Substrats (DiFMUP) wird die Entstehung des DiFMU photometrisch gemessen. Abkürzungen: DiFMUP: 6,8-difluoro-4-methylumbelliferyl phosphate.

\subsubsection{Malachit-Grün Phosphatase-Assay}

Mit Hilfe des Malachit-Grün Phospharase-Assays sollte die Eigenschaft des SHP2-Proteins untersucht werden, wobei die Phosphatase-Aktivität über die Bestimmung des freiwerdenden Phosphats gemessen wurde. Zur Quantifizierung des Phosphatumsatzes wurde eine Eichkurve erstellt, in der $\mathrm{KH}_{2} \mathrm{PO}_{4}$ in einer Konzentration von 0 bis 2000 pmol angesetzt wurde. Nach Zugabe einer Ammoniummolybdatlösung (0,034\% Malachitgrün, $10 \mathrm{mM}$ Ammoniummolybdat in $1 \mathrm{~N} \mathrm{HCl}, 3,4 \%$ Ethanol, 0,001\% Tween 20) bildete sich der farbige Komplex Malachit-Molybdatphosphat, dessen Farbintensität bei 620-650 nm in einem „EL 800 Universal Microplate Reader“ (Bio-Tek Instruments Inc., Winooski, Vt.) gemessen wurde. In der Abbildung 2.4 ist der farbige Komplex Malachit-Molybdatposhphat gezeigt. Freies Phosphat reagiert mit Ammoniummolybdat, wobei Ammonium frei gesetzt wird. Durch die Anwesenheit des Malachitgrüns wird der grüne Komplex MalachitMolybdatphosphat gebildet, dessen Farbintensität bei 620-650 nm gemessen wird. Je mehr Phosphat vorhanden ist, umso mehr Malachit-Molybdatphosphat entsteht. Die Proteine (Rekombinante Proteine, Proteine aus EBV-transformierten Lymphozyten und AmnionzellenProteinextrakt) wurden in phosphatfreier Lösung (25 mM HEPES, pH 7,2, $50 \mathrm{mM} \mathrm{NaCl}$, 5 mM DTT, 2,5 mM EDTA) auf eine Konzentration von 0,1 $\mu \mathrm{g} / \mu \mathrm{l}$ in einem Volumen von 25 $\mu \mathrm{l}$ eingestellt und mit $200 \mu \mathrm{M}$ des spezifischen Phosphopeptids (T-S-T-E-P-Q-pY-Q-P-G-EN-L) 15 min bei RT inkubiert. Durch Hinzufügen von $100 \mu \mathrm{l}$ Ammoniummolybdatlösung wurde die Reaktion gestartet. Das Experiment wurde nach 15 min gestoppt und die Phosphatase-Aktivität durch die Messung des freien Phosphates unter Verwendung der Eichkurve bestimmt. Alle Werte der Messungen resultieren aus einem Mittelwert einer Dreifachbestimmung. Um die spezifische Aktivität der untersuchten Proteine zu ermitteln [Morbach et al., 1993], wurden die Inkubationszeit und die eingesetzte Proteinmenge festgelegt. Mögliche Kontaminationen von freiem Phosphat in der Protein-Lösung wurden 
durch die Inkubation des Proteins mit Ammoniummolybdatlösung ohne spezifisches Phosphopeptid entdeckt.

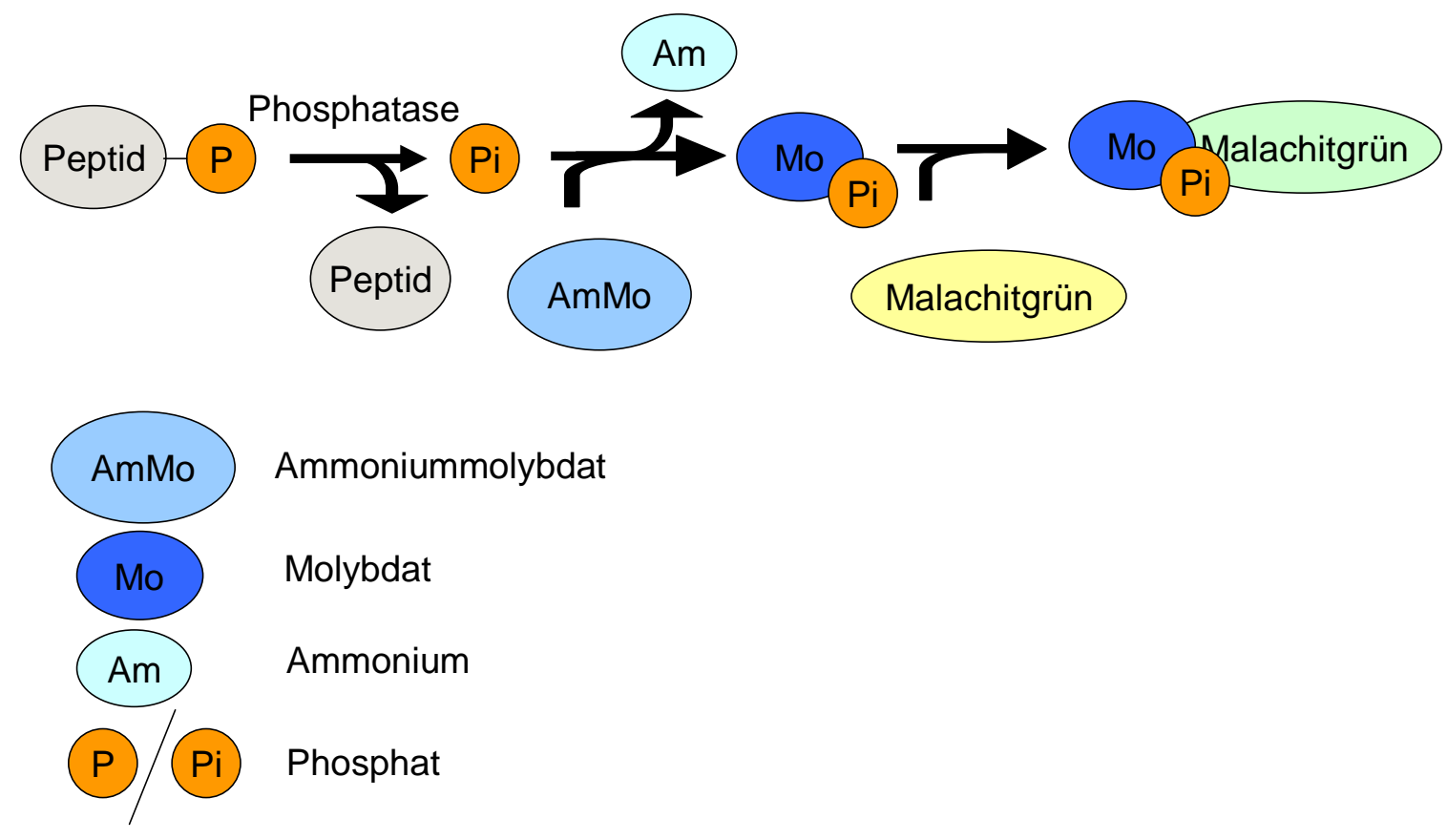

Abb. 2.4: Übersichtsdarstellung der Bildung der Farbige komplex Malachit Molybdatpohphat. Gezeigt ist die Bildung des freien Phophats mit Molybdat und Malachitgrün. Freies Phosphat reagiert mit Ammoniummolybdat, wobei Ammonium freigesetzt wird und bei Anwesenheit von Malachitgrün sich des farbige Komplex Malachit-Molybdatphophat bildet, dessen Farbintensität bei 620-650 nm gemessen wird.

\subsubsection{Elektrophoretischer Mobilitäts-Shift-Assay (EMSA)}

[Dent et al., 1993]

Der Elektrophoretische Mobilitäts-Shift-Assay ist eine Methode zur Untersuchung von Interaktionen zwischen DNA-Sequenzen und Kernproteinen. Die Methode gibt Auskunft darüber, welche Proteine in vitro mit der DNA interagieren können. Als Sonde werden synthetische Oligonukleotide mit der zu untersuchenden DNA-Sequenz (Promotorabschnitte) verwendet. Die einzelsträngigen Oligomere werden zu Doppelsträngen hybridisiert und radioaktiv markiert (2.2.2.7.). Während der Bindungsreaktion wird die Sonde gemeinsam mit Kernextrakt (2.2.6.2) inkubiert. Zur Durchführung einer Bindungsreaktion wurden folgende Komponenten verwendet: 


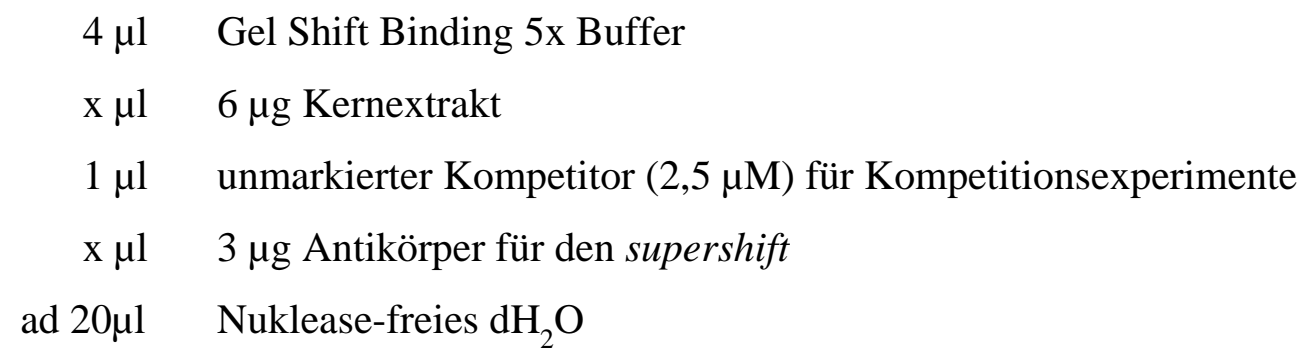

Der Ansatz wurde 30 min bei RT inkubiert. Danach wurde $1 \mu \mathrm{l}$ markierte Sonde dazugegeben und 30 min bei RT inkubiert. Nach Beendigung des einstündigen Vorlaufs in 1x TBE-Puffer bei 200V, 20mA und $4^{\circ} \mathrm{C}$ wurde der Ansatz mit 10x Gel Loading Puffer auf einem nicht denaturierenden Polyacrylamidgel (2.2.3.2.) mit 1x TBE als Laufpuffer für 2 h bei $220 \mathrm{~V}$, $4^{\circ} \mathrm{C}$, aufgetrennt. Nach der Elektrophorese wurde das Gel auf Whatman $3 \mathrm{~mm}$-Papier von den Glasplatten abgenommen, mit Frischhaltefolie abgedeckt und für mindestens 40 min bei $80^{\circ} \mathrm{C}$ auf einem Vakuumgeltrockner (Bachofer, Reutlingen) getrocknet. Zur Auswertung wurde das getrocknete Gel mit einem Röntgenfilm in einer Autoradiographie-Kassette bei $-70^{\circ} \mathrm{C}$ oder mit einer Phosphorimagermembran (Bio-Rad, Hercules, USA) bei RT exponiert. Anschließend erfolgte das Scannen in einem Phosphorimager (Personal Molecular Imager FX, Bio-Rad, Hercules, USA) mit Hilfe des Quantity One-Software-Programms. Die Analyse erfolgte je nach Stärke der Signale entweder für 24 h oder für mehrere Tage. Besitzt die Sonde Bindungsstellen für im Kernextrakt enthaltene Proteine, so können diese an die DNA binden. Dabei entstehen DNA-Protein-Komplexe, die aufgrund des höheren Molekulargewichts im Gel langsamer wandern als die freie Sonde. Um die Spezifität der Komplexe zu überprüfen, werden Kompetitionsexperimente (spezifisch oder nicht-spezifisch) mit unmarkierter Sonde bzw. supershift durchgeführt. Für die Kompetition wird die nicht radioaktive Sonde im molaren Überschuss zum Bindungsansatz gegeben. Können die Proteine eines Komplexes den spezifischen Kompetitor binden, so wird die Sonde durch die nicht markierten Oligomere verdrängt, und die entsprechende Bande wird schwächer oder verschwindet völlig. Durch einen supershift kann mit Hilfe von Antikörpern das Protein selbst identifiziert werden. Erkennt ein Antikörper DNA-gebundene Proteine, so bindet er zusätzlich am DNA-Protein-Komplex und führt zu einer weiteren Erhöhung des Molekulargewichts (supershift) oder er blockiert die DNA-Bindungsstelle des Proteins, so dass keine Bindung zwischen DNA und Protein zustande kommt und keine Bande sichtbar wird. Weiterhin wurde eine Mutationsanalyse der Primerpaare durchgeführt, bei denen ein shift stattgefunden hat. 
Die möglichen Bindungsstellen für Transkriptionsfaktoren wurden in den Primerpaaren so mutiert, dass kein shift stattfinden kann.

\subsubsection{Zellbiologische Methoden}

\subsubsection{Zellkultur eukaryontischer Zellen}

Die adhärent wachsenden NIH/3T3 Zellen wurden in DMEM-Medium (PAN, Nürnberg) unter Zusatz von 1,2\% Penicillin/Streptomycin und 10\% FKS in oberflächenbehandelten Gewebekulturflaschen kultiviert. Die Inkubation erfolgte im Brutschrank mit 5\% $\mathrm{CO}_{2}$ bei $37^{\circ} \mathrm{C}$. In Abhängigkeit von der Proliferationsrate wurden die Zellen ein- bis zweimal pro Woche geteilt. Die Zellen wurden dabei mit 1x DPBS (PAN) gewaschen und mit einer Trypsin/EDTA-Lösung (0,05\% Trypsin/ 0,02\% EDTA in Ca/Mg-freier PBS-Lösung; PAN, Nürnberg) so lange inkubiert, bis sich die Zellen vom Boden der Kulturflasche gelöst haben. Nach dem Ablösen der Zellen wurde die Wirkung des Trypsins durch Zugabe von Medium gestoppt und 10\% dieser Zellsuspension zur Weiterkultur verwendet.

\subsubsection{Kryokonservierung und Revitalisierung eukaryontischer Zellen}

Die bis zu einer Konfluenz von 80-90\% gewachsenen Zellen wurden mit DPBS gewaschen, trypsiniert und in einer entsprechenden Menge Kulturmedium mit 8\% DMSO resuspendiert. Nach 7 Tagen Aufbewahrung bei $-70^{\circ} \mathrm{C}$ wurden sie in flüssigem Stickstoff konserviert. Zur Revitalisierung wurden die Zellen schnell aufgetaut, in vorgewärmtes Kulturmedium überführt und über Nacht inkubiert. Am nächsten Morgen wurde das Medium zur vollständigen Entfernung des DMSO gewechselt.

\subsubsection{Transfektion eukaryontischer Zellen}

Zur quantitativen Bestimmung von Reportergenaktivitäten wurden NIH/3T3 Zellen mit verschiedenen Reportergenkonstrukten transfiziert. Als Transfektionsreagenz wurde Roti ${ }^{\circledR}$ Fect der Firma Roth (Karlsruhe) verwendet. Hierbei handelt es sich um einen Lipidkomplex aus einem polykationischen Lipid in Kombination mit einem neutralen Kolipid. Es 
kondensiert Nukleinsäuren zu kompakten Strukturen (Roti ${ }^{\circledR}$-Fect/Nukleinsäure-Komplexe), schirmt deren negative Ladungen ab und bewirkt deren Aufnahme in die Zelle.

Für die Transfektionsexperimente wurden NIH/3T3 Zellen verwendet, die sich in einer permanenten Wachstumsphase befanden. Einen Tag vor der Transfektion wurden die Zellen auf 12-Well Platten so ausplattiert, dass am folgenden Tag eine Konfluenz von 60-80\% erreicht wurde. $60 \mu \mathrm{l}$ DMEM-Medium ohne Zusätze wurde mit $1 \mu \mathrm{g}$ DNA und $4 \mu \mathrm{l}$ Transfektionsreagenz gemischt und zur Komplexbildung 30 min bei RT inkubiert. Nachdem die Zellen mit DPBS gewaschen und mit Kulturmedium ohne Antibiotika bedeckt worden waren, erfolgte die Zugabe des Transfektionsreagenz. Anschließend wurde für 2-4 h unter Kulturbedingungen inkubiert. Zuletzt wurde das Transfektionsmedium durch Kulturmedium mit Antibiotikazusatz ausgetauscht und die Zellen zwecks Proteinexpression weitere 24-36 h unter Kulturbedingungen inkubiert.

\subsubsection{Transformation von humanen Lymphozyten durch EBV}

B-Zellen des Menschen können durch das Epstein-Barr-Virus (EBV) immortalisiert und dadurch in Kultur gehalten werden. Die EBV-transfizierten B-Zellen behalten das EBVGenom in latenter Form als zirkularisierte DNA. Zur Isolierung der Lymphozyten wurde das heparinisierte Blut der Patientenen im Volumenverhältnis 1:1 mit RPMI verdünnt. In ein weiteres Röhrchen wurden $3 \mathrm{ml}$ Ficoll eingefüllt. Auf das Ficoll wurde vorsichtig das verdünnte Blut geschichtet und bei 800 x g für 15 min bei RT zentrifugiert. Die Lymphozyten erschienen als milchige Schicht an der Grenzfläche zum Ficoll, das Serum bildete den Überstand. Anschließend wurden die Lymphozyten an der Grenzschicht zwischen Ficoll und Serum abgesaugt. Es erfolgten 2 Waschschritte mit je $3 \mathrm{ml}$ RPMI und eine Zentrifugation bei 600 x g für 7 min und bei $25^{\circ} \mathrm{C}$. Das Pellet wurde vom Überstand befreit, mit Nährmedium (RPMI $1640+$ FKS, Glu, P/S) resuspensiert und die Zellzahl bestimmt. Alle 8 Tage wurde der Überstand der B95-8 EBV-Kultur abgenommen (ca. 7 ml pro Kulturflache) und in sterilen Röhrchen 10 min bei 800 x g zentrifugiert. Der Überstand wurde 2x durch einen Aufsteckfilter Minisart SM16555 SK (0,45 $\mu \mathrm{m})$ gegeben, um Zellreste herauszufiltern. Die isolierten Lymphozyten wurden in den filtrierten Überstand der B95-8 EBV-Linie (Humangenetik, Berlin) resuspendiert und $1 \mathrm{ml}$ in einem sterilen Röhrchen mit planer Fläche liegend bei $37^{\circ} \mathrm{C}$ inkubiert. Nach 24 h wurde das Medium durch RPMI mit Cyclosporin A (0,5 ml Kultur mit $2 \mu \mathrm{g} / \mathrm{ml}$ Cyclosporin A) ersetzt. Die Behandlung mit $2 \mu \mathrm{g} / \mathrm{ml}$ Cyclosporin 
A wurde 2-3x pro Woche für ca. 2-3 Wochen beibehalten und danach wurde der Mediumwechsel mit $1 \mu \mathrm{g} / \mathrm{ml}$ Cyclosporin A durchgeführt. Während des Wachstums in den Röhrchen wurde die Kultur nicht zentriguiert. Wenn eine bestimmte Zelldichte erreicht war, wurde die Zellsuspension in eine $50 \mathrm{ml}$ Kulturflasche übertragen und das Medium 1x pro Woche gewechselt. Alle Arbeiten erfolgten unter sterilen Bedingungen unter einer Sicherheitswerkbank.

\subsubsection{Herstellung von Interleukin-Medium aus der Milz der Ratte}

Die Milz einer Ratte wurde isoliert und in einem Glas-Potter homogenisiert. Der Ansatz wurde für 10 min bei 5000 x g zentrifugiert und das Pellet mit $40 \mathrm{ml}$ RPMI-Medium und $5 \mu \mathrm{g} / \mathrm{ml}$ Con A (Concancavalin A) resuspendiert. Nach einer Inkubation von $4 \mathrm{~h}$ bei $37^{\circ} \mathrm{C}$ im Wasserbad wurde der Ansatz 10 min bei 5000 x g zentrifugiert und in $20 \mathrm{ml}$ RPMI mit 10\% FKS und $5 \mu \mathrm{g} / \mathrm{ml}$ Con A (s.o.) resuspendiert und in eine Petrischale überführt. Nach einer Inkubation von $24 \mathrm{~h}$ bei $37^{\circ} \mathrm{C}$ mit $5 \% \mathrm{CO}_{2}$ im Brutschrank wurde der Ansatz 10 min bei $8000 \mathrm{x}$ g zentrifugiert und der Überstand aliquotiert und bis zur Verwendung bei $-20^{\circ} \mathrm{C}$ gelagert.

\subsubsection{Quantitativer Nachweis von Reporter-Enzymen}

Der quantitative Nachweis der Aktivität der Reporter-Enzyme Luciferase und $\beta$-Galaktosidase erfolgte über die Messung von Lichtemissionsreaktionen in RLUs (relative light units) durch ein Luminometer (Typ Orion, Fa. Berthold, Bad Wildbad). Das rekombinante Gen des Enzyms Luciferase aus dem Leuchtkäfer Photimus pyralis [De Wet et al., 1987] wird häufig als Reportergen verwendet, da die auf die Oxidation des KäferLuciferins zurückzuführende Biolumineszenzreaktion einfach nachgewiesen werden kann. Direkt nach der automatischen Injektion des Substrats durch das Luminometer startet die lichtemittierende Reaktion.

Solange das Substrat im Überschuss vorliegt, ist die Lichtemission proportional zur Luciferase-Aktivität der Probe, was eine indirekte Bestimmung der Expression des Reportergens erlaubt. In der ATP-und $\mathrm{Mg}^{2+}$-abhängigen Reaktion wird zunächst eine AcylAMP Zwischenstufe gebildet, die in Gegenwart von Sauerstoff zu Oxyluciferin oxidiert wird. Angeregtes Oxyluciferin fällt nachfolgend in den Grundzustand zurück, wobei ein Photon 
emittiert wird. Zur Normalisierung der Transfektionseffizienz wurde ein $\beta$-Galaktosidase exprimierender Vektor (pCMV- $\beta$-Gal) im Verhältnis 1:10 bis 1:20 zu dem zu testenden Konstrukt kotransfiziert. Dadurch war es möglich, die Werte der Luciferase-Aktivität trotz etwaiger Schwankungen der Transfektionseffizienz zu normalisieren und miteinander zu vergleichen.

\subsubsection{Messung der Luciferase-Aktivität}

[Ausubel et al., 1992]

Zur Bestimmung der Luciferase-Aktivität wurden $200 \mu$ l des Luciferase-Reaktionspuffers in 96-Well-Platten vorgelegt und $30 \mu \mathrm{l}$ Zellextrakte zugegeben. Zum Starten der Lichtreaktion wurden $100 \mu \mathrm{l}$ der Luciferin-Injektionslösung durch einen Injektor des Luminometers eingespritzt und die nachfolgende Lichtemission nach Verstreichen einer Vorlaufzeit von $20 \mathrm{~s}$ über weitere $20 \mathrm{~s}$ hinweg gemessen.

\subsubsection{Messung der $\beta$-Galaktosidase-Aktivität}

[Jain und Magrath, 1991]

Die Chemilumineszenzmessung der $\beta$-Galaktosidase-Aktivität erfolgte unter Verwendung desselben Zellextrakts wie zur Luciferase-Bestimmung [Fulton und Van Ness, 1993] mit dem „Galacto-Light-Kit" (Applied Biosystems). $10 \mu \mathrm{l}$ des Zellextrakts wurden in eine 96-WellPlatte vorgelegt. Die Stammlösung des Substrats Galacton wurde 1:100 mit dem gelieferten Reaktionspuffer verdünnt und in einem Abstand von $30 \mathrm{~s}$ je $70 \mu \mathrm{l}$ durch das Luminometer injiziert. Es folgte eine Inkubation für $1 \mathrm{~h}$ bei RT im Dunkeln. Anschließend wurden $100 \mu \mathrm{l}$ des „Light Emission Accelerators" zugesetzt und nach einer Vorlaufzeit von 20 s über eine Zeitspanne von 10 s hinweg die Lichtemission jeder Probe detektiert. Die Inkubationszeit mit Reaktionspuffer muss für jede Probe identisch sein. 


\subsubsection{Herunterregulierung der Genexpression mittels RNA-Interferenz}

Der Terminus RNA-Interferenz (RNAi) beschreibt die Verwendung von doppelsträngiger RNA, um spezifische mRNAs für die Degradierung zu markieren, wodurch die Expression der entsprechenden Gene verringert wird. RNAi ist eines aus einer breiten Klasse von RNAsilencing-Phänomenen, die in Pflanzen, Tieren und Pilzen gefunden worden sind [Cogoni und Macino, 2000; Elbashir et al., 2001a, b; Tuschl, 2001]. Die Entdeckung von RNAi hat das Verständnis verändert, wie die Zellen ihre Genome überwachen. Sie führte zur Entwicklung neuer Strategien, um Genfunktionen zu blockieren, und könnte in Zukunft zu RNAbasierenden Medikamenten führen, um eventuell menschliche Krankheiten zu behandeln.

\subsubsection{1 Überblick über den Mechanismus von RNAi}

Im ersten Schritt wird doppelsträngige RNA in 21-23 Nukleotide, small interfering RNAs (siRNA), geteilt, welche auch als guide RNAs bezeichnet werden [Hammond et al., 2001b, Sharp, 2001]. Untersuchungen haben gezeigt, dass siRNAs produziert werden, wenn das Enzym Dicer, ein Mitglied der RNase III-Familie der dsRNA-spezifischen Ribonukleasen, prozessiv dsRNA (direkt oder über ein Transgen oder Virus eingeführt) in ATP-abhängiger Weise schneidet. Das sukzessive Schneiden degradiert die RNA in 19-21bp-Duplexe (siRNAs), die jedes einen 2-Nukleotid-Überhang am 3'-Ende besitzen [Bernstein et al., 2001; Hutvagner et al., 2002]. Im Effektor-Schritt binden die siRNA-Duplexe an einen NukleaseKomplex, um den sog. RISC (ㅁNA-induced silencing complex) zu bilden. Das ATPabhängige Entwinden der siRNA-Duplexe ist für die Aktivierung von RISC notwendig. Der aktive RISC geht gezielt gegen homologe Transkripte durch Basenpaarung vor und schneidet die mRNA 12 Nukleotide vom 3'-Terminus der siRNA [Hammond et al., 2001a; Sharp, 2001] 

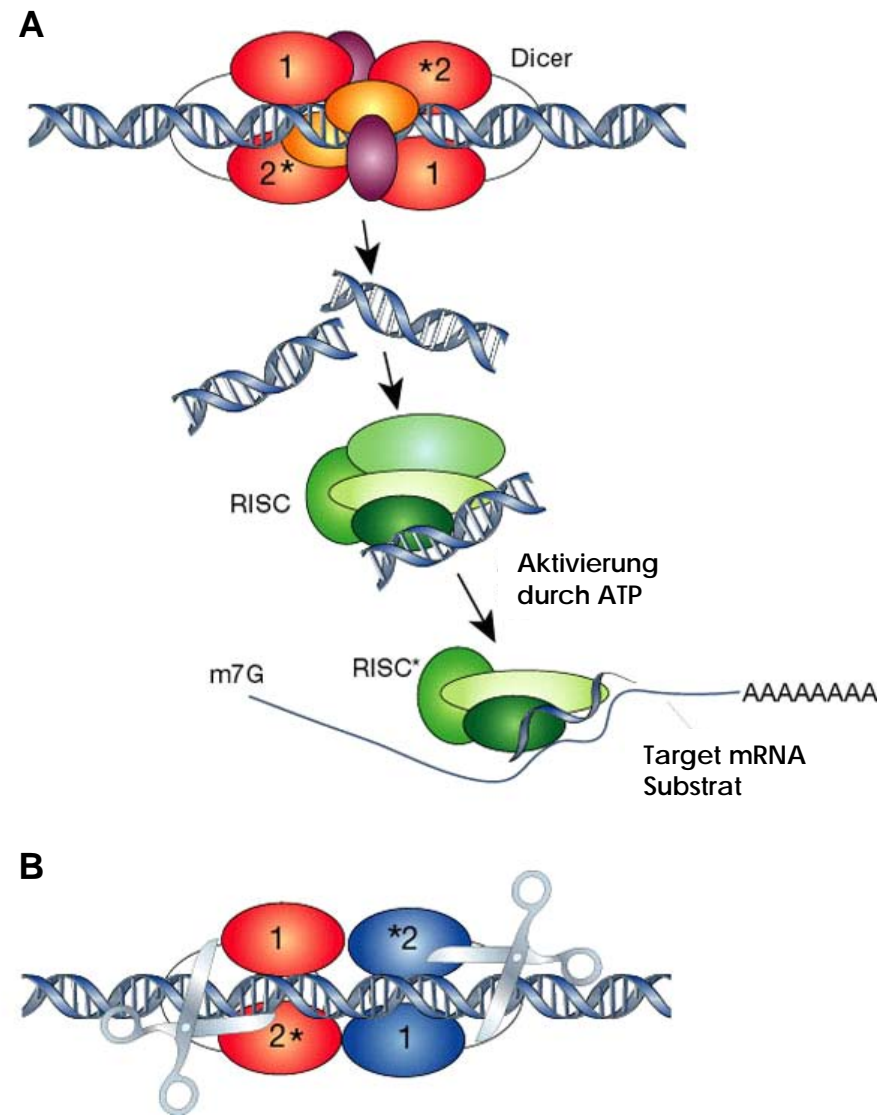

Abb. 2.5: Dicer und RISC (RNA-induced silencing complex) [Hannon, 2002]. A. RNAi wird durch das Enzym Dicer initiiert (2 Dicer-Moleküle mit jeweils 5 Domänen sind gezeigt), welches doppelsträngige RNA in 22-Nukleotide kleine small interfering RNAs prozessiert. Basierend auf dem bekannten Mechanismus für die RNase III-Enzymfamilie wird angenommen, dass Dicer als Dimer arbeitet. Das Schneiden in genau gleich große Fragmente wird durch den Fakt bestimmt, dass jeweils eines der aktiven Zentren in jedem Dicer-Protein defekt ist (*), so dass das Schneiden im Abstand von 9-11 Nukleotiden durch bakterielle RNase III zu einem im Abstand von 22 Nukleotiden durch die Dicer-Familie verändert ist. Die siRNAs werden in eine Multikomponenten-Nuklease (RISC, grün) inkorporiert. Kürzliche Arbeiten schlagen vor, dass RISC von einer latenten Form, die doppelsträngige siRNA enthält, in eine aktive Form (RISC*) durch Entwindung der siRNAs überführt werden muss. RISC* verwendet dann die entwundenen siRNAs als einen Führer für die Substratselektion. B. Schematische Darstellung von Dicer-Bindung und Schneiden von dsRNA (zur Übersicht sind nicht alle Domänen von Dicer gezeigt, und die beiden Dicer-Moleküle werden in verschiedenen Farben dargestellt). Abweichungen von dem Konsensus-RNase III-aktiven Zentrum in der zweiten RNase III-Domäne inaktivieren das katalytische Zentrum, was zum Schneiden in 22-Nukleotid-Abständen führt. 


\subsubsection{Entwicklung der Hairpin-Oligonukleotide}

Das in dieser Arbeit verwendete RNAi-System basiert auf der in vivo Transkription der siRNAs mit Hilfe des pSU6 (pSilencer $\left.{ }^{\mathrm{TM}} 1.0-\mathrm{U} 6\right)$ siRNA Expressionsvektor und erlaubt eine Expression von siRNAs. In diesen Vektor werden zwei hybridisierte DNA-Oligonukleotide mit ApaI/EcoRI kloniert, welche für sog. shRNAs (short hairpin-RNAs) kodieren.

Die doppelsträngigen Bereiche dieser shRNAs sind homolog zu einer 19 bp-Region im PTPN11-Gen. Das Insert hat die folgende Sequenz:

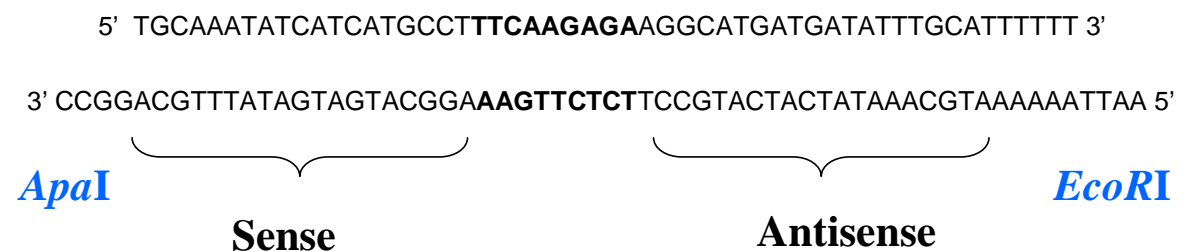

Die Primärtranskripte des Vektors, durch RNA Polymerase III synthetisiert, dienen als Substrat für das Enzym Dicer, das die shRNAs ATP-abhängig zu kurzen dsRNAs prozessiert. Die prozessierten Produkte (siRNAs) besitzen am 3'-Ende zwei überhängende Uridine und stellen die eigentlich aktiven Effektoren der RNA-Interferenz dar. Für die Induktion der RNA-Interferenz in NIH/3T3-Zellen wurden die entsprechenden pSU6-Konstrukte mittels Roti $^{\circledR}$-Fect der Firma Roth (Karlsruhe) transfiziert (2.2.8.3). 24 h nach der Transfektion wurden die Zellen zur Isolierung von Proteinen, zur Verifizierung des gene silencing und zur Untersuchung der Effekte durch Luciferase- und ß-Galakosidase-Aktivität geerntet.

\subsubsection{Erzeugung transgener Mäuse}

Die Erzeugung transgener Mäuse erfolgte über den „Transgenen Service“ des Max-PlanckInstituts für experimentelle Medizin in Göttingen. Die Methoden zur Erzeugung transgener Mäuse wurden prinzipiell nach Hogan et al. [1986] durchgeführt.

\subsubsection{Vorbereiten der DNA zur Mikroinjektion}

Alle zur Mikroinjektion vorgesehenen Konstrukte wurden zur Kontrolle sequenziert (2.19), und wenn möglich durch transiente Transfektion eukaryontischer Zellen (NIH/3T3) auf ihre Funktionalität hin getestet. Laut Literatur [Brinster et al., 1985] integriert DNA in 
linearisierter Form am besten, die Beschaffenheit der Enden spielt dagegen für die Integrationseffizienz keine Rolle. Das DNA-Konstrukt wurde über Restriktion des Vektorrückgrats mit entsprechenden Restriktionsenzymen aus dem Plasmid freigesetzt und über ein Agarosegel (ohne Ethidiumbromid) vom Vektorrückgrat getrennt. Da DNA-Mengen von $100 \mu$ g gespalten wurden, wurden mehrere Taschen eines Gels beladen. Die äußeren Taschen erhielten dabei nur etwa 1/10 der DNA/Dye-Loading. Nach dem Gellauf wurden diese Taschen und der DNA-Längenstandard ausgeschnitten und die Gelstücke im Ethidiumbromid-Bad angefärbt. Nach dem Anfärben wurde das Gel zusammengesetzt und auf dem UV-Tisch die gesuchte Bande zwischen den angefärbten Bereichen ausgeschnitten. Die Elution der DNA erfolgte mit Glasmilch (2.2.1.7). Um nach der Gelelution jegliche verbliebenen Partikel zu entfernen, wurde das Eluat mit Mikroinjektionspuffer (5 mM Tris/HCl pH 7,4, 0,1 mM EDTA) auf 30 ng/ $\mu$ l verdünnt und aufgereinigt. Die Konzentration der DNA wurde über Gelelektrophorese (2.2.1.9) bestimmt. In Zusammenarbeit mit Herrn Dr. Riedesel (MPI für Experimentelle Medizin, Göttingen) wurde die DNA nach erfolgter Aufreinigung in den männlichen Pronukleus von befruchteten Mäuseeizellen mikroinjiziert. Die Oozyten wurden dann scheinschwangeren Mäusen der Linie FVB reimplantiert. 


\section{Ergebnisse}

\subsection{Untersuchung des PTPN11-Promotors}

Das Noonan-Gen PTPN11 kodiert für die Nichtrezeptor Protein-Tyrosin-Phosphatase SHP2, die ubiquitär exprimiert ist. Über die transkriptionelle Regulation von PTPN11 gibt es jedoch keine experimentellen Daten. Um den endogenen PTPN11-Promotor zur Generierung einer transgenen Maus einsetzen zu können, sollte zunächst der wesentliche Promotor-Bereich eingegrenzt werden. Die intergenische Region zwischen PTPN11 und dem ca. $10 \mathrm{~kb}$ 5'gelegenen Gen RPL6 wurde sowohl theoretisch mit Hilfe von verschiedenen Computerprogrammen als auch experimentell mittels Promotor-Luciferase-Assay und Elektrophoretische Mobilitäts-Shift-Assay (EMSA) untersucht.

\subsubsection{Bioinformatik}

\subsubsection{Analyse der Homologie zwischen murinem, humanem und Ratten-Promotor von PTPN11}

Evolutionär konservierte Bereiche (d.h. Bereiche mit hoher Interspezies-Homologie) in intergenischen Regionen können Hinweise auf das Vorhandensein von Promotoren und regulatorischen Sequenzen geben und somit die experimentelle Promotor-Analyse vereinfachen. Daher wurde zunächst die Homologie zwischen murinem, humanem und Ratten-PTPN11-Promotor mit Hilfe der Computerprogramme BLAST (NCBI, blast two sequences) und DCODE analysiert. In Abbildung 3.1 ist eine Übersichtsdarstellung der murinen und humanen intergenischen Region zwischen PTPN11 und RPL6 gezeigt. Diese intergenische Region besteht bei Maus und Mensch aus mehr als 70\% repetetiven Sequenzen und nur 473 bp (bei Maus) bzw. 570 bp (beim Mensch) vor dem Translationsstartkodon ATG beginnt eine single-copy-Sequenz. Das Alignment dieser single-copy-Sequenz zwischen Mensch/Maus und Maus/Ratte durch blast two sequences ist in Abbildung 3.2 dargestellt. Das Computerprogramm vergleicht zwei oder mehr Sequenzen und gibt das Ergebnis als Dot Plot aus. Im Fall von PTPN11 zeigen nur ca. 300 bp eine Homologie von 79\% zwischen Mensch 
vs. Maus bzw. 500 bp eine Homologie von 84\% zwischen Maus vs. Ratte. Zur Bestätigung des Dot Plot Alignments wurde das DCODE Computerprogramm Evolutionary Conserved Regions (ECR) angewendet. In Abbildung 3.3. ist das Alignment der murinen Sequenz als Basis gegen die humane und Ratten-Sequenz des PTPN11-Promotors gezeigt, wobei das erste Exon (in blau gekennzeichnet), die 5'UTR (in gelb gekennzeichnet), ein intergenisches Element (putativer Promotor (in rot)) und die repetitiven Sequenzen (in grün) dargestellt sind. Diese Sequenzabschnitte wurden für weitere bioinformatische Analysen verwendet.
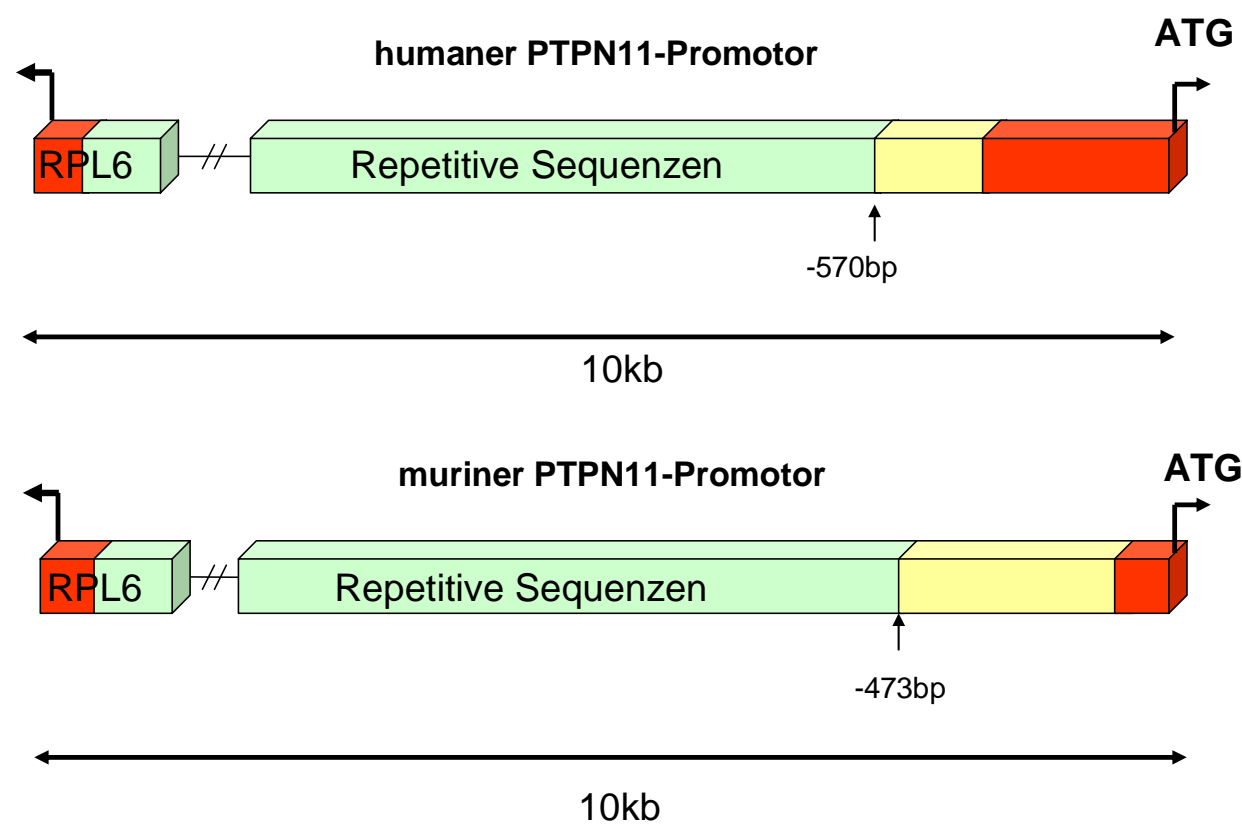

Abb. 3.1: Übersichtsdarstellung der humanen und murinen intergenischen Region zwischen PTPN11 und RPL6 (Zusammenfassung der Computeranalysen). Zwischen PTPN11 und RPL6 liegen 10 kb. Die intergenische Region ist reich an repetitiven Sequenzen (in grün gekennzeichnet) und enthält eine single-copysequence, die erst 570 bp vor ATG in der humanen Sequenz und 473 bp vor ATG in der murinen Sequenz beginnt. Rot gekennzeichnet ist der Transkriptionsstart.

\section{A. Dot Plot Maus-Mensch}

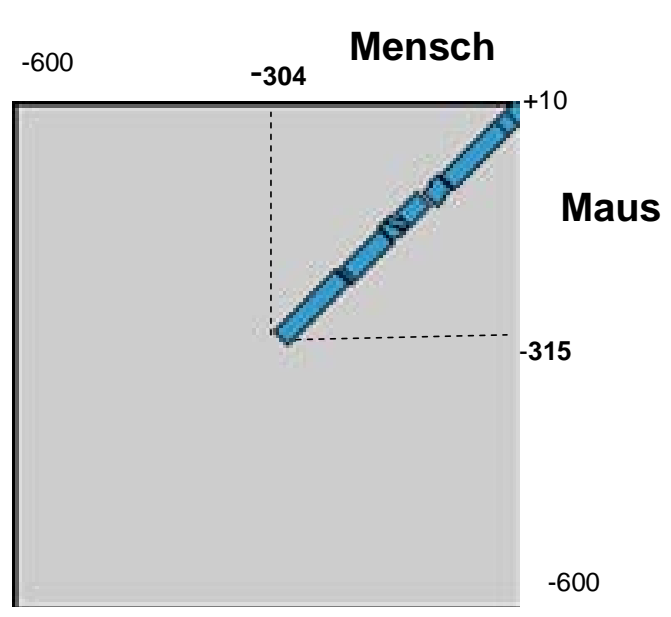

B. Dot Plot Maus-Ratte

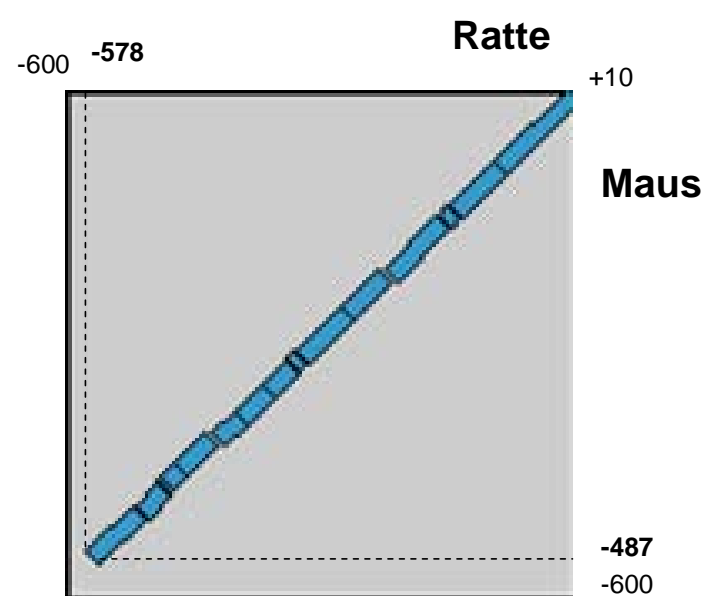


Abb. 3.2: Darstellung der Ergebnisse des Alignments zwischen murinem, humanem und Ratten-Promotor von PTPN11. Es wurde ein two-sequences-Alignment der ersten 600 bp des PTPN11-Promotor-Bereichs mit Hilfe von blast two sequences von NCBI (A. und B.) durchgeführt. Dargestellt ist die 79\%ige Identität zwischen murinem und humanem Promotor und die 84\%ige Identität zwischen murinem und Ratten-Promotor von PTPN11.

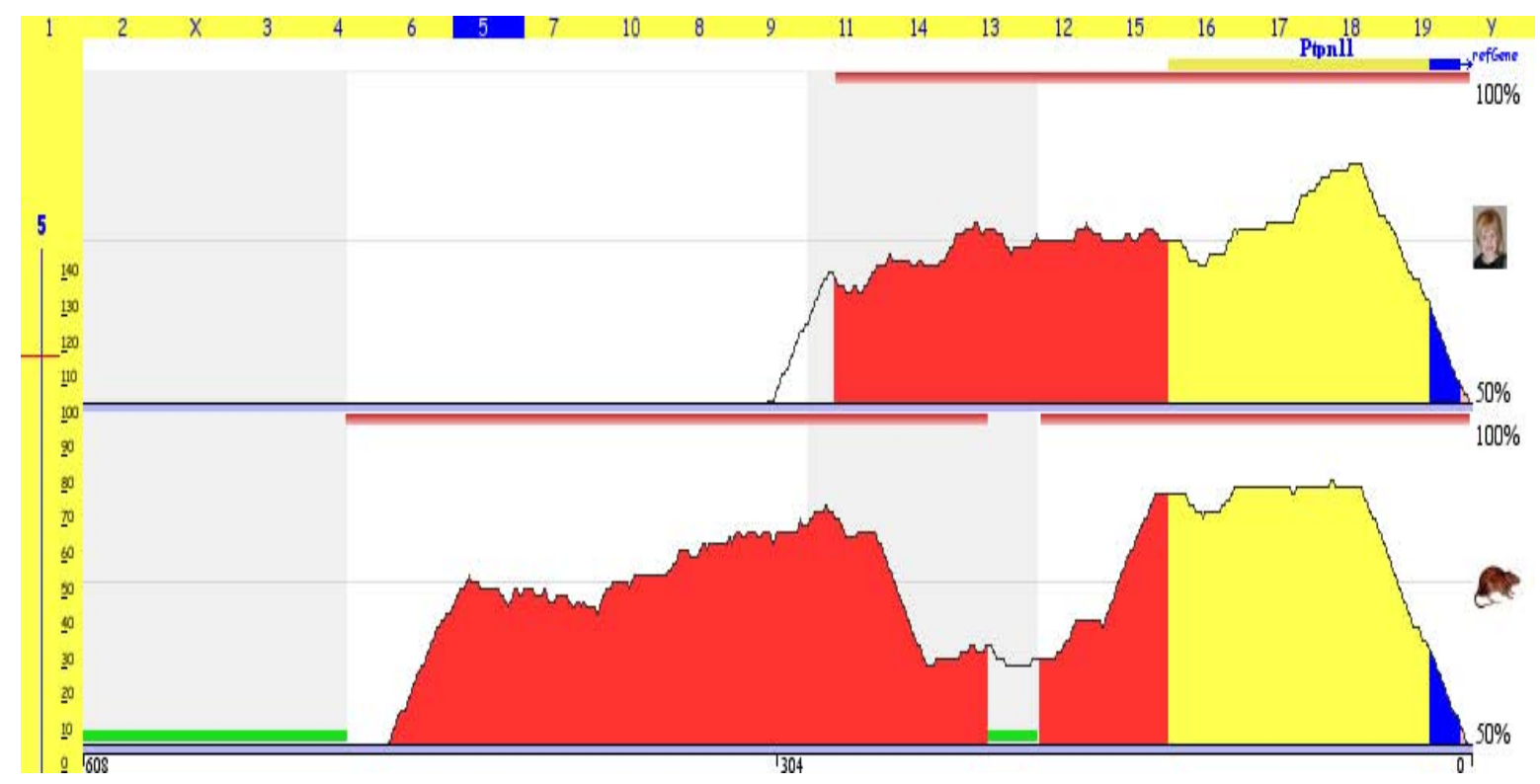

Abb. 3.3: Graphische Darstellung der Evolutionary Conserved Regions (ECR) des PTPN11-Gens. Gezeigt ist das Alignment der Basis-Sequenz des murinen Promotors (oben) mit den Promotor-Sequenzen von Mensch (mitte) und Ratte (unten) mit Hilfe von DCODE (http://www.dcode.org). Blau: das erste Exon von PTPN11,;gelb: 5’UTR; rot: putativer Promotor; grün: repetitive Elemente. Gezeigt ist die relative Position des Alignments von 0 bis $608 \mathrm{bp}$.

\subsubsection{Putative Bindungsstellen von Transkriptionsfaktoren}

Die zwischen Maus, Mensch und Ratte sehr homologen intergenischen Bereiche (600 bp vor ATG) wurden als putativer Promotor von PTPN11 betrachtet und mit Hilfe von spezieller Software (Genomatix, Transcription Element Search System (TESS), Transcriptional Factor Search (TFSearch), ClustalW und Boxshade) auf mögliche Bindungstellen für Transkriptionsfaktoren (TF) hin untersucht. Die Ergebnisse der verschiedenen Computerprogramme wurden anschließend verglichen und die gemeinsamen Transkriptionsfaktoren ausgewählt. Dabei wurden mögliche Bindungstellen für SP1, CREB und STAT identifiziert (Abb. 3.4), die in allen drei Spezies konserviert sind. 
refseq|NM_011202|Mus refseq|NM_013088|Rattus refseq|NM_OO2834|Homo consensus

refseq|NM_011202|Mus refseq|NM_013088|Rat tus refseq|NM_002834|Homo consensus

refseq|NM_011202|Mus refseq|NM_013088|Rattus refseq|NM_O02834|Homo consensus

refseq| NM_011202|Mus refseq|NM_013088|Rattus refseq |NM_002834 | Homo consensus

refseq|NM_011202|Mus refseq|NM_013088|Rattus refseq|NM_002834|Homo consensus

refseq|NM_011202|Mus refseq|NM_013088|Rattus refseq|NM_002834|Homo consensus

refseq|NM_011202 |Mus refseq|NM_013088|Rattus refseq|NM_002834|Homo consensus

refseq|NM_011202|Mus refseq|NM_013088|Rattus refseq|NM_002834|Homo consensus

refseq|NM_011202|Mus refseq|NM_013088|Rattus refseq|NM_OO2834|Homo consensus

refseq|NM 011202 |Mus refseq|NM_013088|Rattus refseq |NM_OO2834|Homo consensus

refseq|NM 011202|Mus refseq|NM_013088|Rattus refseq|NM_002834|Homo consensus

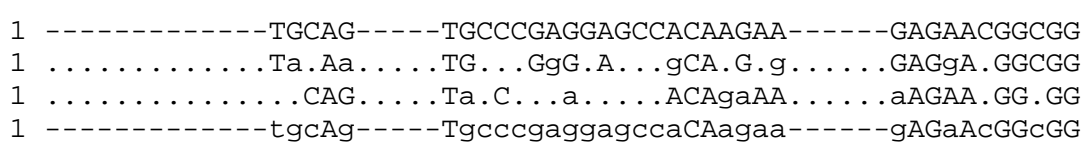

37 ATCCGGTAGAACCAAATTTACAGAAGGTTGTGGGCTGCCCCA - - - - - TACAGGTAG - GT 51 ATCCGGTAGAAC . gAA. TTACAGgAGGTTGTGGGCTGCCCCA . . . . . TACAGGT . . . . 50 A. . C. . . AGg . . CggA . . ACAG. AGGT . aT . ... T. CCCCA . . . . . . ACAG. TAa . . . 61 AtcCgGtAGaaccaaAtt tACAGaAGGTtgTgggcTgCCCCA - - - - - tACAGgTag-gt

$9 \odot$ GTTGGGAATCGAACTCGTGTTCCCCC - TCCCTTA - - TTTGTTTGCTT - CTTTTCC - - - CG 98 G. TGGGAA. CGAACTCG . GTTCCCCC. TCC . . . . . . TTATTTG . TT . CTTTTC . . . . CG 98 GT.GaG.g.CGA..T.GTG...C...T...T.A. .T. . .T.TG..... ...CC...CG 121 GttGgGaatCGAacTCGtGttcCccc-Tccctta--tttgTtTGctt-CttttCc---CG

143 TGTGCAGCCGCCCTGGATGCATATTGTGTATTGTGTCCTCGCACCTATGTGCGACG - - TC 151 TGTGCA. CCGC. CTGGATGCgTA. TGTGTA . . . . . . . CTCGCAC . ATGTGCGgCG . . TC

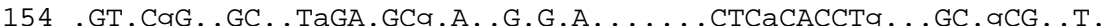
181 tGTgCagccGCCCTgGAtGCatAt tGtGtAttgtgtcCTCgCACctatgtGCgaCG - - TC

201 CCCGTTTAGAAGAATCGTCCAGGCGTTCACGGGTGTAG-CCGCACCGATTCAGAGGAGGA 200 CC. G. T. . GAAGAATC . . CC. GGCGTTCA . G. . TGTAa . CCGCAC. GATT . gGAGGAGGA 200 CC.G. . . . GAgGAA. . . . . A.GC.TT. . . a.TGTg . . . GG. g. CG . .TC.G.GGAG . . 241 CCcGtttaGAaGAAtCgtccagGCgTTcacgggTGTag-cCGcaccGatTcaGaGGAGga

260 A- - -TCCCACACCAAACTCCCTAGC-ACTGCTCAGGGCCCCGCAAACCGGAAGCAGATAG $256 \mathrm{~g}$. . . . CCC. . . CCAA. CTCC. . AGC . ACTG . TCAGGGCCC. GCAAACCGGAAGCAGA. AG 245 ......CCCgCgC.g ...T.CC.gGC.g..GCTCgG. .C.CCGC.gACCGGAAGCAGg.AG 301 a---tcCCaCaCcaaacTcCctaGC-actGcTCaGggCcCcGCaaACCGGAAGCAGatAG

316 TGGCCGTGGCGGCGGCGCGCGATGACGTCACGCAGGCGCCGGCGGCCAGGGGCGGGGGCG 312 TGGC . GTGGCGGCGG . GCG . GATGAC . TCACG . . GGCGCCGGCGGC . AGGGGCGGGGaCG 294 TGGC.G.GG . . . . . GCG . GCGgTGACaTCACG . gGGCG. CGGCGGC . AaGGGCGGGGGCG 361 TGGCcGtGGcgGcgGcGcGcGaTGACgTCACGcaGGCGcCGGCGGCCAgGGGCGGGGgCG

376 CGGGCGAGGGCGGAGCGAGCCGGGCGGCGGGGCGGCCGCGCAGTGTCCGGGATCC - - AGG $370 \ldots . .$. AGGGCGGAGCGAGCCGGGCGGCGGGGCGGCCGCGCAGTGTCCGGGATCC . . AGG 350 ...... gagGCGGAGCGAGCCGGGC. G. GGGGCaGC . GCaCAGT . TCCGGGATCC . . AGG 421 cgggcgagGGCGGAGCGAGCCGGGCgGcGGGGCgGCCGCgCAGTgTCCGGGATCC - - AGG

434 CCTGGCAGGGGGTTGTGCGCGCGCGGCCGGCCGGCTCTGCCCGCACCCGTGTCGGCTCCG 422 CCTG. CAGGGG . TTGTGCGCGCG . . GCCGGCCGGCTCTGCCCGC . CCCGTGTCGGCTCC . $40 \odot$ CCTGG . AGGGGG . T. TG . GCGCG . . GCCGGC . GGCTCTGCCC . . . . . CG . GTC . G. TCC . 481 CCTGgCAGGGGgtTgTGcGCGCGcgGCCGGCCGGCTCTGCCCgcaccCGtGTCgGcTCCg

494 GAGCGGGGCCTCGCTCGGGCCCCCTCCATGTGACGGTACCCCGCGGAGCCTGAGCGAGCA 479 GAGCGGGGCCTCaCTCGG . CCCCCTCCATGTGACGG . gCC . CG . GGAGCCTGAG . GAGCA 452 GAGCGGG . CCTC. CTCGGGCC. . C. C. ATGTGAC . . . gCCC . GCGGAGCCTGAGCaAG . A 541 GAGCGGGgCCTCgCTCGGgCCcCCtCCATGTGACgGtaCCcCGcGGAGCCTGAGcgAGcA

554 GCGGGTCCGT-GCGGAGCCGGAGA-CGGGAGGAACATGACATCGCGGAG 536 GCGGGTCCGT. GCGGAGCCGGAGg. CGGGAGGAACATGACATC. CGGAG 509 GCGGGTCCGT . GCGGAGCCGGAGg . CGGGAGGAACATGACATCGCGGAG 601 GCGGGTCCGT-GCGGAGCCGGAGa-CGGGAGGAACATGACATCgCGGAG

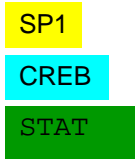

Abb. 3.4: Darstellung der Ergebnisse des ClustalW-Alignments zwischen murinem, humanem und

Ratten-Promotor von PTPN11. Dargestellt ist das Alignment des 600 bp langen Promotor-Fragmentes und der putativen Bindungsstellen für die Transkriptionsfaktoren SP1, CREB und STAT, die in allen drei Spezies konserviert sind. 


\subsubsection{Experimentelle Bestätigung des Minimalpromotors von PTPN11}

Um die Ergebnisse der Computeranalysen experimentell zu bestätigen wurden verschiedene Bereiche des humanen und des murinen PTPN11-Promotors (bis Transkriptionsstart (TS) oder ATG) vor das Luciferase-Gen kloniert (Abb. 3.5). Nur bei einem funktionellen Promotorbereich wird nach Transfektion in Säugerzellen die Luciferase exprimiert. Die Aktivität der Luciferase gibt daher Aufschluss über die Funktionalität und Effizienz des Promotorbereiches.

Die verwendeten PTPN11-Promotor-Luciferase-Konstrukte sind in Abbildung 3.6 für den humanen Promotor und in Abbildung. 3.7 für den murinen Promotor gezeigt. Für den humanen PTPN11-Promotor wurden vier Konstrukte mit verschiedenen Längen 5’ vom TS (2,2 kb, 1,4 kb 0,6 kb und 0,3 kb) und zwei Konstrukte 5' von ATG (0,8 kb und 0,4 kb) hergestellt. Es wurden drei Konstrukte bis TS ( 2 kb, 1 kb und 0,1 kb) und sechs Konstrukte bis ATG (2,2 kb, 1,1 kb, 0,3 kb, 0,2 kb und 0,1 kb) für den murinen PTPN11-Promotor hergestellt. Die Konstrukte wurden nach ihrer Größe sowie einem Indexbuchstaben (h oder m) für die Spezies benannt.

Die verschiedenen PTPN11-Promotor-Luciferase-Konstrukte wurden in NIH/3T3-Zellen transfiziert und die Aktivität der Luciferase $24 \mathrm{~h}$ später gemessen. Zum Abgleich der Transfektionseffizienzen erfolgte stets eine Kotransfektion mit dem $\beta$-Galaktosidaseexprimierenden Vektor pCMV- $\beta$-Gal und eine Messung der $\beta$-Galaktosidase-Aktivitäten. Durch die Berechnung des Verhältnisses der Luciferase-Aktivität zur $\beta$-GalaktosidaseAktivität können die Ergebnisse verschiedener Transfektionen trotz schwankender Transfektionseffizienz verglichen werden. In den Abbildungen 3.6 und 3.7 sind die relativen Werte für die bezüglich der Transfektionseffizienzen abgeglichenen Luciferase-Aktivitäten der Konstrukte des humanen bzw. des murinen Promotors dargestellt. Den jeweils längsten Konstrukten h2,2Luc(TS) und h0,8Luc(ATG) des humanen PTPN11-Promotors wurde per Definiton ein Wert von 100 zugeordnet. Die Messung der relativen Luciferase-Aktivitäten des Konstruktes h1,4Luc(TS) ergab eine Zunahme um 83\%, während die Konstrukte h0,6Luc(TS) und h0,3Luc(TS) eine Erhöhung der Aktivität um 173\% bzw. 243\% zeigten im Vergleich zu h2,2Luc(TS). Die Messung der relativen Luciferase-Aktivitäten des Konstruktes h0,4Luc(ATG) ergab eine Erhöhung um 38\% im Vergleich zu h0,8Luc(ATG).

Bei der Analyse des murinen Promotors wurde den Konstrukten m2Luc(TS) und m2,2Luc (ATG) der Wert 100 zugeordnet. Die Messung der relativen Luciferase-Aktivitäten des Konstruktes m0,9Luc(TS) zeigte eine Erhöhung um 50\%, während das Konstrukt 
m0,1Luc(TS) eine Verminderung um 90\% aufwies. Die Messung der relativen LuciferaseAktivitäten des Konstruktes m0,3Luc(ATG) ergab eine Erhöhung von 250\%, während m1Luc(ATG) 75\% und die Konstrukte m0,2Luc(ATG) und m0,1Luc(ATG) eine Verminderung von 25\% und 90\% im Vergleich zu m2,2Luc(ATG) aufwiesen.

Die höchsten Luciferase-Aktivitäten wurde sowohl bei den murinen als auch bei den humanen PTPN11-Promotor-Konstrukten für das 300 bp lange Promotor-Fragment gemessen. Dieser Bereich zeigt auch die höchste Homologie für PTPN11 zwischen Maus und Mensch. Sowohl die Konstrukte, die länger als 300 bp sind, als auch die kleineren Konstrukte zeigen bei Maus und Mensch eine geringere Luciferase-Aktivität. Worauf dieser inhibierende Effekt von zusätzlichen 5' Sequenzen zurückzuführen ist, wurde nicht untersucht. Denkbar sind z.B. ein reines Kulturartefakt (etwa die Störung der Zugänglichkeit des Kernpromotors durch zusätzliche irrelevante DNA) oder die Anwesenheit von echten inhibierenden Sequenzen (d.h. Bindungstellen für transkriptionelle Repressoren).

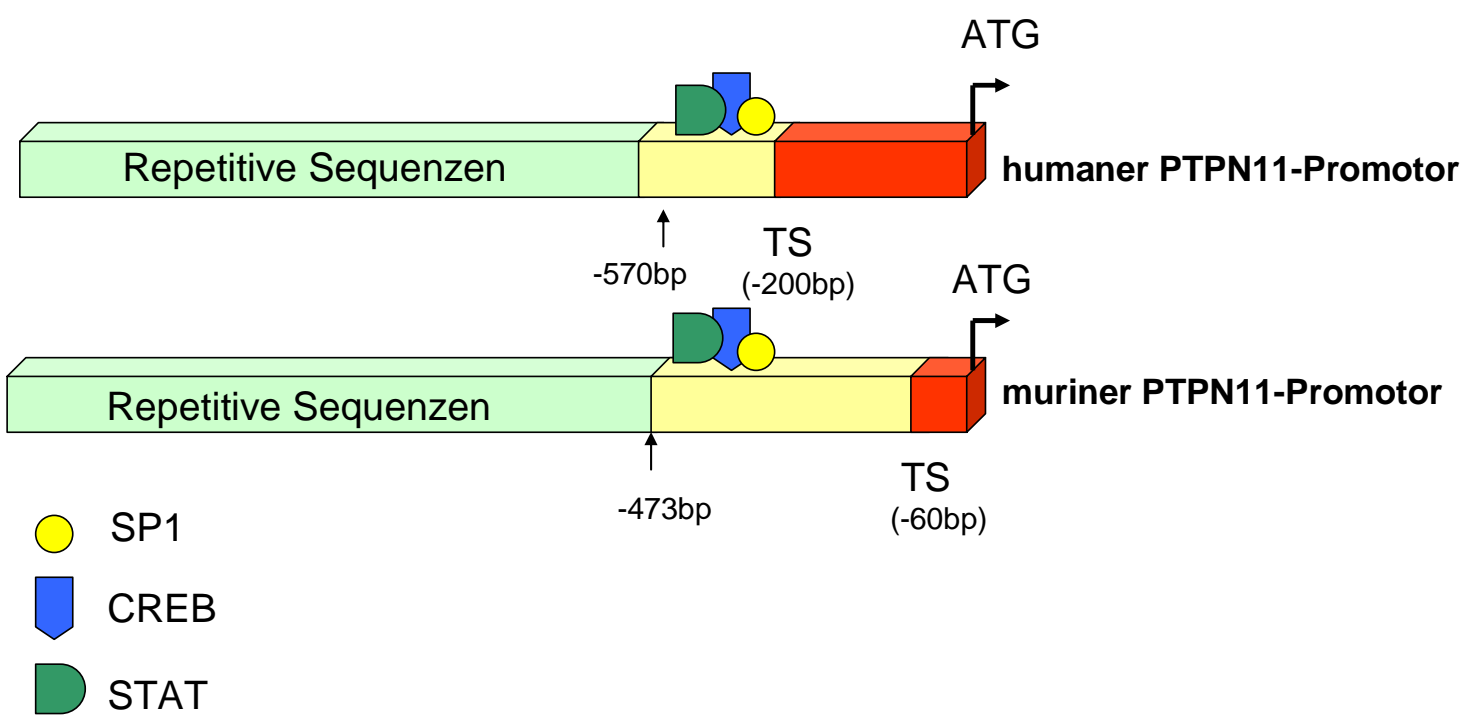

TS:Transkriptionsstart

Abb. 3.5: Übersichtsdarstellung des PTPN11-Promotors von Mensch und Maus. Gezeigt sind der humane und der murine PTPN11-Promotor mit repetitiven Sequenzen, Transkriptionsstart (TS), sowie den putativen Bindungsstellen für die Transkriptionsfaktoren SP1, CREB und STAT. 


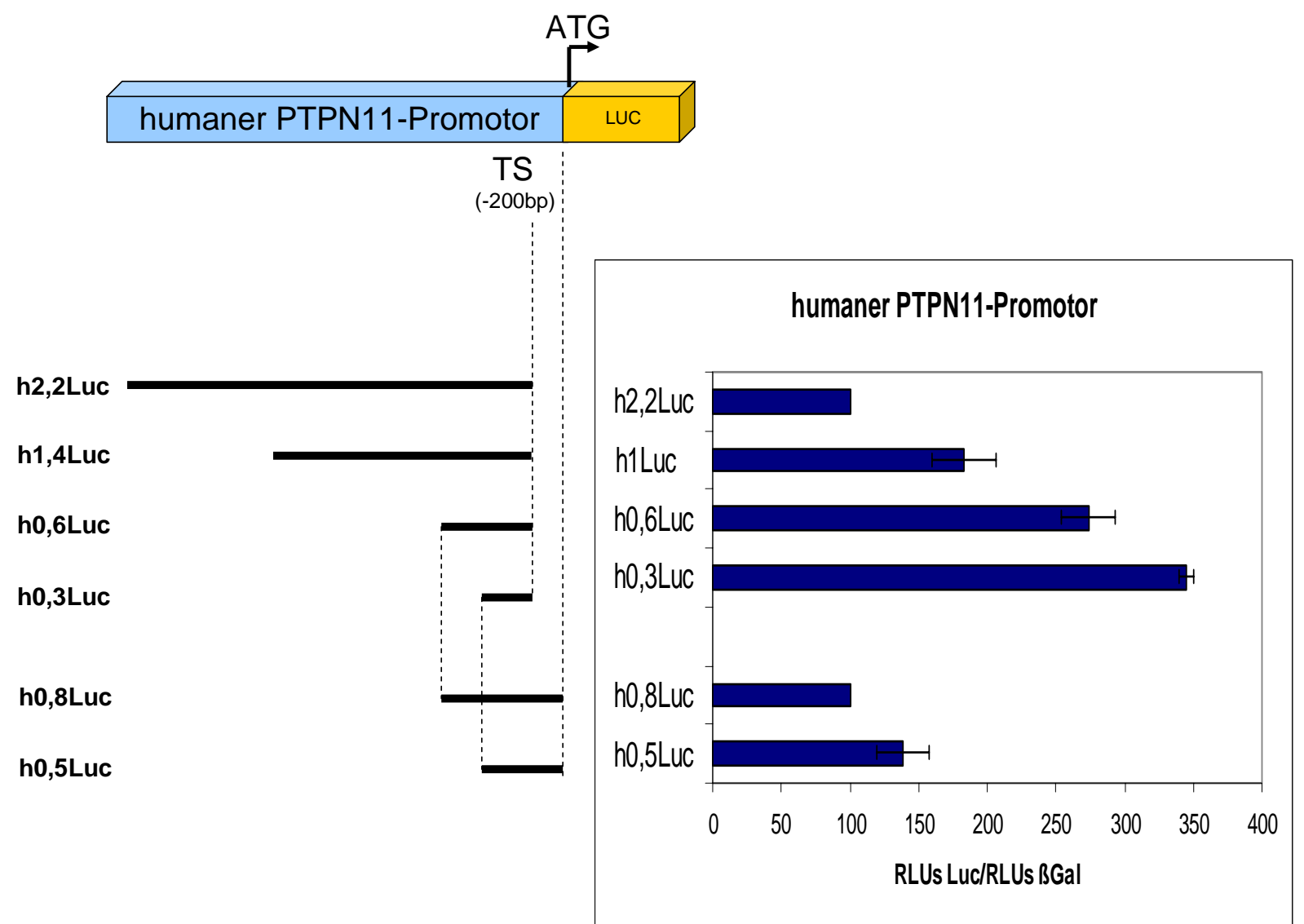

Abb. 3.6: Graphische Darstellung der Ergebnisse der Luciferase-Aktivitäts-Messung nach Transfektion von NIH/3T3-Zellen mit den verschiedenen humanen Promotor-Luciferase-Konstrukten. Gezeigt sind die relativen Werte für die normalisierten Luciferase-Aktivitäten der Konstrukte h2,2Luc, h1,4Luc, h0,6Luc und h0,3Luc, die sich bis zum Transkriptionsstart (TS) erstrecken. h2,2Luc wurde ein Wert von 100 zugeordnet. Eine deutliche Zunahme der relativen Luciferase-Aktivitäten wurde für die Konstrukte h1,4Luc(TS), h0,6Luc(TS) und h0,3Luc(TS) im Vergleich zu h2,2Luc(TS) beobachtet. Auch das kürzere h0,5Luc(ATG)-Konstrukt zeigt eine höhere Luciferase-Aktivität im Vergleich zu h0,8Luc(ATG). 


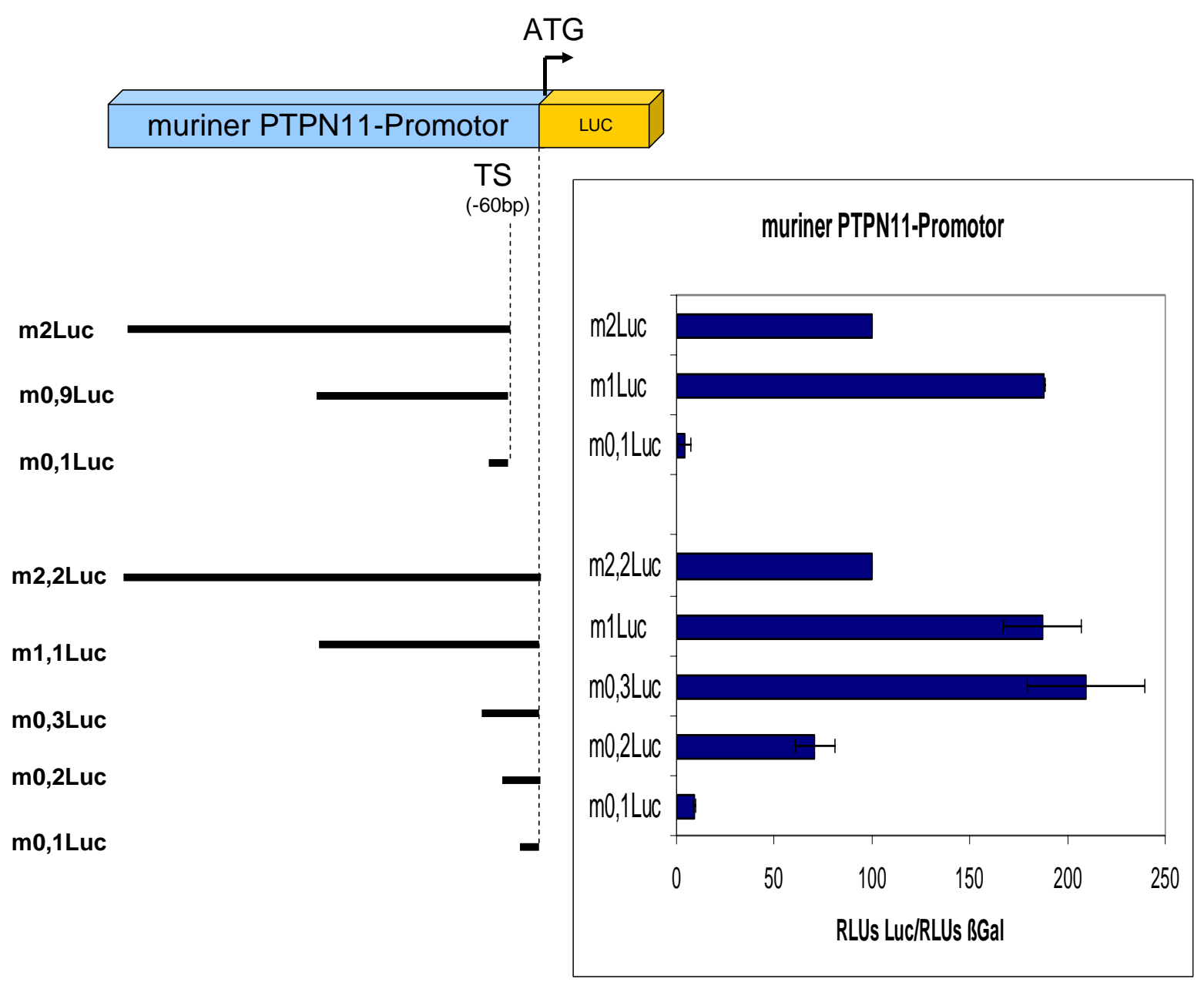

Abb. 3.7: Graphische Darstellung der Ergebnisse der Luciferase-Aktivitäts-Messung nach der Transfektion von NIH/3T3-Zellen mit verschiedenen murinen Promotor-Luciferase-Konstrukten. Gezeigt sind die relativen Werte für die normalisierten Luciferase-Aktivitäten der Konstrukte m2Luc, m0,9Luc, und m0,1Luc, die sich bis Transkriptionsstart (TS) erstrecken, m2Luc wurde ein Wert von 100 zugeordnet. Ein deutliche Abnahme der relativen Luciferase-Aktivitäten wurde für die Konstrukte m2Luc(TS) und m0,1Luc(TS) im Vergleich zu m1Luc(TS) beobachtet. Das m0,3Luc(ATG) Konstrukt zeigt eine höhere Luciferase-Aktivität im Vergleich zu m2,2Luc(ATG), m1Luc(ATG), m0,2Luc(ATG) und m0,1Luc(ATG).

\subsubsection{Identifizierung von Bindungsstellen für die Transkriptionsfaktoren SP1, CREB und STAT im PTPN11-Promotor}

Anhand der Computeranalyse und aufgrund der Transfektionsexperimente wurde ein Bereich bis ca. 500 bp 5' von ATG beim Menschen (ca. 300 bp bei der Maus) als Promotor und SP1, CREB und STAT als Kandidaten für die Regulation von PTPN11 identifiziert. Um dieses Ergebnis experimentell zu bestätigen, wurden EMSA-Experimente durchgeführt. Dazu 
wurden für die 300 bp des murinen PTPN11-Minimalpromotors zehn sich überlappende Primerpaare (40 bp) entworfen, die den gesamten Bereich abdecken. Nach der Inkubation der radioaktiv markierten Primerpaare mit Kernextrakt aus NIH/3T3-Zellen wurde eine nichtdenaturierende Gelelektrophorese wie unter 2.2.7 beschrieben durchgeführt. Als Negativkontrolle wurden Primerpaare ohne Inkubation mit NIH/3T3-Kernextrakt verwendet. Findet eine Bindung zwischen DNA und Kernproteinen statt, so läuft dieser Komplex bei der gelelektorphoretischen Auftrennung langsamer im Vergleich zu freier DNA und doppelsträngigen Oligonukleotiden und wird als motility shift bezeichnet. Die für den EMSA verwendeten Primerpaare sind in Abbildung 3.8 schematisch dargestellt. Das Primerpaar 229/-191 enthält zwei putative Bindungsstellen für SP1. Die Primerpaare -260/-222 und 291/-253 enthalten die putativen CREB- bzw. STAT-Bindungsstellen. Als Positivkontrollen wurden die Oligonukleotide mit Konsensus-Sequenzen der SP1- und CREB-Bindungsstellen verwendet.

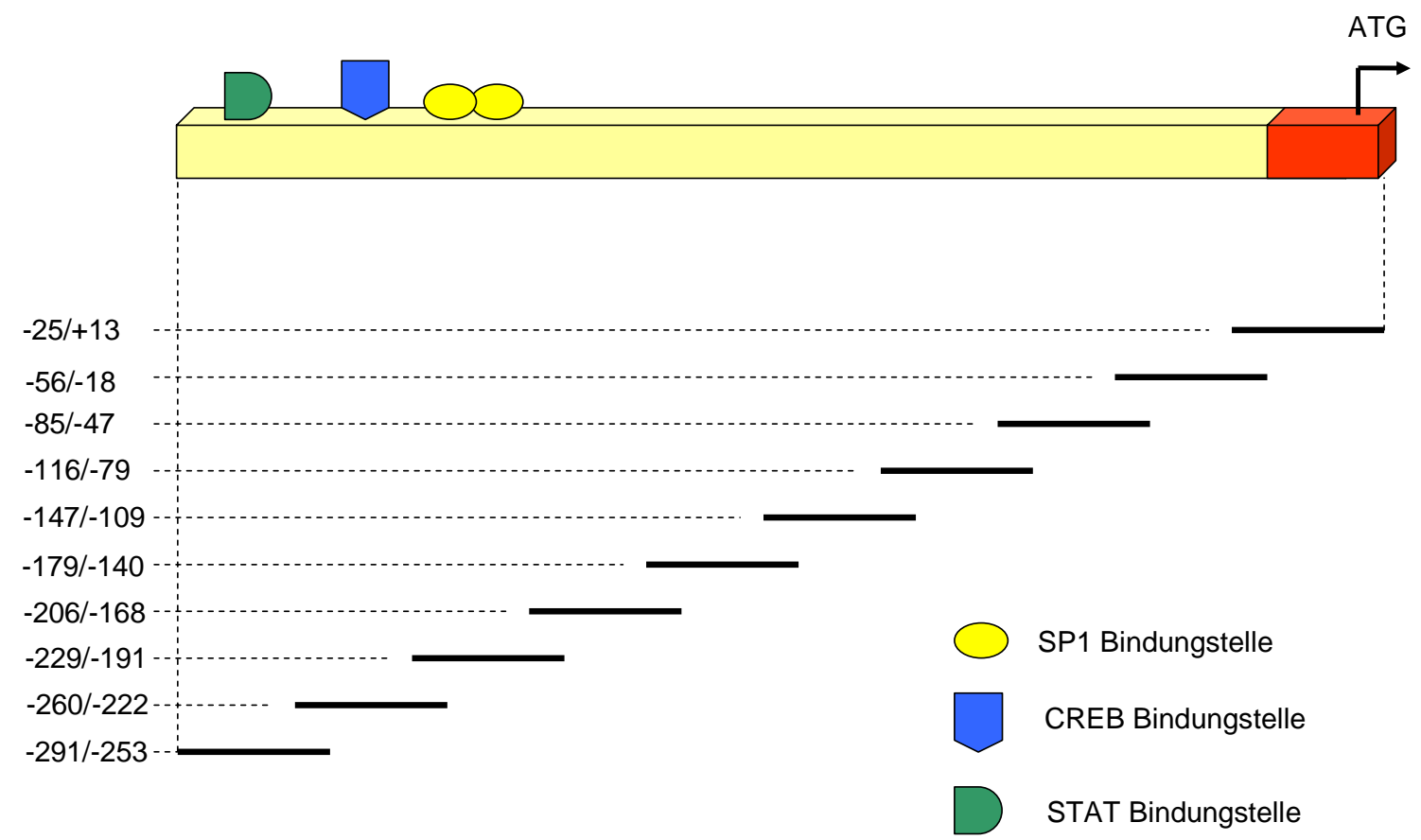

Abb. 3.8: Übersichtsdarstellung der für EMSA verwendeten Primerpaare des murinen PTPN11Promotors. Gezeigt sind die zehn überlappenden Primerpaare, die für EMSA verwendet wurden, und ihre Position relativ zum PTPN11-ATG sowie die Lage der putativen Bindungsstellen für SP1, CREB und STAT.

Wie in Abbildung 3.9 B dargestellt ist ein shift mit den Primerpaaren aufgetreten, die die putativen Bindungsstellen für SP1, CREB und STAT (-229/-191, -260/-222 und -291/-253) enthalten. Die übrigen Primerpaare zeigten keine Verringerung in der Laufgeschwindigkeit im Vergleich zu den Positivkontrollen SP1 und CREB (Abb. 3.9 A.). 
Zur Bestätigung des shift wurden spezifische und nicht-spezifische Kompetitionsexperimente mit den Primerpaaren -229/-191, -260/-222 und -291/-253 durchgeführt. Bei der spezifischen Kompetition wurden zusätzlich für die jeweilige Transkriptionsfaktoren-Bindungsstelle spezifische, nicht-markierte Oligonukleotide im 100fachen Überschuss eingesetzt, wodurch die Bindung des Transkriptionsfaktors an das markierte Primerpaar behindert wird. Nach der Elektrophorese ist zu erkennen, dass ein shift weder in der Positivkontrolle (SP1) noch in den drei untersuchten Primerpaaren 229/-191, -260/-222 und -291/-253 stattgefunden hat (Abb. 3.9 C.). Wurden bei der Inkubation von markierten Primerpaaren mit Kernextrakt unspezifische, nicht-markierte Oligonukleotide eingesetzt, wurde ein shift beobachtet (Abb. 3.9 D.). Dies zeigt, dass die Interaktion von den Primerpaaren 229/-191, -260/-222 und -291/-253 mit den Kernproteinen sequenz-spezifisch sind.

A.
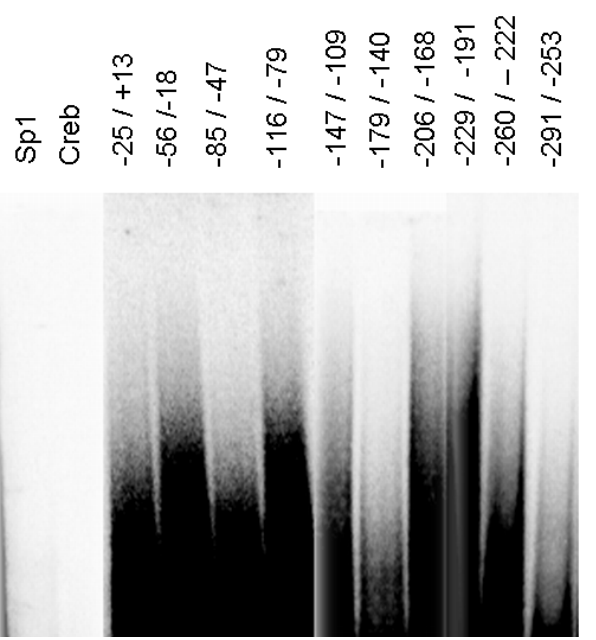

C.

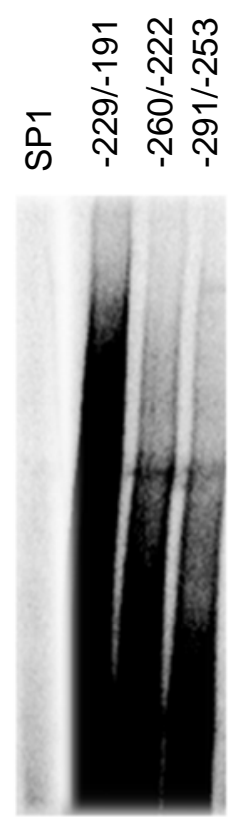

B.
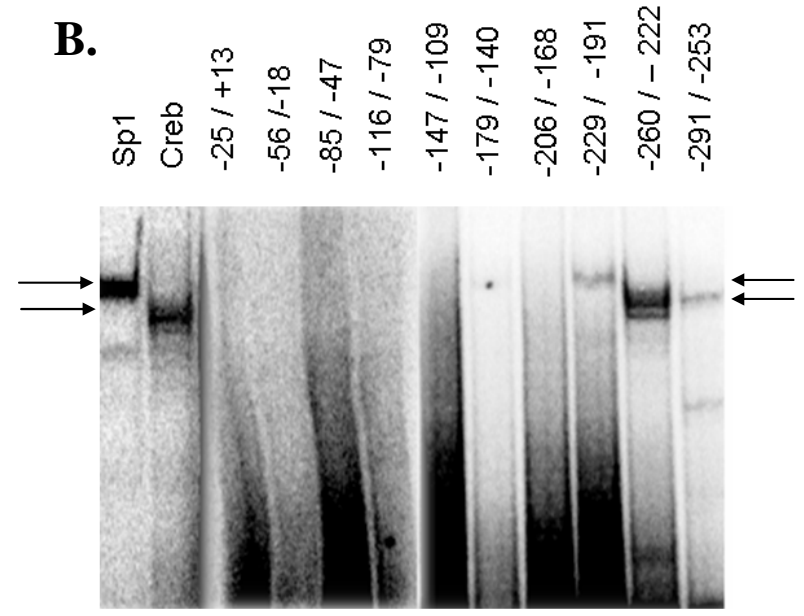

D.
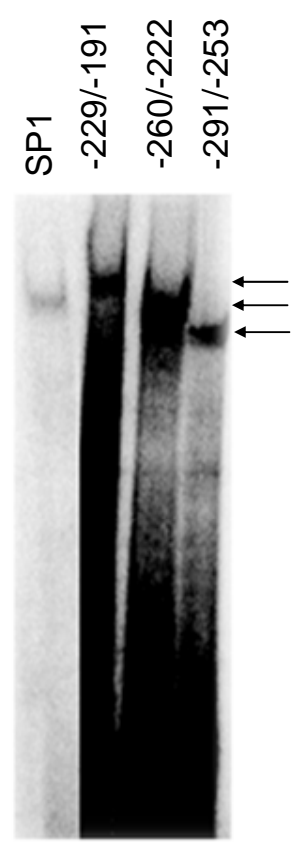
Abb. 3.9: Ergebnisse des EMSA für 300 bp des murinen PTPN11-Promotors. A. Die radioaktiv-markierten Oligonukleotide wurden ohne Inkubation mit Kernextrakt elektrophoretisch aufgetrennt (als Negativkontrolle).

B. Die radioaktiv-markierten Primerpaare wurden mit Kernextrakt inkubiert und anschließend wie unter A behandelt. Die Primerpaare -229/-191, -260/-222 und -291/-253 zeigen einen shift wie die Positivkontrollen SP1 und CREB. C. Spezifisches Kompetitor-Experiment: Zusätzlich zur Inkubation mit Kernextrakt wurden nicht markierte, spezifische Oligonukleotide (SP1 bzw. CREB-Sequenz) in 100fachem Überschuss zugesetzt, der shift bei 229/-191, -260/-222, -291/-253 entfällt. D. Nicht-spezifisches Kompetitor-Experiment: die Proben wurden wie unter B behandelt, zusätzlich wurden nicht markierte, nicht spezifische Oligonukleotide in 100fachem Überschuss eingesetzt. Der shift bleibt erhalten

\subsubsection{Supershift-Experimente}

Um die Spezifität eines EMSA-Ergebnisses zu beweisen, kann ein Antikörper gegen den putativen Transkriptionsfaktor in die Reaktion eingesetzt werden. Bei der sich anschließenden gelelektorphoretischen Auftrennung läuft der DNA-Transkriptionsfaktor-AntikörperKomplex noch langsamer als der Komplex von DNA und Kernprotein und wird dann als supershift bezeichnet.

Der Versuch, einen supershift mit SP1 und SP1-Antikörper (Fa. Santa Cruz, Santa Cruz, Delaware, USA) zu erhalten, wurde unter verschiedenen Bedingungen (Inkubation bei $4^{\circ} \mathrm{C}$, RT, 30 min, ÜN) durchgeführt. In keinem Fall konnte ein supershift beobachtet werden.

\subsubsection{Mutationsanalyse}

Um auf anderem Wege die Spezifität der EMSA-Ergebnisse weiter zu belegen, wurde eine Mutationsanalyse für die Oligonukleotide durchgeführt, die einen shift gezeigt hatten. Die Oligonukleotide -229/-191, -260/-222 und -291/-253 wurden in der Bindungsstelle der jeweiligen Transkripionsfaktoren mutiert (Tab. 3.1). Wenn die Bindungsstellen spezifisch für die jeweiligen Transkriptionsfaktoren sind, sollte bei dem EMSA mit den mutierten Oligonukleotiden kein shift zu sehen sein. In der Tabelle 3.1 sind die forward-Primer für die Mutationsanalyse gezeigt. In rot gekennzeichnet sind die mutierten Nukleotide der putativen Bindungsstellen. Im Fall des Primerpaares -229/-191 wurden jeweils zwei Nukleotide pro SP1-Bindungsstelle (-229/-191mut1F und -229/-191mut2F) mutiert bzw. beide SP1Bindungsstellen mutiert (-229/-191mut12F). Bei dem Primerpaar -291/-253 wurden zwei verschiedene mutierte Oligonukleotide für die STAT-Bindungsstelle getestet (-291/253mutF1 und -291/-253mutF2). Zur Kontrolle der Methode wurden in die Konsensus- 
Sequenzen der SP1- und CREB- Bindungsstellen die gleichen Mutationen eingeführt wie in den zu testenden Primerpaaren.

\begin{tabular}{ll}
\hline Name & Sequenz \\
\hline SP1F & 5' '-ggA TTC GAT CGG GGC GGG GCG AGC- 3' \\
SP1mutF & 5' -ggA TTC GAT CGG TTC GGG GCG AGC- 3' \\
CREB F & 5' -ggA GAG ATT GCC TGA CGT CAG AGA GCT AG- 3' \\
CREBmut F & 5' -ggA GAG ATT GCC TGT TGT CAG AGA GCT AG- 3' \\
-229/-191 & 5' -ggC GGC CAG GGG CGG GGG CGC GGG CGA GGG CGG AGC GAG C- 3' \\
-229/-191mut1F & 5' -ggC GGC CAG GTT CGG GGG CGC GGG CGA GGG CGG AGC GAG C- 3' \\
-229/-191mut2F & 5' -ggC GGC CAG GGG CGG GGG CGC GGG CGA GTT CGG AGC GAG C- 3' \\
-229/-191mut12F & 5' -ggC GGC CAG GTT CGG GGG CGC GGG CGA GTT CGG AGC GAG C- 3' \\
-260/-222 & 5' -ggG CGG CGC GCG ATG ACG TCA CGC AGG CGC CGG CGG CCA G- 3' \\
-260/-222mutF & 5' -ggG CGG CGC GCG ATG TTG TCA CGC AGG CGC CGG CGG CCA G- 3' \\
-291/-253 & 5' -ggC GCA AAC CGG AAG CAG ATA GTG GCC GTG GCG GCG GCG C- 3' \\
-291/ -253mutF & 5' -ggC GCA AAC CTA AAG CAG ATA GTG GCC GTG GCG GCG GCG C- 3' \\
-291/-253mutF2 & 5' -ggC GCA AAA AGG AAG CAA ATA GTG GCC GTG GCG GCG GCG C-3' \\
\hline
\end{tabular}

Tab. 3.1: Forward-Primer der Primerpaare: Gezeigt sind die forward-Primer, die für die Mutationsanalyse verwendet wurden. In rot sind die mutierten Nukleotide gekennzeichnet.

Die Durchführung des EMSA-Experiments mit den mutierten Primerpaaren ergab, dass bei den Oligonukleotiden 260/-222mut (CREB-Bindungsstelle), SP1mut und CREBmut kein shift erhalten wurde. Dies zeigt, dass die Methode funktioniert und eine spezifische CREBBindungsstelle vorhanden ist. Bei -229/-191mut.1 (SP1-Bindungsstelle), -229/-191mut.2 (SP1-Bindungsstelle) und -291/-253mut (STAT-Bindungsstelle) trat ein shift auf. Daher wurde ein zweites EMSA-Experiment mit den Oligonukleotiden -229/-191mut.1,2 (beide SP1-Bindungsstellen) und -291/-253mut2 (neue Mutation in STAT-Bindungsstelle) durchgeführt, bei dem für keines der Oligonukleotide ein shift erhalten wurde. Zusammenfassend kann gesagt werden, dass die für den PTPN11-Promotor vorhergesagten Bindungsstellen für die Transkriptionsfaktoren SP1, CREB und STAT spezifisch sind und PTPN11 höchstwahrscheinlich durch diese Transkriptionsfaktoren reguliert wird. 
A. B.

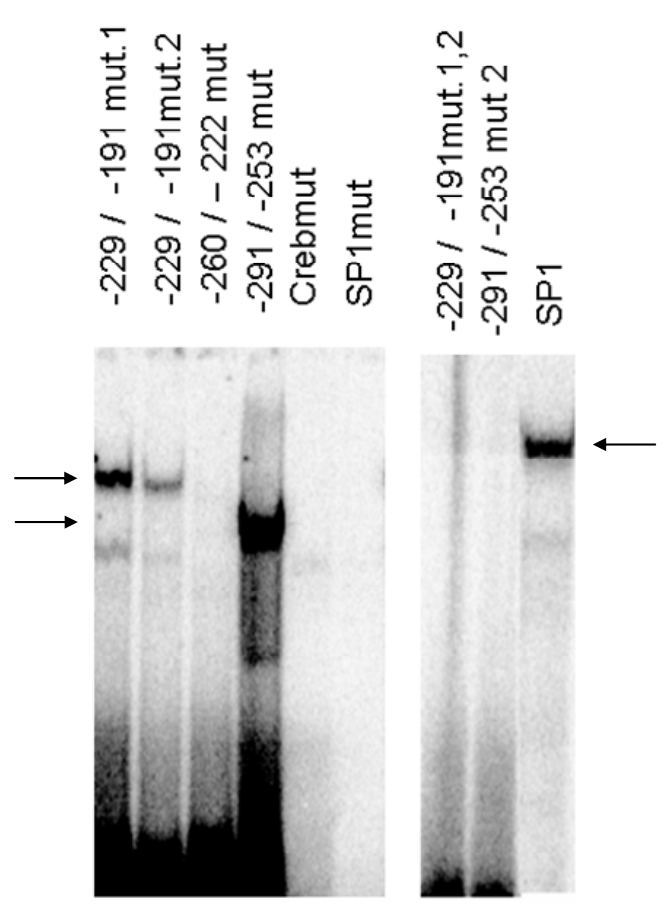

Abb. 3.10: Ergebnisse des EMSA mit den mutierten Bindungsstellen für SP1, CREB und STAT. Die markierten und mutierten Primerpaare (Tab. 3.1) wurden mit NIH/3T3-Kernextrakt inkubiert und elektrophoretisch aufgetrennt. A. Bei den Primerpaaren -260/-222mut sowie bei den Positivkontrollen SP1mut und CREBmut wurde kein shift erhalten. Bei den Primerpaaren -229/-191mut.1 und -229/-191mut.1 trat der shift aufgrund der Existenz der zweiten SP1-Bindungsstelle auf. Der shift bei 291/-253mut ist auf eine fehlerhaft eingeführte Mutation in der STAT-Bindungsstelle zurückzuführen. B. Ein zweites EMSA-Experiment mit den Primerpaaren 229/-191mut1,2 und -291/-253mut2 (neue Mutation) zeigte, dass es zu keinem shift bei beiden Oligonukleotiden gekommen ist, die Positivkontrolle mit dem nicht-mutierten SP1-Primerpaar jedoch einen shift zeigt.

\subsubsection{Mutationssuche im PTPN11-Promotor bei Noonan-Patienten}

Alle bislang bekannten PTPN11-Mutationen führen zu einer Zunahme der Aktivität des Proteins. Es ist also denkbar, dass Promotormutationen, die die Transkription steigern, pathogen wirken können. Es wurden 46 Patienten, bei denen keine Mutation in der kodierenden Sequenz von PTPN11 gefunden wurde, analysiert. Es wurden zwei Sequenzvarianten gefunden, nämlich bei 14\% der Patienten wurde -174 G/C und bei 8\% -273 A/G nachgewiesen. In einem Patienten wurden beide Polymorphismen gefunden. 


\subsection{Identifizierung von großen Deletionen im PTPN11- Gen}

Bei der Suche nach Mutationen im PTPN11-Gen von Noonan-Patienten wurden missenseMutationen und zwei kleine Deletionen von 3 bp Länge [Yoshida et al., 2004; Lee et al., 2005] gefunden. Bisher sind jedoch noch keine größeren Deletionen in PTPN11 als Ursache für Noonan-Syndrom (NS) bekannt. Eine Deletion des gesamten Gens würde in einem Verlust der Funktion resultieren und ist daher nicht plausibel für NS. Das PTPN11-Gen und die Domänen von SHP2 sind in Abbildung 3.11 gezeigt. SHP2 enthält zwei SH2-Domänen, die entsprechend ihrer Position N-SH2 und C-SH2 genannt werden und von den Exons 2 und 3 bzw. von den Exons 4, 5 und z.T. 6 kodiert werden. Die katalytisch aktive PTP-Domäne wird von den Exons 6 bis 13 kodiert und interagiert über dessen N-SH2-Bindungsdomäne mit der N-terminalen SH2-Domäne. Hierdurch wird die PTP-Domäne inaktiviert. Am Cterminalen Ende von SHP2, das von den Exons 14 und 15 kodiert wird, befinden sich zudem zwei Tyrosin-Phosphorylierungsstellen (AS-Position 542 und 580), die nach Ligandenbindung phosphoryliert sein können. Eine Deletion von Exon 3 und/oder 15 würde keinen frameshift erzeugen, sondern nur die N-SH2-Domäne bzw. die N-SH2Bindungsdomäne deletieren. Dies könnte einen Verlust der Autoinhibition und eine Erhöhung der Phosphatase-Aktivität von SHP2 verursachen. Im Rahmen dieser Arbeit sollten daher Noonan-Patienten mittels Taqman-Analyse auf große Deletionen im PTPN11-Gen hin untersucht werden.

\section{PTPN11}

Deletion?

Deletion?

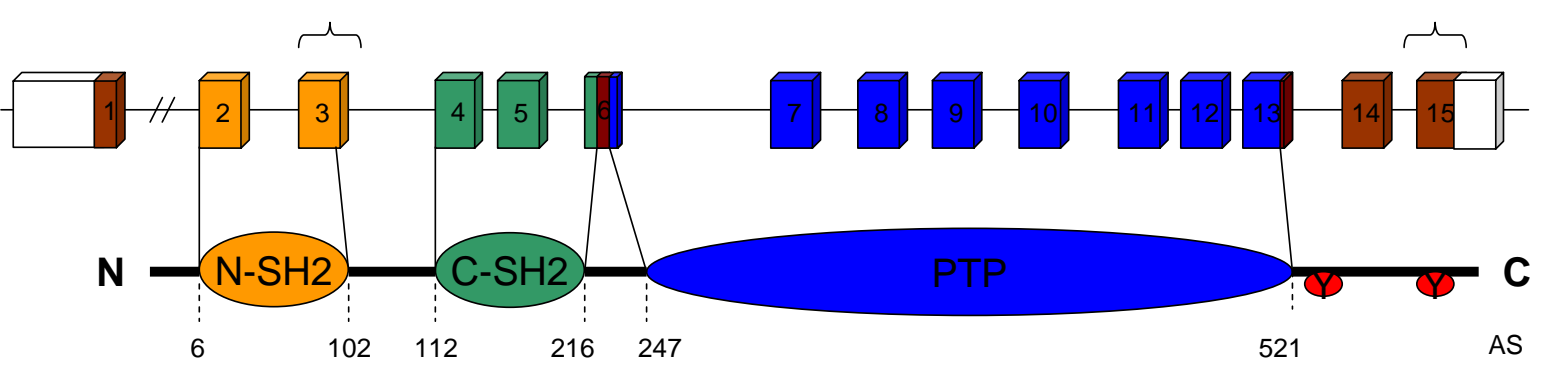

SHP2

Abb. 3.11: Graphische Darstellung des PTPN11-Gens und dessen Genprodukt SHP2 (nach www.expasy/uniprot.org). Gezeigt sind die Exon/Intron-Organisation des PTPN11-Gens und die Proteindomänen von SHP2. N-SH2 (orange) wird von Exon 2 und 3 kodiert, C-SH2 von Exon 4, 5 und 6. Die 
katalytisch aktive Phosphatase-Domäne PTP wird von den Exons 6 bis 13 kodiert. Am C-Terminus von SHP2 befinden sich zwei Tyrosin-Phosphorylierungsstellen.

\subsubsection{Taqman-Analyse}

Die Deletionsanalyse mittels quantitativer PCR (Taqman-Analyse) wurde für NoonanPatienten durchgeführt, bei denen im Rahmen einer konventionellen Noonan-Diagnostik keine Mutation gefunden wurde. Die Durchführung der Taqman-Analyse erfolgte wie unter 2.2.5.4 beschrieben. Durch die Messung eines Standards mit verschiedenen DNAKonzentrationen einer Kontroll-Person, sowohl für das Referenzamplikon als auch für jedes Testamplikon, errechnet das Programm SDS 2.1 die theoretisch eingesetzten DNAKonzentrationen der Testpersonen für jedes Amplikon. Im Normalfall sollten die für Testamplikon und Referenzamplikon interpolierten DNA-Konzentrationen einer Person identisch sein. Errechnet das Programm jedoch einen signifikant höheren Wert für das Referenzamplikon, obwohl identische DNA-Mengen eingesetzt wurden, liegt in der Region des Testamplikons eine Deletion vor.

Es wurde das Verhältnis zwischen den interpolierten DNA-Konzentrationen des Testamplikons zum Referenzamplikon jeder Probe berechnet. Dadurch wird der Effekt unterschiedlicher Effizienzen der verschiedenen Amplikons, d.h. die Abhängigkeit der PCREffizienz von der eingesetzten DNA-Konzentration eingerechnet. Erfahrungsgemäß liegt bei einem Verhältnis von kleiner 0,78 eine Deletion vor [Boehm et al., 2004]. In solchen Fällen wurde der Assay wiederholt und, falls reproduzierbar, die angrenzenden Exons überprüft.

Zunächst wurden 42 Patienten bezüglich der Amplikons NS3 (Exon 3) und NS15 (Exon 15) mittels Taqman-Analyse getestet (Abb. 3.12). Bei Patienten mit auffälligen Ergebnissen in dem Amplikon NS3 wurden zwei neue Amplikons, die in Exon 2 (NS2) und 4 (NS4) liegen, getestet. Damit wurde eine alleinige Deletion des Exons 3 bei den Patienten 22411, 22412, 22417, 22432 und 22434 wegen des unter 0,78 liegenden relativen Verhältnisses der Amplikons NS2, NS3 und NS4 ausgeschlossen (Abb. 3.12). Bei den Patienten 24633, 25640 und 24653 kam es zu einer reproduzierbaren Auffälligkeit im Bereich des NS3. Dieses durch die Taqman-Analyse erhaltene Ergebnis musste jedoch durch weitere Methoden verifiziert werden (3.2.2). 


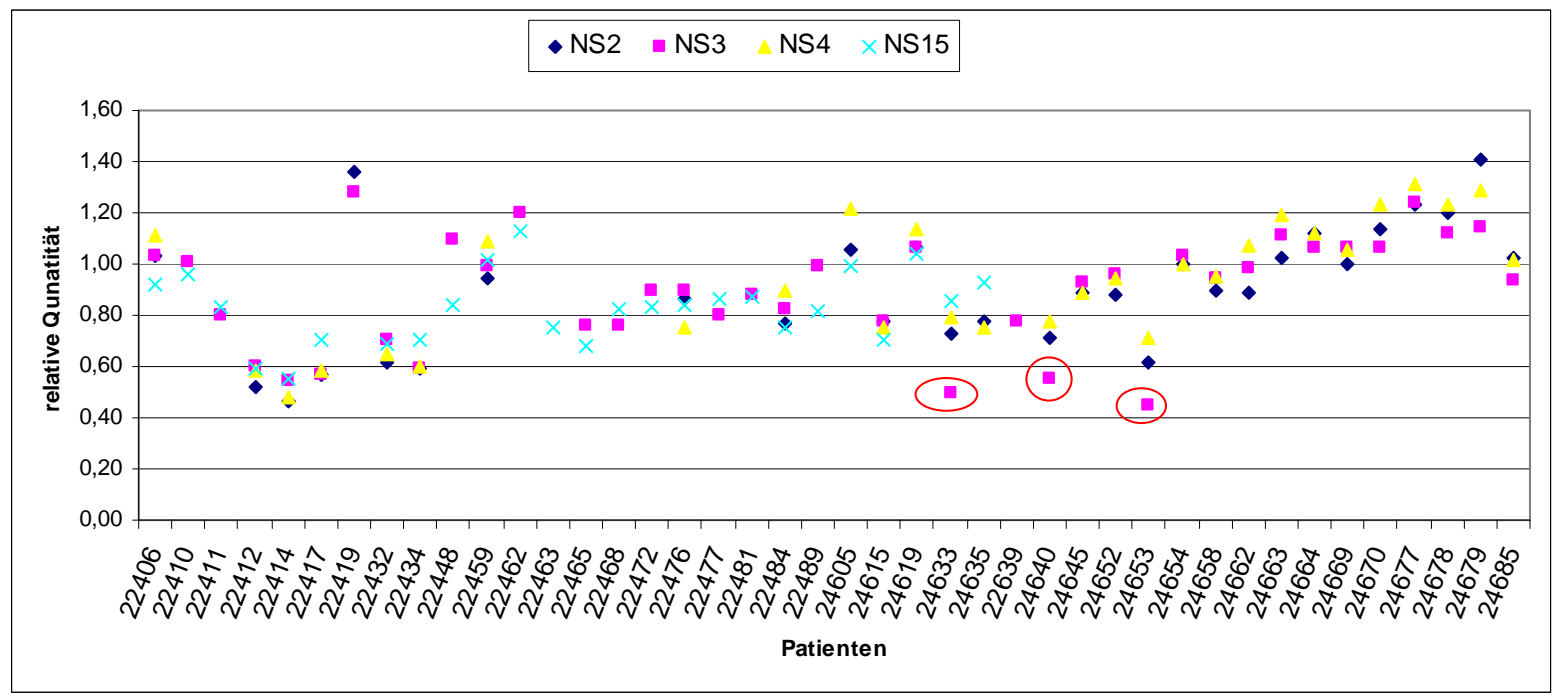

Abb. 3.12: Darstellung der Ergebnisse der Taqman-Analyse der Amplikons NS2, NS3, NS4 und NS15. Aufgetragen wurde die errechnete relative DNA-Quantität jedes Patienten für die analysierten TaqmanAmplikons. Auffällige Ergebnisse sind rot eingekreist.

\subsubsection{Verifizierung der Ergebnisse der quantitativen real time-PCR- Analysen bei den Patienten 24633, 24640 und 24653}

\subsubsection{Longrange PCR-Analyse}

Um die Grenzen der vermuteten Deletionen bei den Patienten 24633, 24640 und 24653 zu bestimmen, wurden weitere Amplikons in den Bereichen der Exons 2 (NS2) und 4 (NS4) analysiert. Dort konnte keine Deletion festgestellt werden. Durch eine PCR, die die Deletion einschloss, und eine anschließende Sequenzierung des PCR-Produkts sollte die genaue Lage und Größe der Deletion bestimmt werden. Für die PCR wurden die Primer NS3DelF/R verwendet, wodurch im Falle des Wildtyps ein PCR-Produkt einer Länge von ca. 4,7 kb entstehen sollte. Bei den Patienten 24633, 24640 und 24653 sollte sowohl die 4,7 kb-Bande als auch eine kleinere Bande, die durch das deletierte Allel entsteht, sichtbar sein.

Bei den Patienten 24633, 24640 und 24653 gelang eine die Deletion umfassende longrange PCR aufgrund der schlechten Qualität der DNA nicht. Es wurde um eine neue Blutprobe gebeten, um eine Bestätigung oder einen Ausschluss der Deletion vornehmen zu können. Bei der PCR an der frisch isolierten DNA wurde nur das Wildtyp-PCR-Produkt amplifiziert. Eine Deletion in diesem Bereich konnte nicht nachgewiesen werden kann. Da von Patient 24640 keine neue Blutprobe erhalten wurde, konnte eine Verifizierung der Deletion nicht durchgeführt werden. 
A.

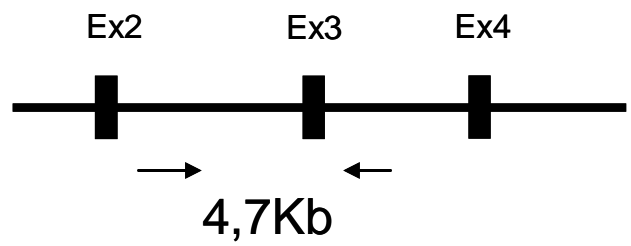

B.

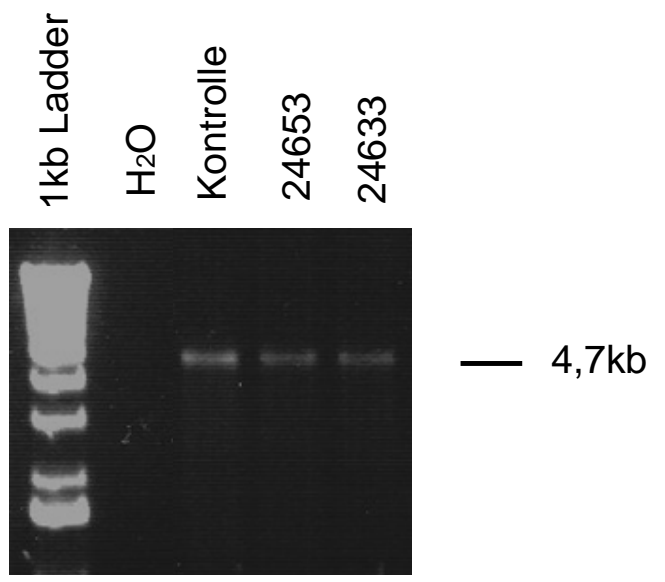

Abb. 3.13: Longrange PCR über Exon 2-4 bei Patient 24633, 24640 und 24653. A. Dargestellt ist ein Abschnitt des PTPN11-Gens und sowohl die Lage der verwendeten Primer für die longrange PCR als auch die erwarteten Größen der Banden. B. Ergebnis der longrange PCR mit der neuen genomischen DNA der Patienten 24633 und 24653 sowie einer Kontroll-DNA. Die 4,7 kb Bande wurde sowohl für die Kontroll-DNA als auch für die Patienten-DNA erhalten.

\subsubsection{Southern Blot-Analysen}

Mit der verbleibenden DNA vom Patienten 24640 sowie mit der neuen DNA von dem Patienten 24633 und 24653 wurden Southern Blot-Analysen durchgeführt, um die vermutete Deletion zu beweisen. Für 24640 wurden keine Signale erhalten, wohl aufgrund der schlechten DNA-Qualität. Es wurden zwei verschiedene Assays durchgeführt. Bei den in Abbildung 3.14 dargestellten Southern Blot-Analysen wurde die genomische DNA der Patienten 24633, 24640 und 24653 und einer Kontroll-Person mit den Restriktionsendonukleasen BglI bzw. SstI geschnitten. Die geschnittene DNA wurde gelelektrophoretisch aufgetrennt und, wie unter Abschnitt 2.2.4.1 beschrieben, auf eine Membran übertragen. Die verwendete Sonde wurde durch PCR mit den Primern NSDel3F/R amplifiziert, in pGEM-T-easy kloniert und zur Kontrolle sequenziert. Das Insert wurde durch EcoRI aus dem Vektor geschnitten und nach Agarosegelelekrophorese (2.2.1.8) isoliert. Die 
radioaktive Markierung und anschließende Hybridisierung mit der auf der Membran fixierten DNA erfolgte wie unter 2.2.2.7 bzw. 2.2.4.2 beschrieben.

Bei der Kontroll-Person wurde auf dem Autoradiographie-Film eine 4 kb (BglI) bzw. 7,5 kb (SstI) große Bande erwartet (Abb. 3.14 A.). Sollte eine Deletion in einem Allel der Patienten vorliegen, so würde die in diesem Bereich liegende BglI-Schnittstelle oder SstI-Schnittstelle fehlen, wodurch neben den 4 kb bzw. 7,5 kb großen Wildtyp-Banden eine 7,6 kb große Bande bei der BglI-Restriktion oder eine 10,9 kb große Bande bei der SstI-Restriktion entstehen sollten. Da die Deletion heterozygot ist und der Patient daher ein normales Allel besitzt, wird eine Wildtyp-Bande auch bei den Patienten erwartet. Die Entwicklung des AutoradiographieFilms zeigte die Wildtyp-Banden und bestätigte die Ergebnisse der longrange PCR (Abb. 3.13 B.), d.h. die Deletion von Exon 3 konnte nicht bestätigt werden.

A.
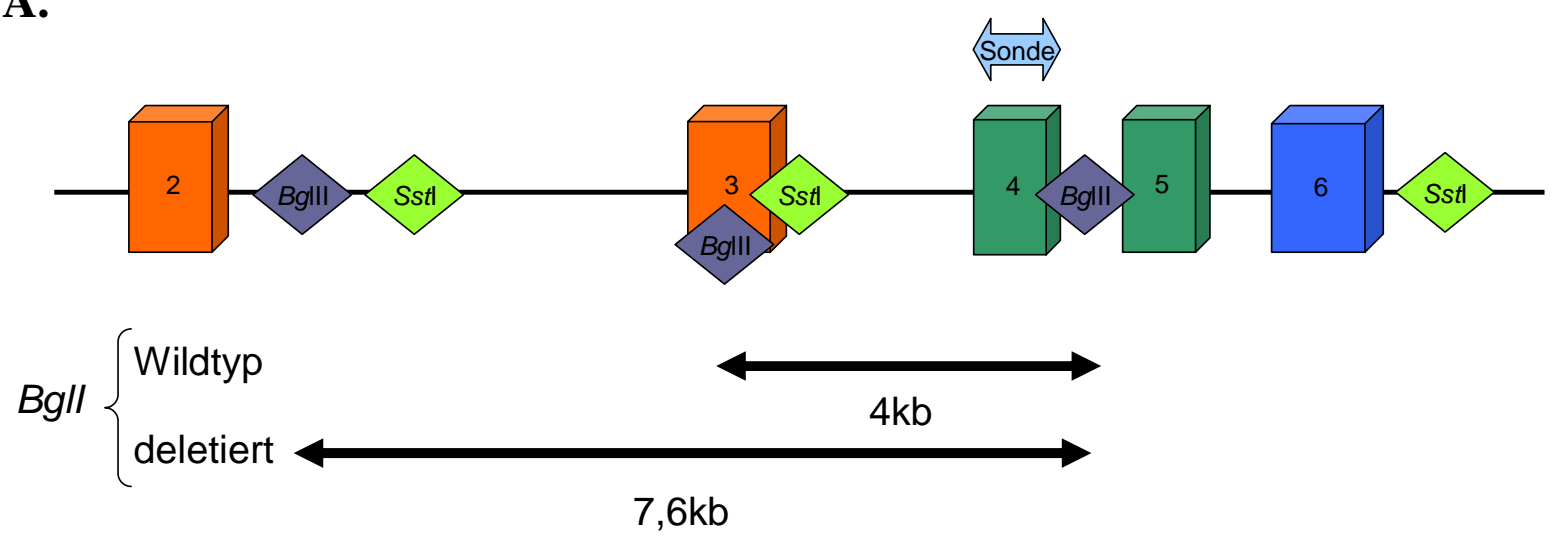

Sstl $\left\{\begin{array}{l}\text { Wildtyp } \\ \text { deletiert }\end{array}\right.$

$7,5 \mathrm{~kb}$

$10,9 \mathrm{~kb}$ 
B.

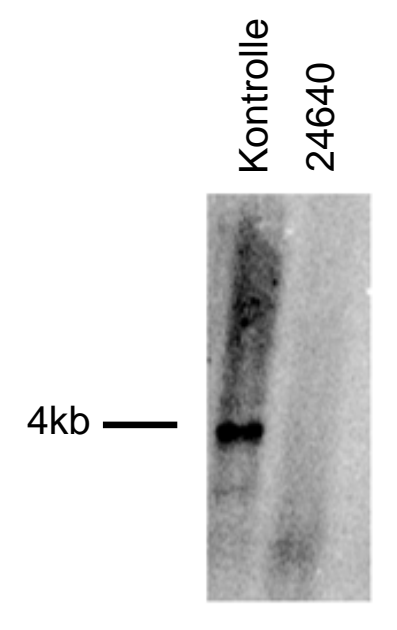

D.

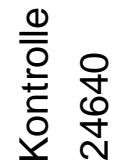

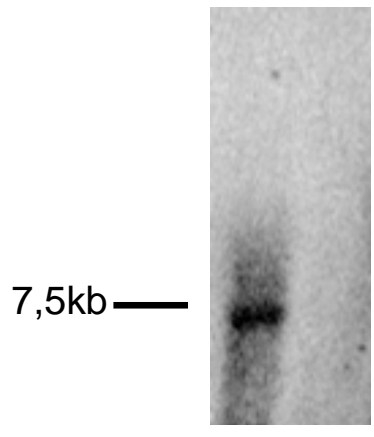

C.

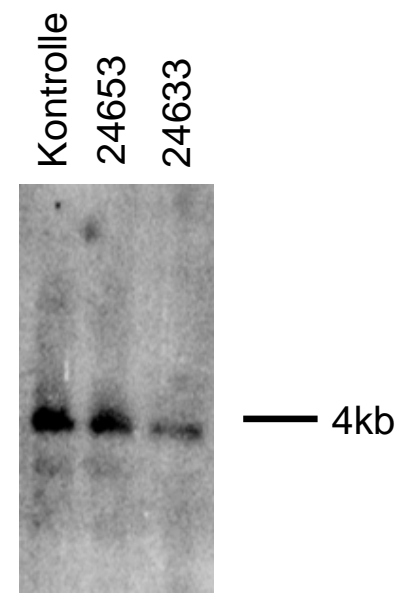

E.
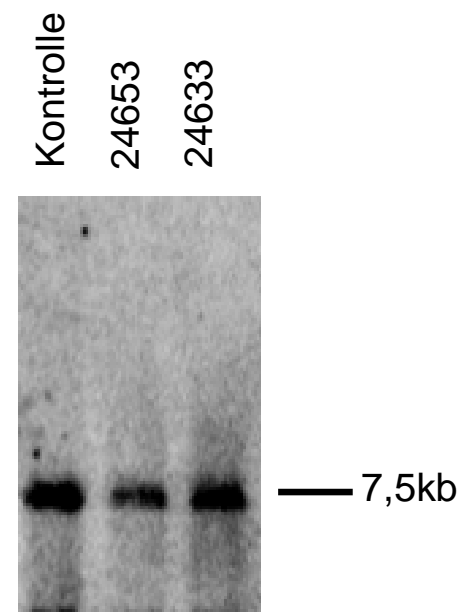

Abb. 3.14: Southern Blot-Analysen bei den Patienten 24633, 24630 und 24653. A. Dargestellt ist ein Abschnitt des PTPN11-Gens mit den BglI-Schnittstellen und SstI-Schnittstellen, der verwendeten Sonde und den erwarteten Größen der Banden bei den Southern Blot-Analysen. B. C. D. E. Ergebnisse der Southern BlotAnalysen mit dem Enzym BglI (B. und C.) und SstI (D. und E.) der Patienten 24640, 24633 und 24653 sowie einer Kontroll-DNA. Die Southern Blot-Analyse der Kontroll-DNA, der DNA der Patienten 24633 und 24653 zeigten die erwarteten 4 kb (B. und C.) bzw. 7,5 kb (D. und E.) Wildtyp-Banden.

\subsection{Bestimmung der Phosphatase-Aktivität von SHP2}

Das PTPN11-Genprodukt, das SHP2-Protein, besitzt eine Tyrosin-Phosphatase-Aktivität. Mutationen im PTPN11-Gen sollen eine Überaktivität des SHP2 bewirken, was zelluläre Regulationsmechanismen stört und letztendlich die Krankheitsursache beim Noonan- 
Syndrom darstellen soll. In diesem Teil der Arbeit sollten die Auswirkungen der Mutationen in PTPN11 auf die Aktivität von SHP2 untersucht werden. Dazu wurde die PhosphataseAktivität von SHP2-Varianten in vitro mit Hilfe es ein Reporter-Luciferase-Konstrukts und eines Malachit-Grün-Assays bestimmt.

\subsubsection{SOCS-1-Luciferase-Assay}

SHP2 reguliert u.a. STAT-Signalwege durch Dephosphorylierung von STAT, welches dadurch inaktiv wird. Ein Zielgen von STAT1 ist das SOCS-1-Gen. Dephosphoryliertes STAT1 kann die Transkription von SOCS-1 nicht aktivieren (Abb. 3.15). Der biologische Effekt der Mutationen in PTPN11 auf die Aktivität von SHP2 wurde in vitro mit Hilfe eines SOCS-1-Luciferase-Reporterkonstrukts untersucht, bei dem der SOCS-1-Promotor vor das Luciferase-Gen kloniert wurde. Eine Überaktivität in SHP2-Mutanten sollte zu einem höheren Dephosphorylierungsgrad von STAT1 führen, was dann in einer Abnahme der SOCS-1Promotor- und damit der Luciferase-Aktivität führen sollte (Abb. 3.17).

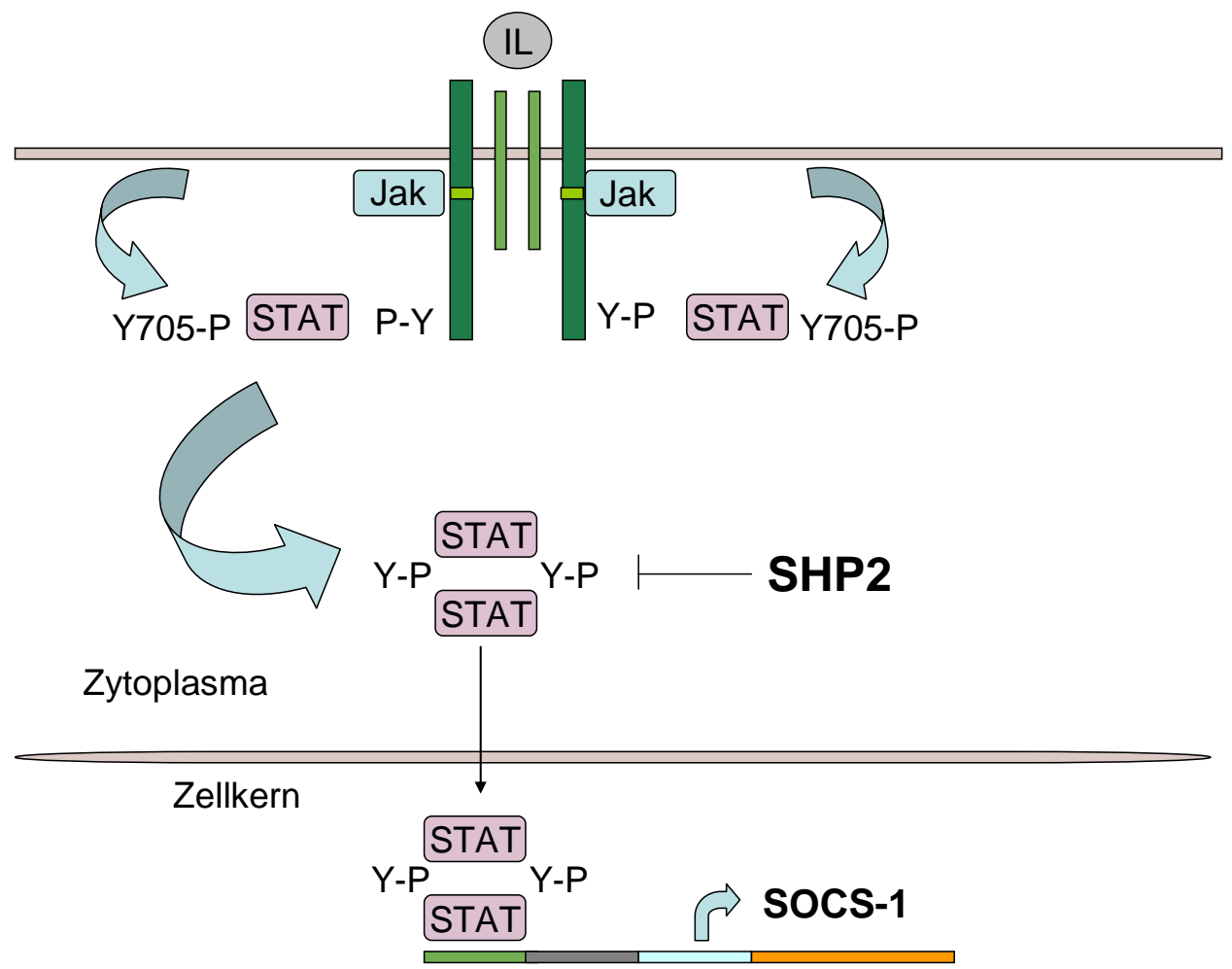

Abb. 3.15: Schematische Darstellung der Rolle von SHP2 im STAT-Signalweg. Die Phosphorylierung von STAT durch einen Tyrosin-Rezeptor führt zu einem phosphoryliertem STAT-Dimer, das in den Zellkern geht und die Transkription von SOCS-1 startet. SHP2 dephosphoryliert STAT, wodurch die Expression von SOCS-1 inhibiert wird. 
Die offenen Leserahmen des Wildtyp-PTPN11 (WT) wie auch der PTPN11-Mutanten N308D- und T468M-PTPN11 wurden mit einem c-myc-Tag und der humanen endogenen 3’UTR zusammen aus dem Vektor 2,2-Promotor-cDNA-c-myc-3’UTR-pBSC (3.4.1) mit den Restriktionsenzymen $\mathrm{NcoI}$ und $\mathrm{XhoI}$ isoliert und in pTriEx1.1 Neo einkloniert (Abb. 3.16). Mit Hilfe der in vitro-Mutagenese (2.2.5.2) wurden zusätzlich die Mutationen T52I, Y279C, S285F und P491L in die WT-Sequenz eingeführt. Das SOCS-1-Luciferase-Konstrukt (720Luc) wurde von D. Boinska [Schlüter et al., 2000] zur Verfügung gestellt.

A.

\begin{tabular}{|l|l|}
\hline humaner SOCS1-Promotor & Luc \\
\hline
\end{tabular}

B.

\begin{tabular}{|l|l|l|l|}
\hline Promotor & humane PTPN11-cDNA & है & î humane PTPN11-3'UTR \\
\hline
\end{tabular}

Abb. 3.16: Übersichtsdarstellung des SOCS-1-Luciferase-Fusions-Konstrukts und der PTPN11-cDNA im Expressionsvektor. A. SOCS-1-Luciferase-Fusions-Konstrukt. Das Konstrukt besteht aus SOCS-1-Promotor und dem Luciferase-Gen (Luc). B. PTPN11-cDNA im Expressionsvektor pTriEx1.1 Neo. Die Größenverhältnisse entsprechen nicht den wahren Verhältnissen.

NIH/3T3-Zellen wurden mit den oben beschriebenen Konstrukten transfiziert und die resultierenden Luciferase-Aktivitäten gemessen (2.2.9.1). Zur Normalisierung der Transfektionseffizienzen erfolgte eine Kotransfektion mit dem $\beta$-Galaktosidaseexprimierenden Vektor pCMV- $\beta$-Gal und eine Messung der $\beta$-Galaktosidase-Aktivitäten (2.2.9.2). Es wurden die relativen Werte berechnet, wobei der Wert des WildtypFusionskonstrukts als 100 definiert wurde. In Abbildung 3.17 ist der Mittelwert aus den Ergebnissen von fünf Transfektionen für die verschiedenen Konstrukte graphisch dargestellt. Transfizierte Zellen mit den Konstrukten T52I, Y279C, S285F, N308D, T468M, P491L zeigten eine Abnahme der relativen Luciferase-Aktivität um 40\% im Vergleich zum WTKonstrukt, was auf eine Überaktivität von SHP2 hinweist. Entsprechend des oben skizzierten Modells weist dies auf eine Überaktivität der SHP2 Mutanten hin. 


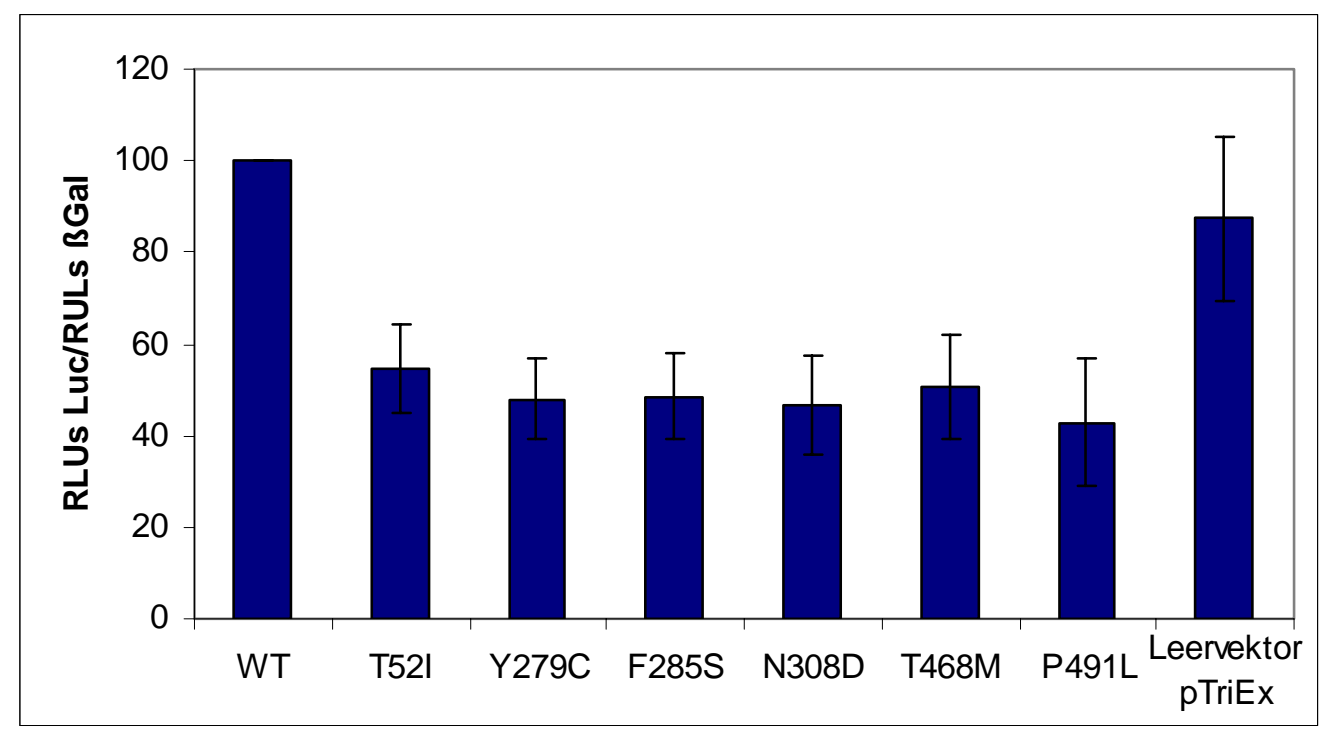

Abb. 3.17: Biologische Effekte von PTPN11-Mutationen im SOCS-1-Promotor-Assay. Die Ergebnisse der SOCS-1-Luciferase-Aktivitäts-Messung nach der Transfektion von NIH/3T3-Zellen mit den SHP2-Varianten T52I, Y279C-, S285F-, N308D-, T468M-, P491L- sowie WT-SHP2 wurden graphisch dargestellt. Dem WTSHP2-Konstrukt wurde per Definition ein Wert von 100 zugeordnet. Die Messung der relativen LuciferaseAktivitäten der Konstrukte mit den Mutationen ergab eine Verminderung um 40\%. Der Leervektor pTriEx wurde als Kontrolle verwendet.

Der STAT-Signalweg wird nach einer Bindung von vielen Wachstumsfaktoren, Zytokinen oder Hormonen an die jeweiligen Rezeptoren aktiviert. STAT wird phosphoryliert und dimerisiert, wandert in den Zellkern und aktiviert die Transkription der Zielgene (z.B. SOCS1). Daher wurden die oben beschriebenen Transfektionen auch unter Stimulation des STATSignalwegs durch Interleukin (IL) -haltiges Medium (2.2.8.5) durchgeführt. Zunächst wurde der Effekt der IL-Stimulation auf die Aktivierung von SOCS-1-Luciferase analysiert und anschließend wieder der Einfluß der WT-, N308D- und T468M-SHP2-Konstrukte untersucht. NIH/3T3-Zellen wurden mit dem SOCS-1-Luciferase-Konstrukt in bzw. ohne IL-haltigem Medium transfiziert und die resultierenden Luciferase-Aktivitäten gemessen. Wieder erfolgte eine Normalisierung über Kotransfektion mit pCMV- $\beta-G a l$. Anschließend wurden die relativen Werte berechnet. Die Luciferase-Aktivität ohne IL wurde als 100 definiert. Transfizierte Zellen mit SOCS-1-Luciferase in IL-haltigem Medium zeigten eine Zunahme der relativen Luciferase-Aktivität um 80\% im Vergleich zu SOCS-1-Luciferase ohne ILStimulation (Abb. 3.18). Die Ergebnisse der IL-Stimulation deuten auf eine Aktivierung des STAT-Signalweges hin. 


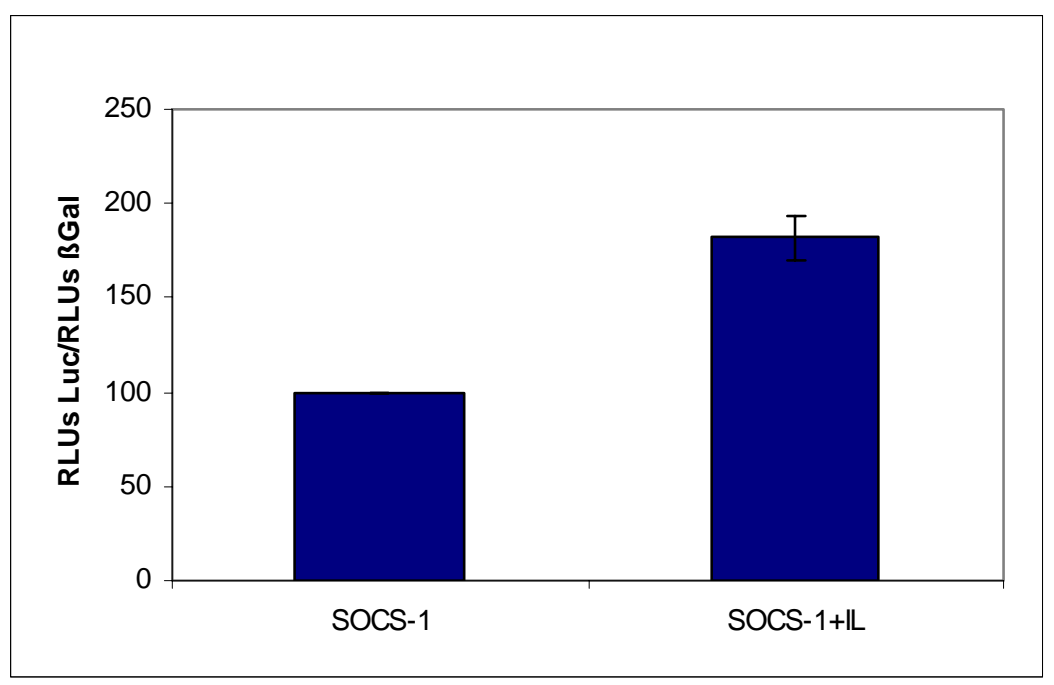

Abb. 3.18: Graphische Darstellung der Ergebnisse der SOCS-1-Aktivitäts-Messung nach der Transfektion von NIH/3T3-Zellen ohne und mit IL-Simulation. Gezeigt sind die relativen Luciferase-Aktivitäten der Konstrukte SOCS-1-Luciferase mit und ohne IL-Stimulation. Dem SOCS-1-Luciferase-Konstrukt ohne Stimulation wurde per Definition ein Wert von 100 zugeordnet. Die Ergebnisse der IL- Stimulation deuten auf eine Aktivierung des STAT-Signalwegs hin.

Anschließend wurden die WT-, N308D- bzw. T468M-SHP2-Konstrukte in die Transfektionen mit und ohne IL-haltigem Medium einbezogen. In Abbildung 3.19 ist der Mittelwert aus den Ergebnissen von fünf Transfektionen für die verschiedenen SHP2Konstrukte graphisch gezeigt. Dem WT-SHP2-Konstrukt ohne IL-Stimualtion wurde wieder ein Wert von 100 zugeordnet. Die Messung der relativen Luciferase-Aktivitäten der N308Dund T468M-SHP2 ohne IL-Stimulation ergab eine Verminderung der Luciferase-Aktivität um 60\% bzw. 50\%. WT-, N308D- und T468M-SHP2 mit IL-Stimulation zeigten eine Zunahme der relativen Luciferase-Aktivität von 60\% bzw. 40\% und 50\% im Vergleich zu WT-, N308D-, T468M-SHP2 ohne IL. Die Ergebnisse des Assays zeigen eine Aktivierung des STAT-Signalwegs durch IL-Stimulation und wiederum eine Supression des Signalwegs durch SHP2-Mutanten. 


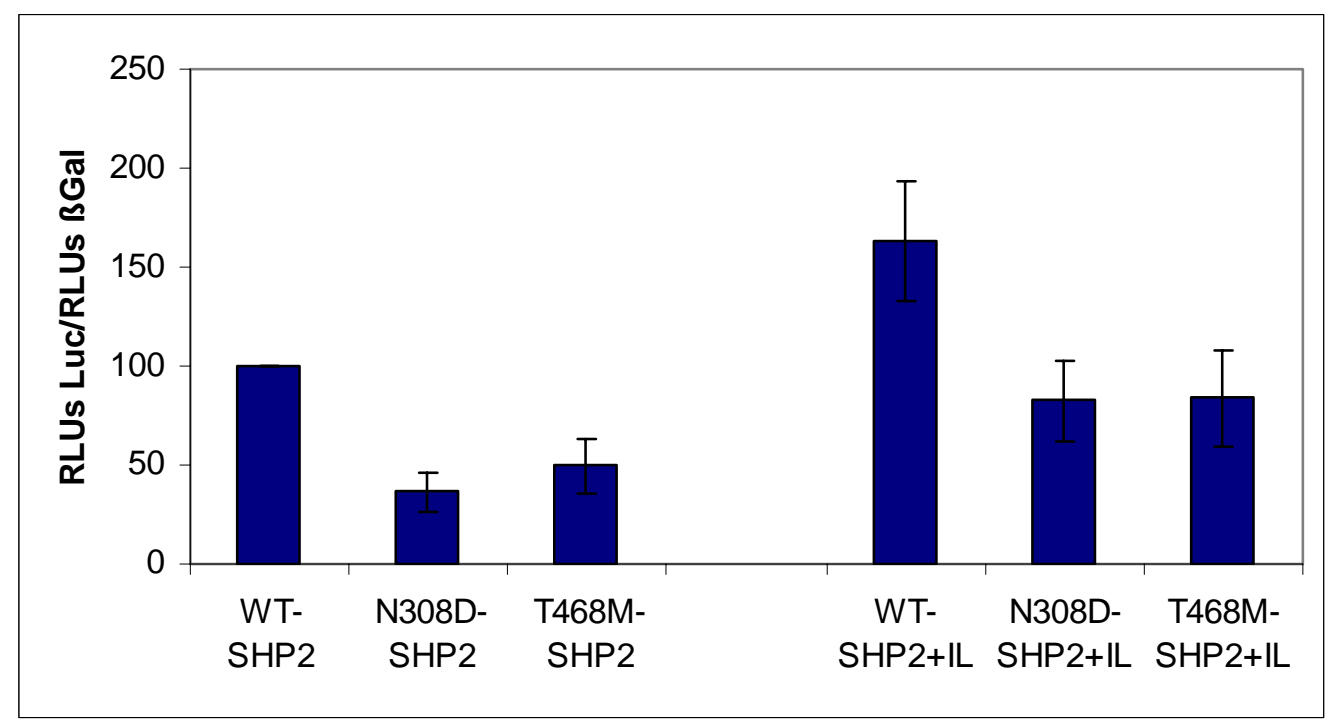

Abb. 3.19: Graphische Darstellung der Ergebnisse der SOCS-1-Luciferase-Aktivitäts-Messung nach der Transfektion von NIH/3T3-Zellen mit WT-, N308D- undT468M-SHP2- Konstrukten ohne und mit ILStimulation. Gezeigt sind die relativen Werte der Luciferase-Aktivitäten der Konstrukte WT-, N308D- und T468M-SHP2. Dem WT-SHP2-Konstrukt wurde per Definition ein Wert von 100 zugeordnet. Die Messungen der relativen Luciferase-Aktivitäten der N308D-, T468M-SHP2-Konstrukte zeigen eine Verminderung um 40\% bzw. 50\%. WT-, N308D- und T468M-SHP2-Konstrukte mit einer IL-Stimulation zeigen eine Zunahme der relativen Luciferase-Aktivität von 60\% bzw. 40 und 50 \% im Vergleich zur Transfektion ohne IL-Zusatz.

\subsubsection{Allelspezifische Inhibition von PTPN11-Mutanten durch siRNA}

Es wurde untersucht, ob unter Verwendung von siRNA gegen eine PTPN11-Mutation dieses Allel spezifisch unterdrückt werden kann, um die Überaktivität der mutierten Phosphatase auszuschalten ohne das Wildtypallel zu beeinflussen.

Um die Wirkung der siRNA zu überprüfen wurde derselbe STAT-Signalweg wie in 3.3.1 als in vitro-System benutzt. Ein sense- und antisense-Strang für die N308D- bzw. WT-Sequenz, jeweils durch eine Loop-Sequenz getrennt, wurden in den pSilencerU6-Vektor kloniert (2.2.10.2). NIH/3T3-Zellen wurden mit WT- oder N308D-SHP2 im pTriEx, SOCS-1Luciferase und WT- oder N308D-siRNA kotransfiziert, um zu testen, ob die Effekte der Mutation N308D allelspezifisch suprimiert werden können. Es erfolgte wiederum eine Normalisierung aller Transfektionen mit pCMV- $\beta$-Gal (Abb. 3.20).

Eine niedrige SOCS-1-Aktivität zeigt einen niedrigen Phosphorylierungsgrad von STAT und damit eine Überaktivität von SHP2. Dem WT-SHP2 mit Leervektor pSilencerU6 kotransfiziert wurde per Definition ein Wert von 100 zugeordnet. Die Messungen der relativen Luciferase-Aktivitäten des Leervektors pTriEx mit Leervektor pSilencerU6, WT-, 
N308D-siRNA zeigten ungefähr dasselbe Verhältnis wie WT-SHP2 mit Leervektor pSilencerU6, WT-, N308D-siRNA. Transfizierte Zellen mit N308D-SHP2 und U6-, WT- oder N308D-siRNA zeigten eine Abnahme der relativen Luciferase-Aktivität um 40\% im Vergleich zu der Transfektion mit WT-SHP2 und Leervektor pSilencerU6, WT- oder N308DSiRNA.

Tendenziell ist ein geringer Effekt der siRNA-Transfektion auf die SHP2-Aktivität zu sehen. Die Effekte von WT- und N308D-siRNA sind nicht sequenzspezifisch (beide siRNAs reprimieren die Wirkung des N308D-SHP2-Konstrukts).

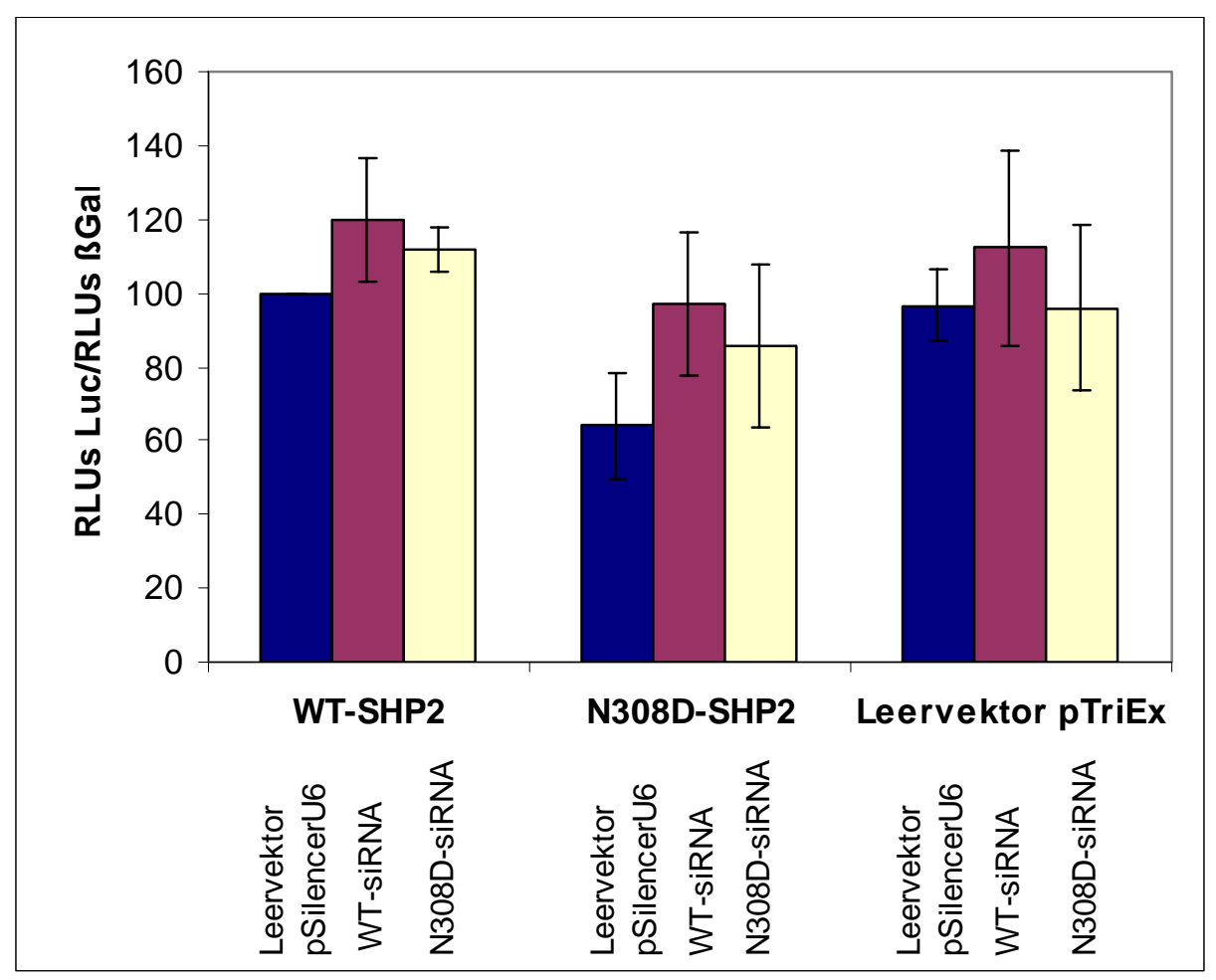

Abb. 3.20: Regulation der Überaktivität von N308D-SHP2 durch siRNA. Gezeigt sind die relativen Werte für die Luciferase-Aktivitäten von WT-SHP2, N308D-SHP2 und dem Leervektor pTriEx (als Kontrolle). Dem WT-SHP2 mit Leervektor pSilencerU6 kotransfiziert wurde per Definition ein Wert von 100 zugeordnet.

\subsubsection{Messung der SHP2 Phospatase-Aktivität mittels Malachit-Grün- Assay}

Die Phosphatase-Aktivität von SHP2 (WT vs. Mutanten) wurde in vitro mit Hilfe des SOCS1-Luciferase-Assay (3.3.1) untersucht. Dieser Assay zeigte eine Abnahme der relativen Luciferase-Aktivität der SHP2-Konstrukte mit einer Mutation im Vergleich zum WildtypKonstrukt, was auf eine Überaktivität von SHP2 hinweist. 
Die Überaktivität von SHP2 in NS-Patienten-Material wurde jedoch noch nicht gezeigt. Daher sollte die Phosphatase-Aktivität in verschiedenen Zellextrakten aus EBV-Lymphozyten (2.2.8.4) durch den Malachit-Grün-Assay bestimmt werden. Ziel war es dabei, einen biochemischen Test zu etablieren, mit dessen Hilfe rasch Hinweise auf aktivierende Mutationen in SHP2 bei Patienten gefunden werden könnten. Dies könnte als Voruntersuchung dienen, da bei NS-Patienten eine Mutation in PTPN11 nur in ca. 40-50\% der Patienten vorliegt. Nur bei Patienten mit einer erhöhten Phosphatase-Aktivität würde sich dann eine Sequenzanalyse anschließen. Folgende Zell- und Proteinextrakte wurden untersucht:

1. Rekombinantes SHP2-Protein aus in vitro Transkription/Translation (2.2.6.4).

2. EBV-Lymphozyten (2.2.8.4) von Patienten und Kontroll-Personen (Tab. 3.2)

\begin{tabular}{ll}
\hline EBV-Ly & Bemerkung \\
\hline Co1 & Kontrolle \\
Co2 & Kontrolle \\
Co3 & Kontrolle \\
Co4 & Kontrolle \\
NS+Y279C & NS-Patient/LEOPARD-Syndrom.[Digilio et al., 2002] \\
NS+F285S & NS-Patient [Kosaki et al., 2002] \\
NS+N308D & NS-Patient [Tartaglia et al., 2002] \\
NS+N308D & NS-Patient [Tartaglia et al., 2002] \\
NS+P491L & NS-Patient (Göttinger Diagnostik) \\
NS+P491L & NS-Patient (Göttinger Diagnostik) \\
NS+M504V & NS-Patient [Tartaglia et al., 2001] \\
NS-1 & Klinisch eindeutig NS, keine Mutation \\
NS-X1 & HCM-Patient \\
\hline
\end{tabular}

Tab. 3.2: EBV-Lymphozyten (EBV-Ly) von NS-Patienten und Kontroll-Personen.

Abkürzungen: HCM: Hypertrophe Kardiomyopathie 


\subsubsection{Expression von rekombinanten SHP2-Proteinen}

Zur weiteren Überprüfung der Phosphatase-Aktivität von SHP2 und zur Etablierung des Malachit-Grün-Assays wurde rekombinantes SHP2 durch in vitro Transkription/Translation hergestellt (2.2.6.4). Das hier verwendete TNT® T7 Expressway Plus Expression System von Invitrogen ist geeignet für die in vitro Transkription eukaryontischer DNA-Sequenzen. Für die Transkription benötigt man zirkuläre Plasmid-DNA oder ein PCR-Fragment, welche den Promotor für die T7 RNA-Polymerase vor der Gensequenz, die transkribiert bzw. translatiert werden soll, enthalten. Es wurden die SHP2-Konstrukte (WT und Mutante: T52I, Y279C, F285S, N308D, T468M und P491L), die bereits beim SOCS-1-Luciferase-Assay (3.3.1) verwendet wurden, eingesetzt. Als Positivkontrolle wurde die in vitro Transkription/Translation mit dem $\beta$-Galaktosidase-exprimierenden Vektor pEXP1-GWlac durchgeführt. Nach der in vitro-Synthese der Proteine wurde eine Messung der $\beta$ Galaktosidase-Aktivität und eine Western Blot-Analyse zur Überprüfung der Methode durchgeführt. In der Tabelle 3.3 sind die $\beta$-Galaktosidase-Aktivitäten gemessen mit $1 \mu \mathrm{l}$ der $50 \mu$ l-Reaktion zusammengefaßt. pEXP1-GWlac zeigt die höchste Expression von $\beta$ Galaktosidase, während die SHP2-Konstrukte (WT und Mutanten) wie erwartet nur einen Hintergrund-Wert zeigen.

\begin{tabular}{ll}
\hline Name & RLUs $\beta$-Galaktosidase \\
\hline pEXP1-GWlac & 11937,42 \\
WT & 278,84 \\
T52I & 226,95 \\
Y279C & 235,07 \\
F285S & 233,38 \\
N308D & 135,09 \\
T468M & 148,75 \\
P491L & 186,35
\end{tabular}

Tab. 3.3: Messung der $\beta$-Galaktosidase-Aktivitäten der rekombinanten SHP2-Proteine. Gezeigt sind die relativen $\beta$-Galaktosidase-Einheiten (RLUs) der rekombinanten SHP2-Proteine und $\beta$-Galaktosidase (Positivkontrolle), die durch in vitro Transkription/Translation synthetisiert worden sind. 
Als weitere Kontrolle der Methode der in vitro Transkription/Translation wurde eine Western Blot-Analyse der rekombinanten SHP2-Proteine durchgeführt. $5 \mu \mathrm{l}$ der $50 \mu \mathrm{l}$ Reaktion wurden über SDS-PAGE aufgetrennt und auf eine Nitrocellulose-Membran transferriert (2.2.6.8). Die Proteine wurden mit Hilfe eines c-ymc-spezifischen Antikörpers detektiert (2.2.6.10). Die rekombinanten SHP2-Proteine, die alle einen c-myc-Tag besitzen, und eine Größe von 68,7 kDa haben, konnten so in allen Reaktionen nachgewiesen werden. Dagegen konnte bei der Reaktion mit dem $\beta$-Galaktosidase exprimierenden Vektor pEXP1-GWlac bei der Western Blot-Analyse kein SHP2 detektiert werden.

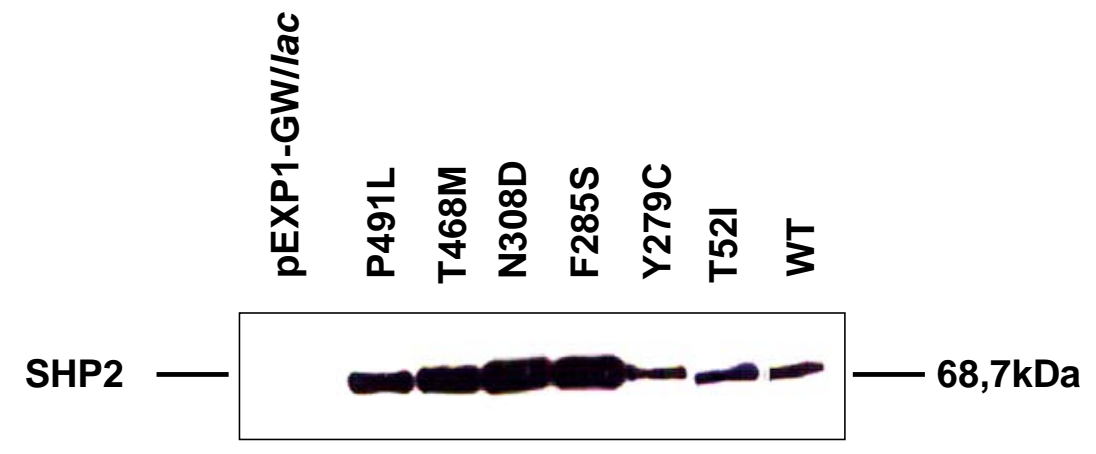

Abb. 3.21: Analyse der rekombinanten SHP2-Proteine mittels eines Western Blot-Experiments. $5 \mu$ der in vitro Transkription/Translations-Reaktion der SHP2-Konstrukte WT-, T52I-, Y279C-, F285S-, N308D-, T468M-, P491L-SHP2 und der Kontrolle pEXP1-GWlac wurden über SDS-PAGE elektrophoretisch aufgetrennt und auf eine Nitrocellulose-Membran übertragen. Der Nachweis der rekombinanten SHP2-Proteine erfolgte mit Hilfe eines c-myc-Tag spezifischen Antikörpers. In den WT-, T52I-, Y279C-, S285C-, N308D-, T468M-, P491L-SHP2 konnte rekombinantes SHP2 (68,7 kDa) nachgewiesen werden. pEXP1-Gwlac wurde als Negativkontrolle verwendet.

Nachdem die rekombinanten SHP2-Varianten synthetisiert und nachgewiesen werden konnten, wurde die Phosphatase-Aktivität in den Proben mittels eines Malachit-Grün-Assays gemessen (2.2.6.12). Zur Absicherung und Quantifizierung der Ergebnisse musste zuvor die mögliche Kontamination von freiem Phosphat in jeder Probe geprüft werden. Daher wurden 1-5 $\mu$ l rekombinantes Protein mit Ammoniummolybdatlösung inkubiert. Jede Probe bildete einen grünen Ammoniummolybdatphosphat-Komplex, was auf die Anwesenheit von freiem Phosphat hinweist. Um das freie Phosphat aus den Proben zu entfernen, wurde eine Dialyse durchgeführt. Die Dialyse führte allerdings zum Verlust von Protein und PhosphataseAktivität. 


\subsubsection{Messung der SHP2-Phosphatase-Aktivität von Patienten-Material}

Um die Phosphatase-Aktivität von Patienten-Material zu untersuchen, wurde Gesamtprotein sowohl aus frischen Lymphozyten-Präparationen (2.2.6.1) als auch aus EBV-transformierten Lymphozyten (2.2.8.4) isoliert. Jede Probe wurde auf mögliche Kontamination mit freiem Phosphat geprüft, indem sie mit Ammoniummolybdatlösung inkubiert wurde. Die Proben, die mit freiem Phosphat kontaminiert waren, bildeten einen grünen Molybdatphosphat-Komplex. Um die verschiedenen Proben untereinander vergleichen zu können, sollte die Konzentration des Gesamprotein-Gehaltes bestimmt werden. Dies wurde allerdings durch das Vorhandensein von Hämoglobin-Resten in den Proteinextrakten der frischen Lymphozyten gestört, sodass eine Normalisierung der Phosphatase-Aktivität über die Proteinmenge nicht möglich war. Die Proteinextrakte der EBV-Lymphozyten wiesen ebenfalls Kontaminationen mit freiem Phosphat auf, welches durch intensives Waschen mit TBS beseitigt werden sollte. Dies führte allerdings zu einem ausgeprägten Verlust an Protein. Aufgrund dieser Schwierigkeiten durch Kontaminationen mit Hämoglobin bzw. freiem Phosphat in den Proben konnte der Malachit-Grün-Assay nicht weiter verwendet werden und sollte durch die Etablierung eines ELISA ersetzt werden.

\subsubsection{ELISA zur Bestimmung der Phosphatase-Aktivität von SHP2 in Patienten- Material}

Um die Phosphatase-Aktivität in Proteinextrakten der in vitro Transkription/Translation (2.2.6.4) und aus EBV-transformierten Lymphozyten (2.2.8.4) zu untersuchen, wurde ein indirekter ELISA durchgeführt (2.2.6.11.1). Zunächst mußte die Menge des gebundenen Antigens bestimmt werden, um anschließend die Phosphatase-Aktivität von SHP2 aus verschiedenen Proben messen zu können. Dazu wurden verschiedene Mengen des Antigens (Zellextrakt) auf eine Mikrotiterplatte gecoated, mit einem anti-SHP2-Antikörper detektiert und mit einem zweiten Antikörper, der mit Peroxidase gekoppelt ist, durch PeroxidaseSubstrat dargestellt. Zur Etablierung der zu verwendenden Konzentration von Proteinextrakt und erstem Antikörper (anti-SHP2) wurde zunächst eine ELISA-Analyse durchgeführt, bei

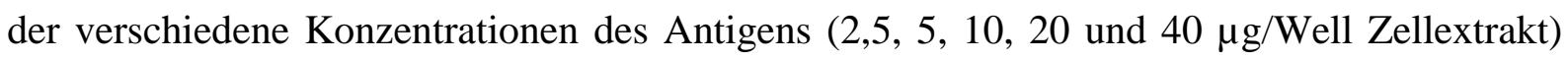
und des ersten Antikörpers (1:100, 1:200, 1:400, 1:800 und 1:1600 anti-SHP2) ausgetestet wurden. In Abbildung 3.22 A sind die Messungen für die Etablierung des indirekten ELISA gezeigt. Sowohl bei der 1:100-Verdünnung als auch bei der 1:800- und 1:1600-Verdünnung 
wurde kein wesentlicher Unterschied im Bereich zwischen 2,5 und $40 \mu \mathrm{g} /$ Well Zellextrakt beobachtet. Dagegen zeigen die 1:200- und die 1:400-Verdünnung weitgehend lineare Eichkurven. Daraufhin wurden für weitere Untersuchungen 1 und $20 \mu \mathrm{g}$ Zellextrakt pro Well und eine 1:200-Verdünnung des Antikörpers anti-SHP2 eingesetzt. Anschließend wurde ein erstes Experiment mit dem rekombinanten WT-SHP2 und dem Proteinextrakt von EBVLymphozyten N308D-Ly durchgeführt, bei dem die Menge des gebundenen Antigens bestimmt werden sollte. Der Proteinextrakt von Y279C-EBV-Ly wurde dabei als Eichkurve verwendet (Abb. 3.22 B.). Da ab $10 \mu \mathrm{g} / \mu \mathrm{l}$ eingesetztem Zellextrakt eine Sättigung eintrat, wurde zur weiteren Analyse die Eichkurve nur bis $8 \mu \mathrm{g} / \mu \mathrm{l}$ verwendet. Dieses Experiment zeigt, dass die Bestimmung der SHP2-Proteinmenge nur mit Proben gleichen Ursprungs (z.B. beide EBV-Lymphozyten) möglich ist.

A.

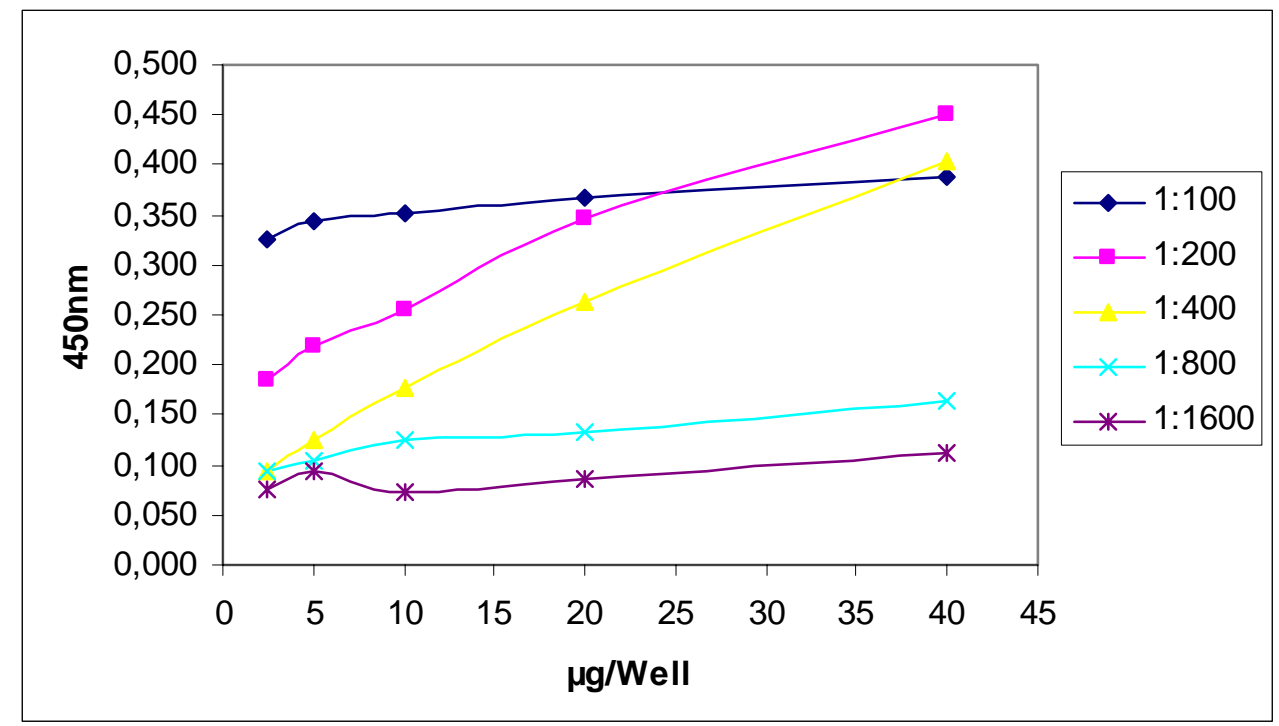

B.

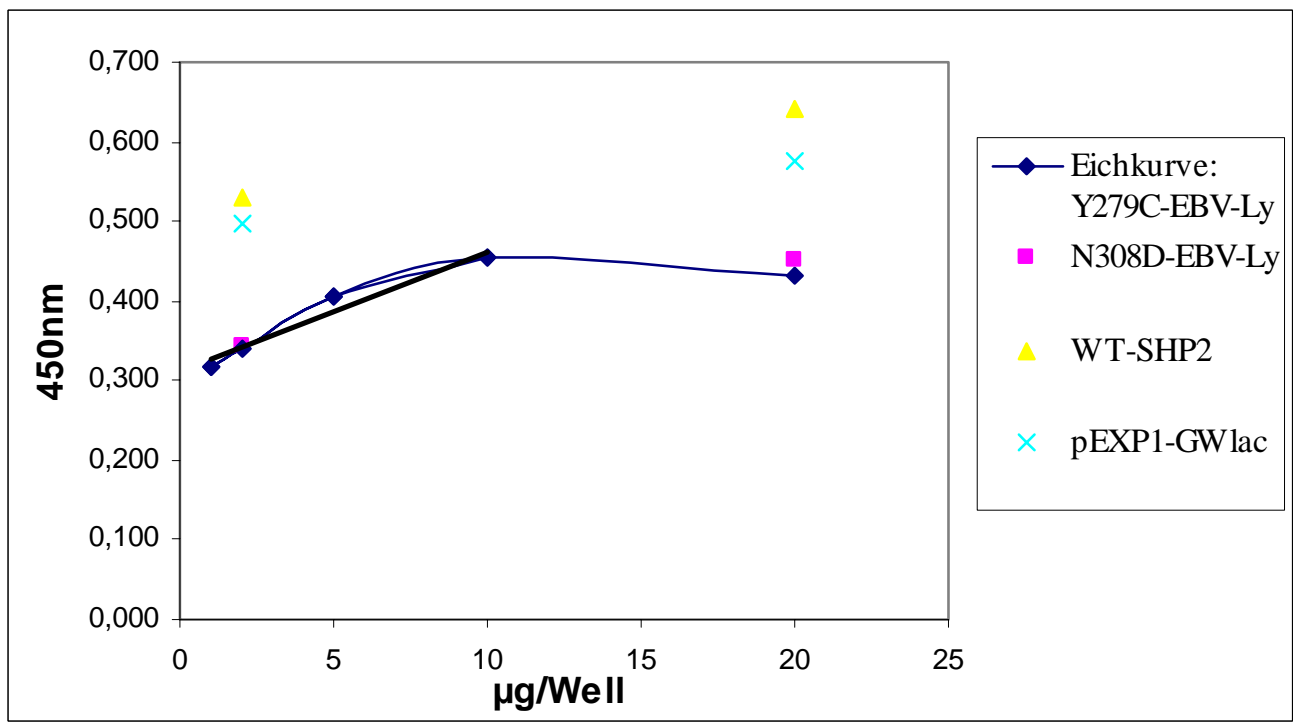


Abb. 3.22: Indirekter ELISA zur quantitativen Bestimmung des Antigens SHP2. A. Dargestellt ist das Experiment zur Etablierung des indirekten ELISA mit fünf verschiedenen anti-SHP2-Antikörper-Verdünnungen (1:200, 1:400, 1:800 und 1:1600) und verschiedenen Konzentrationen des Antigens (2,5, 5, 10, 20 und 40 $\mu \mathrm{g} /$ Well Zellextrakt). B. Gezeigt ist die Eichkurve von 1, 2,5 und $10 \mu \mathrm{g} / \mu \mathrm{l}$ Y279C-EBV-Ly mit dem Sättigungsbereich (von 10 bis $20 \mu \mathrm{g} / \mu \mathrm{l}$ ). Es wurde eine Messung von je 1 und $20 \mu \mathrm{g} / \mu \mathrm{l}$ der Zellextrakte von N308D-EBV-Lymphozyten und den rekombinanten Proteinen WT-SHP2 und pEXP1-GWlac durchgeführt.

Nach der quantitativen Bestimmung des Antigens durch den indirekten ELISA sollte die Phosphatase-Aktivität des Antigens SHP2 aus dem Patienten-Material mit Hilfe eines EnzymAntigen-Assays (2.2.6.11.2) untersucht werden. Dazu wurde in diesem Experiment der Antikörper gegen SHP2 auf die Mikrotiterplatte gecoated, der dann das SHP2-Antigen aus dem zu untersuchenden Proteinextrakt bindet. Die Aktivität von SHP2 wird anschließend durch die Katalysierung von DIFMUP zu DIFMU als Enzym-Substrat gemessen. Sowohl von vier verschiedenen Kontroll-EBV-Lymphozyten (Co1, Co2, Co3 und Co4) als auch von den Patienten-Materialien N308D-EBV-Lymphozyten, Y279C-EBV-Lymphozyten, NS-1-EBVLymphozyten und NS-X1-EBV-Lymphozyten wurden pro well $20 \mu \mathrm{g} / \mu \mathrm{l}$ eingesetzt und die Phosphatase-Aktivität bestimmt. Als Kontrolle für die Bindung des Antikörpers an die Kunststoffoberfläche der Mikrotiterplatte wurde die Messung von einigen Wells mit den Antikörpern anti-SOCS-1, anti-c-myc oder keinem Antikörper durchgeführt und ohne Antigen inkubiert. Die Ergebnisse des Assays sind in Abbildung 3.23 gezeigt. Bei allen vier Kontroll-EBV-Lymphozyten als auch bei NS-1-EBV-Lymphozyten und NS-X1-EBVLymphozyten wurde eine $\mathrm{OD}_{358} / \mathrm{OD}_{452}$ von ca. 50000 gemessen. Bei NS+N308D-EBVLymphozyten und NS+Y279C-EBV-Lymphozyten wurden eine $\mathrm{OD}_{358} / \mathrm{OD}_{452}$ von 92625 bzw. 75472 gemessen. Das Experiment wird trotzdem nicht als spezifisch eingeordnet, da die Negativkontrolle (Messung von anti-SOCS-1, anti-c-myc oder kein Antikörper) einen ähnlichen Meßwert von ca. 47000 zeigte, wie die Kontroll-EBV-Lymphozyten. Die Meßwerte der Negativkontrollen sind in Abbildung 3.23 zur besseren Darstellung bei $60 \mu \mathrm{g} / \mu \mathrm{l}$ Zellextrakt eingezeichnet. 


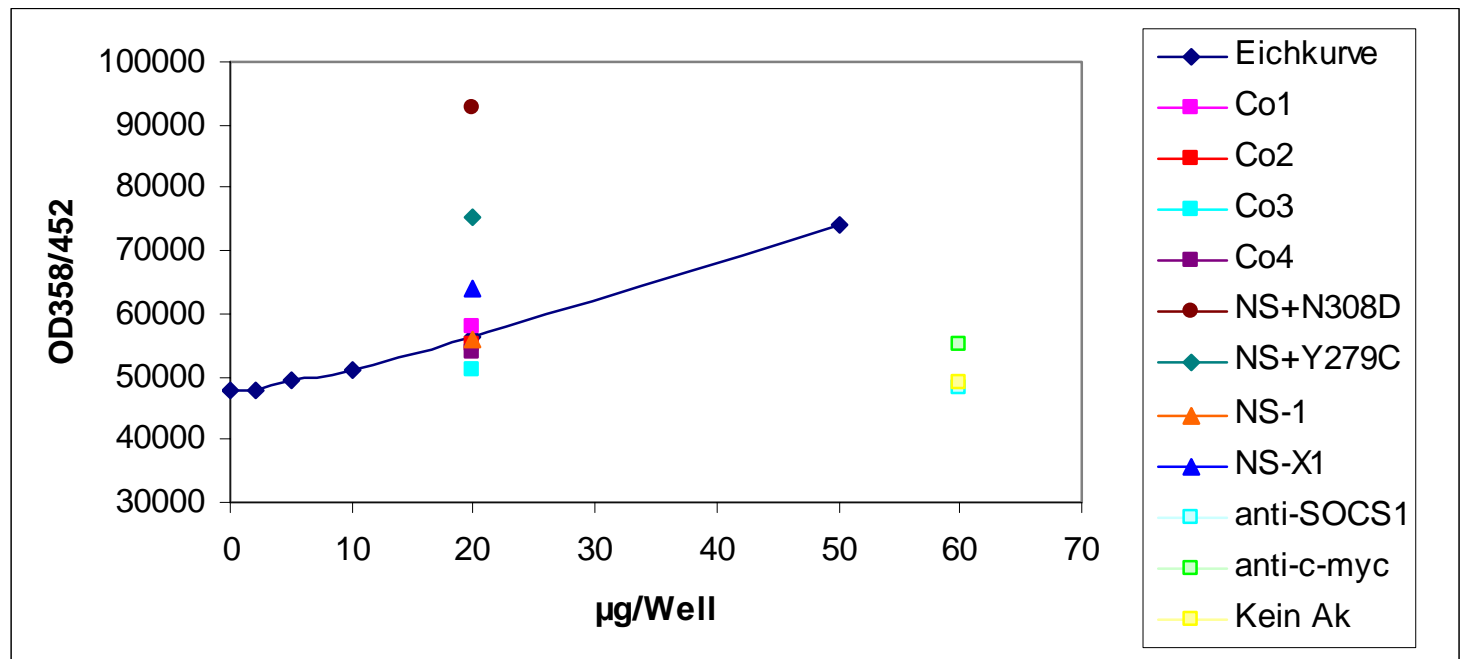

Abb. 3.23: Enzym-Antigen-Assay zur Bestimmung der Phosphatase-Aktivität von SHP2 in PatientenMaterial (EBV-Lymphozyten). Es wurden vier verschiedene Kontroll-EBV-Lymphozyten, N308D-EBVLymphozyten, Y279C-EBV-Lymphozyten, NS-1-EBV-Lymphozyten und NS-X1-EBV-Lymphozyten und drei verschiedene Kontrollen der Bindungsantikörper an der Kunststoffoberfläche (anti-SOCS-1, anti-c-myc oder kein Antikörper ohne Antigen) verwendet.

\subsection{Herstellung eines transgenen Mausmodells für das Noonan-Syndrom}

\subsubsection{Klonierung der Konstrukte PTPN11-WT , -N308D und -T468M}

Um den Effekt von PTPN11-Mutationen in vivo zu untersuchen, wurden drei Konstrukte zur Herstellung transgener Mäuse generiert (Abb. 3.24): ein Wildtyp-PTPN11-Konstrukt als Kontrolle der PTPN11-Überexpression, ein PTPN11-Konstrukt mit der Mutation N308D, die die häufigste Mutation bei NS darstellt, und ein PTPN11-Konstrukt mit der Mutation T468M, die als Ursache für eine allelische Variante des NS, das LEOPARD Syndrom, gilt.

Der Promotorbereich von PTPN11 war wie unter 3.1 charakterisiert worden. Um ein möglichst nahe an der endogenen Regulation angelehntes System zu erhalten, wurde ein 2,2kb langer Promotor benutzt, der möglicherweise auch negative regulatorische Elemente besitzt.

Das Fragment wurde aus dem Vektor m2,2Luc(ATG) (3.1.2) mit SstI und NcoI isoliert und in pBSC einkloniert. Die humane WT-PTPN11-cDNA wurde freundlicherweise von Dr. S. M. Hosseini zur Verfügung gestellt und lag im Vektor pCR®II TOPO vor. Mit Hilfe der in vitro 
Mutagenese (2.2.5.2) wurden die Mutationen N308D und T468M in die WT-PTPN11Sequenz eingeführt. Mit den Primern NS-NcoI-F und NS-Ba-R wurden die WT-, N308D-, und T468M-PTPN11 cDNAs amplifiziert und über primer-ständige Schnittstellen in den Vektor 2,2Promotor-pBSC einkloniert.

Um das transgene SHP2 in der Maus unabhängig vom endogenen SHP2 detektieren zu können, wurde das Konstrukt mit einem cmyc-Tag versehen. Die cmyc-tag-Sequenz wurde durch zwei komplementäre Oligonukleotide (c-myc-Ba-F und c-myc-BclI-R) hergestellt und nach BamHI-Restriktion in BamHI/SmaI geschnittenen pBSC einkloniert (c-myc-pBSC). Die benötigte Sequenz der 3’UTR wurde aus der humanen PTPN11-Sequenz mit den Primern 3UBclI-F und 3U-H3-R amplifiziert und mit BclI und EcoRI in c-myc-pBSC einkloniert. Aus diesem Klon wurde das c-myc-3’UTR-Fragment mit BamHI und EcoRI isoliert und hierüber in das Konstrukt 2,2-Promotor-PTPN11-pBSC eingefügt. Um den offenen Leserahmen zu überprüfen, wurde nach jedem Klonierungsschritt eine Sequenzanalyse durchgeführt. Das gesamte transgene Konstrukt 2,2Promotor-PTPN11-c-myc-3’UTR-pBSC besitzt eine Länge von $5,7 \mathrm{~kb}$.

Die drei verschiedenen transgenen Konstrukte wurden wie folgt benannt:

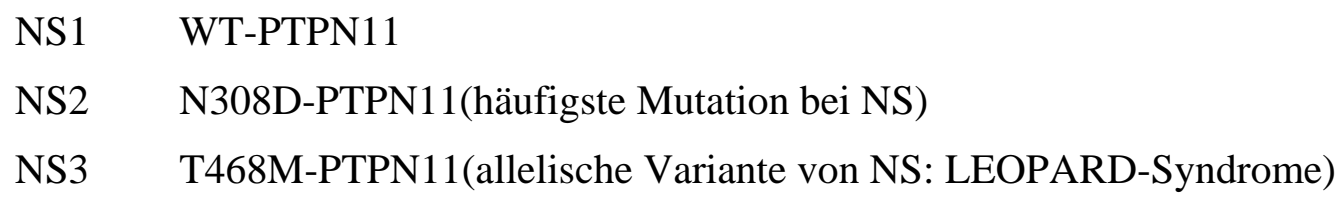

Für die Mikroinjektion wurden die Inserts (Abb. 3.24 A) aus dem Vektor mit Hilfe der Restriktionsenzyme SstI und XhoI ausgeschnitten, aufgereinigt (2.2.11.1) und auf eine Konzentration von $30 \mathrm{ng} / \mu \mathrm{l}$ eingestellt (Abb. 3.24 B.). In Zusammenarbeit mit dem MaxPlanck-Institut für experimentelle Medizin (Göttingen) wurde die DNA der NS1-, NS2- und NS3-Konstrukte in den männlichen Pronukleus befruchteter Mausoozyten injiziert. Anschließend wurden die Oozyten in scheinschwangere FVB-Mäuse transferriert. Insgesamt wurden 23 Nachkommen von NS1, 43 Nachkommen von NS2 und 45 Nachkommen von NS3 geboren. 
A.

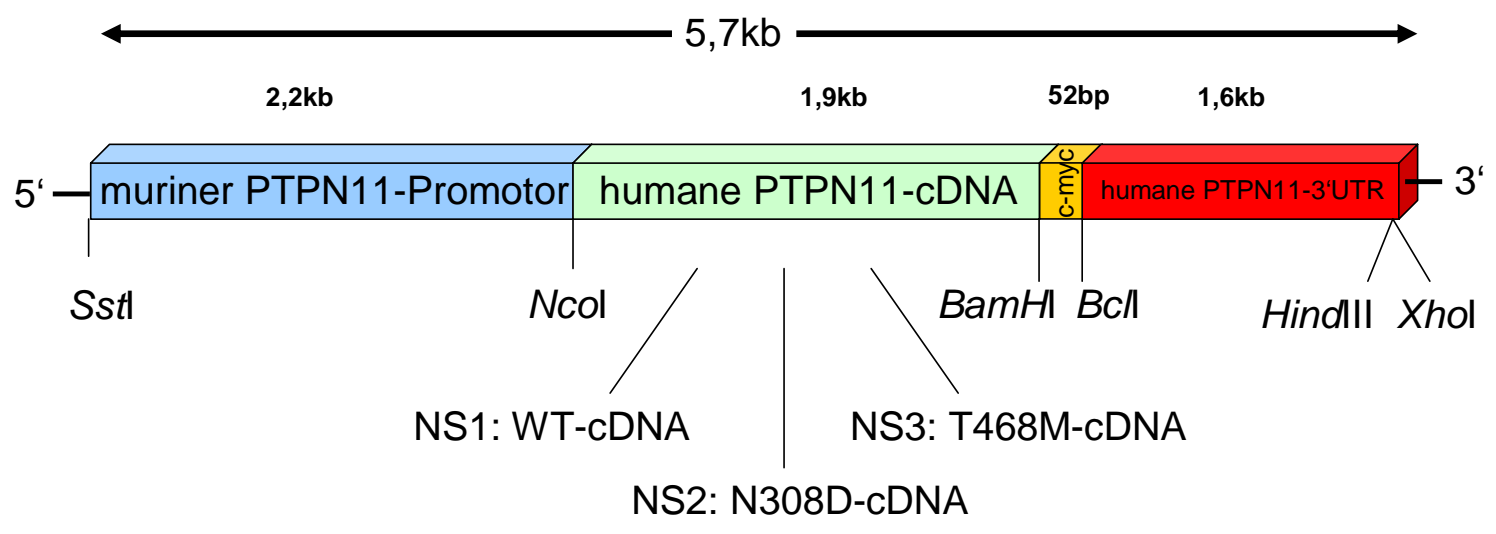

B.

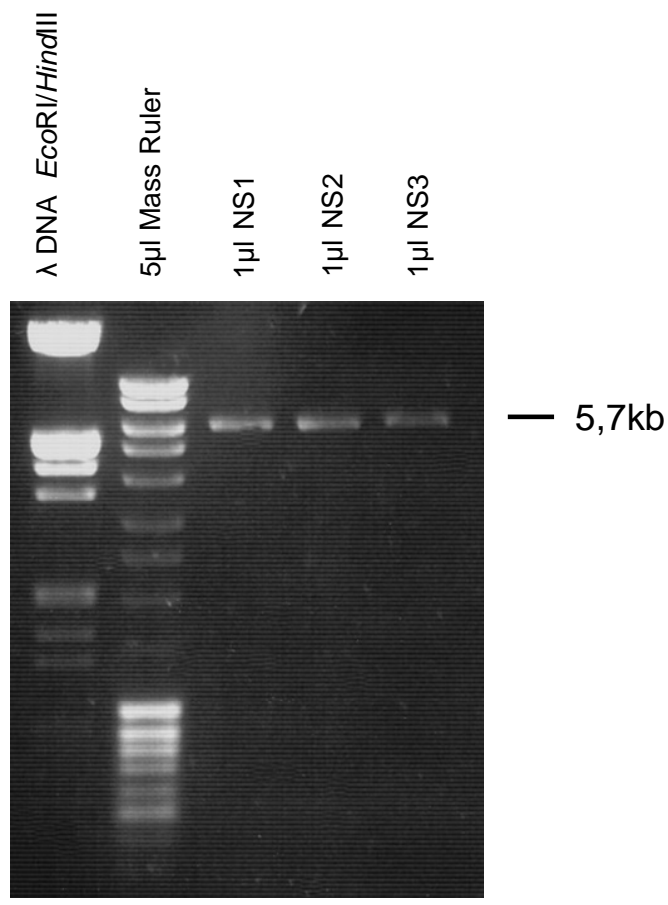

Abb. 3.24: PTPN11-Konstrukte zur Erzeugung transgener Mäuse. A. Das Konstrukt enthält den endogenen Promotor von 2,2 kb Länge, die humane PTPN11-cDNA (WT oder Mutanten: N308D, T468M), einen c-mycTag und die 3'UTR von PTPN11. B. Nach Aufreinigung der Inserts über ein Agarosegel, Glasmilch und Filtration wurde eine Konzentration von $30 \mathrm{ng} / \mu \mathrm{l}$ eingestellt und das zur Injektion vorbereitete Fragment nochmals auf dem Gel überprüft.

\subsubsection{PCR zur Genotypisierung der F0-(Founder) und F1-Generation der transgenen PTPN11-Mäuse}

Für die Genotypisierung der transgenen F0-Tiere (Founder) und der heterozygoten F1Generation wurde zunächst genomische DNA aus der Schwanzspitze drei Wochen alter 
Mäuse isoliert (2.2.1.1). Hieran wurde eine PCR mit den Primern NS4-TaqF und NS4-TaqR (die spezifisch das Exon 4 des humanen PTPN11 amplifizieren) durchgeführt. Das entstehende Produkt besitzt eine Größe von 120 bp. Als Positivkontrolle wurde eine PCR an einem Gemisch aus DNA des Konstruktes (2,2Promotor-PTPN11-c-myc-3’UTR-pBSC) mit genomischer DNA einer Wildtyp-Maus (FVB) durchgeführt. Als Negativkontrolle diente genomische DNA einer FVB-Wildtyp-Maus.

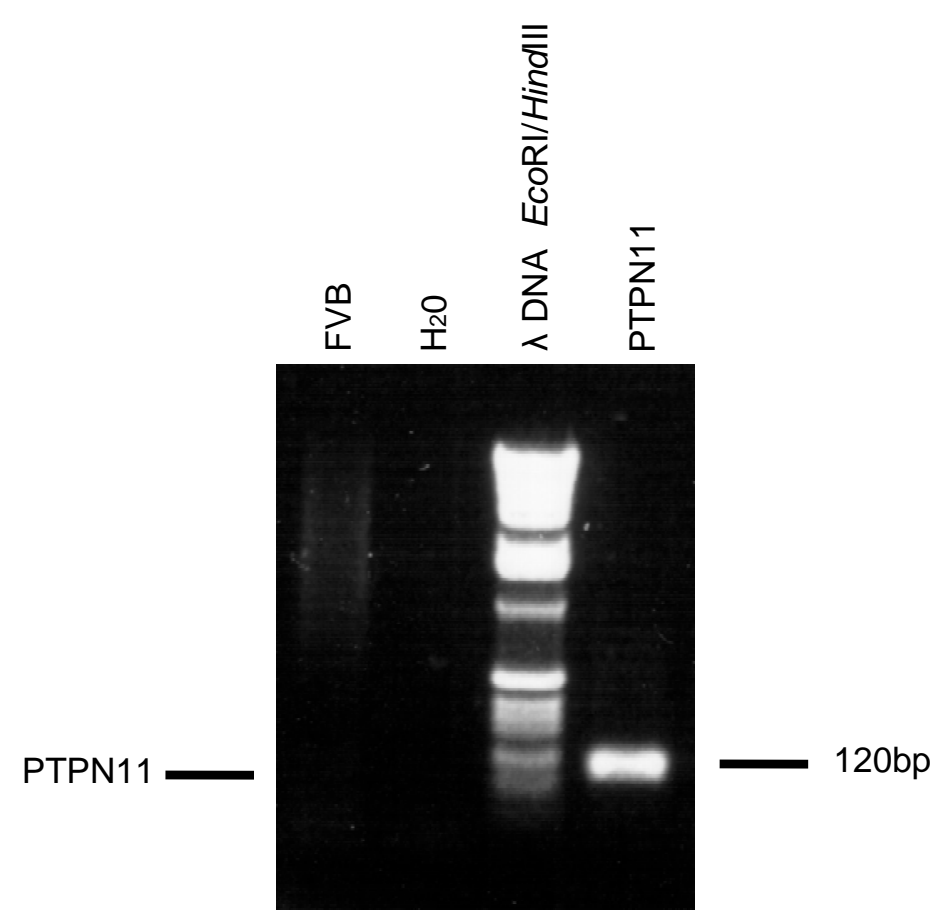

Abb. 3.25: Genotypisierungs-PCR für transgene PTPN11-Mäuse. Die PCR mit den humanspezifischen Primern NS4-TaqF und NS4-TaqR ergibt an WT-FVB DNA kein Produkt. Wenn 1 ng Konstrukt-DNA zugegeben werden, entsteht ein 120 bp großes Produkt. $\mathrm{H}_{2} \mathrm{O}$ : Nullprobe, $\lambda$ DNA EcoRI/HindIII: Längenstandardt.

\subsubsection{Nachweis der Expression des transgenen NS1-Konstruktes in NIH/3T3-Zellen}

Vor der Injektion der DNA-Konstrukte in Oozyten wurde getestet, ob sie prinzipiell in vitro exprimiert werden können. Hierfür wurden zunächst NIH/3T3-Zellen mit dem transgenen NS1-Konstrukt transfiziert. Aus den NIH/3T3-Zellen wurden 24 h nach der Transfektion die Gesamtproteine isoliert. In Western Blot-Analysen konnte das SHP2-cmyc-Fusionsprotein mit Hilfe eines c-myc-spezifischen Antikörpers detektiert werden. Das SHP2-c-mycFusionsprotein besitzt ein Molekulargewicht von 68,7 kDa (SHP2 $=68 \mathrm{kDa}, \mathrm{cmyc}=0,7 \mathrm{kDa})$ (Abb. 3.26). Als Positivkontrolle wurde rekombinantes WT-SHP2 und als Negativkontrolle $\beta$ - 
Galaktosidase verwendet. Somit konnte gezeigt werden, dass das transgene NS1-Konstrukt in vitro exprimiert wird, und dass es mit Hilfe des cmyc-spezifischen Antikörpers detektiert werden kann. Da die Konstrukte NS2 und NS3 bis auf die eingeführten Mutationen vollkommen identisch mit NS1 sind, wurde für diese Konstrukte der in vitro-Test nicht durchgeführt.

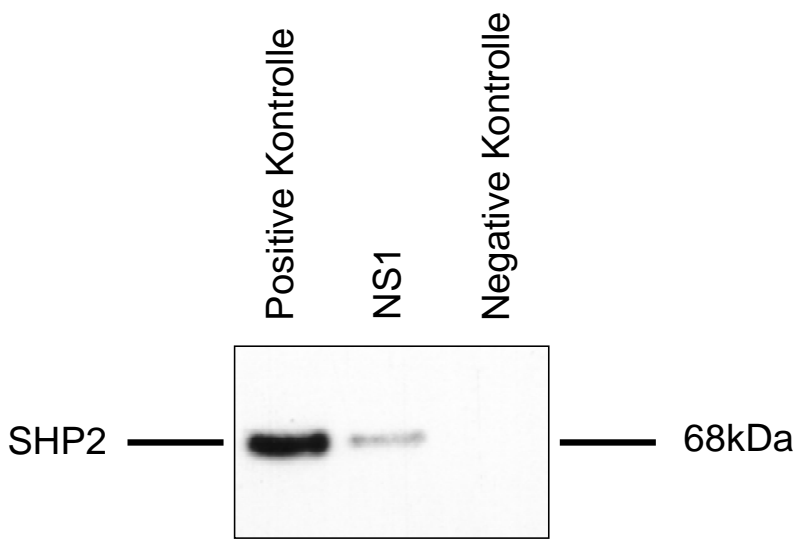

Abb. 3.26: Nachweis des transgenen NS1-Gen-Produktes auf Proteinebene mittels einer Western BlotAnalyse. Das transgene NS1-Konstrukt wurde in NIH/3T3-Zellen transfiziert. Nach 24 h wurden die Proteine isoliert und die Expression des transgenen NS1-Konstruktes mit Hilfe eines cmyc-spezifischen Antikörpers nachgewiesen. Das SHP2-cmyc-Fusionsprotein besitzt ein Molekulargewicht von 68,7 kDa (SHP2 = 68 kDa, cmyc $=0,7 \mathrm{kDa})$. Als Positivkontrolle wurde rekombinantes WT-SHP2 und als Negativkontrolle $\beta$ Galaktosidase verwendet.

\subsubsection{Nachweis der Funktionalität der transgenen NS1-, NS2- und NS3- Fusionsproteine über einen SOCS-1-Luciferase-Assay}

Um nachzuweisen, dass das transgene SHP2 von NS1, NS2 und NS3 ebenfalls einen regulierenden Effekt auf die SOCS-1-Transkription ausübt, wurde der SOCS-1-LuciferaseAssay (3.3.1) mit dem jeweiligen transgenen Konstrukt wiederholt. Hierfür wurden NIH/3T3Zellen mit dem transgenen NS1-, NS2 oder NS3-Konstrukt (1 $\mu \mathrm{g})$ sowie mit den Vektoren SOCS-1-Luciferase $(1 \mu \mathrm{g})$ und pCMV- $\beta$-Gal $(0,05 \mu \mathrm{g})$ kotransfiziert, und die LuciferaseAktivität wurde gemessen. In Abbildung 3.27 ist der Mittelwert aus den Ergebnissen von fünf Transfektionen für die verschiedenen Konstrukte graphisch dargestellt. Eine 40\%- bzw. 30\%ige Abnahme der relativen Luciferase-Aktivitäten bestätigt die biologische Aktivität der SHP-2 Varianten. 


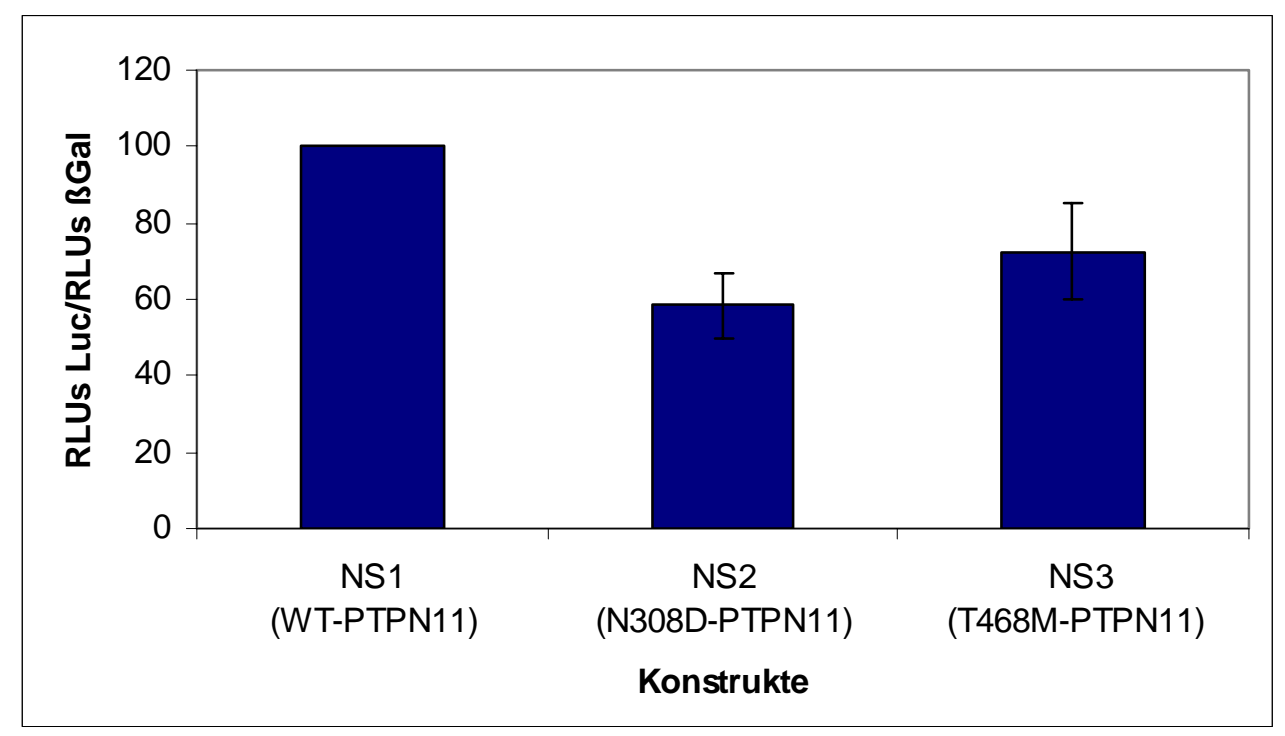

Abb. 3.27: Nachweis der Funktionalität der Transgen-Konstrukte NS1, NS2 und NS3 im SOCS-1Luciferase-Assay. NIH/3T3-Zellen wurden mit den transgenen NS1-, NS2- bzw. NS3-Konstrukten und mit SOCS-1-Promotor-Luciferase sowie pCMV- $\beta$-Gal kotransfiziert. Gezeigt sind die relativen Werte für die bezüglich der Transfektionseffizienzen abgeglichenen Luciferase-Aktivitäten der Konstrukte NS1, NS2 und NS3. Dem NS1-Konstrukt (WT-PTPN11) wurde per Definition ein Wert von 100 zugeordnet. Die Messung der relativen Luciferase-Aktivitäten der Konstrukte mit den Mutationen (NS2 und NS3) ergab eine Verminderung um $40 \%$ bzw $30 \%$.

\subsubsection{Relative Kopienzahlbestimmung an genomischer DNA der verschiedenen Founder (F0) und ausgewählter Verpaarungen}

Für die weitere Zucht der NS1-, NS2- und NS3-Founder sollten drei Mäuse eingesetzt werden, deren Transgen-Kopienzahl im Genom im hohen, mittleren und unteren Bereich liegt. Um zu überprüfen, welche Kopienzahlen der Konstrukte im Genom der Founder vorlagen, wurde eine relative Kopienzahlbestimmung durchgeführt (2.2.5.4).

In Abbildung 3.28 sind die Kopienzahlbestimmungen für die jeweiligen NS1, NS2 und NS3Founder gezeigt.

In Tabelle 3.4 sind die ausgewählten Linien und ihre relative Kopienzahl aufgelistet. 
A.

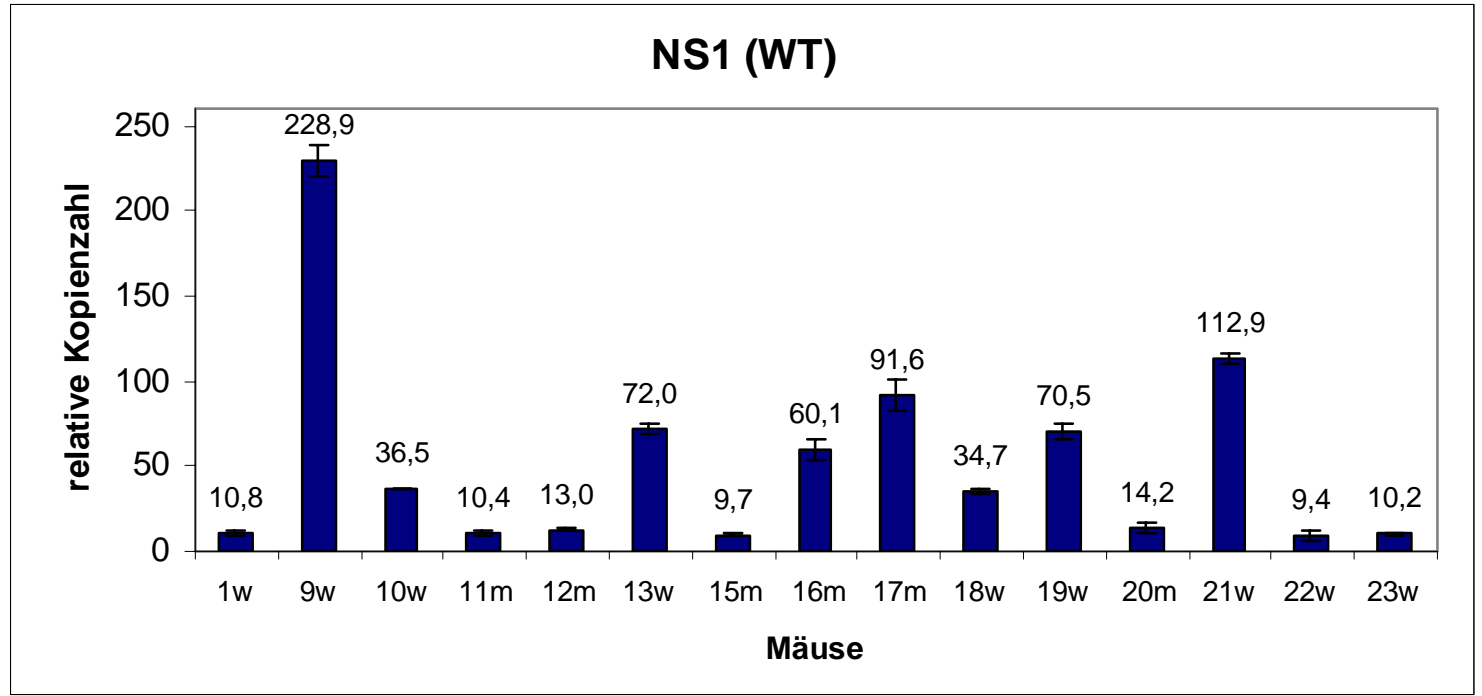

B.

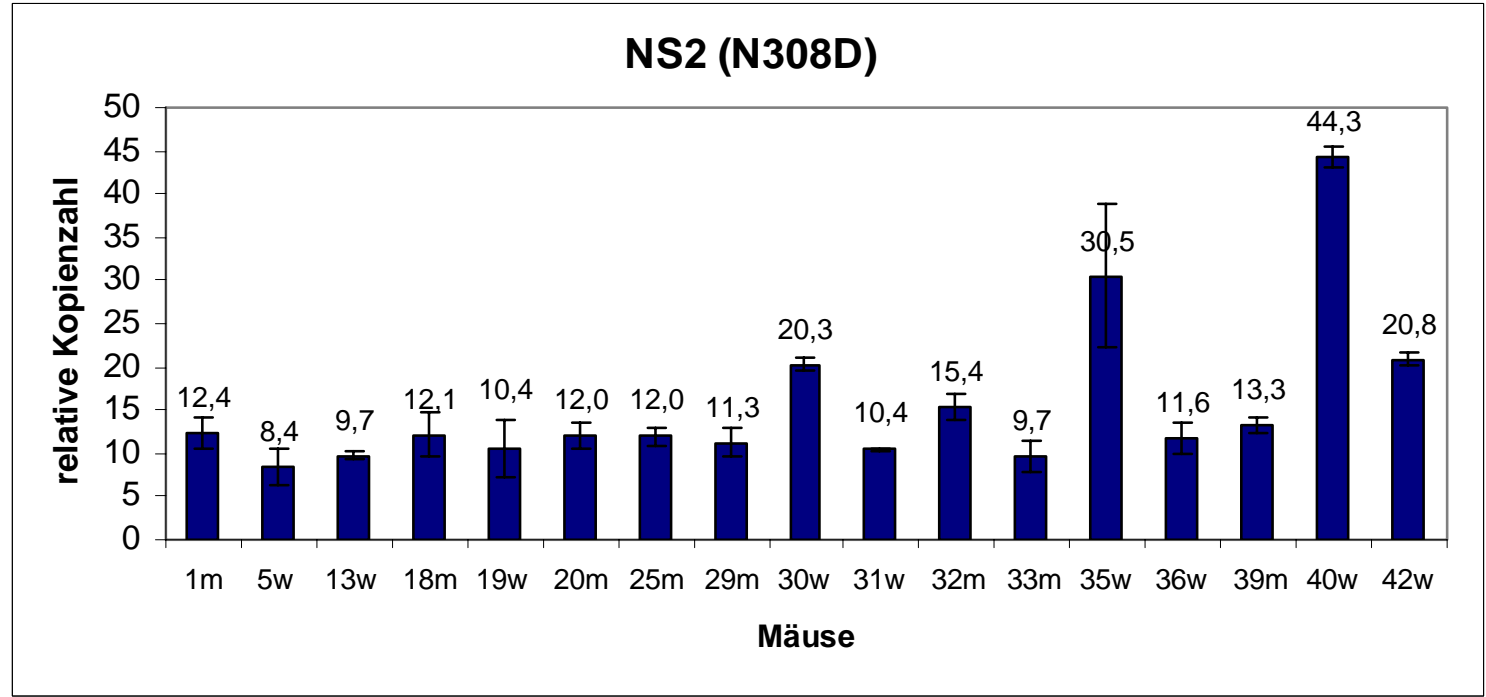

C.

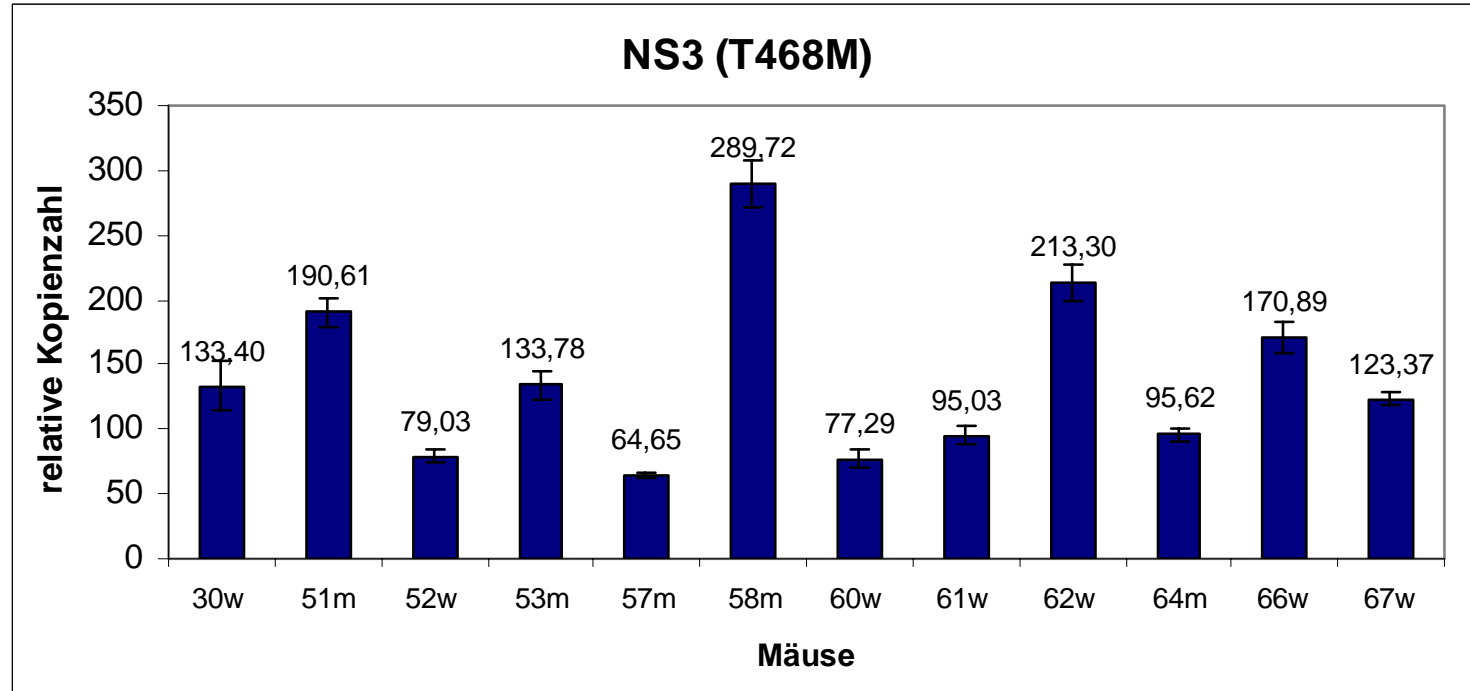


Abb. 3.28: Relative Kopienzahlbestimmung der NS1-, NS2- und NS3-Founder. Um zu überprüfen, wie viele Kopien der NS1-, NS2-, NS3-Konstrukte in das Genom der jeweiligen Founder integriert sind, wurde eine relative Kopienzahlbestimmung durchgeführt. Die Kopienzahlen wurden miteinander in Relation gesetzt, um bestimmen zu können, welche der Founder für die weitere Verpaarung mit FVB-Mäusen eingesetzt werden sollten. A. -C. Gezeigt ist die relative Kopienzahl von NS1 (A.), NS2 (B.) und NS3 (C.) im Genom

\begin{tabular}{llll}
\hline Bemerkung & NS1 & NS2 & NS3 \\
\hline höchste Kopienzahl & 21 & 40 & 58,66 \\
mittlere Kopienzahl & 16 & 30 & 30,53 \\
tiefste Kopienzahl & 11 & 25 & 64,57 \\
\hline
\end{tabular}

Tab. 3.4: Übersicht der relativen Kopienzahlen der ausgewählten Founder von NS1, NS2 und NS3.

\subsubsection{Bestimmung der Zahl der Integrationen der NS1-, NS2- und NS3- Konstrukte im Genom durch Taqman- und Southern Blot-Analyse}

Für die weitere Zucht sollten die Linien weiter verwendet werden, die nur eine Integration des Konstrukts im Genom haben. Die Integrationszahlbestimmung wurde mit zwei unabhängigen Methoden, der Taqman- und der Southern Blot-Analyse, durchgeführt. Es wurden fünf Nachkommen der F1-Generation, bei denen das NS1-, NS2- oder NS3-Konstrukt mittels PCR nachgewiesen wurde, zusammen mit den jeweiligen Foundern durch Taqman-Analyse (2.2.5.4) überprüft. Die Kopienzahl der Founder wurde anschließend mit der Kopienzahl der fünf Nachkommen verglichen. Wenn eine einzige Integration des Konstrukts im Genom vorhanden ist, wird eine gleiche Kopienzahl sowohl der Founder als auch der Nachkommen erwartet.

In Abbildung 3.29 A ist die relative Kopienzahl der Linien NS1\#16 und NS1\#21 dargestellt. Bei der Linie NS1\#11, die mit relativer niedriger Kopienzahl ausgewählt wurde, wurde keine Transmission festgestellt und daher keine weitere Analyse durchgeführt. Die Linien NS1\#16, \#21 und NS2\#25 zeigen eine gleiche Kopienzahl zwischen Founder und Nachkommen, haben also eine einzige Integration des Konstrukts im Genom. Bei der Linie NS2\#40 wurden unterschiedliche Kopienzahlen zwischen Founder und Nachkommen gemessen. NS2\#40 zeigt zwei oder drei Integrationen des NS2-Konstrukts im Genom (Abb. 3.29 B.). Bei der NS2\#30Linie wurde keine Kopienzahlbestimmung aufgrund der Abwesenheit der Expression des NS2-Konstrukts (Abb. 3.31 A.) durchgeführt. Die Bestimmungen der Kopienzahl bei 
NS3\#30, NS3\#58, NS3\#64, NS3\#53 und NS3\#66 sind in Abbildung 3.29 C zusammengefaßt. Bei den Linien NS3\#30 und NS3\#58 wurden unterschiedliche Kopienzahlen zwischen Foundern und deren Nachkommen gemessen. Diese zwei Linien besitzen zwei oder drei Integrationen des NS3-Konstrukts im Genom. Sowohl NS3\#64 als auch NS3\#53 und NS3\#66 zeigen eine gleiche Kopienzahl beim jeweiligen Founder und dessen Nachkommen.

A.
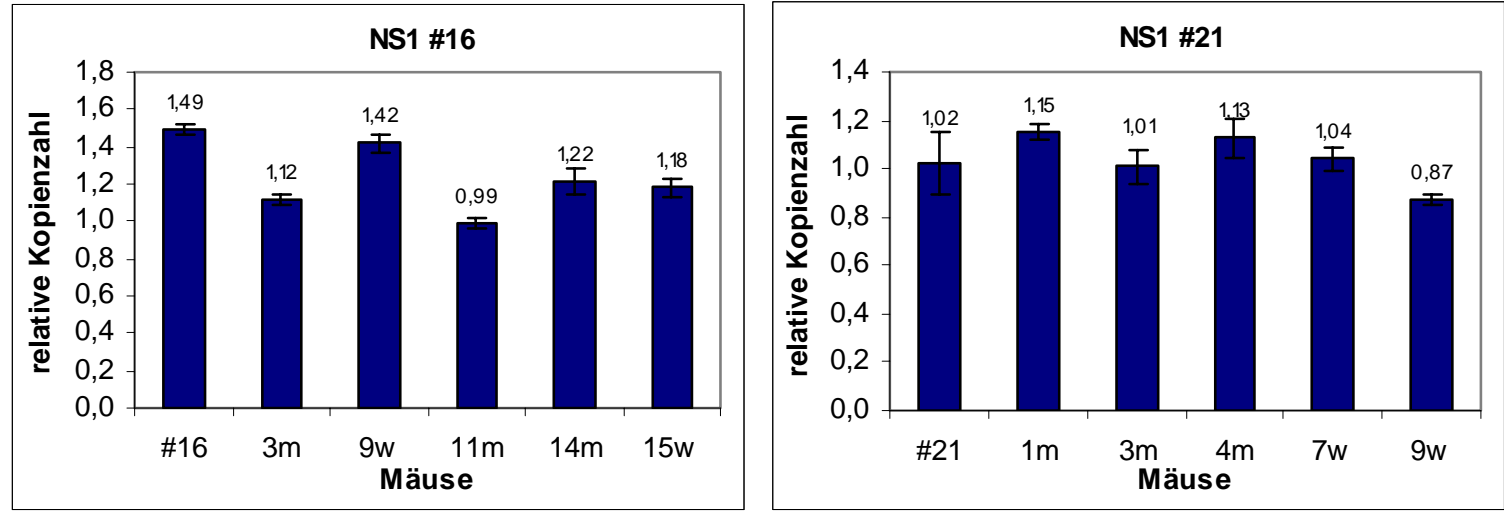

B.
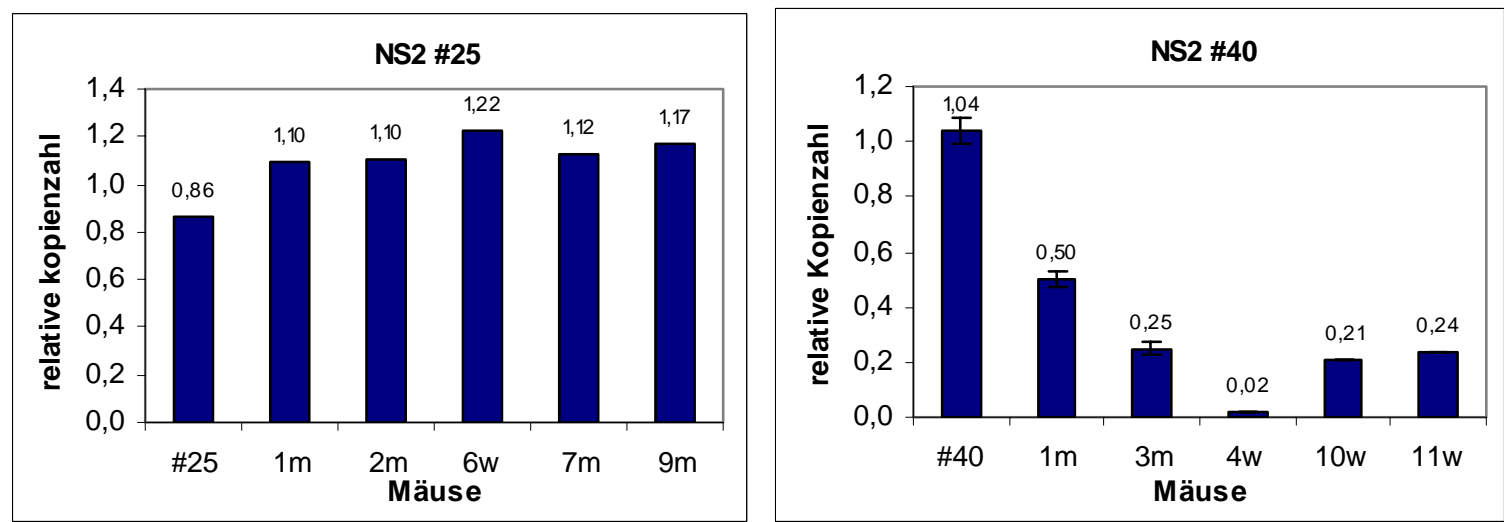

C.
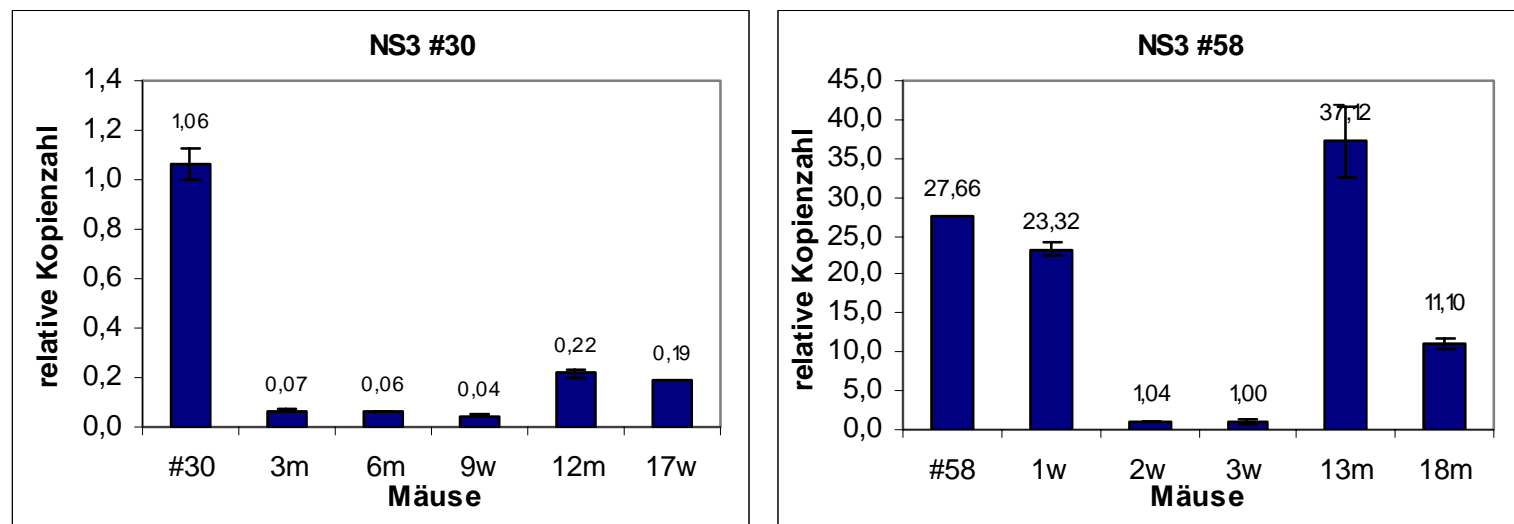

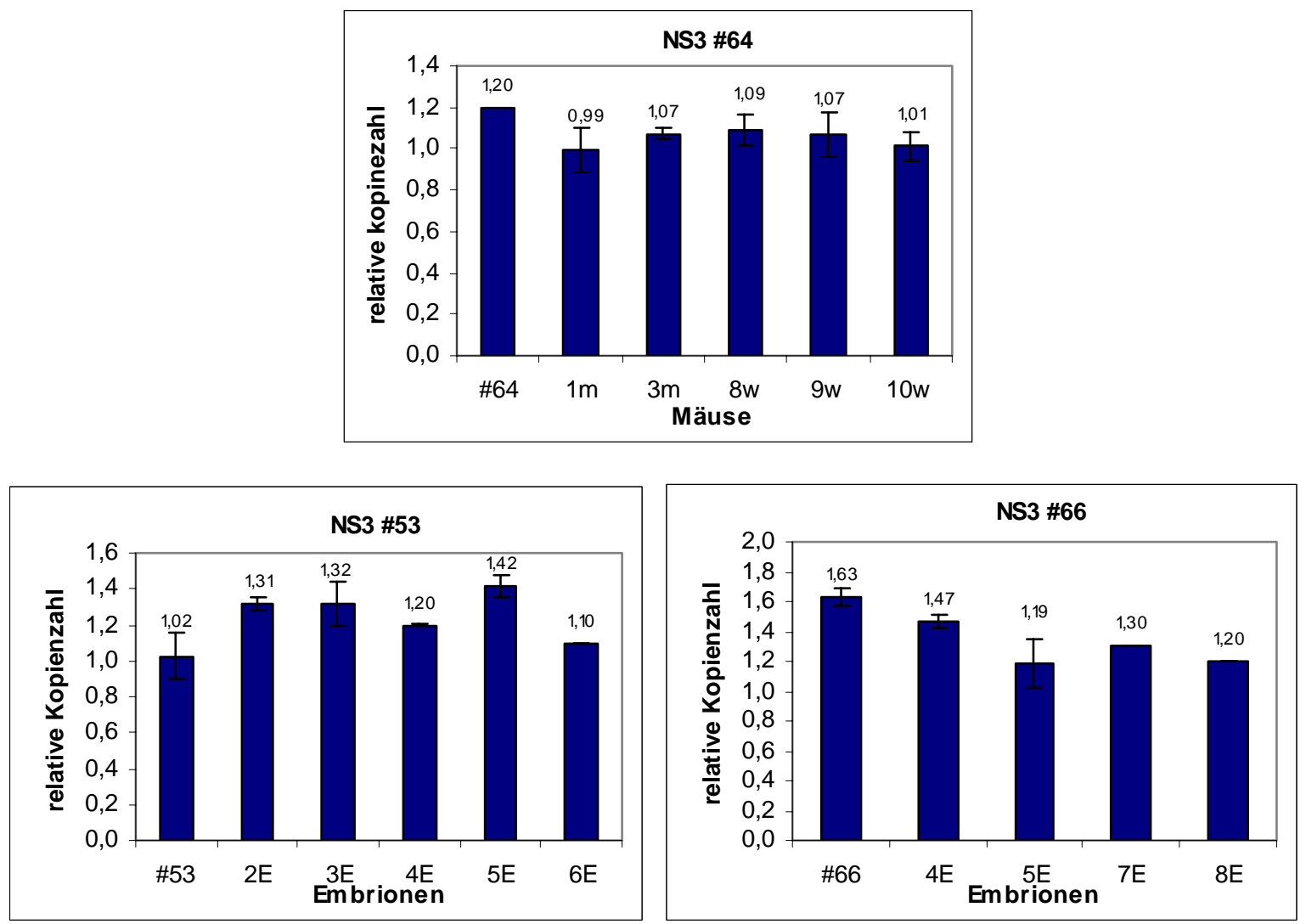

Abb. 3.29: Relative Kopienzahlbestimmung der NS1-, NS2- und NS3-Founder mit jeweils fünf

Nachkommen. A. Gezeigt sind die relative Kopienzahlbestimmung der Linien NS1\#16 und NS1\#21 mit jeweils fünf Nachkommen. Die relative Kopienzahl ist gleichmäßig sowohl für NS1\#16 als auch für NS1\#21, und beide Linien besitzen daher je eine Integration. B. Dargestellt sind die relativen Kopienzahlbestimmungen der Linien NS2\#25 und NS2\#40 mit je fünf Nachkommen. Die Kopienzahlbestimmung der NS2\#25 zeigt eine Gleichmäßigkeit, aber bei den Nachkommen der Linie NS2\#40 wurden verschiedene Kopienzahlen pro Nachkommen gemessen. C. Gezeigt sind die relativen Kopienzahlen der verschiedenen Linien von NS3. Unterschiedliche Kopienzahlen wurden bei den Nachkommen der Linien NS3\#30 und NS3\#58 festgestellt. Die Nachkommen der Linie NS3\#64 und die Embryonen der Linien NS3\#53 und NS3\#66 zeigen ähnliche Kopienzahlen.

Um die Zahl der Integrationen zu bestimmen, wurde parallel zur Taqman-Analyse eine Southern Blot-Analyse bei den verschiedenen Linien durchgeführt. Bei dem in Abbildung 3.30 A dargestellten Southern Blot-Analyse wurde genomische DNA der transgenen Mäuse und von Kontroll-FVB-Mäusen mit der Restriktionsendonuklease KpnI geschnitten. Die geschnittene DNA wurde gelelektrophoretisch aufgetrennt und, wie unter Abschnitt 2.2.4.1 beschrieben, auf eine Membran übertragen. Die verwendete Sonde wurde mit den Restriktionsenzymen BglI/PstI aus WT-PTP11-cDNA-pCRTOPO isoliert. Die radioaktive 
Markierung und anschließende Hybridisierung mit der auf der Membran fixierten DNA erfolgte wie unter 2.2.5 beschrieben.

Bei der Kontroll-FVB-Maus wurde auf dem Autoradiographie-Film keine Bande aufgrund der Spezifität der Sonde für die humane PTPN11-cDNA erwartet. Bei den transgenen Mäusen werden zwei Banden pro Integration erwartet, wodurch neben der 5,7 kb großen KonstruktBande eine weitere Bande pro Integration entstehen sollte. Die Größe der Nebenbanden hängt von der Entfernung der nächsten 3’ gelegenen KpnI-Schnittstelle zum integrierten Konstrukt ab (Abb. 3.30 A.). Falls eine transgene Linie mehr als eine Integration des Konstrukts im Genom besitzt, werden bei der Southern Blot-Analyse mehr als zwei Banden erhalten, wobei die 5,7 kb große Bande ein besonders starkes Signal geben sollte. In Abbildung 3.30 B, C und D sind die Southern Blot-Analysen für die verschiedenen Linien der NS1-, NS2- und NS3Konstrukte dargestellt. Die Entwicklung der Autoradiographie-Filme zeigte nur die 5,7 kb großen Bande. Die erwarteten weiteren Banden wurde ganz schwach bei NS2\#40 und NS3\#58 beobachtet oder nicht detektiert. Diese Banden könnten zu groß sein, um mit einer guten Effizienz auf die Membran übertragen worden zu sein.

Bei den Linien NS1\#16, NS1\#21 (Abb. 3.30 B.), NS2\#25 (Abb. 3.30 C.) und NS3\#64 (Abb. 3.30 D.) zeigen sowohl Founder als auch die jeweils fünf Nachkommen die gleiche Intensität der 5,7 kb großen Bande (Abb. 3.30 A.). Im Falle von NS2\#40 (Abb. 3.30 C.), NS3\#30 und NS3\#58 (Abb. 3.30 D.) zeigt die 5,7 kb große Bande mehr oder weniger intensive Signalstärken, je nachdem wie viele Kopien pro Integration im Genom vorhanden sind. Diese Ergebnisse bestätigen die Integrationszahlbestimmungen mittels Taqman-Analyse.

Bei NS2\#40 wurden die zwei Integrationen durch Verpaarung von F1-Tieren mit FVB-Tieren voneinander getrennt. Daraufhin entstanden die Linien NS2\#401 und NS2\#402. Die NS3Linien, die mehr als eine Integration besitzen, wurden nicht weiter verwendet (NS3\#30 und NS3\#58). Es wurde daher eine Integrationsbestimmung von NS3\#53, NS3\#57 und NS3\#66Founder durchgeführt. Diese Founder wurden mit je zwei weiblichen WT-FVB-Mäusen verpaart und anschließend die Embryonen einer schwangeren Maus präpariert, um die Integrationszahl zu bestimmen. Für NS3\#53 und NS3\#66 wurde nur eine Taqman-Analyse durchgeführt (siehe oben 3.4.6). NS3\#57 hatte nicht transmittiert und wurde deshalb nicht weiter verwendet. 


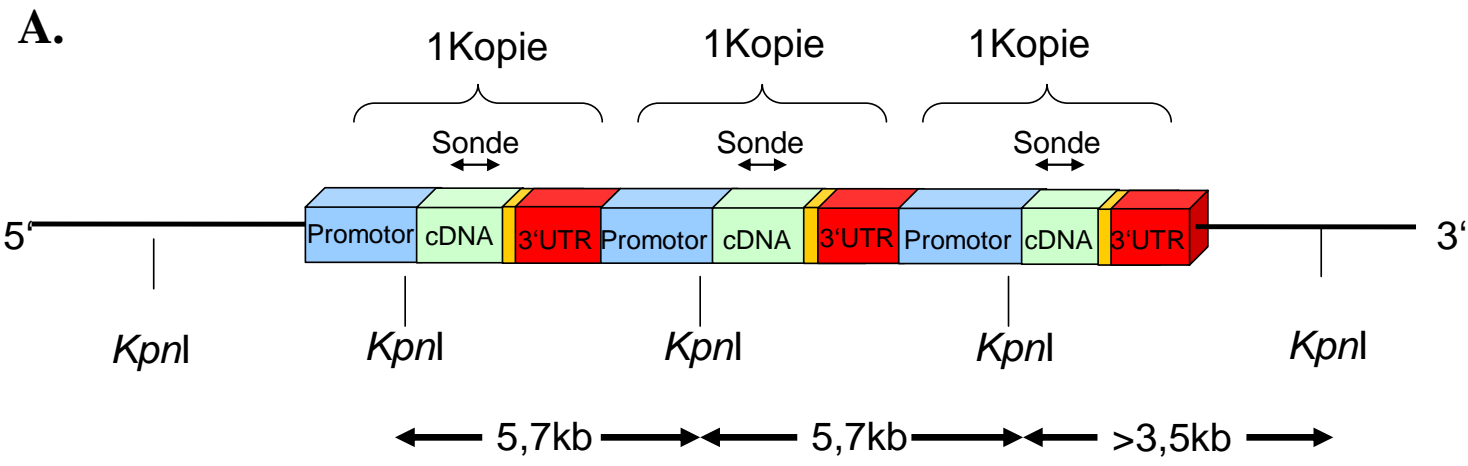

B.
\#

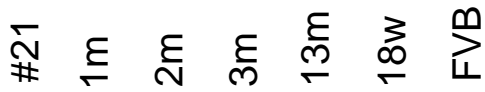
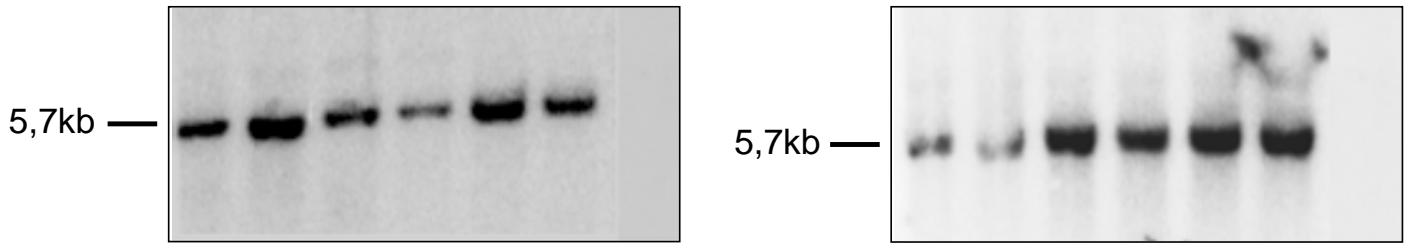

C.

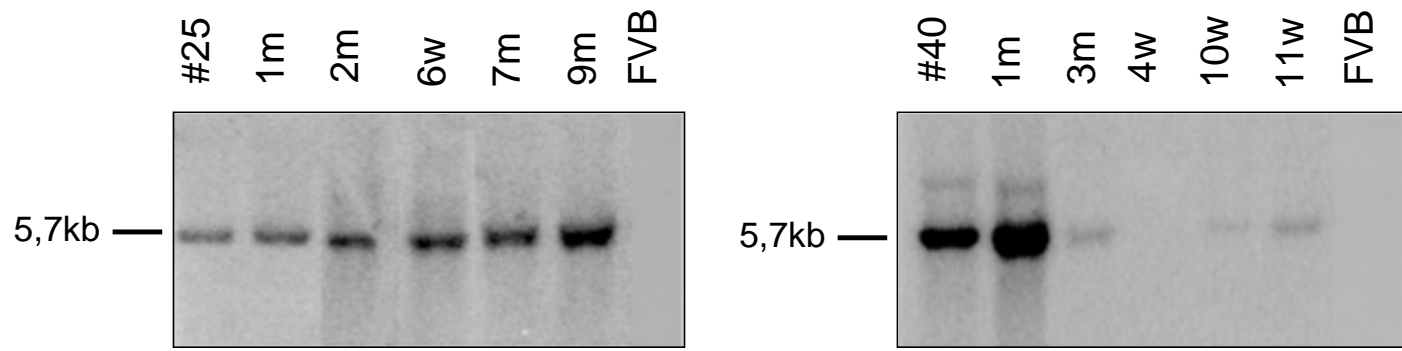

D.

円

\#
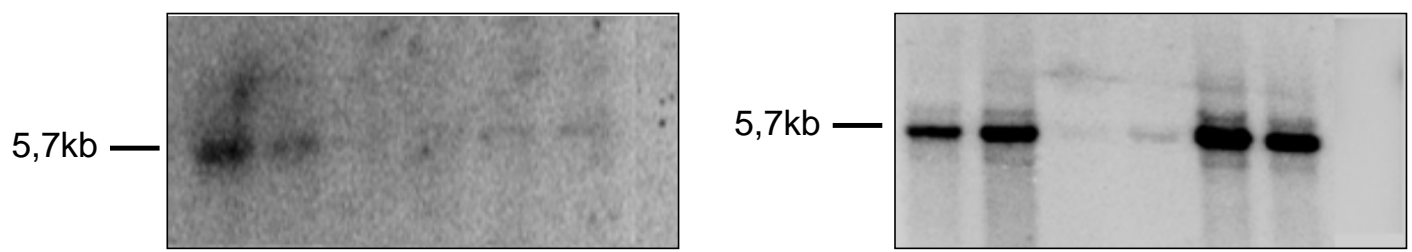


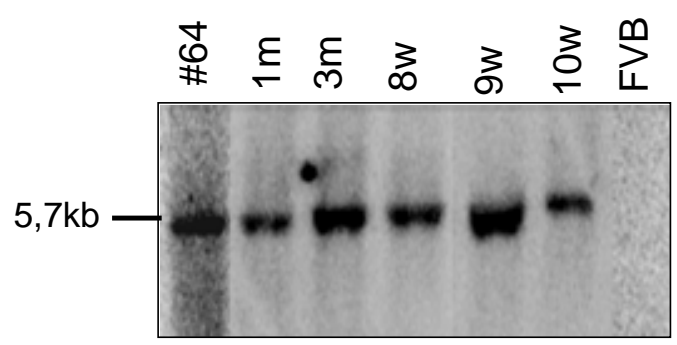

Abb. 3.30: Southern Blot-Analyse zur Integrationszahlbestimmung der NS1-, NS2- und NS3-Konstrukte im Genom. A. Dargestellt ist ein Abschnitt der Integration des Konstrukts im Genom mit den KpnISchnittstellen sowie der verwendeten Sonde und den erwarteten Größen der Banden bei der Southern BlotAnalyse. B. C. D. Ergebnisse der Southern Blot-Analysen mit dem Enzym KpnI und genomischer DNA der Founder und der jeweils fünf Nachkommen von NS1\#16 und NS1\#21 (B.), NS2\#25 und NS2\#40 (C.), NS3\#30 NS3\#58 und NS\#64 (D.) und genomischer DNA von WT-FVB als Negativkontrolle. Die Entwicklung der Autoradiographie-Filme der NS1\#16, NS1\#21 (B.), NS2\#25 (C.) und NS3\#63 (D.) zeigten die 5,7 kb große Bande bei der DNA der transgenen Mäusen, jedoch keine Bande bei der DNA der FVB-Maus. Bei NS2\#40 (C.), NS3\#30 und NS3\#58 (D.) trat die 5,7kb-Bande in verschiedenen Intensitäten auf, und eine schwache Nebenbande wurde detektiert.

\subsubsection{Expressionsanalysen in NS1-, NS2- und NS3-transgenen Mäusen}

\subsubsection{Analyse der Expression der transgenen PTPN11-Varianten auf RNA-Ebene}

Um die Expression des transgenen PTPN11 nachzuweisen, wurde eine RT-PCR durchgeführt. Gesamt-RNA wurde aus dem Herzen der transgenen Mäuse der Linien NS1\#16 und \#21, der Linien NS2\#25, \#30 und \#40 und der Linien NS3\#30, \#58, \#66 sowie aus den Embryonen von NS3\#53 und \#64 isoliert. Nach einer DNAseI-Behandlung (2.2.2.9) und vor der reversen Transkription wurde eine Kontroll-PCR mit den späteren Test-Oligonukleotiden durchgeführt. Dieser Test dient dem Nachweis von verbliebener genomischer DNA (es sollte also kein PCR-Produkt entstehen). Dieser Schritt war erforderlich, da das Konstrukt kein Intron enthält und zwischen genomischer DNA (aufgrund von Kontamination in der RNAPräparation) und cDNA nach der RT-Reaktion nicht unterschieden werden kann. Nach der DNaseI-Behandlung wurde die cDNA durch eine reverse Transkription (2.2.5.3) an GesamtRNA generiert. Für die PCR an der erhaltenen cDNA wurden PTPN11-spezifische Primer (NS4-TaqF und NS4-TaqR) zur Überprüfung der NS1-, NS2- und NS3-Expression eingesetzt. Eine PCR mit diesen Primern ergibt ein 120 bp großes Fragment. Als Vergleichswert wurde 
ein cDNA-Fragment von GAPDH (Glyzerinaldehyd-3-Phosphat-Dehydrogenase) mit Hilfe der PCR amplifiziert (444 bp).

In Abbildung $3.31 \mathrm{~A}$ ist eine DNAseI-Behandlung und eine RT-PCR an cDNA aus HerzRNA der Linien NS1\#16, NS1\#21 NS2\#25, NS2\#30 und NS2\#40 dargestellt. Das PTPN11Konstrukt wird in allen Linien außer NS2\#30 exprimiert. Wie bereits in Abschnitt 3.4.6 beschrieben, wurden bei NS2\#40 zwei neue Linien aufgrund der Anwesenheit von zwei Integrationen im Genom generiert. Die Expression der zwei neuen Linien NS2\#401 und NS2\#402 wurde ebenfalls überprüft (Abb. 3.31 B.). Beide Linien zeigen eine Expression des transgenen PTPN11. Die Ergebnisse der RT-PCR-Analysen der Linien NS3\#30, NS3\#58 und NS3\#64 sind in Abbildung 3.31 C und von NS3\#53 und \#66 in Abbildung 3.31 D dargestellt. Diese Linien exprimieren das NS3.

A.

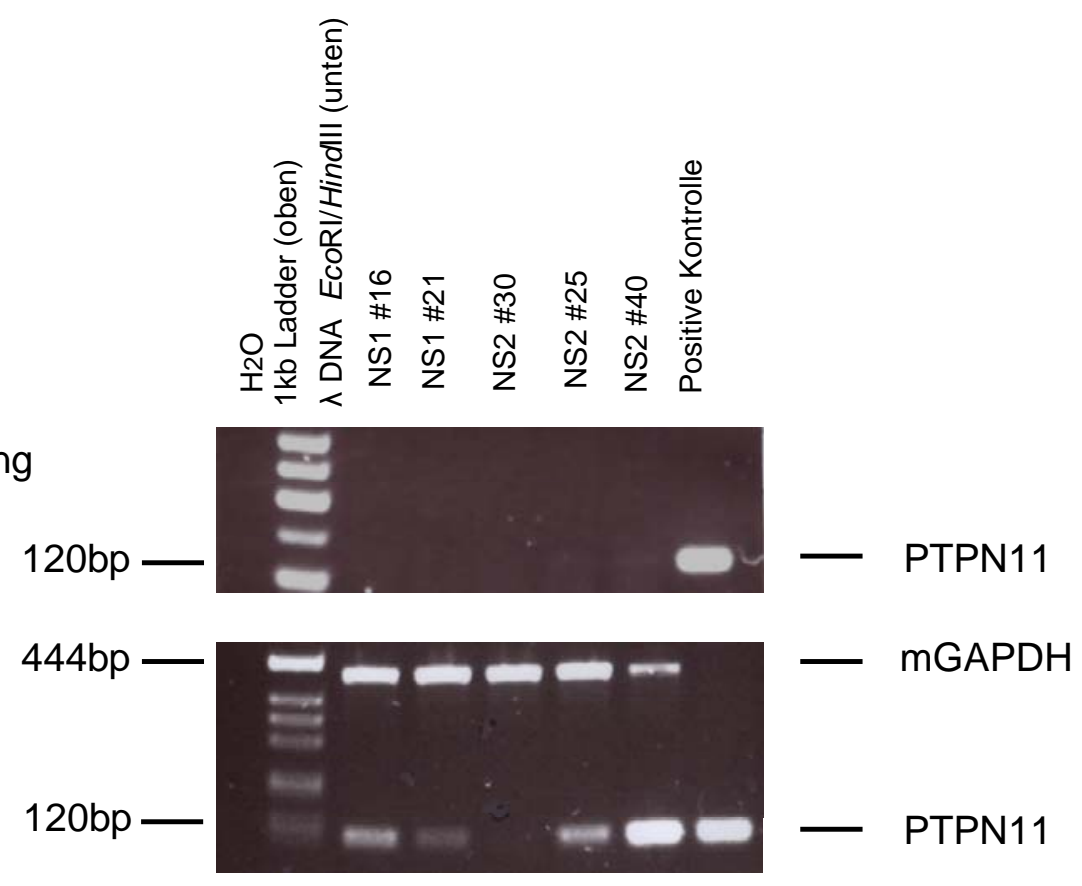

DNAsel-Behandlung

RT-PCR 
B.

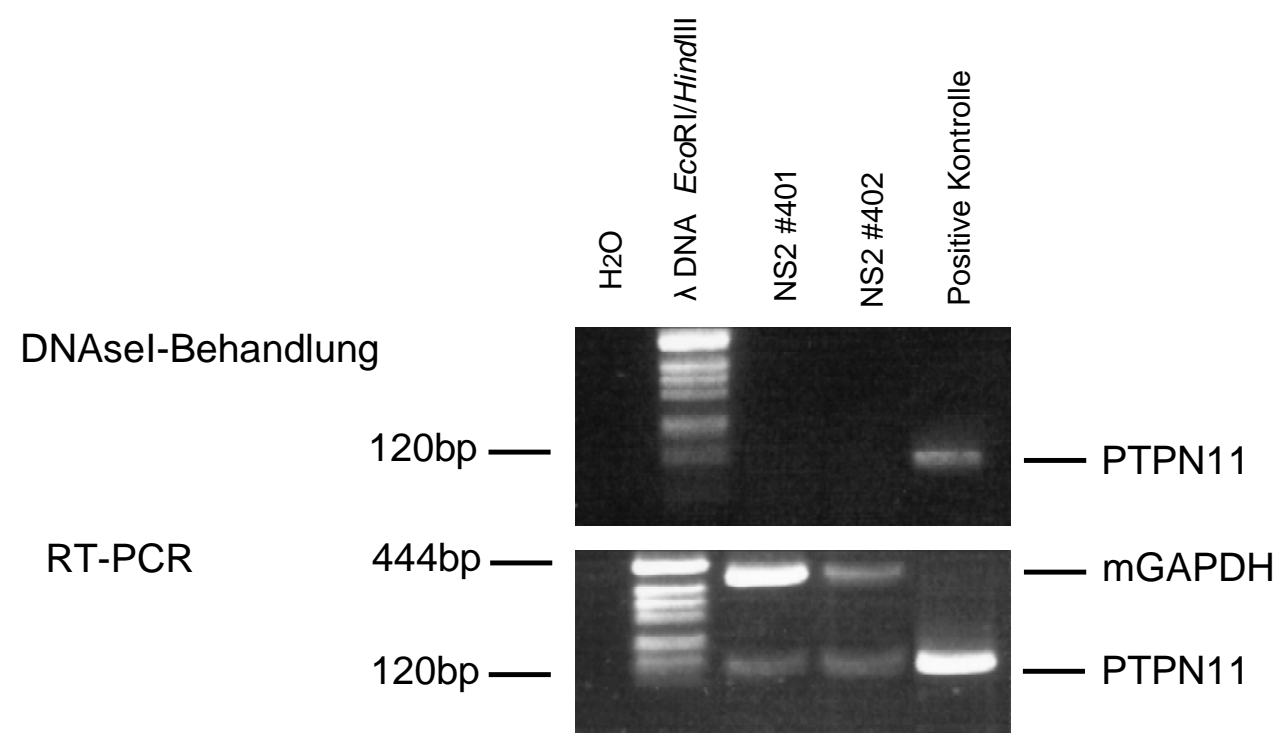

C.

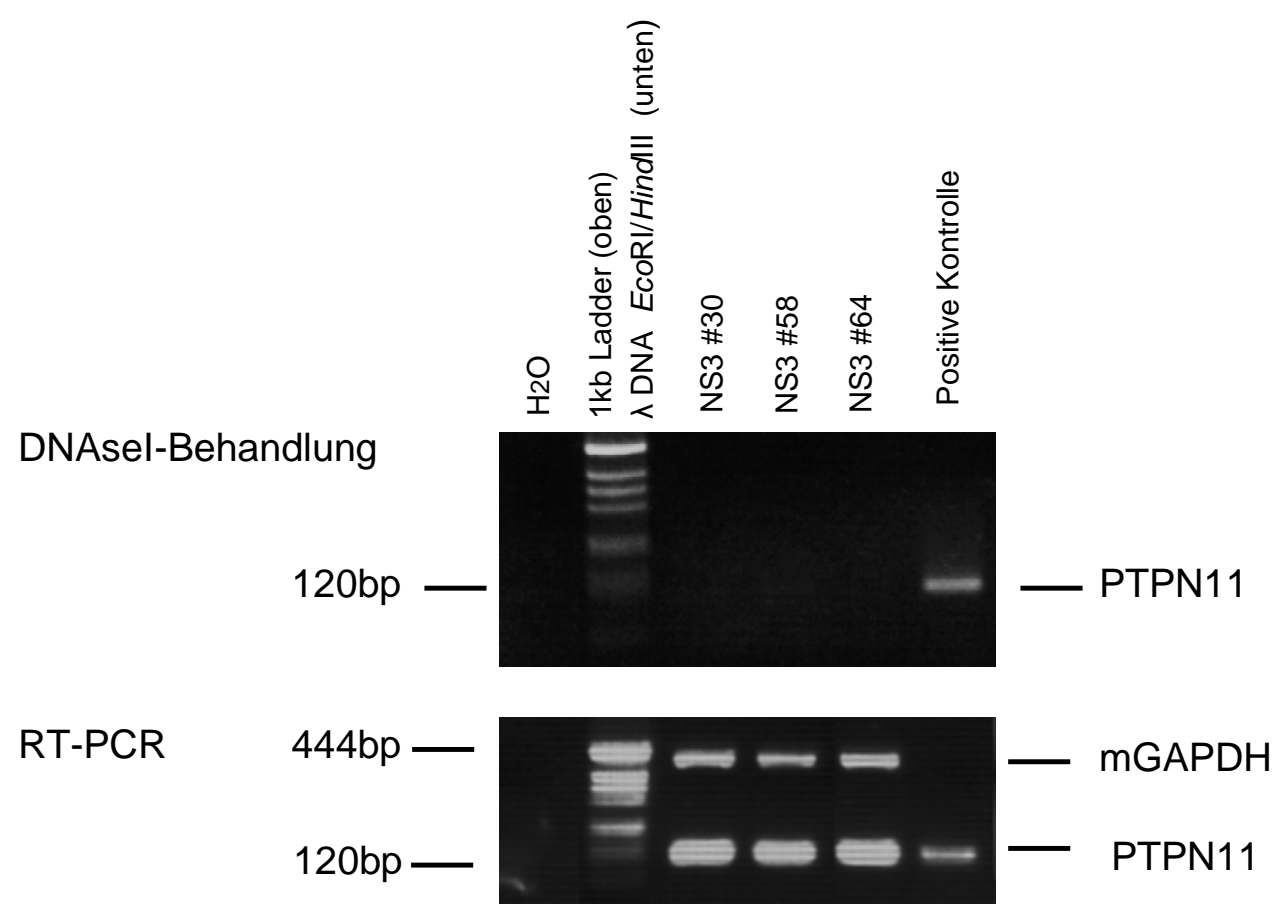


D.

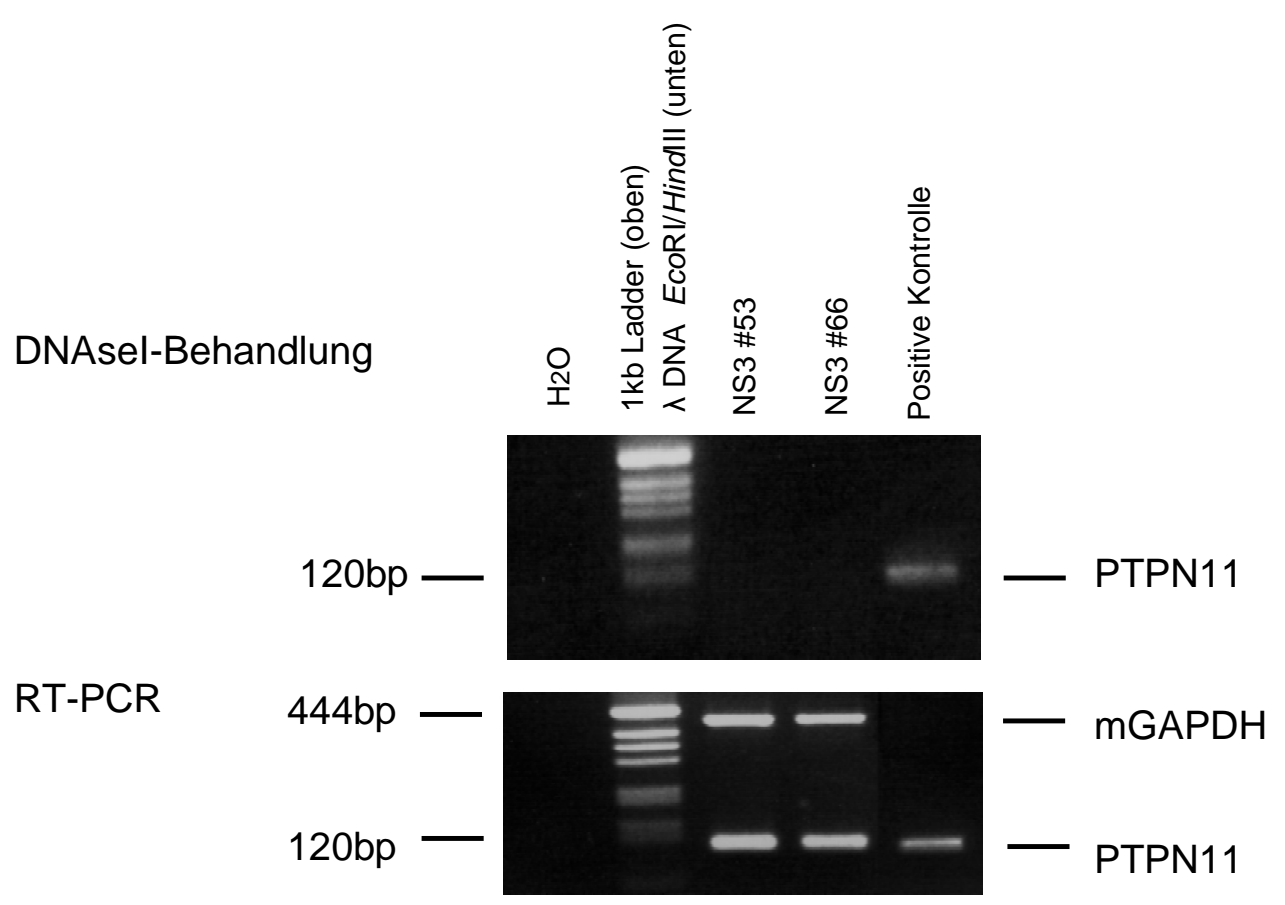

Abb. 3. 31: RT-PCR zur Analyse der Expression des transgenen PTPN11 bei NS1, NS2 und NS3. Aus den Herzen der verschiedenen transgenen PTPN11-Mäuse wurde RNA isoliert und cDNA nach DNaseI-Behandlung und Kontroll-PCR (jeweils oberes Bild) hergestellt. Anschließend wurde eine PCR mit den PTPN11spezifischen Primern (NS4-TaqF und NS4-TaqR) durchgeführt. Das PCR-Produkt besitzt eine Größe von 120 bp. Als Vergleichswert wurde ein cDNA-Fragment von GAPDH amplifiziert (444 bp). A. Transgenes PTPN11 wird in den Maus-Linien NS1\#16, NS1\#21, NS2\#25 und NS2\#40 exprimiert. NS2\#30 zeigt keine transgene PTPN11-Expression. B. Expression des transgenen PTPN11 der zwei Linien NS2\#401 und NS2\#402, die aus NS2\#40 generiert worden sind. C. und D. Expression des transgenen PTPN11 der Maus-Linien NS3\#30, NS3\#58 und NS3\#64 (C) und der Linien NS3\#53 und NS3\#66 (D).

\subsubsection{Untersuchung der Expression der transgenen SHP2-Varianten auf Proteinebene}

Um das SHP2-Protein in den NS1-, NS2- und NS3-transgenen Mäusen spezifisch nachzuweisen, wurden Gesamtproteine aus den Herzen transgener Mäuse und aus WT-FVBMäusen isoliert (2.2.6.3). Die Proteine wurden über Western Blots analysiert und das SHP2cmyc-Fusionsprotein wurde mit Hilfe eines cmyc-spezifischen Antikörpers detektiert. Das SHP2-cmyc-Fusionsprotein besitzt ein Molekulargewicht von 68,7 kDa (SHP2 = 68 kDa, cmyc $=0,7 \mathrm{kDa}$ ) (Abb. 3.32). In Abbildung 3.32 ist eine Western Blot-Analyse mit Proteinen aus Herzen von NS1\#16-, NS1\#21- und NS2\#25-Mäuse, rekombinantem WT-SHP2 (Positivkontrolle) und aus Herzprotein aus WT-FVB-Tiere gezeigt. 
Der Immunoblot mit einem c-myc-Antikörper ergab trotz stringenter Bedingungen unspezifische Banden. Zu erkennen ist jedoch, dass die Bande bei $68 \mathrm{kDa}$ bei FVB nicht vorliegt und somit vermutlich das spezifische Transgen repräsentiert.

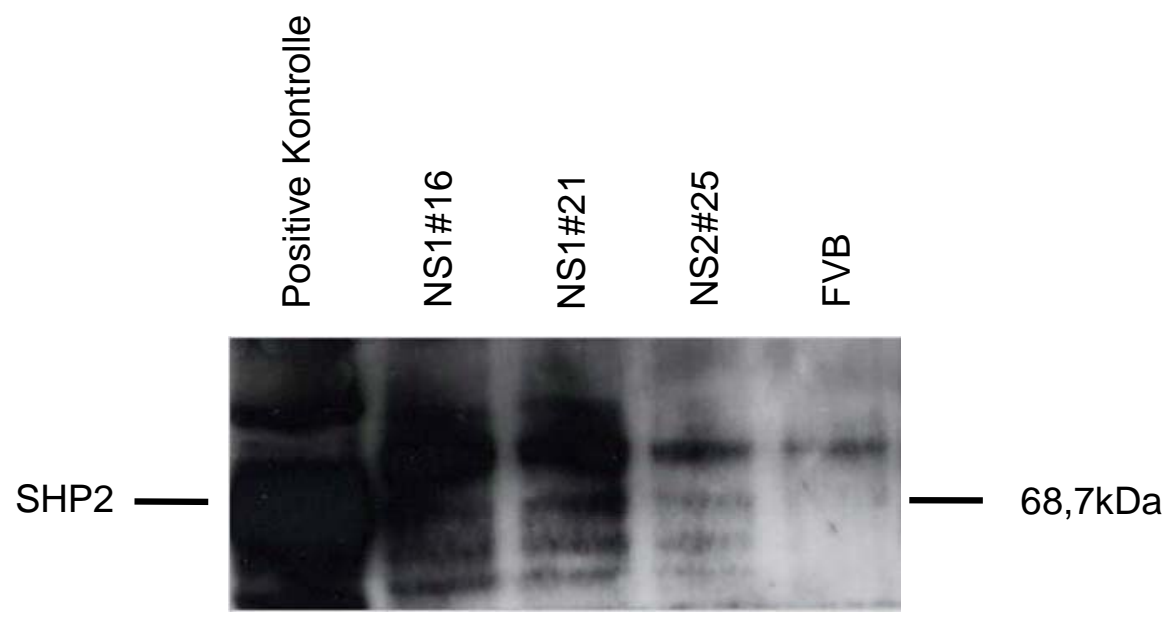

Abb. 3.32: Western Blot-Analyse zum Nachweis des transgenen SHP2. Gezeigt ist eine Western BlotAnalyse von Herz-Proteinlysaten der Linien NS1\#16, NS1\#21, NS2\#25, rekombinantem WT-SHP2 als Positivkontrolle und FVB als Negativkontrolle mit Hilfe eines cmyc-spezifischen Antikörpers. Das transgene SHP2-Protein besitzt ein Molekulargewicht von 68,7 kDa.

\subsubsection{Wurfgröße der transgenen Linien}

Die Untersuchung der Wurfgröße und der Anzahl homozygoter transgener Tiere kann bereits einen Hinweis auf einen Phänotyp einer transgenen Mauslinie geben. Daher wurden die Wurfgrößen und die Genotypen der Nachkommen bestimmt. Die Nachkommen der F2Generation, bei denen das NS1-, NS2- oder NS3-Konstrukt mittels PCR nachgewiesen wurde, wurden zusammen mit der jeweiligen F1-Generation mit Hilfe der Taqman-Analyse (2.2.5.4) auf ihre Homozygotie hin untersucht. In der F1-Generation waren 50\% der geborenen Tiere der Linien von NS1 sowie von NS2\#40, NS3\#64 und NS3\#66 heterozygot transgen (T/-) und 50\% WT (-/-). Bei der Linie NS2\#25 wurden mehr WT-Tiere (64,5\%) geboren. Bei NS3\#53 wurde ein einziges heterozygotes Tier geboren, das drei Tage später starb. Die Wurfgröße aller Linien außer NS3\#53 lag zwischen sieben und zehn Tieren pro Wurf, was eine normale Wurfgröße darstellt.

In der F2-Generation zeigte die statistische Auswertung der Genotypen, dass die Vererbung des Transgens nicht den Mendelschen Regeln (25\% T/T, 50\%T/- und 25 -/-) folgt. In der Tabelle 3.5 ist zu erkennen, dass mehr heterozygote und weniger homozygote Tiere als 
erwartet geboren wurden. Die Wurfgröße lag bei den NS1-Linien bei acht, bei NS2 zwischen sechs und acht und bei NS3\#64 bei fünf Tieren pro Wurf.

\begin{tabular}{|c|c|c|c|}
\hline \multicolumn{3}{|c|}{ Anzahl der F1-Generation-Tiere } & $\begin{array}{c}\text { Anzahl der Würfe } \\
\text { (Anzahl der Tiere) }\end{array}$ \\
\hline & Anzahl T/- & Anzahl-I- & $1(10)$ \\
\hline NS1\#16 & $5(50 \%)$ & $5(50 \%)$ & $2(18)$ \\
\hline NS1\#21 & $8(50 \%)$ & $8(50 \%)$ & $4(31)$ \\
\hline NS2\#25 & $11(35,5 \%)$ & $20(64,5 \%)$ & $4(39)$ \\
\hline NS2\#40 & $22(56,4 \%)$ & $17(43,6 \%)$ & $1(1)$ \\
\hline NS3\#53 & $1(100 \%)$ & & $3(28)$ \\
\hline NS3\#66 & $16(57,1 \%)$ & $12(42,8 \%)$ & $3(23)$ \\
\hline
\end{tabular}

\begin{tabular}{|c|c|c|c|c|}
\cline { 2 - 4 } \multicolumn{1}{c|}{} & \multicolumn{3}{c|}{ Anzahl der F2-Generation-Tiere } & Anzahl der Würfe \\
\cline { 2 - 4 } \multicolumn{1}{c|}{} & Anzahl T/T & Anzahl T/- & Anzahl-I- & (Anzahl der Tiere) \\
\hline NS1\#16 & $3(5,8 \%)$ & $28(67,3 \%)$ & $12(26,9 \%)$ & $6(52)$ \\
\hline NS1\#21 & $6(10,2 \%)$ & $29(49,1 \%)$ & $16(27,1 \%)$ & $7(59)$ \\
\hline NS2\#25 & $2(25 \%)$ & $4(50 \%)$ & $2(25 \%)$ & $1(8)$ \\
\hline NS2\#401 & $1(8,3 \%)$ & $9(75 \%)$ & $2(16,6 \%)$ & $2(12)$ \\
\hline NS2\#402 & $2(4,8 \%)$ & $14(34,1 \%)$ & $13(31,7 \%)$ & $4(41)$ \\
\hline NS3\#53 & N.a. & N.a & N.a & N.a \\
\hline NS3\#64 & $3(18,8 \%)$ & $3(18,8 \%)$ & $3(18,8 \%)$ & $3(16)$ \\
\hline NS3\#66 & N.a & N.a & N.a & N.a \\
\hline
\end{tabular}

Tab. 3.5: Größe der Würfe und Genetyp. Dargestellt sind die Anzahl der Würfe und die Verteilung der Genotypen der verschiedene Linien NS1, NS2 und NS3. In Klammern ist der Prozentsatz der homozygoten, heterozygoten Transgene bzw. nicht transgener Geschwister angegeben. N.a. = nicht auswertbar

\subsubsection{Makroskopische Untersuchung des Herzens}

Bei Patienten mit Noonan-Syndrom bestehen häufig angeborene Herzfehler wie Pulmonalstenose, Septumdefekte und hypertrophe Kardiomyopathie. Daher wurde eine phänotypische Analyse des Herzens der verschiedenen transgenen PTPN11-Mäuse vorgenommen. Zur Untersuchung wurde das Herz mit der Lunge aus jeweils einer WT-FVBMaus und einer transgenen Maus der Linien NS1\#16, NS1\#21, NS2\#25, NS2\#401 und NS2\#402 in Zusammenarbeit mit Dr. Männer (Abteilung Anatomie, Universität Göttingen) 
präpariert und fixiert. Nach der Fixierung wurden die Herzen mit der Lunge unter einem Mikroskop analysiert und fotografiert (Abb. 3.33). Die Herzen aus NS1\#16 und NS1\#21 (Abb. $3.33 \mathrm{~B} / \mathrm{H}$ und $\mathrm{C} / \mathrm{I}$ ) zeigen keine makroskopisch sichtbaren phänotypischen Veränderungen im Vergleich zu dem Herz einer WT-FVB-Maus (Abb. 3.33 A/G). Bei NS2\#25 und NS2\#401 wurde eine leichte Vergrößerung des rechten Ventrikels (Abb. 3.33 D/J und E/K) und bei NS2\#402 eine leichte Vergrößerung des linken Ventrikels beobachtet (Abb. $3.33 \mathrm{~F} / \mathrm{L}$ ). Um mögliche kardiovaskulare Anomalien bei den transgenen Mäusen aufzudecken, wurde weiterhin eine detaillierte Untersuchung der Herzklappen vorgenommen. Eine Veränderung konnte dabei bei allen untersuchten Transgenen und der WT-FVB-Maus nicht festgestellt werden.
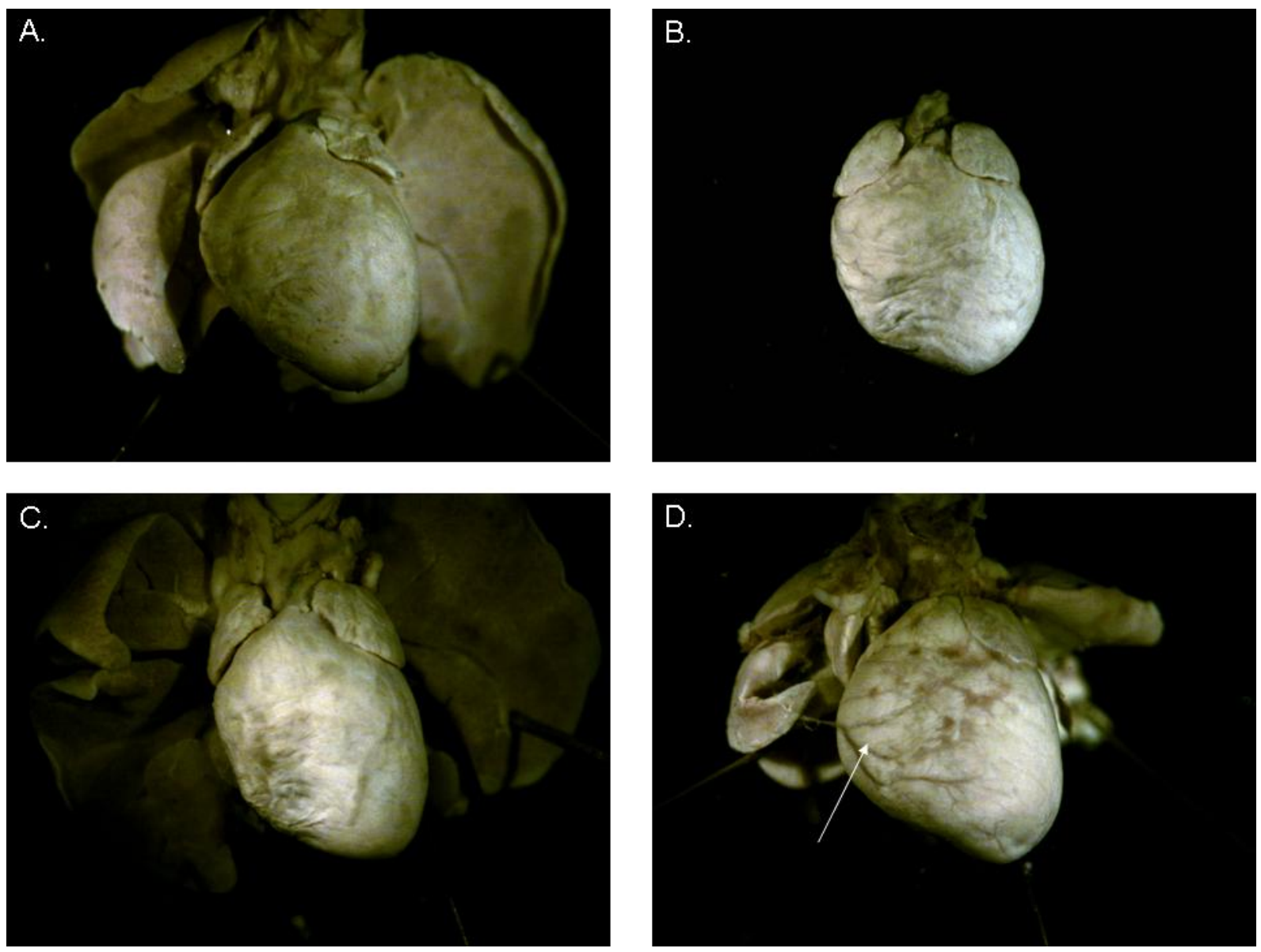

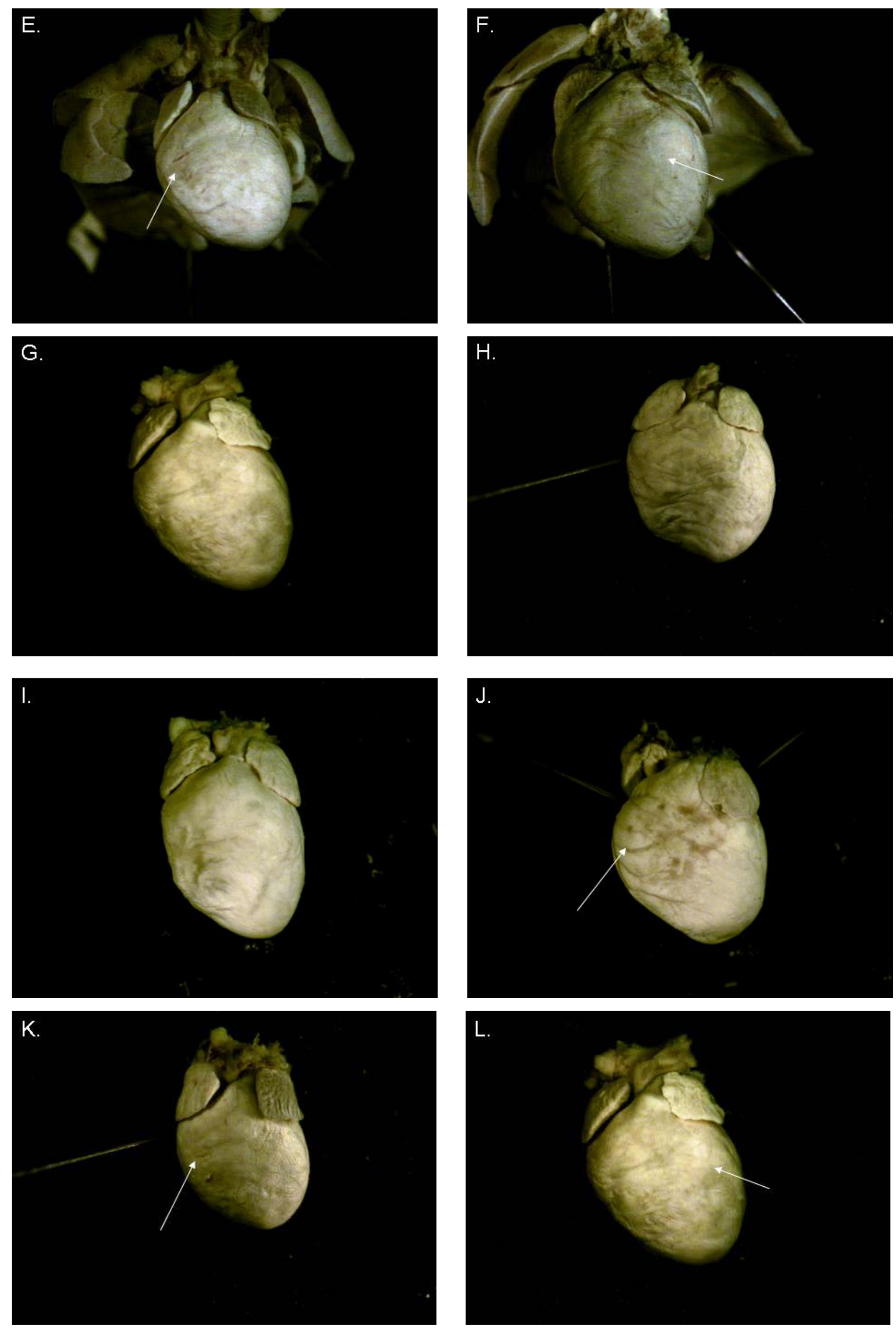
Abb. 3.33. Makroskopische Untersuchung des Herzes. Dargestellt ist das fixierte Herz mit Lunge (A.-F.) bzw. ohne Lunge (G.-L.) jeweils einer Maus der Linien NS1\#16 (B./H.), NS1\#21 (C./I.), NS2\#25 (D./J.), NS2\#401 (E./K.), NS2\#402 (F./L.) und WT-FVB (A./G.). 


\section{Diskussion}

\subsection{Zusammenfassung der Ergebnisse}

Im ersten Teil der vorliegenden Arbeit wurde der PTPN11-Promotor untersucht. Zunächst wurde der Promotor-Bereich auf ca. 300 bp vor dem Translationsstartkodon ATG durch Computerprogramme eingegrenzt und mit Hilfe eines Promotor-Luciferase-Assays bestätigt. Weiterhin wurden die Bindungsstellen für die Transkriptionsfaktoren SP1, CREB und STAT mittels EMSA identifiziert.

Im zweiten Teil der Arbeit wurde nach großen Deletionen im PTPN11-Gen von NS-Patienten gesucht. Dazu wurden bei 42 NS-Patienten, bei denen in der Sequenzierung keine Mutation gefunden wurde, Taqman-Analysen für zwei Amplikons vorgenommen. Drei Patienten erschienen auffällig und wurden weiter untersucht. Bei keinem dieser Patienten konnte die vermutete Deletion durch eine unabhängige Methode (longrange PCR oder Southern BlotAnalyse) bestätigt werden.

Im dritten Teil der Arbeit wurden die Auswirkungen der Mutationen in PTPN11 auf die Aktivität von SHP2 ermittelt. Mit Hilfe eines Promoter/Reporter-Assays, der auf der Phosphatase-Aktivität von SHP2 und der STAT1-abhängigen Expression von SOCS-1 beruht, wurde die Aktivität des WT-SHP2 und verschiedener Mutanten bestimmt und dabei eine Überaktivität von SHP2-Varianten gezeigt.

Es wurde versucht, mit Hilfe von siRNA eine allelspezische Repression einer Mutante zu erreichen. Dies gelang nicht.

Der vierte Teil der Arbeit befasst sich mit der Generierung eines transgenen Mausmodells für das NS. Es wurden drei Konstrukte mit verschiedenen SHP2-Mutationen hergestellt. Vor der Injektion der Konstrukte in befruchtete Eizellen wurden die Expression und die Funktionalität der Konstrukte in vitro getestet. Nach einer Kopienzahlbestimmung wurden drei Mäuse pro Konstrukt zur weiteren Verpaarung mit Wildtyp-FVB-Mäusen ausgewählt. Um einen Hinweis auf den Phänotyp zu erhalten, wurden die Wurfgröße und die Anzahl homozygoter transgener Tiere bestimmt. Weiterhin wurde eine makroskopische Untersuchung des Herzens durchgeführt. Hierbei wurde eine leichte Vergrößerung des rechten Ventrikel bei NS2\#25 und NS2\#401 und eine leichte Vergrößerung des linken Ventrikels bei NS2\#402 beobachtet. 


\subsection{SHP2: Signalwege und biologische Funktionen}

Zelluläre Aktivitäten werden durch extrazelluläre Signale und intrazelluläre Signaltransduktionswege reguliert. Prozesse wie Zellproliferation, -differenzierung, -migration, -metabolismus, Adhäsion und Apoptose gehören zu den auf diese Weise regulierten Mechanismen.

Liganden in löslicher oder auch gebundener Form leiten durch ihre Bindung an spezifische Zelloberflächenrezeptoren intrazelluläre Signalweiterleitungskaskaden ein und regulieren so die Genexpression und die davon abhängigen physiologischen und biochemischen Prozesse. Eine der Hauptklassen dieser Zelloberflächenrezeptoren bilden die Gruppe der IL (Interleukin)-6-Typ Zytokine, die über die Rezeptoruntereinheit gp130 wirken, und die Rezeptortyrosinkinasen (RTKs), deren intrinsische Tyrosinkinaseaktivität äußerst bedeutend für die Signalübertragung extrazellulärer Stimuli in die Zelle ist. Extrazelluläre Signale werden sowohl von transmembranständigen als auch zytoplasmatischen Tyrosinkinasen durch die Phosphorylierung einer Vielzahl zellulärer Substrate bis zum Zellkern weitergeleitet.

Proteine können durch Phosphorylierung mittels Proteintyrosinkinasen (PTK) und Dephosphorylierung mittels Proteintyrosinphosphatasen (PTP) aktiviert bzw. deaktiviert werden. SHP2 ist eine PTP, die ubiquitär exprimiert ist, und steht in Verbindung mit verschiedenen Signalwegen als Antwort sowohl bei Wachstumsfaktoren, z.B. PDGF (plateletderived growth factor), EGF (epidermal growth factor), FGF (fibrobalst growth factor) und IGF-1 (insulin-like growth factor I ), als auch bei Zytokinen (IL-3 und EPO (erytropoietin)), Insulin und IFN (interferon).

NS wird in 40-50\% der Fälle durch Mutationen im PTPN11-Gen, das SHP2 kodiert, verursacht. Mutationen in PTPN11 verändern die Konformation von SHP2 und ihre Phosphatase-Aktivität, und das führt zur Veränderung der Signalwege, die von SHP2 reguliert werden. Um einen Zusammenhang der intrazellulären Signalskaskaden aufzuzeigen, wird in diesem Absatz ein Überblick vorgestellt.

\subsubsection{Gruppe der IL-6-Typ-Zytokine}

Die Gruppe der IL (Interleukin)-6-Typ-Zytokine besteht aus IL-6, IL-10, IL-11, IL-12, LIF (leukemia inhibitory factor), OSM (oncostatin M), CNTF (ciliary neurotrophic factor), CT-1 (cardiotrophon-1) und CLC (cardiotrophon like cytokine), EPO, G-CSG (granulocyte colonystimulating factor), GH (growth hormone), Prolactin, $\alpha / \beta$ IFN und Leptin. Die 
Ligandenbindung aktiviert Signalkaskaden, die eine Änderung der Genexpression und darüber die Differenzierung, Apoptose, Proliferation und Migration der Zellen induzieren können. IL-6-Typ-Zytokine signalisieren über die Rezeptoruntereinheit gp130. Die Signaltransduktion führt zur Aktivierung der Jak (Janus-Kinase)-Tyrosinkinase, die die Tyrosine des zytoplasmatischen Teils von gp130 phosphoryliert. Diese Phosphotyrosine dienen anschließend als Rekrutierungsstellen für Transkriptionsfaktoren der STAT-Familie und anderer an der Signaltransduktion beteiligter Proteine, wie SHP2 und SOCS, die alle über ihre spezifischen SH2-Domänen und Phosphotyrosine binden. Nach der Tyrosinphosphorylierung von gp130 und Rekrutierung von SHP2 an das Tyr ${ }^{759}$ von gp130 wird ein weiterer Signaltransduktionsweg aktiviert, der Ras/Raf/MAPK-Weg [Heinrich et al., 2003].

\subsection{2 gp130}

Rezeptoren, die IL-6-Typ-Zytokine erkennen, sind in non-signalling spezifische $\alpha$-Rezeptoren (IL-6R $\alpha$, IL-11R $\alpha$ und CNTFR $\alpha$ ) und signalling Rezeptoren (gp130, LIFR uns OSMR) unterteilt [Heinrich et al., 1998; Ishihara et al., 2002].

IL-6, IL-11 und CNTF binden zuerst an non-signalling spezifische $\alpha$-Rezeptoren und das führt zur ligandeninduzierten Dimerisierung von gp130 als Homo- (IL-6 und IL-11) oder Heterodimer (CNTF). Der Rest der IL-6-Typ-Zytokine bindet an das gp130/LIFR Heterodimer (LID, CR-1 und CLC) oder an das Heterodimer gp130/OSMR (OSM) (Abb. 4.1, $4.2)$.

Obwohl gp130 ubiquitär exprimiert wird, ist die Wirkung der IL-6-Typ-Zytokine aufgrund der limitierten Expression anderer Rezeptoren, wie z.B. der $\alpha$-Rezeptoren, begrenzt.

\section{IL-6}

\begin{tabular}{|l|l|l|l|l|}
\hline$\alpha \mathrm{A}$ & $\mathrm{aB}$ & $\mathrm{aC}$ & $\mathrm{\alpha D}$ \\
\hline
\end{tabular}
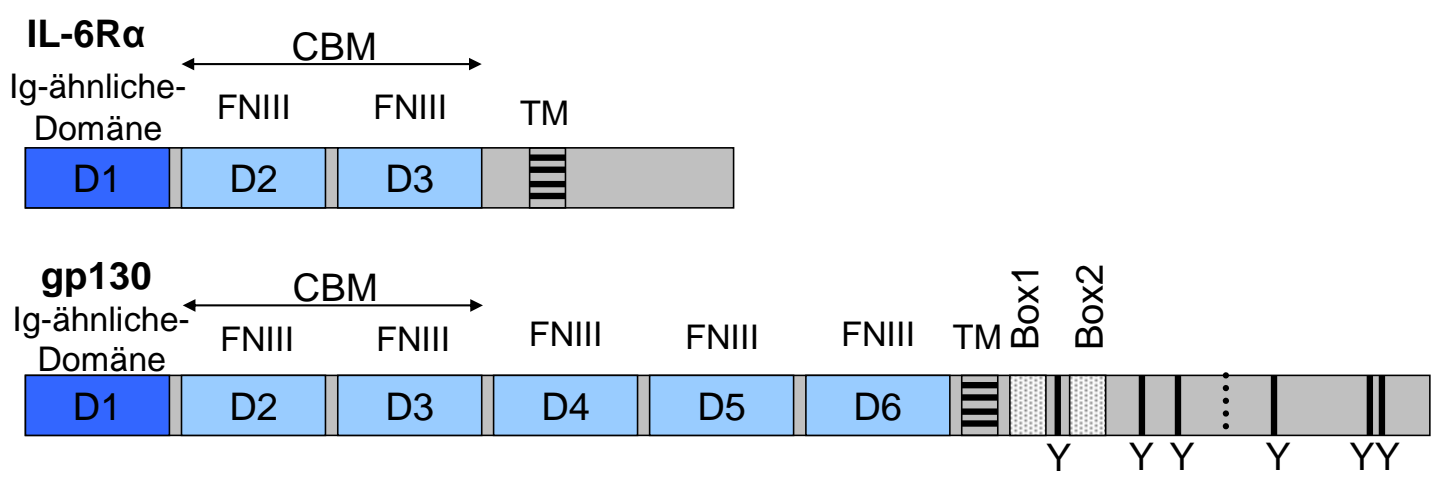
Abb. 4.1: Die Strukturen von IL-6, IL6Ra, gp130 [Heinrich et al., 2003]. Abkürzung: FNIII: Fibronectin type III; CMB: Cytokine Binding Module.
gp130/gp130
LIFR/gp130
OSMR/gp130

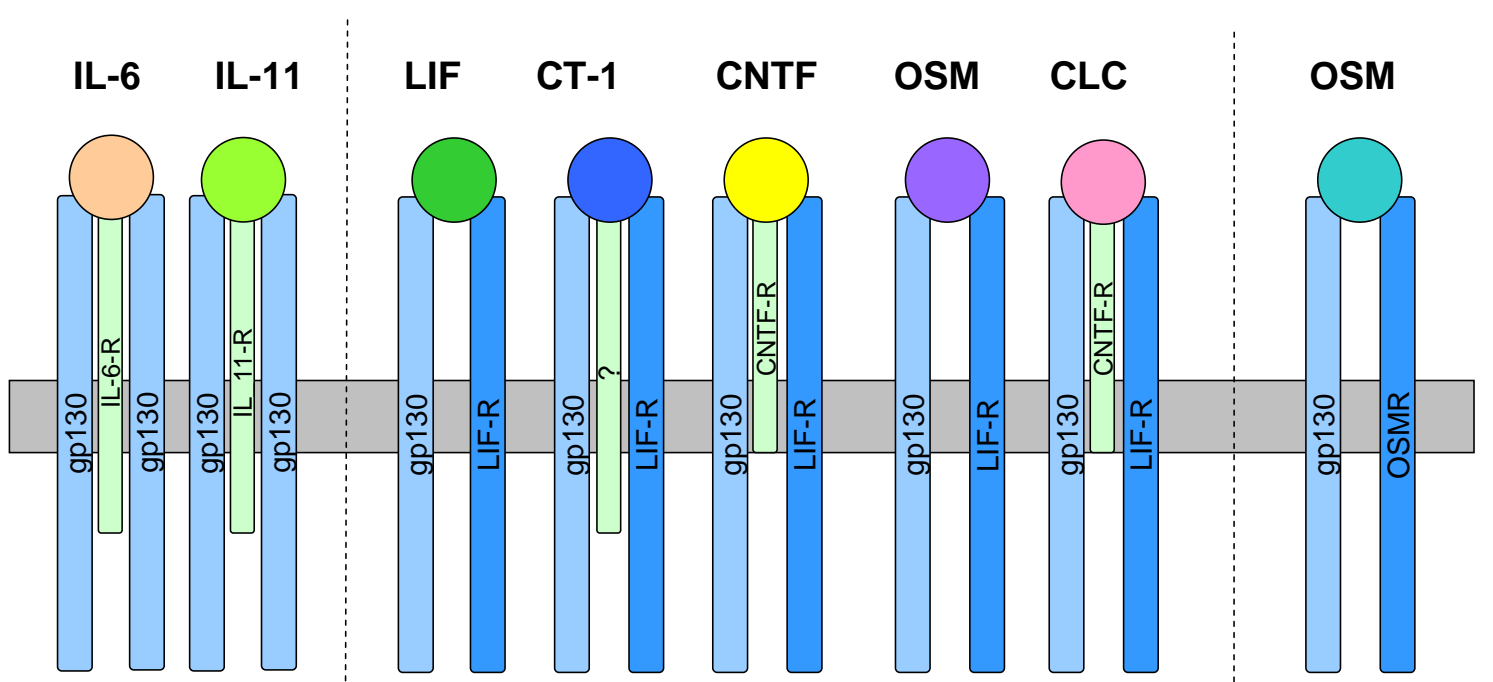

Abb. 4.2: Schematische Darstellung der IL-6-Typ-Zytokine und ihrer Rezeptorkomplexe [Heinrich et al., 2003]. IL-6-Typ-Zytokine signalisieren über die Rezeptoruntereinheit gp130 als Homo- (IL-6 und IL-11) oder Heterodimer mit LIFR (LIF, CT-1, CNTF, OSM und CLC) oder OSMR (OSM). Abkürzung: IL: Interleukin; LIF: leukemia inhibitory factor; OSM: oncostatin M; CNTF: ciliary neutrophic factor; CT-1: cardiotrophon-1: CLC: cardiotrophon like cytokine.

\subsubsection{Rezeptortyrosinkinasen (RTKs)}

Die Proteintyrosinkinasen werden in zwei Gruppen eingeteilt: Die erste Gruppe stellt die zytosolischen Tyrosinkinasen dar, die sich ausschließlich im Zytoplasma befinden (SRC- und Jak-Familie (4.2.1.2)) und dort mit Proteinen, die an der Zellmembran lokalisiert sind, reagieren. Die zweite Gruppe umfasst Transmembranproteine, die sog. Rezeptortyrosinkinasen (RTK). Unter den RTKs finden sich EGFR (epidermal growth factor receptor), PDGFR (platelet-derived growth factor receptor), FGF (fibrobalst growth factor), IR (insulin receptor), HGFR (hepytocyte gowth factor receptor), NGFR (nerve gowth factor receptor) [Schlessinger, 2000]. Der erste Schritt der Signalübertragung durch RTKs ist die Bindung des jeweiligen Liganden an seinen Rezeptor. Der Liganden-induzierten Konformationsänderung folgt in der Regel eine Dimerisierung zweier Rezeptormonomere, wodurch die Transphosphorylierung zytoplasmatischer Tyrosinreste durch die intrinsische Tyrosinkinase-Aktivität ermöglicht wird [Chatterjee-Kishore et al., 2000]. Die Phosphotyrosine wirken als Bindungsmotiv von SH2- oder PTB (Phosphotyrosine Bindungs)- 
Domänen der Signalproteine. Proteine, die eine SH2-Domäne besitzen, haben meistens eine intrinsische Aktivität, wie z.B. PTK-Aktivität (Src-Kinase), PTP-Aktivität (SHP2), Phospholipase C-Aktivität (PLC $\gamma$ ) oder Ras-Gap-Aktivität. Andere Proteine, die SH2- oder SH3-Domänen besitzen, verwenden diese Domänen als Adapter wie, z.B. Grb2, das als Adapter zum Ras/MAPK-Signalweg fungiert.

\subsubsection{Der Jak/STAT-Signaltransduktionsweg}

Nach der Ligandenbindung an seinen IL-6-Typ-Zytokinrezeptor kommt es zur Assoziation mit gp130. Im Gegensatz zu Rezeptortyrosinkinasen besitzt gp130 keine eigene KinaseDomäne. Dafür sind sog. Janus-Kinasen an die zytoplasmatische Domäne von gp130 assoziiert, von denen vier bekannt sind: Jak1, Jak2, Jak3 und Tyk2 (Abb. 4.3). Janus-Kinasen interagieren mit den konservierten Membran-proximalen Box1/Box2-Regionen der ZytokinRezeptoren [Tanner et al., 1995; Pellegrini et al., 1997]. Dabei sind die prolinreiche Box1 wie auch die Interbox1-2 wichtig für die Rezeptorbindung der Jaks. Die Mutation Trp ${ }^{666}$ in gp130 verhindert die Bindung mit Jak, und das führt zu einer Inaktivierung des Rezeptors [Murakami et al., 1991; Haan et al., 2000]. Die an hydrophoben Aminosäuren reiche Box2 erhöht die Affinität der Bindungspartner zueinander [Haan et al., 2002].

Nachdem der initiale Schritt der IL-6-Signaltransduktion eine Aktivierung der Janus-Kinasen durch gegenseitige Phosphorylierung bedingt, phosphorylieren diese fünf intrazellulären Tyrosin-Reste $\left(\mathrm{Tyr}^{683}, \mathrm{Tyr}^{759}, \mathrm{Tyr}^{767}, \mathrm{Tyr}^{814}, \mathrm{Tyr}^{905}, \mathrm{Tyr}^{915}\right.$ ) der signaltransduzierenden Rezeptoruntereinheit gp130. Die einzelnen Tyrosine scheinen unterschiedliche Signale im Zellinneren zu generieren und für verschiedene Aufgaben zuständig zu sein [Schmitz et al., 2000]. STAT (signal transducer and activator of transcription) beschreibt die Funktion dieser Transkriptionsfaktoren als Bindeglied in der Zytokin-Signaltransduktion (Abb. 4.5). Sie können mit ihrer SH2-Domäne an Phosphotyrosin-Reste von gp130 binden. Dabei bindet STAT3 spezifisch an die Phosphotyrosin-Reste $\operatorname{Tyr}^{767}$ und $\mathrm{Tyr}^{814}$. Die Phosphotyrosin-Reste $\mathrm{Tyr}^{905}$ und Tyr ${ }^{915}$ können sowohl von STAT3, als auch von STAT1 gebunden werden [Stahl et al., 1995; Hemmann et al., 1996]. Nach Phosphorylierung von $\mathrm{Tyr}^{701}$ in STAT1 bzw. $\mathrm{Tyr}^{705}$ in STAT3 vermittelt die STAT coiled-coil-Domäne die Bildung von Homo- oder Heterodimere. STAT kann auch an Phosphotyrosin-Reste von RTKs binden und durch die intrinsische Tyrosin-Aktivität der RTKs phosphoryliert werden [Herrington et al., 2000; Bowman et al., 2000]. 
Die STAT-Dimere binden an IL-6-responsive enhancer in den Promotoren von IL-6Zielgenen und regulieren somit deren Transkription (Abb. 4.5). Zu den Zielgenen von IL-6 zählen unter anderem APP (acute phase protein)-Gene wie CRP (C-reaktives Protein), $\alpha_{2} \mathrm{M}$ ( $\alpha_{2}-$ Makroglobulin), TIMP (tissue inhibitor of metalloproteinases), Gene der Transkriptionsfaktoren Jun B, AP1, aber auch andere Gene wie hsp90 (heat shock protein 90) oder gp130 [Heinrich et al., 1998].

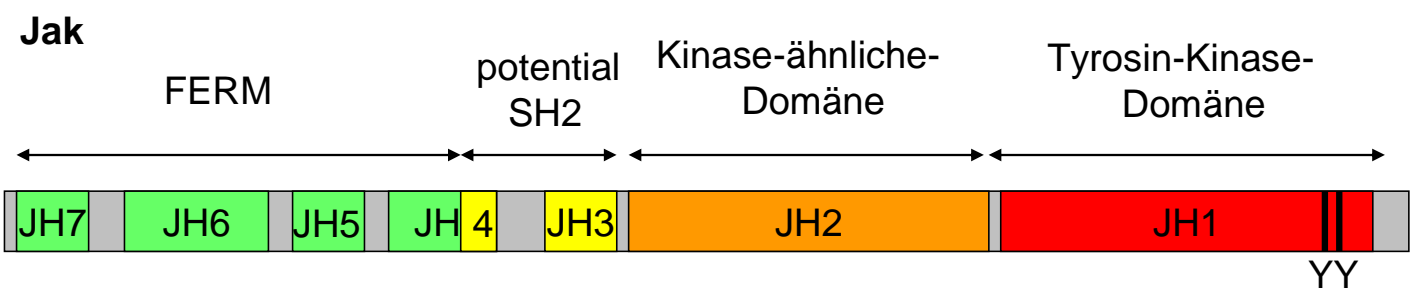

\section{STAT}

\begin{tabular}{|c|c|c|c|c||c|}
\hline N-terminal & Colied-coil-Domäne & $\begin{array}{c}\text { DNA-Bindungs- } \\
\text { Domäne }\end{array}$ & linker & SH2 & \\
\hline \multicolumn{4}{c}{ YS }
\end{tabular}

Abb. 4.3: Jak- und STAT- Struktur [Heinrich et al., 2003]. Für die Aktivierung der Proteine wichtige Tyrosin- und Serinreste sind markiert. Abkürzung: JH: Janus-Homologie-Region; SH2: Src-HomologieDomäne).

\subsubsection{Die Ras/Raf/MAPK-Kaskade}

Nach Tyrosinphosphorylierung von gp130 und Rekrutierung von SHP2 an das $\operatorname{Tyr}^{759}$ oder von RTK und Rekrutierung der SH2-Domäne von Proteinadaptern wird ein weiterer Signaltransduktionsweg aktiviert, der Ras/Raf/MAPK (mitogen activated protein kinase)Weg. Es handelt sich hierbei um eine Kaskade hintereinander geschalteter Proteinkinasen, die an der Regulation von Wachstums- und Differenzierungsreaktionen beteiligt sind. Phosphorylierte Adapter-Proteine wie SHP2 oder Shc binden Grb2 (growth factor receptor bound protein 2), welches mit dem Guanin-Nukleotid-Austauschfaktor SOS (son of sevenless) über SH3-Domänen assoziiert ist. Hierdurch wird SOS in die Nähe der Plasmamembran transloziert und überführt das membrangebundene GDP-Ras in seinen aktivierten Zustand GTP-Ras. Ras aktiviert die Serin/Threonin-Kinase Raf-1 (Abb. 4.5). Über eine Kaskade von Ser/Thr/Tyr-Kinasen (MAPKK, z.B: MEK1 (MAPK/ERK)) und Ser/ThrKinasen (MAPK, z.B. ERK1/2) werden eine Reihe von Transkriptionsfaktoren wie NF-IL-6 und AP1 aktiviert, die zur Expression von Ras-induzierbaren Genen führen [Heirnich et al., 
1998; Senaldi et al., 1999]. Gab1 (Grb2-associated binder-1) ist auch in der Ras/Raf/MAPKKaskade beteiligt. Gab1 bindet an Membranen durch die PH (Pleckstrin homology)- Domäne und an Gbr2, SHP2, PI3K (phosphotidylinositol 3 kinase). SHP2 bindet an Tyr ${ }^{627}$ und $\mathrm{Tyr}^{659}$ von Gab1 [Cunnick et al., 2001], und das führt zur MEK1- und ERK2 -Aktivierung [Cunnick et al., 2001].

PI3K enthält die regulatorische Subdomäne p85 und die katalytische Subdomäne p110. Die Aktivierung der IL-6-Typ-Zytokine fördert die Interaktion zwischen p110 und p85 von PI3K [Chung et al., 2000]. PI3K reguliert Ser/Thr-Kinasen wie PDK-1 (phosphoinositol-dependent kinase), AKT und die Isoform PKC (protein kinase C). AKT wird phosphoryliert und das führt zur Regulierung von pro-apoptotischen Proteinen (Bad (Bcl-2/Bcl- $\mathrm{X}_{\mathrm{L}}$-antagonist) und FKHR (forkhead Transkriptionsfaktoren) und daher zum Überleben und der Proliferation der Zellen [Negoro et al., 2001]. IL-6 führt zur Aktivierung der PI3K/AKT-Signalwege, die sowohl gegen Apoptose schützen als auch in multiple myeloma cells die Proliferation positiv beeinflussen [Shi et al., 2002].

\subsubsection{Abschaltmechanismen der IL-6-Signaltransduktion und RTK}

Um eine Überstimulierung zu vermeiden, existieren feedback Mechanismen wie die Dephosphorylierung von Signal-Proteinen durch zytoplasmatische Phosphatasen oder die Synthese intrazellulärer Inhibitoren.

\subsubsection{Proteintyrosinphosphatasen}

Als Proteintyrosinphosphatasen, die die IL-6-Typ Zytokine regulieren, finden sich SHP2 und

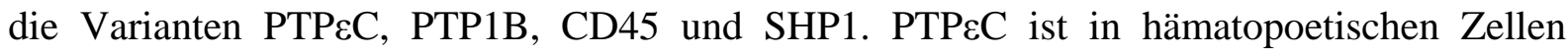
exprimiert und hemmt die Aktivierung der IL-6-induzierten gp130, Jak und STAT [Tanuma et al., 2000 und 2001]. PTP1B, CD45 und SHP1 regulieren die Jak- und STAT-Aktivierung [Shuai et al., 2003]. SHP2 ist ein ubiquitär exprimiertes Protein, welches bei der Signaltransduktion von Zytokinen und Wachtumsfaktoren eine wichtige Rolle spielt. SHP2 enthält zwei SH2-Domänen (N-SH2 und C-SH2) und eine katalytische Phosphatase-Domäne (PTP) (Abb. 4.4). In Abwesenheit von phosphorylierten Tyrosinen der Bindungspartner blockiert N-SH2 die PTP-Domäne. Wenn N-SH2 an die Phosphotyrosine der Rezeptoren oder Bindungspartner bindet, ist die PTP-Domäne frei und aktiv. SHP2 bindet an das phosphorylierte Tyr $^{759}$ von gp130 (die auch SOCS-3 binden kann, aber nicht SOCS-1), und 
hat eine positive Wirkung auf den Ras/MAPK-Signalweg [Schmitz et al., 2003]. SHP2 bindet auch an $\mathrm{Tyr}^{627}$ und $\mathrm{Tyr}^{659}$ von Gab1, die nach Zytokinstimulierung phosphoryliert sind. SHP2 und Gab1 regulieren den MAPK/PI3K-Signalweg. Außerdem hemmt SHP2 den Jak/STATSignalweg durch Dephosphorylierung von STAT (Abb. 4.5).

Unklar ist, welche der vielen Signalwege zu einem NS führen. Das Costello-Syndrom ist ein Fehlbildungssyndrom mit Ähnlichkeiten zum NS. Mutationen im HRas-Gen wurden bei 13 Patienten mit Costello-Syndrom festgestellt. HRas aktiviert den MAPK- und PI3K-Signalweg [Aoki et al., 2005]. Daher könnte für NS die Aktivierung des Ras/MAPK-Signalwegs ebenfalls wichtig sein.

\section{SHP2}

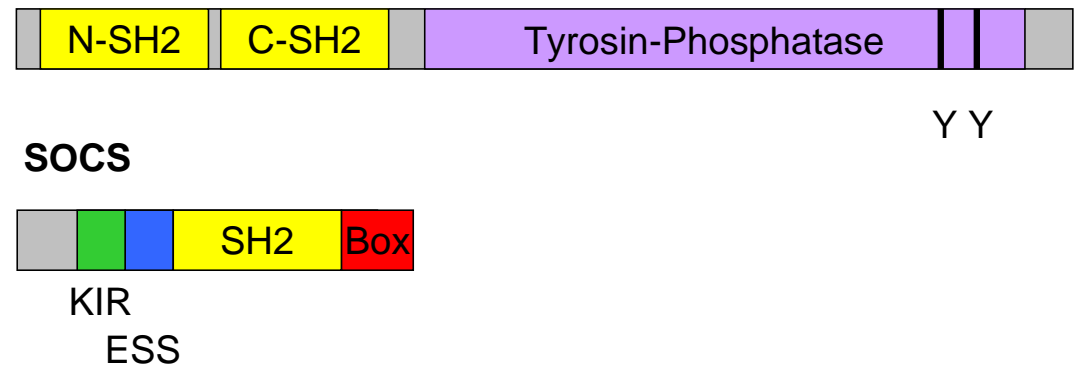

Abb 4.4: Domänenstruktur von der Tyrosin-Phosphatase SHP2 und den SOCS-Proteinen[Heinrich et al., 2003]. Abkürzung: SH2: Src-Homologie-Domäne; KIR: Kinase-Inhibitions-Region; ESS: extended SH2Subdomäne.

\subsubsection{Intrazelluläre Inhibitoren: SOCS}

Die SOCS-Proteine bilden eine weitere Familie von Inhibitoren der ZytokinSignaltransduktion. Sie wurden unabhängig voneinander durch verschiedene Arbeitsgruppen entdeckt, wodurch eine Vielzahl von Bezeichnungen wie SOCS (suppressors of cytokine signaling), JAB (Jak-binding protein), SSI (STAT-induced STAT inhibitor) und CIS (cytokineinducible SH2 containing proteins) entstanden ist [Starr et al., 1997; Endo et al., 1997; Naka et al., 1997]. Die Familie der SOCS-Proteine zählt zurzeit acht Mitglieder (CIS, SOCS-1SOCS-7), die sich durch einen variablen N-Terminus, eine zentrale SH2-Domäne und eine konservierte C-terminale SOCS-Box auszeichnen (Abb. 4.4) [Hilton et al., 1998].

Den SOCS-Proteinen ist die Hemmung der Zytokin-Signaltransduktion durch einen feedback loop gemeinsam, der jedoch je nach Protein auf unterschiedlichen Mechanismen basiert: So konnte für SOCS-1 und SOCS-3 gezeigt werden, dass sie über ihre SH2-Domänen und die ESS (extended SH2-Subdomäne) mit dem Tyr ${ }^{1007}$ in der Kinasedomäne von Jak2 interagieren und die Kinaseaktivität inhibieren [Sasaki et al., 1999], wobei SOCS-3 eine geringere 
Affinität zu Jak2 aufweist. Ferner assoziiert SOCS-1 auch mit Jak1, Jak3 und Tyk2 [Yasukawa et al., 1999]. Seine KIR (kinase inhibitory region) blockiert als nichtphosphoryliertes Substrat das aktive Zentrum der Kinase.

Neben der Interaktion von SOCS-3 mit Jak2 zeigen neuere Studien auch Interaktionen von SOCS-3 mit SHP2 und mit dem phosphoryliertem Tyr $^{759}$ im gp130. Die Assoziation der SH2Domäne von SOCS-3 mit dem Phosphotyrosin 759 scheint für die inhibitorische Aktivität essentiell zu sein [Schmitz et al., 2000; Nicholson et al., 2000].

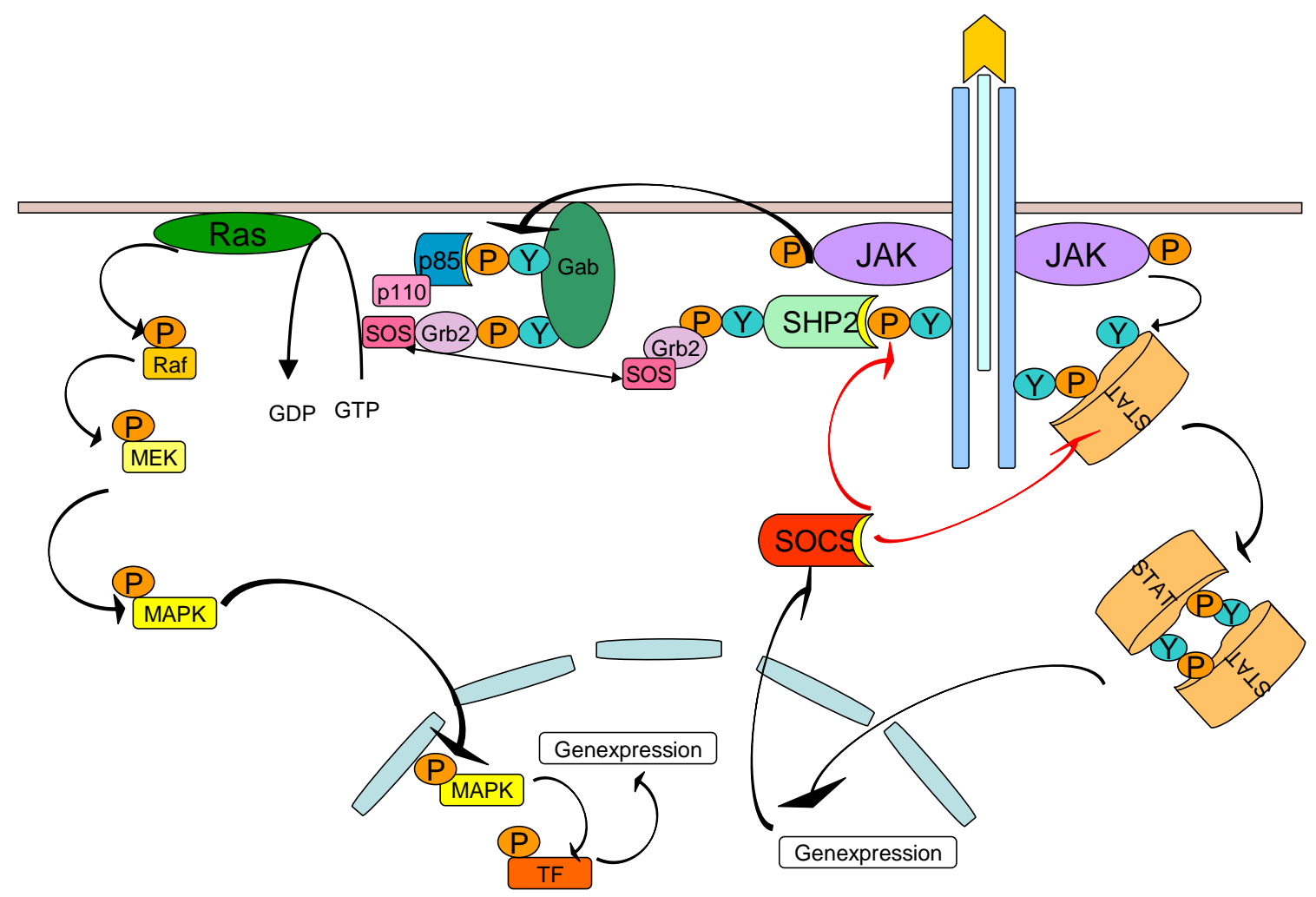

Abb. 4.5: Verschiedene Wege der IL-6-Signaltransduktion. Durch Liganden-induzierte Dimerisierung von gp130 erfolgt sowohl die Aktivierung des Jak/STAT-Signaltransduktionsweges als auch der Ras/Raf/MAPKinase-Kaskade. Schematische Darstellung der Negativregulation des IL-6-Signaltransduktionsweges durch SHP2 und SOCS.

\subsection{Protein-Tyrosinphosphatasen: Die Proteinfamilie}

Protein-Tyrosinphosphatasen (PTPs) und -kinasen (PTKs) wirken antagonistisch auf den Phosphorylierungsstatus von regulatorischen Proteinen (häufig Transkriptionsfaktoren) und steuern so Wachstum, Zelldifferenzierung, Apoptose u.v.m. Wenn es zu einer Störung der Balance zwischen PTPs and PTKs kommt, z.B. durch Deletion oder Mutation, resultiert dies in Erkrankungen wie z.B. Autoimmunität, Diabetes oder Krebs (Tab. 4.1). 


\begin{tabular}{ll}
\hline PTP & Krankheit \\
\hline PTPRC (CD45) & SCID \\
& Multiple Sklerose \\
PTPRN (IA-2) & Antigen für Autoimmun-Diabetes \\
PTPRN2 (phogrin) & Antigen für Autoimmun-Diabetes \\
PTPN1 (PTP1B) & Insulinresistenz, Fettleibigkeit \\
PTPN6 (SHP1) & Sezary-Syndrom \\
PTPN9 (PTP-MEG2) & Autismus \\
PTPN11 (SHP2) & Noonan-Syndrom \\
PTPN22 (LYP) & Einzelnukleotide Polymorphismus in Typ I-Diabetes \\
PTEN (PTEN) & Bannayan-Zonana \\
& Cowden-Syndrom und Lhermitte-Duclos-Erkrankung \\
MTM1 (myotubularin) & Myotubuläre Myopathie \\
MTMR2 (MTMR2) & Charcot-Marie-Tooth Typ 4B \\
MTMR13 (MTMR13) & Charcot-Marie-Tooth Typ 4B \\
EPM2A (laforin) & Progressive Myoclonusepilepsie (Ladora’s disease ) \\
ACP1 (LMPTP) & Polymorphismus assoziiert mit vielen häufigen Erkrankungen \\
\hline
\end{tabular}

Tab. 4.1:Beteiligung von PTPs in der Pathogenese menschlicher Krankheiten oder Krebs [Alonso et al., 2004].

PTPs können in zwei Gruppen unterteilt werden: in Tyrosin-spezifische und in dualspezifische (Dephosphorylierung der Tyrosin-, Serin- und Threonin-Reste) PTPs.

SHP2 wird zur Gruppe der Tyrosin-spezifischen PTPs zugeordnet. Diese Proteinfamilie wiederum teilt sich auf in die transmembranen, Rezeptor-ähnlichen Tyrosinphosphatasen (RPTP) und in die intrazellulären, Nichtrezeptor-PTPs (NRPTP). Die RPTPs enthalten zwei zytoplasmatische Domänen (eine membran-proximale Domäne (D1) und eine membrandistale Domäne (D2)), eine einzige Transmembrandomäne sowie eine extrazelluläre Domäne (Abb. 4.6). 


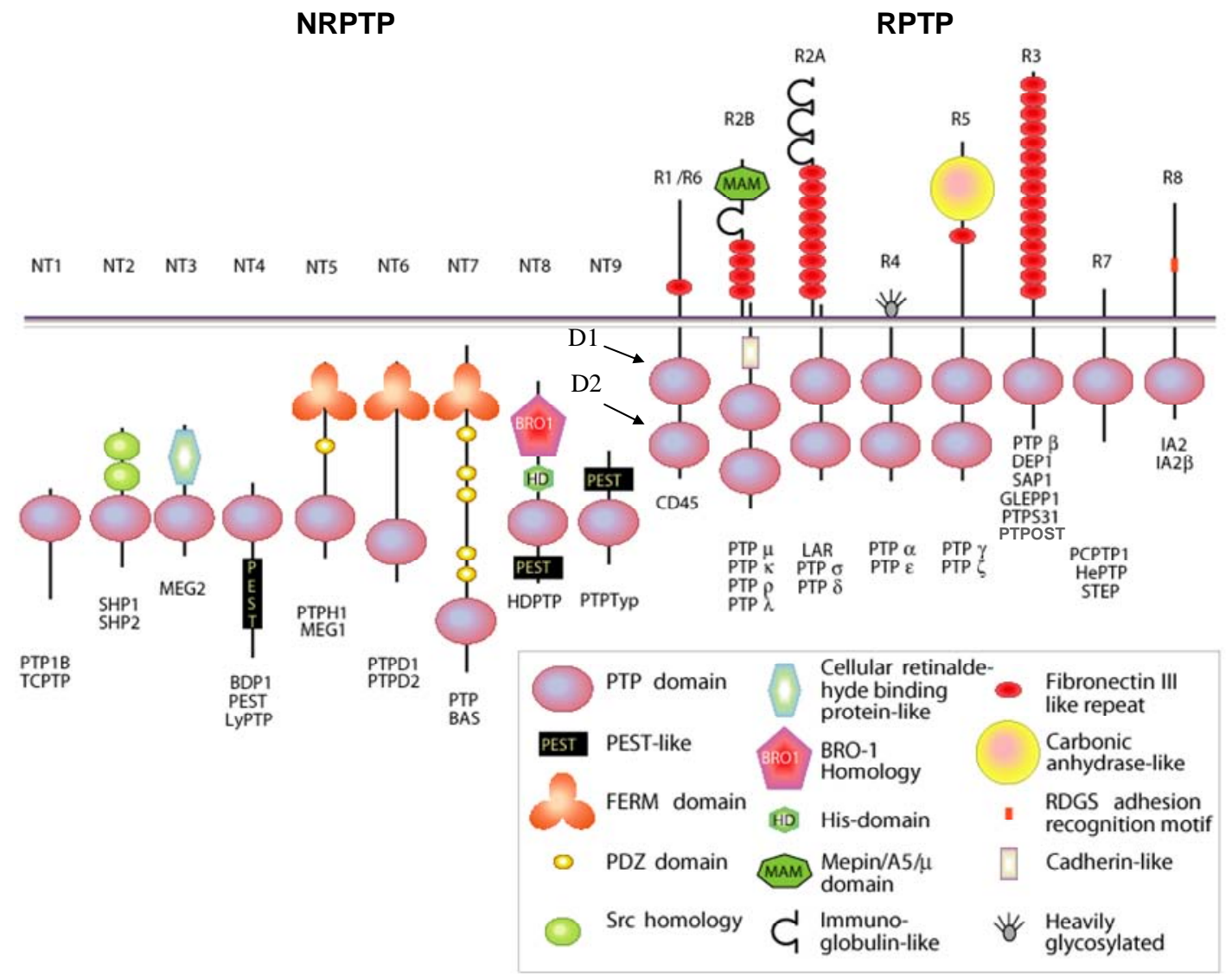

Abb. 4.6: Übersichtsdarstellung der Tyrosin-spezifischen PTPs [Andersen et al., 2004]. Mitglieder der PTP-Familie: neun NRPTP (NT) und acht RPTP (R) und ihre Domänenstruktur. Abkürzung: NRPTP: Nichtrezeptor-Protein-Tyrosinphosphatase; RPTP: Rezeptor-ähnliche Tyrosinphosphatasen; PTP: ProteinTyrosinphosphatase; D1: zytoplasmatische membran-proximale Domäne; D2: zytoplasmatische membran-distale Domäne.

Sowohl SHP1 als auch SHP2 sind auf dem Chromosom 12 lokalisiert und stellen damit die einzigen verwandten PTPs dar, die auf ein und demselben Chromosom liegen. TCPTP/PTP1B, PTPD1/PTPD2 und PTP $\alpha / P T P \varepsilon$ befinden sich jeweils auf verschiedenen Chromosomen (Abb. 4.7). PTPs befinden sich nicht auf den Chromosomen X, Y, 16, 17, 21 und 22. Die Chromosomen 5, 8, und 13 enthalten nur Pseudogene [Andersen et al., 2004]. 


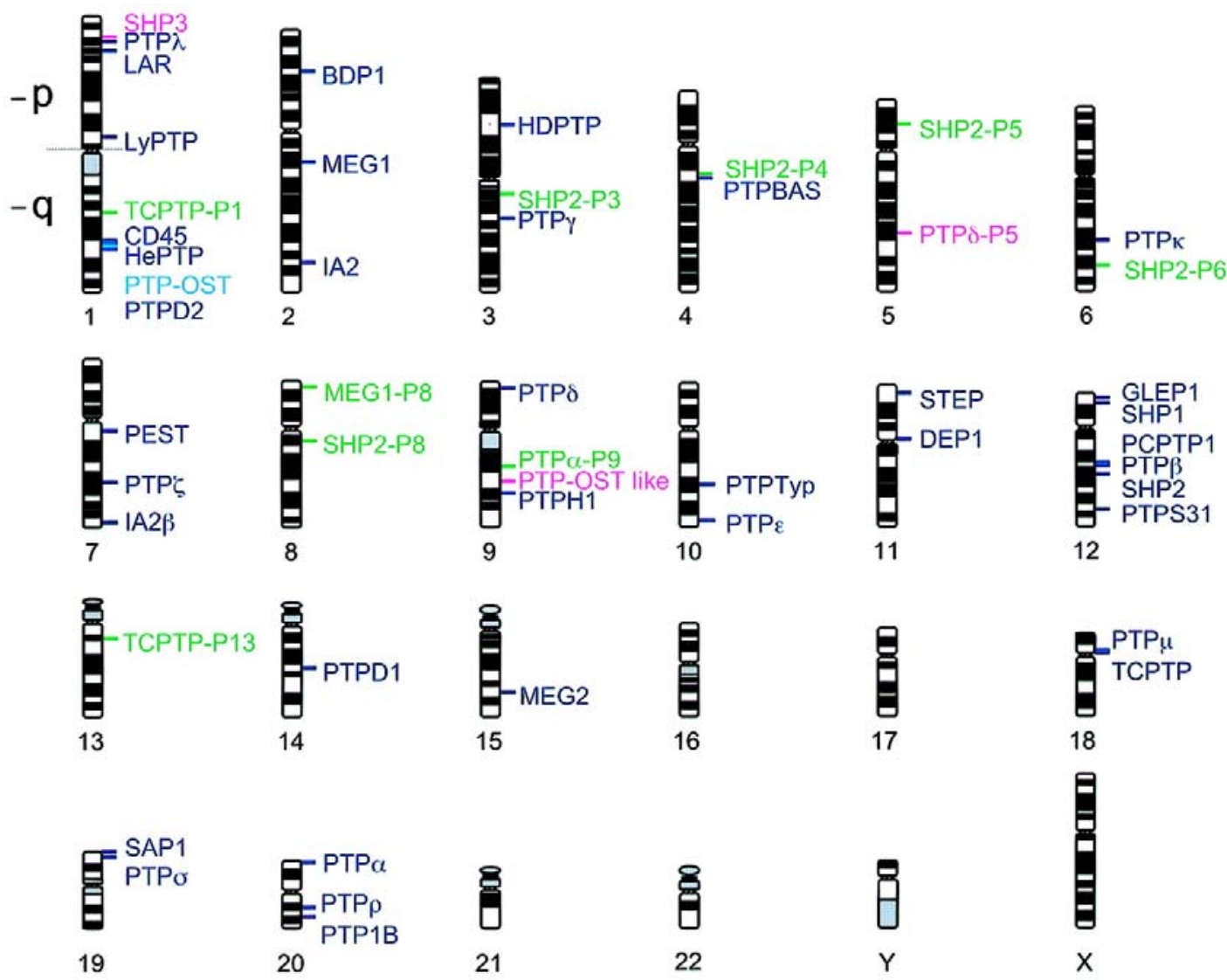

Abb. 4.7: Lokalisierung der Tyrosin-spezifischen PTPs im humanen Genom [Andersen et al., 2004]. PTPs im humanen Genom: Blau: Gene; Grün: Pseudogene ohne Intron-Sequenzen; Rosa: Pseudogene mit ersichtlicher Exon-Struktur. SHP1 und SHP2 sind auf dem Chromosom 12 lokalisiert.

Mittels ausführlicher in-silico Analyse von cDNA- und EST-Sequenzen und Abgleich mit der humanen genomischen Sequenz konnten Andersen et al. [2001, 2004] insgesamt 38 humane PTP kodierende Gene identifizieren. Die Analyse der Sequenzhomologie erlaubte die Einteilung in 17 Subtypen, darunter 8 RPTP- und 9 NPTP-Subtypen. Die 38 humanen PTPs dieser 17 Subtypen sind mit allen 38 orthologen murinen PTPs und mit 34 orthologen RattenPTPs als Dendogramm (phylogenetischer Baum) in Abbildung 4.8 gezeigt. Dieses Dendogram zeigt die paraloge und orthologe Verwandtschaft und die Übersicht der Symbole der PTP-Gene [Wain et al., 2002]. Von der HUGO-Nomenklatur abweichende, häufiger verwendete Namen der PTP-Proteine sind ebenfalls verzeichnet. 
0.1

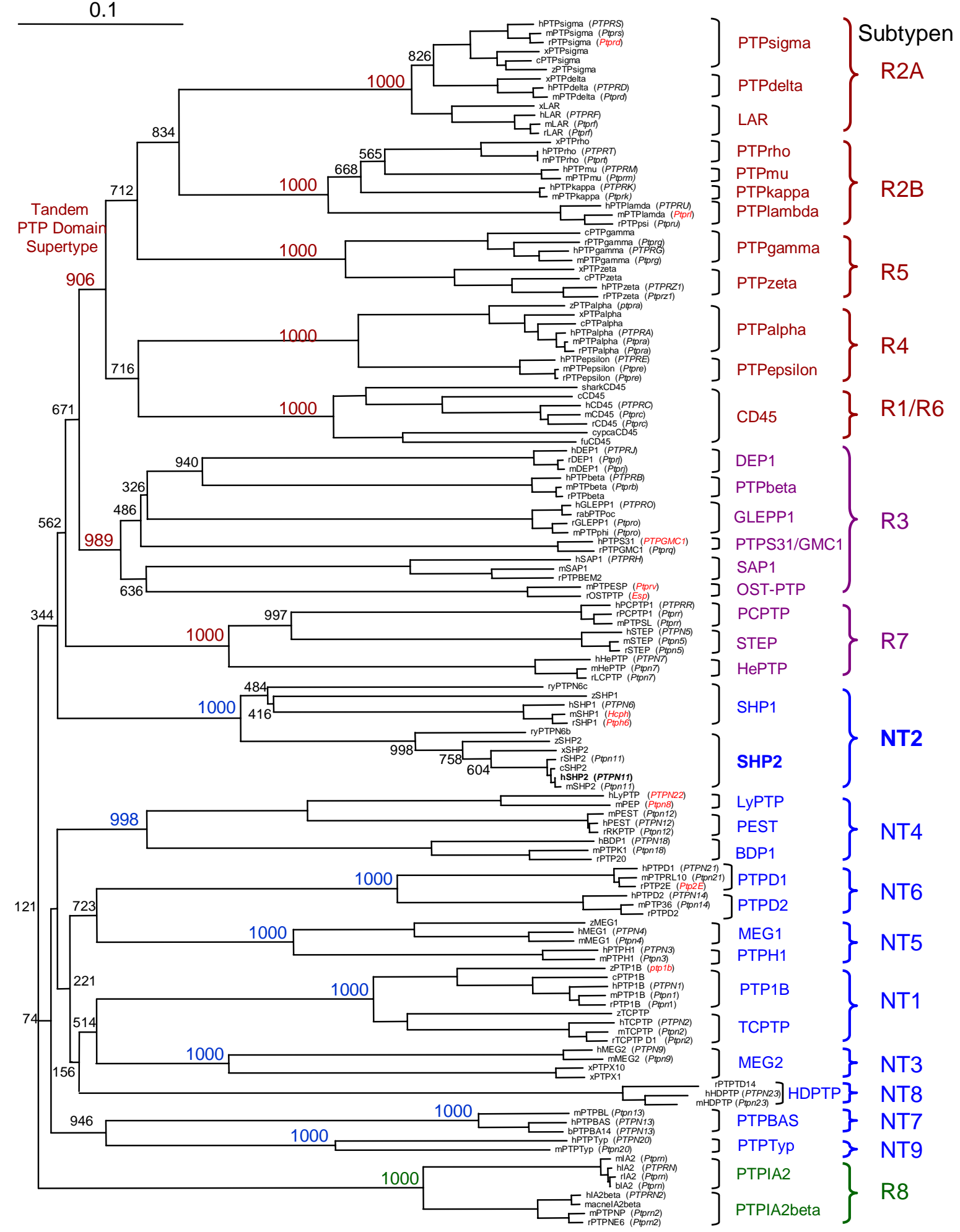

Abb. 4.8: Übersichtdarstellung der paralogen und orthologen Verwandtschaft der PTPs [Andersen et al.,

2004]. Der horizontale Abstand im Dendogram zeigt den Grad der Sequenzabweichung an (je größer der Abstand, desto mehr Divergenz). Die obere Skala stellt die Distanz äquivalent zu 10 Substitutionen pro 100 Aminosäuren dar. Die 17 PTP-Domänen sind in neun nichttransmembrane Subgruppen (NT1-NT9), fünf rezeptor-ähnliche Subgruppen (R1/R6-, R2A, R2B, R4, R5) und drei single domain receptor-like PTPSubgruppen (R3, R7 und R8) eingeteilt. Die inkonsistente Gen-Nomenklatur ist in rot gekennzeichnet. 


\subsubsection{Die 5'-untranslatierte Region des humanen und murinen PTPN11- Gens}

Funktionelle Charakterisierungen des Promotors bei Protein-Tyrosinphosphatasen wurden bislang für CD45 (Gen: PTPRC) [Bruyns et al., 1996], PTPع (Gen: PTPRE) [Tanuma et al., 1999] und PTP1B (Gen: PTPN1) [Olivier et al., 2004] durchgeführt. Im Rahmen dieser Arbeit wurde nun der PTPN11-Promotor näher charakterisiert und eingegrenzt. Zwei verschiedene Promotor-Alignments zwischen Maus/Mensch und Maus/Ratte zeigten ca. 300 bp mit einer 79\%igen Homologie bzw. ca. 500 bp mit 84\% Homologie. Nach Analyse des intergenischen Bereichs mittels Repeatmasker wurden mehr als 70\% repetitive Sequenzen in dieser Region festgestellt. Erst 473 bp bei der Maus und 570 bp beim Mensch vor dem Translationsstartkodon ATG beginnt eine single-copy-Sequenz.

In den meisten Genen erfolgt der Transkriptionsstart Gene an der sog. TATA-Box nach Bindung verschiedener Faktoren inklusive der RNA-Polymerase II. Diese TATA-Box weist eine relativ konservierte räumliche Lokalisation 25-30 bp upstream des Startkodons auf [Lewin, 2000]. Die in dieser Arbeit identifizierte Promotorregion enthält kein TATAähnliches Element und gehört damit zu den sog. TATA-losen Promotoren. Zu dieser Gruppe gehören nur wenige Gene, die z.B. für die normalen Zellfunktionen zuständig sind (z.B. sog. housekeeping-Gene und adrenerge Rezeptoren). Auch die Promotoren von CD45, PTP $\varepsilon$ und PTP1B gehören zu dieser Gruppe. In Abwesenheit der TATA- oder CAAT-Elemente im Promotor wurde der Transkriptionsstart mit SP1-Bindungsstellen und GC-reichen Regionen assoziiert [Scanga et al., 1998; Koga et al., 2005]. Bei dem Gen PTPRE, welches für die

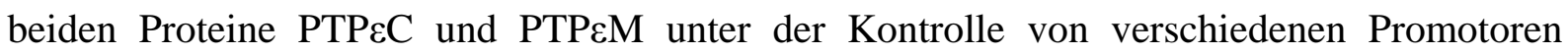
kodiert, wurden andere Cis-acting Elemente beschrieben, die den Promotor regulieren. Der Promotor, der zur Synthese der transmembranen Variante PTP\&M führt, enthält eine CAATBox und Bindungstellen für AP1, AP2 und c-myc. Der Promotor für die zytosolische Variante PTP\&C enthält die Transkriptionsinitiator-(Inr) Sequenz und Bindungstellen für Ap2, NF-IL6, PU.I, CPBP und SP1. Der Promotor von PTPN1 enthält eine p210 Bcr-Abl responsive sequence (PRS), die die Bindungstellen für Egf-1, SP1 und SP3 enthält, sowie eine enhancerSequenz, die die YB-1 Bindungstelle besitzt [Fukada et al., 2003].

Mit Hilfe von spezieller Software (3.1.1.2) und den EMSA-Experimenten wurden drei verschiedene Transkriptionsfaktoren, die den PTPN11-Promotor regulieren, identifiziert. Zwei SP1-Bindungstellen finden sich im Sequenzbereich -191/-229 von PTPN11. SP1 ist ein Transkriptionsfaktor, der sowohl ubiquitär als auch gewebespezifisch Gene reguliert [Zhou et 
al., 2001]. SP1 bindet den PIC (pre-initiation complex) an TATA-lose Promotoren durch die Interaktion mit einer Komponente von TFIID (Initiationskomplex) [Smale, 2001]. An der Position -284 von PTPN11 befindet sich die STAT- (signal transducer and activator of transcription) Bindungsstelle, die von homo- bzw. heterodimerem STAT gebunden werden kann [Horvath, 1997]. Die Interaktion STAT/SP1 (wenn STAT1 oder 3 sich im Kern befinden) ist ein zusätzliches Element für die Spezifität des Transkriptionsstarts [Look et al., 1995]. Weiterhin befindet sich an der Position -249 eine CREB- (cAMP responsive element binding protein) Bindungsstelle. CREB wurde in verschiedenen Geweben, wie z.B. in Kardiomyozyten [Fentzke et al., 2001], in testikulären Zellen [Fimia et al., 2001] und im neuronalen System [Mantamadiotis et al., 2002] als Regulator der Genexpression beschrieben und kann demnach für die gewebespezifische PTPN11-Transkription verantwortlich sein. Ein TATA-loser Promotor mit SP1, CREB und STAT als Transkriptionsfaktoren wurde auch bei Cardiotrophin-1 [Erdmann et al., 1998] und Maml1 [Wu et al., 2004] gefunden.

Um den endogenen Promotor von PTPN11 einzugrenzen, wurde ein Reporter-LuciferaseAssay durchgeführt. Verschiedene Längen ausgehend vom Transkriptionsstart oder vom ATG des murinen bzw. humanen PTPN11-Promotors wurden vor das Luciferasegen kloniert. Die Messung der Promotoraktivität erfolgte in NIH/3T3-Zellen. Die ca. 300 bp großen Konstrukte zeigten dabei die höchste Luciferase-Aktivität. Die größeren Konstrukte (>300 bp) zeigten eine Verminderung der Luciferase-Aktivität. Sie enthalten $80 \%$ repetitive Sequenzen, die methyliert sein können und angrenzende Promotoren inaktivieren können [Brahmachari et al., 1997]. Bei den kleineren Konstrukten ( $<300$ bp) zeigt das Fehlen von Bindungsstellen für die Transkriptionsfaktoren wie SP1, CREB und STAT, dass diese Konstrukte weniger Luciferase-Aktivität als 0,3Luc aufweisen. SP1-Bindungsstellen sind häufig in CpG-reichen Regionen vorhanden und stehen in einem direkten Zusammenhang mit der Hypomethylierung der CpG-Inseln, was in einer aktiven Form des Promotors resultiert [Butler et al., 2002]. Mutationen oder Deletionen der SP1-Bindungsstellen (wie z.B. bei hTAF ${ }_{\mathrm{II}} 55$ [Zhou et al., 2001] und CD99 [Lee et al., 2001] beschrieben) mindern die Promotoraktivität. Eine Mutation im UGT1A1-Gen-Promotor führt zum Gilbert-Meulengracht-Syndrom [Skarke et al., 2004]. Es war daher plausibel zu untersuchen, ob Mutationen im Promotorbereich des PTPN11-Gens über eine Fehlregulation der PTPN11-Transkription als mögliche Ursache von NS fungieren können. Daher wurde der humane PTPN11-Promotor bei 46 Patienten analysiert, die keine Mutation in der kodierenden Sequenz zeigten. Es wurden zwei verschiedene Sequenzvarianten (-174 G/C und -273 A/G) gefunden, die bei KontrollPersonen jedoch auch entdeckt wurden. Diese Sequenzvarianten enthalten zudem keine 
Bindungsstellen von Transkriptionsfaktoren. Aus diesem Grund wurde ausgeschlossen, dass die Sequenzvarianten eine Veränderung der PTPN11-Regulierung verursachen.

\subsection{Große Deletionen im PTPN11-Gen als Ursache für das Noonan-Syndrom?}

40-50\% der Patienten mit der klinischen Verdachtsdiagnose Noonan-Syndrom tragen eine Mutation im PTPN11-Gen. Zwei kleine Deletionen von 3 bp in Exon 3 wurden je bei einem Kind mit schwerem NS mit Hydrops fetalis und juveniler myelomonocytärer Leukämie (delG60 [Yoshida et al., 2004]) und bei einem Kind mit NS und schweren multiplen Herzanomalien (delD61 [Lee et al.; 2005]) beschrieben. Sowohl die Mutation delG60 als auch die Mutation del61D befinden sich in der N-SH2-Domäne, die für die Stabilität der inaktiven Konformation verantwortlich ist. Ansonsten wurden bisher keine nonsense, frameshift oder splicing Defekte in PTPN11 entdeckt. Da die Erhöhung der PhosphataseAktivität als Krankheitsursache angesehen werden muss [Tartaglia et al., 2003; Fragalle et al., 2004; Daten dieser Arbeit] erscheinen inaktivierende Mutationen (nonsense, framshift, Deletionen) als Ursache für NS sehr unwahrscheinlich, da diese einen Verlust der Funktion von SHP2 zur Folge hätten. Ein splicing-Defekt wäre aber denkbar, wenn das splice-Produkt den Leserahmen erhält und die katalytisch wichtigen Aminosäure-Reste der PTP-Domäne nicht negativ beeinflusst werden. Als mögliche Ursache für das NS könnten daher große in frame Deletionen vermutet werden, die ein gain of function von SHP2 bewirken würden. Ein Beispiel hierfür ist die autosomaldominante Hypokalzämie (ADH). ADH wird von missenseMutationen im CaSR (Calcin-sensing receptor)-Gen verursacht. Lienhardt et al. [2000] konnten eine Deletion von 181 AS am C-Terminus der CaSR beobachten, die dadurch ein gain of function des Rezeptors bewirkt.

Die kristallographischen Daten von SHP2 in der inaktiven Konformation zeigen eine komplexe Interdomäne mit Wasserstoffbrückenbindungen mit den Aminosäuren N58, G60, D61, Y62, A72 (Exon 3) und G464, C459, R465, G503 und Q506 (Exon 12 und 13) [Hof et al., 1998]. Diese Aminosäuren der N-SH2 bzw. katalytischen Domäne sind wichtig für die Stabilisierung des Proteins. Eine Deletion von Exon 3 und/oder 15 würde keinen verschobenen Leserahmen bewirken, sondern nur die Bindungsdomäne der N-SH2 deletieren, was zu einem Verlust der inaktiven Konformation und so möglicherweise zu einer Überaktivität von SHP2 und zu einem NS-Phänotyp führen würde. 
Im Rahmen dieser Arbeit wurden bei 42 Patienten zwei Amplikons, NS3 (Exon 3) und NS15 (Exon 15), mittels Taqman-Analyse auf Deletionen hin untersucht. Bei Patienten mit auffälligen Ergebnissen in dem Amplikon NS3 wurden zwei weitere Amplikons, die in Exon 2 (NS2) und 4 (NS4) liegen, überprüft. Bei drei Patienten (24633, 24640 und 24653) wurde eine putative Deletion in Exon 3 mit weiteren unabhängigen Methoden (longrange PCR und Southern Blot-Analyse) untersucht. Von diesen drei Patienten, die in der Taqman-Analyse Auffälligkeiten zeigten, stellten sich zwei Ergebnisse als falschpositiv heraus, bei einem weiteren Patienten kann derzeitig keine Aussage getroffen werden. Als problematisch bei der Taqman-Analyse erwies sich teilweise die Verwendung von länger gelagerter DNA, wodurch vermutlich auch die erwähnten falschpositiven Ergebnisse verursacht wurden. Die minderwertige Qualität lange gelagerter DNA erschwert auch die Bestätigung einer Deletion mittels longrange PCR oder Southern Blot-Analyse. Erst durch eine neue Blutprobe konnte mittels der alternativen Methoden gezeigt werden, dass es sich bei den Taqman-PCR Analyseergebnissen an alter DNA bei zwei der drei Patienten um falschpositive Ergebnisse handelt. Grundsätzlich schließt dies aber nicht aus, dass Deletionen des gesamten Exons 3 bei Patienten mit NS vorkommen können. Zukünftig sollte ein größeres Kollektiv klinisch gut charakterisierter Patienten mit NS und ohne Punktmutationen in PTPN11 auf Deletionen des Exons 3 hin untersucht werden.

\subsection{Wirkung der Überaktivität des mutierten SHP2}

In der vorliegenden Arbeit wurde untersucht, welche Auswirkungen die Mutationen in PTPN11 auf die Aktivität von SHP2 ausüben. SHP2 beeinflusst je nach Bindungspartner und Interaktionen verschiedene Signalnetzwerke. Es hat eine positive Wirkung auf die Ras/MAPK-Kaskade [Saxton et al., 1997; Maroun et al., 2000; Shi et al., 2000; Cunnick et al., 2002], auf Kinasen der Src-Familie (SFK) [Zhang et al., 2004] sowie auf die IL-1/TNFabhängige NF-kB-Aktivierung [You M. et al., 2001]. Eine inhibierende Rolle spielt SHP2 beim Jak/STAT-Signalweg. SHP2 kann sowohl eine positive als auch eine negative Rolle in PI3K-Signalwegen nach der Aktivierung von Wachstumsfaktor-Rezeptoren [Wu et al., 2001; Zhang et al., 2002] spielen.

Der negativ regulierende Einfluß von SHP2 beim Jak/STAT-Signalweg wurde verwendet, um die Auswirkungen der PTPN11-Mutationen auf die Aktivität von SHP2 in vitro zu untersuchen. Ein Zielgen des Jak/STAT-Signalwegs ist SOCS-1. 
Bei einer erhöhten SHP2-Aktivität sollte die SOCS-1-Transkription gedrosselt werden. Mit Hilfe eines SOCS-1-Promotor-Luciferase-Reporterkonstrukts wurde die Aktivität von WTSHP2 und SHP2-Varianten nach Transfektion in NIH/3T3 gemessen. Untersucht wurden die Mutationen Y279C, S285F, N308D, T468M, T52I undP491L, von denen die ersten vier bekannte Mutationen sind, während die letzten beiden (T52I und P491L) neue Mutationen darstellen, die in der Göttinger Diagnostik für NS gefunden wurden. Für alle mutierten SHP2Konstrukte wurde eine Abnahme der SOCS-1-Expression gezeigt und dadurch die Überaktivität der mutierten SHP2-Varianten nachgewiesen.

Der STAT-Signalweg wird nach einer Bindung von vielen Wachstumsfaktoren, Zytokinen oder Hormonen an die jeweiligen Rezeptoren aktiviert. Durch die Verwendung von ILhaltigem Medium wurde dieser stimuliert. Dies lässt sich z.B. durch eine Zunahme der SOCS1-Promoter gesteuerten Luciferase-Expression zeigen. Da SHP2 die Expression von SOCS-1 negativ reguliert, wurde eine Abnahme der Luciferase-Aktivität durch die Kotransfektion mit WT-, N308D- und T468M-SHP2 auch unter stimulierenden Bedingungen beobachtet. Die Zunahme der Aktivität der SHP2-Varianten (wt. vs. mutiert) folgte demselben Schema, sowohl mit als auch ohne IL-haltigem Medium

\subsubsection{Allelspezifische Repression von mutierten PTPN11-Allelen}

Da die Mutationen in PTPN11 dominant über einen gain of function-Mechanismus wirken, wurde versucht, eine allelspezifische Inhibition einer N308D-Mutation, der häufigsten NSMutation, mit Hilfe von siRNA durchzuführen. Dazu wurden siRNA-Vektoren spezifisch für die WT-PTPN11-Sequenz als auch für die N308D-Mutation generiert. Zur Messung des Einflusses der siRNAs auf die Aktivität von SHP2 wurde wiederum der SOCS-1-LuciferaseAssay verwendet. Dabei konnte eine geringe Herunterregulierung der Überaktivität von N308D-SHP2 beobachtet werden (die Luciferase-Expression zeigt eine Zunahme). Jedoch ist diese Herunterregulierung nicht sequenzspezifisch, da sowohl die N308D-siRNA als auch die WT-siRNA die Überaktivität von N308D-SHP2 herunterregulieren. Eine Analyse der Sequenzumgebung durch siRNA-Suchprogramme zeigt, dass keine weiteren Optionen zur Platzierung einer siRNA bestehen

Um die Überaktivität der mutierten SHP2-Allele auf einem anderen Weg zu beeinflussen, ist es denkbar, einen spezifischen chemischen Inhibitor für mutiertes SHP2 zu entwickeln. Bislang wurden die Protein-Tyrosinkinase (PTK)- Inhibitoren, wie ZD1839 (Iressa), STI571 (Gleevec) und Erlotinib (Tarceva) [Traxler, 1997; Bishop et al., 2002; Wollina et al., 2003] 
als Krebstherapeutika entwickelt. Chemische Substanzen als PTP-Inhibitoren hatten bisher jedoch kaum Erfolg. Während PTKs eine hydrophobe Tasche in der ATP-Bindungsstelle aufweisen, die für die Entwicklung oraler Medikamente geeignet ist, besitzen die PTPs eine polare Phosphotyrosin-Bindungsstelle neben einer oberflächlichen PeptidsubstratBindungsstelle. Die bisherigen potenten und kompetitiven PTP-Inhibitoren haben daher verschiedene geladene Phosphotyrosin-Mimen inkorporiert, die zwar eine starke Bindung an die Phosphotyrosin-Bindungsstelle in den PTPs, jedoch nur eine begrenzte Zellpermeabilität zeigen und sich daher schlecht für die in vivo Anwendung eignen.

PTP1B (protein tyrosine phosphatase 1B) ist eine Nichtrezeptor Protein-Tyrosin Phosphatase (NRPTP) (4.2), die als Ziel für Medikamente gegen Diabetes II und Fettsucht verwendet wurde, da die PTP1B Knock-out-Maus einen niedrigen Zuckerspiegel zeigte und gegen eine durch fettreiche Ernährung bedingte Fettsucht geschützt wurde [Klaman et al., 2000; Zinker et al., 2002]. Die ersten entwickelten Inhibitoren gegen PTP1B waren aufgrund der Oxidation des aktiven Zentrums oder aufgrund von Aggregationseffekten wirkungslos [Bleasdale et al., 2001; McGovern et al., 2002]. Combs et al. [2005] konnten jedoch einen (S)-isothiazolidinone ((S)-IZD) heterozyklischen Phosphotyrosin-nachahmenden Inhibitor entwickeln. Nach der Analyse von kristallographischen Daten der PTP1B/InhibitorKomplexe, die in der Protein Data Bank (PDB) zur Verfügung stehen, wurden Isothiazodinone (IZD) als potenteste, kompetitive und reversible Inhibitoren getestet (Abb. 4.9). Dieser Inhibitor wurde ebenfalls gegen andere Phosphatasen, wie TCPTP (T cell protein tyrosine phosphatase), SHP1 und SHP2 verwendet, jedoch zeigte er nur bei TCPTP eine equipotente Wirkung mit PTP1B, da TCPTP eine 74\%ige Homologie zu PTP1B zeigt. TCPTP und PTP1B gehören zu der NT1-Subgruppe (4.1), wohingegen SHP1 und SHP2 zur NT2-Subgruppe gehören, sie werden daher nicht von diesem Inhibitor beeinflusst. Die Entwicklung der IZD für die Behandlung von Diabetes mellitus Typ II bietet eine neue Möglichkeit zur Entwicklung von neuen Tyrosin Phosphatase-Inhibitoren. Daher ist es sinnvoll, eine genaue kristallographische Analyse von SHP2 mit bzw. ohne Mutationen durchzuführen und dadurch die Entwicklung eines Inhibitors, der die Überaktivität von mutiertem SHP2 hemmen könnte, wie die Behandlung von NS zu fördern. 
A.

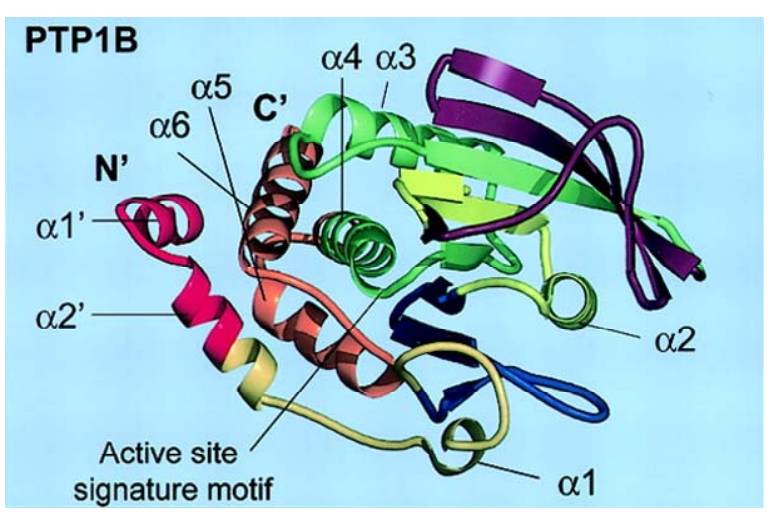

B.

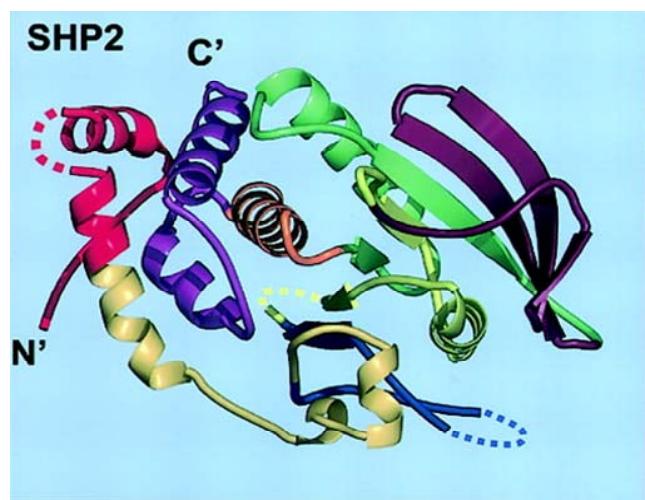

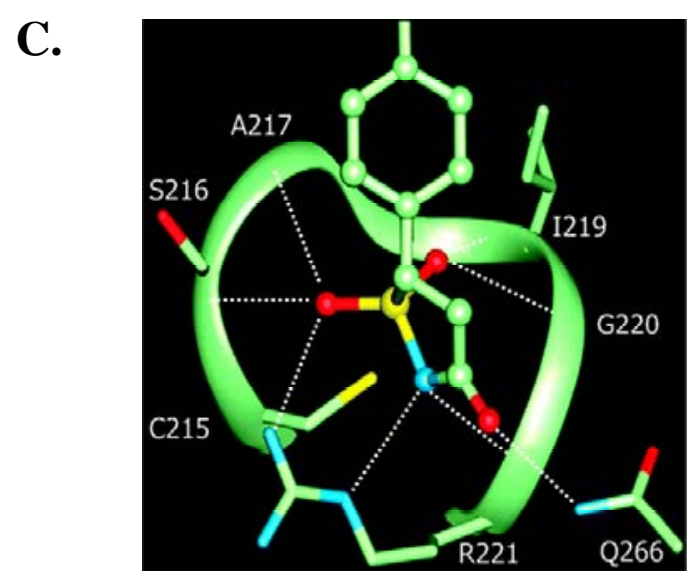

Abb. 4.9: Übersichtsdarstellung der kristallographischen Struktur von PTP1B (A.) und SHP2 (B.) [Andersen et al., 2004]. C.: kristallographische Struktur von PTP1B mit dem (S)-IZD Inhibitor, der in der Phosphatbindungsstelle von PTP1B gebunden ist [Combs et al., 2005].

\subsubsection{Biochemische Überaktivität von SHP2: Test für die Diagnostik}

Eine weitere Fragestellung war, ob die biochemische Überaktivität von SHP2 für die Diagnostik beim NS genutzt werden kann. Ein solcher Assay könnte sehr viel schneller, billiger und einfacher durchgeführt werden als eine PTPN11-Komplettsequenzierung. Daher wurde die Phosphatase-Aktivität von SHP2 in verschiedenen Zellextrakten von PatientenMaterialien mit Hilfe eines Malachit-Grün-Assays untersucht. Einerseits wurden als Kontrollen die rekombinanten SHP2-Proteine aus der in vitro Transkription/Translation (WTSHP2 und SHP2-Mutanten: T52I, Y279C, F285S, N308D, T468M und P491L) und andererseits Gesamtproteinextrakte sowohl aus frischen Lymphozyten-Präparationen als auch aus EBV-transformierten Lymphozyten untersucht. Bevor eine Messung durchgeführt wurde, wurde die Konzentration des Gesamprotein-Gehaltes bestimmt und die mögliche 
Kontamination von freiem Phosphat in jeder Probe geprüft, damit die verschiedenen Messungen untereinander verglichen werden können. Die rekombinanten SHP2-Proteine und die Gesamtproteinextrakte aus EBV-transformierten Lymphozyten enthielten jedoch freies Phosphat, was die Reaktionen störte und was nur durch aufwendige Dialyse entfernt werden konnte. Die Gesamtproteinextrakte aus frischen Lymphozyten-Präparationen (aus Blut) zeigten dagegen eine erhebliche Kontamination mit Hämoglobin, die die Bestimmung des Gesamtprotein-Gehalts störte. Daher wurde einerseits ein indirekter ELISA etabliert, um die SHP2-Proteinmenge zu bestimmen, und andererseits ein Enzym-Antigen-Assay erarbeitet, um die Phosphatase-Aktivität des SHP2 aus dem Patienten-Material zu messen. Der EnzymAntigen-Assay zeigte jedoch keine ausreichende Spezifität, da die Negativkontrolle (Coating mit nicht-SHP2-spezifischen Antikörpern) in etwa denselben Messwert wie das KontrollPatienten-Material (Kontroll-EBV-Lymphozyten) ergab. Trotzdem ist eine Tendenz zu erkennen. Die vier verschiedenen Kontroll-EBV-Lymphozyten (Co1, Co2, Co3 und Co4) zeigten in etwa denselben Messwert, wohingegen die mutierten EBV-Lymphozyten (NS+Y279C und NS+N308D) einen höheren, fast doppelt so hohen Messwert zeigten.

Die Messung der Phosphatase-Aktivität von SHP2 kann auch nach Immunpräzipitation von SHP2 durchgeführt werden. Tartaglia et al. [2003] und Fragalle et al. [2004] wiesen mit dieser Methode eine Erhöhung der Phosphatase-Aktivität bei drei NS-Mutationen (A72S, I282V und N308D) und bei zwei NS/JMML-Mutationen (D61G und E76K) in vitro nach. Die Autoren postulierten ein Model, das einen Zusammenhang zwischen Mutationen im PTPN11Gen und der daraus resultierenden unterschiedlich ausgeprägten Überaktivität von SHP2 und unterschiedlichen Phänotypen sieht. In diesem Modell gibt es drei verschieden abgestufte Ebenen der PTPN11-Mutationen. Mutiertes SHP2 aus NS-Patienten zeigt eine mäßige SHP2Überaktivität. Diese induziert Herzanomalien, Dysmorphien und Veränderungen der SkelettEntwicklung durch Wachstumsfaktor-Signale (z.B. EGF und FGF), ruft aber keine Veränderungen bei hämatopoetischen Zellen hervor. Die PTPN11-Mutationen bei JMML, ALL, AML und MDS wurden fast ausschließlich als somatische Mutationen gefunden und bewirken eine höhere SHP2-Überaktivität als NS-Mutationen. Es wird postuliert, dass diese Mutationen als Keimbahnmutationen bereits die Embryonalentwicklung so stark stören, dass sie bei lebend geborenen NS-Patienten nicht zu finden sind. Die Mutationen bei NS/JMML verursachen eine SHP2-Aktivität, die zwischen der von NS-Mutationen und den somatischen Leukämie-Mutationen liegt. 


\subsection{Transgenes Mausmodell für das Noonan-Syndrom}

Tiermodelle für genetische Krankheiten erlauben es, die Regulation und die Funktion des beteiligten Gens zu untersuchen und den Krankheitsmechanismus auf molekularer Ebene zu klären. Chemische Inhibitoren oder genetische Faktoren (siRNA, Gentherapie durch Substitution u.a.) können in therapeutischen Studien in transgenen Mäusen untersucht werden [Fan et al., 2002; Wang et al., 2003].

Zu Beginn dieser Arbeit existierte noch kein Mausmodell für NS/LS. Es sollte daher für drei mutierte Allele je eine transgene Mauslinie etabliert werden. Während für die Untersuchung von Erkrankungen, die durch einen loss of function Mechanismus entstehen, i.d.R Knock-out Mauslinien benötigt werden, sind für Erkrankungen mit einem gain of function transgene Linien gut geeignet [Yang et al., 1998 und 1999]

Da bisher unklar ist, ob nur mutiertes PTPN11 NS auslöst oder auch eine Überexpression von WT-PTPN11 NS-ähnliche Symptome induzieren kann, sollte auch eine transgene Maus mit Überexpression von WT-PTPN11(NS1) generiert werden. Beim NS-Mausmodell wurde die Mutation N308D(NS2) eingeführt, da diese die häufigste Mutation bei NS-Patienten darstellt. Für das LS-Mausmodell wurde die Mutation T468M(NS3) als typische LS-Mutation in PTPN11 eingeführt [Digilio et al., 2002]. Die Expression und Funktionalität der Konstrukte wurde in vitro vor der Injektion getestet (3.4.3 und 3.4.4). Die Integrationsstellen des Konstrukts im Genom und die Kopienzahl sind zufällig, können aber den resultierenden Phänotyp beeinflussen. Deswegen wurden diese Parameter durch quantitative PCR und Southern Blot-Analyse überprüft, und für weitere Untersuchungen wurden pro Konstrukt drei Linien ausgewählt, die jeweils eine niedrige, mittlere oder hohe Kopienzahl aufwiesen und nur einen Integrationsort zeigten (3.4.5).

Als nächstes wurde die Expression der transgenen cDNAs mittels RT-PCR geprüft. Da die Konstrukte aus humaner PTPN11-cDNA generiert wurden, konnte die Detektion des transgenen Konstrukts mit human-spezifischen Primern erfolgen (sowohl bei der Genotypisierung als auch bei der RT-PCR).

Die SHP2-Transgene besitzen einen cmyc-Tag, der auf DNA-Ebene 52 bp groß ist und auf Proteinebene ein Molekulargewicht von 0,7 kDa ausmacht. Dieser Protein-Tag sollte in vivo die Unterscheidung zwischen endogenem und transgenem SHP2 ermöglichen. Obwohl der cmyc-Tag in vitro getestet wurde, war die Expressionsanalyse des Transgens mittels WesternBlot in Mausgeweben nicht erfolgreich. Trotz stringenter Bedingungen wurden starke unspezifische Banden erhalten. Das transgene SHP2-Protein konnte nicht mit Hilfe eines 
SHP2-spezifischen Antikörpers detektiert werden, da der Unterschied im Molekulargewicht zwischen endogenem und transgenem SHP2 (68 kDa des endogenen und 68,7 kDa des transgenen SHP2) mit SDS-PAGE nicht auflösbar ist. Eine sichere Analyse der Proteinexpression bei den transgenen Linien ist daher nicht gelungen. Alternative cmycAntikörper, die zusätzlich gegen Proteinextrakte der Mauslinie FVB aufgereinigt werden, sollten allerdings in weiterführenden Analysen eine spezifische Identifizierung des transgenen Proteins ermöglichen. Außerdem wird die weitere phänotypische Analyse zeigen, ob die gezeigte RNA-Expression tatsächlich auch in Protein mündet. Dies ist insbesondere dann wahrscheinlich, wenn zwei unabhängige Linien mit nachgewiesener RNA-Expression den identischen Phänotyp zeigen.

Um einen Hinweis auf den Phänotyp der transgenen NS-Mäuse zu erhalten, wurden die Wurfgrößen und die Anzahl homozygoter transgener Tiere bestimmt. Während die Linien NS1, NS2\#40, NS3\#64 und NS3\#66 in der F1-Generation den Mendelschen Regeln (50\% T/und 50\% -/-) folgten, wurden bei NS2\#25 mehr WT-Tiere (-/-) als heterozygote Transgene (T/-) und bei NS3\#53 wurde nur ein einziges heterozygotes Tier geboren. In der F2Generation zeigte die Genotypisierung keiner Linie die Vererbung nach den Mendelschen Regeln (25\% T/T, 50\% T/- und 25\% -/-). Der Grund, dass weniger als 25\% T/T-Tiere erhalten wurden, könnte an der Transgenität der Mäuse liegen. Bei einer transgenen Maus, die eine starke Expression hat, wird möglicherweise eine embryonale Letalität oder ein früher Tod verursacht.

Als zweite Analyse für einen möglichen Phänotyp des transgenen Modells wurde eine makroskopische Untersuchung des Herzens durchgeführt. Es wurde eine leichte Vergrößerung des rechten Ventrikel bei NS2\#25 und NS2\#401 und eine leichte Vergrößerung des linken Ventrikels bei NS2\#402 beobachtet wurde. Trotz einer genaueren Untersuchung der Herzklappen konnte keine Veränderung festgestellt werden. Eine Begründung könnte die variable Expressivität von NS und LS sein [Allason et al., 1985; Bertola et al., 2004]. Zunkünftig sollte deswegen eine größere Zahl transgener Mäuse untersucht werden, um Herzanomalien ausschließen zu können.

Als Alternative für ein transgenes Mausmodell für NS könnte eine Knock-in Maus (Austausch des endogenen SHP2 durch ein mutiertes Allel durch homologe Rekombination) verwendet werden. Die Expression des Knock-in Gens unterliegt im Idealfall derselben Regulation wie das Wildtyp-Allel. Dieser Ansatz ist methodisch sehr viel aufwendiger, aber dem menschlichen Krankheitsgenotyp sehr viel näher. 
Im Verlauf dieser Arbeit wurde von Araki et al. [2004] eine Knock-in Maus mit der D61GMutation in PTPN11 publiziert. Die D61G-Mutation ist neben der oben beschriebenen N308D-Mutation eine der häufigeren Mutationen bei NS-Patienten. PTPN11 ${ }^{\text {D61G/D61G }}$-Tiere sind embryonal letal, wohingegen PTPN11 ${ }^{\text {D61G/+ }}$-Tiere lebensfähig sind. Bei der Verpaarung heterozygoter Tiere entspricht die Genotypverteilung der Nachkommen bei Geburt nicht den Mendelschen Regeln, wohingegen am Tag E11,5 PTPN11 ${ }^{\text {D61G/D61G_Embryonen in erwarteter }}$ Häufigkeit gefunden werden.

Es muss daher von einer embryonalen Lethalität bzw. erhöhten Absterberate für homo- bzw. heterozygote Tiere für die D61G-Mutation ausgegangen werden. Eine Analyse der Embryonen zeigte ödematöse, bluthaltige Leber-Nekrosen bei PTPN11 ${ }^{\text {D61G/D61G }}$-Tieren wohingegen bei PTPN11 ${ }^{\mathrm{D} 61 \mathrm{G} /{ }^{+}}$-Tiere leichte Leberschäden zu beobachten waren. Das Herz der PTPN11 ${ }^{\mathrm{D} 61 \mathrm{G} / \mathrm{D} 61 \mathrm{G}}$-Mäuse zeigte schwere Fehlbildungen, wie z.B. Atrium (ASD)-, Ventrikel-Septumdefekt (VSD), double-outlet right ventricle (DORV) und Dilatation des rechtsventrikulären Ausflusstraktes. Der Herzmuskel war verdünnt. Der Phänotyp bei den PTPN11 ${ }^{\mathrm{D} 61 \mathrm{G} /+}$-Herzen konnte in zwei Gruppen eingeteilt werden. Bei schwerwiegenden Fällen wurden auch bei PTPN11 ${ }^{\mathrm{D} 61 \mathrm{G} /+}$-Mäusen VSD, DORV und Vergrößerung der Klappenprimordia festgestellt, aber keine Verdünnung der Herzmuskulatur. Die anderen PTPN11 ${ }^{\mathrm{D} 61 \mathrm{G} /+}$-Mäuse zeigten eine Vergrößerung der Mitralklappe, hatten aber sonst ein normales Herz. Trotz der Herzanomalien bei den untersuchten Embryonen können auch normale Herzen bei den überlebenden Mäusen gefunden werden. Bei PTPN11 ${ }^{\mathrm{D} 61 \mathrm{G} /{ }^{+}}$-Mäusen wurde weiterhin die Statur und Gesichtsform untersucht. Wie bei NS-Patienten, zeigten PTPN11 ${ }^{\text {D61G/+ }}$-Mäuse eine dreieckige Gesichtsform und Minderwuchs. Fünf Monate alte PTPN11 ${ }^{\text {D61G/+ }}$-Mäuse entwickelten eine myeloproliferative Krankheit. Die PTPN11 Knock-in Maus (D61G) bietet daher ein erstes Mausmodell für die Analyse der Pathogenese von NS.

Bevor Mutationen im PTPN11-Gen als Ursache für NS entdeckt wurden, wurde SHP2 analysiert, um einerseits die biologische Funktion von SHP2 zu untersuchen [Saxton et al., 1997 und 2000] und andererseits die intrazellulären Signalwege zu charakterisieren, die das Zellwachstum and die Differenzierung vermitteln [Qu et al., 1997]. Die beiden Arbeitsgruppen stellten eine PTPN11 Knock-out Maus mit einer Deletion der Aminosäuren 46-110 (Exon 3) her und analysierten diese. Die homozygote SHP2 ${ }^{\triangle 46-110}$-Deletion war letal. Embryonen konnten zwischen E11,5 und E16,5 aufgrund der Resorption der gestorbenen Embryonen nicht analysiert werden. Am Tag E10,5 wurde eine nekrotische homozygote $\mathrm{SHP}^{\Delta 46-110}-$ Maus gefunden. Saxton et al. [1997] zeigten, dass SHP2 ${ }^{\triangle 46-110}$ dazu führt, dass die Zellen nicht vollständig MAPK als Antwort auf FGF (fibroblast growth factor) und PDGF 
(platelet derived growth factor) aktivieren können. SHP2 ist wichtig in der embryonalen Entwicklung und scheint eine Rolle während der Gastrulation in der Organisation der axialen Mesodermstrukturen und der posterioren Entwicklung zu spielen. Saxton et al. [2000] stellte dar, dass SHP2 aufgrund des Einflusses bei Zellform, Bewegung und Adhäsion eine Rolle während des Extremitätenwachstums spielt. Weiterhin konnte gezeigt werden, dass die Differenzierung der homozygoten $\mathrm{SHP}^{\Delta 46-110}$ ES (Embryonale Stamm)- Zellen zu erythroiden Vorläuferzellen vermindert und die Differenzierung zu myeloiden Zellen blockiert ist [Qu et al., 1997]. Die in vitro Messung der Phosphatase-Aktivität aus Proteinextrakten von homozygoten SHP2 ${ }^{\triangle 46-110}$-Mäuse und WT-Mäuse konnte eine Zunahme der Phosphatase-Aktivität der deletierten SHP2-Varianten darstellen. Nach den Ergebnissen bei der PTPN11 ${ }^{\text {D61G/D61G }}$ Knock-in und SHP2 ${ }^{\Delta 46-110}$ Knock-out Maus sollte der Phänotyp der NS1-, NS2- und NS3-transgenen Mäuse detaillierter untersucht werden können. Bei NS1 ist eventuell kein Phänotyp zu erwarten, da diese die WT-cDNA besitzen. Durch die Autoinhibition des SHP2-Moleküls wirkt sich die vermehrte Menge an Enzym nicht aus. Trotzdem wäre es möglich, dass die Überexpression aufgrund der Lokalisierung der Integration des Konstrukts oder der Zahl der Kopien einen leichten Phänotyp verursachen könnte. Der Phänotyp bei NS2 als auch bei NS3 hängt neben der Mutation auch von der Expressionsstärke und damit von der Lokalisierung der Integration des Konstrukts und/oder der Zahl der Kopien ab. Möglicherweise könnten auch homozygote Tiere einer Linie letal sein, unter der Annahme, dass eine zu starke Expression eines mutierten Allels zu embryonaler Letalität führt. Die embryonale Letalität bei den PTPN11 ${ }^{\text {D61G/D61G }}$ Knock-in Mäusen lässt dies möglich erscheinen.

Die heterozygoten transgenen Mäuse sollten Minderwuchs und eine Veränderung der Gesichtform und einige Herzanomalien zeigen. Bei NS3, dem LS-Mausmodell, könnten daneben zusätzlich Lentigines, Herzrhythmusstörungen, AV-Blockierungen und Taubheit erwartet werden.

\subsection{Ausblick}

Der Nachweis von Mutationen im PTPN11-Gen bei ca. 50\% der NS Patienten hat einen ersten Ansatz zum Verständnis der Pathogenese des Noonan-Syndroms ergeben. Es scheint gesichert, das eine enzymatische Überaktivität (bzw. Verlust der Autoinhibition) des SHP2Proteins zu einer Deregulation der nachgeordeneten Signalkaskaden führt. Diese Ergebnisse 
stehen aber erst am Beginn eines echten Verständnisses der Erkrankung und einer möglichen Therapie. Eine Reihe wichtiger Punkte müssen hierfür noch geklärt werden.

Es ist unklar, wie im Detail mutiertes SHP2 den NS-Phänotyp verursacht. Zwar sind Veränderungen bei der Ras/MAPK-Kaskade, beim Jak/STAT-Signalweg und/oder bei den PI3K-Signalwegen beschrieben, die letztendliche Verknüpfung zu den verschiedenen Symptomen fehlt aber noch. So sind auch noch die Bindungspartner von SHP2 nicht ausreichend untersucht und wohl auch nicht alle bekannt. Nach Koimmunpräzipitation sollten die Bindungspartner von SHP2, wie Gab1 [Cunnick et al., 2001; Fragale et al., 2004], Sprouty [Hanufasa et al., 2004] und Paxillin [Ren et al., 2004] untersucht werden, um die Regulierung der Signalwege besser zu verstehen. Weiterhin können andere Kandidaten, die NS verursachen, durch Bindungsstudien (yeast two-hybrid-screening) analysiert werden. Mittels Koimmunpräzipitation von SHP2 und 2D-Immunoblot aus Kontroll- und PatientenEBV-Lymphozyten könnte der Phosphorylierungsgrad von SHP2-Bindungspartnern mit Hilfe eines anti-Phosphotyrosin-Antikörpers analysiert und quantifiziert werden. Kontroll-EBVLymphozyten sollten einen stärkeren Phosphorylierungsgrad der Bindungspartner von SHP2 zeigen als EBV-Lymphozyten von NS-Patienten. Weiterhin könnte ein PhosphotyrosinProfiling-Array die verschiedenen Phosphorylierungsprofile zwischen Zellextrakt von Kontroll- und NS-Patienten-EBV-Lymphozyten näher aufschlüsseln. Die Proteine mit einem unterschiedlichen Profil könnten in vitro weiter analysiert werden. Die Ergebnisse von 2DImmunoblot oder Phosphotyrosin-Profiling-Array könnten mittels Western Blot-Analysen nach der Transfektion von WT-SHP2 und den mutierten SHP2-Varianten über Phosphotyrosin- und Protein-spezifische Antikörper bestätigt werden. Weiterhin wäre eine Untersuchung des Patienten-Materials auf diese identifizierten Proteine hin sinnvoll. Um die veränderte Gen-Expression durch mutiertes SHP2 zu identifizieren, könnte eine mit N308DSHP2 stabil transfizierte Zelllinie über einen cDNA-Array mit einer Kontroll-Zelllinie, die das WT-SHP2 exprimiert, verglichen werden. Mit Hilfe der hier beschriebenen Experimente könnte ein Einblick in die deregulierten Signalwege in NS-Patienten gewonnen und möglicherweise auch ein Grund für den gewebespezifischen Phänotyp gefunden werden.

Für all diese Arbeiten können auch die in dieser Arbeit in Angriff genommenen transgenen Tiermodelle und die publizierten Knock-in-Mäuse einen wertvollen Beitrag liefern.

Alle SHP2-Interaktionspartner oder Komponenten der nachfolgenden Signalketten sind Kandidatengene, die für ein Mutations-Screening bei NS-Patienten ohne PTPN11Mutationen in Frage kommen. 
Vor kurzem wurde Sprouty als mögliches Substrat von SHP2 endeckt [Hanafusa et al., 2004]. Sprouty wird vor allem während der embryonalen Entwicklung exprimiert und wirkt als Inhibitor in Ras/MAPK-Signalwegen. Nach der Aktivierung von Tyrosinkinase-Rezeptoren werden verschiedene Proteine phosphoryliert und aktiviert, wie z.B. SHP2 und Sprouty. Es wurde gezeigt, dass SHP2 Sprouty dephosphorylieren und damit inhibieren kann. Daher sollte die Interaktion zwischen SHP2 und Sprouty bestätigt und untersucht werden, ob Mutationen in Sprouty, die einen Verlust der Funktion zur Folge haben, dieselben Veränderungen im MAPK-Signalweg verursachen wie die Überaktivität von SHP2. Wenn SHP2 eine Überaktivität der Phosphatase hat, ist Sprouty inhibiert und kann den MAPK-Signalweg nicht inhibieren. Komplementär zu den gain of function-Mutationen in SHP2 kommen also loss of function-Mutationen im Sprouty-Gen als Ursache für ein NS in Frage kommen. Dies ist insbesondere ein attraktiver Ansatz, weil auch Familien mit einer rezessiven Vererbung des NS bekannt sind und rezessive Erkrankungen in der Regel auf loss of function-Mutationen beruhen. Gegebenenfalls könnte der biologische Effekt von Sprouty-Mutationen durch einen Transfektionsassay, analog zum oben beschriebenen SOCS-1/Luciferase-Assay untersucht werden. In diesem Fall könnte z.B. der AP1-Promoter benutzt werden, da dieser durch den MAPK-Signalweg, dem Target von Sprouty reguliert wird.

Neben der Annahme von weiteren Genen als Ursache der ungeklärten Formen des NS ist es prinzipiell auch möglich, dass das gesamte Spektrum der PTPN11-Mutationen noch nicht entdeckt wurde, d.h. dass doch noch aktivierende Promotormutationen oder -deletionen mit aktivierender Wirkung gefunden werden. Die in dieser Arbeit beschriebenen negativen Ergebnisse lassen aber vermuten, dass hierdurch, wenn überhaupt, nur ein kleiner Teil der bislang ungeklärten NS-Patienten sich klären lassen wird.

In der vorliegenden Arbeit wurde der PTPN11-Promotor untersucht und festgestellt, dass der Minimal-Promotor ca. 300 bp vor ATG liegt und Bindungsstellen von SP1, STAT und CREB enthält. Mittels Deletionspromotor-Luciferase-Konstrukte könnte die Regulation durch diese Transkriptionsfaktoren nachgewiesen werden. Weiterhin könnten ChIP (Chromatin immunpräzipitation) -Assays durchgeführt werden, die die Regulation in vivo beweisen könnten. Da sich der Phänotyp von NS nur auf spezifische Gewebe und Zellen, wie z.B. Herz und hämatopoetische Zellen auswirkt, könnte eine transgene Promotor-GFP-Maus die in vivoSituation zur Aktivierung von SHP2 detaillierter darstellen [Fukuda et al., 2003; Wang et al., 2005].

Im zweiten Teil der Arbeit wurde nach großen Deletionen im Exon 3 und 15 des PTPN11Gens gesucht, aber es konnte keine Deletion festgestellt werden. Eine Untersuchung von 
kleinen Deletionen wäre trotzdem sinnvoll, da zwei Fälle mit verschiedenen 3 bp-Deletionen in der Literatur beschrieben wurden.

Schließlich erscheint die Idee, den biochemischen Effekt der SHP2-Mutationen (nämlich die enzymatische Überaktivität) als diagnostisches Prinzip auszunutzen, nach wie vor attraktiv. Die Versuche mit dem relativ einfachen und direkten Malachit-Grün-Assay haben keine verwertbaren und reproduzierbaren Ergebnisse erbracht. Der Ansatz könnte weiter entwickelt werden, indem SHP2 aus dem Präparat durch Immunpräzipitation isoliert wird und die Phosphatase-Aktivitäten hierin gemessen werden. Möglicherweise können neuere Fluoreszenz-markierte Substrate eine verbesserte Sensitivität erreichen.

Im vierten Teil der Arbeit wurden transgene Mäuse generiert, die als Mausmodell für NS und LS dienen sollten. Bisher konnte gezeigt werden, dass jede Linie der verschiedenen Konstrukte (NS1, NS2 und NS3) eine Integration besitzt und jede Linie das Transgen exprimiert. Es sollte nun weiter analysiert werden, welchen Phänotyp die heterozygoten und homozygoten Mäuse in Bezug auf Herz, Größe, Skelett und mögliche hämatologische Veränderungen zeigen. 


\section{Zusammenfassung}

Im Rahmen der vorliegenden Arbeit wurden drei Aspekte zum Noonan-Gen untersucht. Im ersten Teil wurden Untersuchungen des PTPN11-Promotors durchgeführt und der PromotorBereich auf ca. 300 bp vor dem Translationsstartkodon ATG durch Computerprogramme und mit Hilfe eines Promotor-Luciferase-Assay eingegrenzt. SP1, CREB und STAT wurden als Transkriptionsfaktoren mittels EMSA identifiziert.

Im zweiten Teil der Arbeit wurde nach großen Deletionen in den Exons 3 und 15 im PTPN11Gen von Patienten, bei denen keine Mutation in der kodierenden Sequenz von PTPN11 gefunden wurde, gesucht. Mittels real time-PCR-Analyse wurden zwei Amplikons gescreent und die drei Patienten mit auffälligen Ergebnissen wurden detaillierter untersucht. Dazu wurden longrange PCR und Southern Blot-Analysen durchgeführt. Bei einem der Patienten konnten aufgrund der langen Lagerung und dadurch bedingter DNA-Degradierung weder eine longrange PCR noch eine Southern Blot-Analyse durchgeführt werden. Bei den anderen zwei Patienten konnte die Deletion weder über die longrange PCR noch über eine Southern BlotAnalyse an frischer DNA bestätigt werden.

Im dritten Teil der Arbeit wurden die Auswirkungen der Mutationen in PTPN11 auf die Aktivität von SHP2 ermittelt. Die Phosphatase-Aktivitäten von WT-SHP2 und der Varianten T52I-, Y279C-, F285S-, N308D-, T468M-, P491L-SHP2 wurden mit Hilfe eines SOCS-1Promotor-Luciferase-Konstrukts nach Transfektion in NIH/3T3-Zellen bestimmt. So konnte eine Überaktivität der mutierten SHP2-Varianten in einem biologischen System gezeigt werden.

Der Versuch einer allelspezifischen Repression der Aktivität von N308D-SHP2 mittels siRNA gelang nicht. Eine leichte Repression, die sich nachweisen ließ, war unspezifisch und beruht möglicherweise auf einem antisense Effekt.

Um die Überaktivität von SHP2 in NS-Patienten-Material zu untersuchen und so einen diagnostischen Test zu entwickeln, wurde die Aktivität von SHP2 mit Hilfe des MalachitGrün-Assays, indirektem ELISA oder Enzym-Antigen-Assays untersucht. Hier konnte kein robust reproduzierbarer Unterschied zwischen Patienten und Kontrollgewebe nachgewiesen werden.

Der vierte Teil der Arbeit befasste sich mit der Generierung eines transgenen Mausmodells für NS. Zunächst wurden drei Konstrukte zur Herstellung der transgenen WT-SHP2(NS1)-, N308D-SHP2(NS2)- und T468M-SHP2(NS3)-Mäuse kloniert. Vor der Injektion der 
transgenen NS1-, NS2 und NS3-Konstrukte in befruchtete Eizellen von FVB-Mäusen wurden die Expression und Funktionalität der Konstrukte in vitro getestet. Nach einer Kopienzahlbestimmung wurden jeweils drei Founder (hohe, mittlere und niedrige Kopienzahl) pro Konstrukt zur weiteren Verpaarung mit Wildtyp-FVB-Mäusen ausgewählt. Mittels Taqman- und Southern Blot-Analysen wurde die Zahl der Intergrationen untersucht und durch RT-PCR und Western Blot-Analyse die Expression analysiert. Um einen Hinweis auf den Phänotyp zu erhalten, wurden die Wurfgrößen und die Anzahl homozygoter transgener Tiere bestimmt. Weiterhin wurde eine makroskopische Untersuchung des Herzens durchgeführt, bei der eine leichte Vergrößerung des rechten Ventrikel bei NS2\#25 und NS2\#401 und eine leichte Vergrößerung des linken Ventrikels bei NS2\#402 beobachtet wurde. 


\section{Literaturverzeichnis}

Allanson J. E., Hall J. G., Hughes H. E., Preus M., Witt R. D. (1985). Noonan syndrome: the changing phenotype. Am. J. Med. Genet. 21:507-514.

Alonso A., Sasin J., Bottini N., Friedverg I., Friedberg I., Osterman A., Godzik A., Hunter T., Dixon J., Mustelin T. (2004). Protein tyrosine phosphatases in the human genome. Cell. 117:699-711.

Altschul S. F., Gish W., Miller W, Myers E. W., and Lipman D. J. (1990). Basic local alignment search tool. J Mol Biol. 215:403-410.

Andersen J. K., Mortensen O. H., Petes G. H., Frake P. G., Iversen L. F., Olsen O. H., Jansen P. G. Andersen H. S., Tonks N. S., Møller N. H. (2001). Structural and evolutionary relationships among protein tyrosine phosphatase domains. Mol Cell Biol. 21:7117-7136.

Andersen J. N., Jansen P. G., Echwald S. M., Mortensen O. H., Fukada T., Tonks R. K., Møller N. H. (2004). A genomic perspective on protein tyrosine phosphatases: gene structure, pseudogenes, and genetic disease linkage. FASEB. 18:8-30.

Aoki Y., Niihori T., Kawame H., Kurosawa K., Ohasi H., Tanaka Y., Filocamo M., Kato K., Suzuki Y., Kure S., Matsubara Y. (2005). Germline mutations in HRAS proto-oncogene cause Costello syndrome. Nat Genet. 37:1038-1040.

Araki T., Mohi M.G., Ismat F. A., Bronson R.T., Williams I. R., Kutok J. L., Yang W., Pao L. I., Gilliland D. G., Epstein J. A., Neel B. G. (2004). Mouse model of Noonan syndrome reveals cell type- and gene dosage- dependent defects of PTPN11 mutations. Nat Med. 8:849-857.

Ausubel F. M., Brent R., Kingston R. E., Moore D. D., Seidman J. G., Smith J. A., Struhl K. (1992). Current Protocols in Molecular Biology. John Wiley \& Sons, Inc., USA. 
Bernstein E., Caudy A. A., Hammond S. M., Hannon G. J. (2001). Role for a bidentate ribonuclease in the initiation step of RNA interference. Nature. 409:363-366.

Bertola D. R., Pereira A. C. de Oliveira P. S. L., Kim C. A., Krieger J. E. (2004). Clinical variability in a Noonan syndrome family with a new PTPN11 gene mutation. Am J Med Genet. 130:378-383.

Birnboim H. C., Doly J. (1979). A rapid alkaline extraction procedure for screening recombinant plasmid DNA. Nucl Acid Res. 7:1513-1523.

Bishop P. C., Myers T., Robey R., Fry D. W., Liu E. T., Blagosklonny M. V. Bates S. E. (2002). Differential sensitivity of cancer cells to inhibitors of the epidermal growth factors receptor familiy. Oncogene. 21:119-27.

Bleasdale J. E., Ogg D. Palazuk B. J., Jacob C. S., Swanson M. L., Wang X. Y., Thompson D. P., Conradi R. A., Mathews W. R., Laborde A. L., Stuchly C. W., Heiybel A., bergfahl K., Bannow C. A., Smith C. W., Svensson C., Liljebris C., Schostarez H. J., May P. D., Stvens F. C., Larsen S. D. (2001). Small molecule peptidomimetics containing a novel phosphotyrosine bioisostere inhibit protein tyrosine phosphatase $1 \mathrm{~b}$ and augment insulin action. Biochemistry. 40:5642-5654.

Boehm D., Herold S., Kuechler A., Liehr T., Laccone F. (2004). Rapid detection of subtelomeric deletion/duplication by novel real-time quantitative PCR using SYBR-Green dye. Hum Mutat. 23:368-378.

Bowman T., Garcia C., Turkson J., Jove R. (2000). STATs in oncogenesis. Oncogen. 19:2489-2495.

Bradford M. M. (1976). A rapid and sensitive method for the quantitation of microgram quantities of protein utilizing the principle of protein-dye binding. Anal Biochem. 72:248-254.

Brahmachari S. K., Sarkar P. S., Raghavan S., Narayan M., Maiti A. K., (1997). Polypurine/polyprymidine sequences as cis-act ing transcriptional regulators. Gene. 190:1726. 
Brinster R. L., Chen H. Y., Trumbauer M. E., Yaglr M. K., Palmiter, R. D. (1985). Factors affecting the efficiency of introducing foreign DNA into mice by microinjecting eggs. Proc Natl Acad Sci. 82:4438-4442.

Bruyns E., Mincheva A., Bruyns R. M., Kirchgessner H., Weitz S., Lichter P., Meuer S., Schraven B. (1996). Sequence, genomic organization and chormosomal localization of the human LPAP (PTPRCAP) and mouse CD45-AP/LSM-1 genes. Genomics. 38:79-83.

Butler J. E. F. and Kadonaga J. T. (2002). The RNA polyymerase II promoter: a key component in the regulation of gene expression. Genes Dev. 16:2583-2592.

Chatterjee-Kishore M., van der Akker F., Stark G. R. (2000). Associtation of STATs with relatives and friends. Trends Cell Biol. 10:106-111.

Chomczynski P., Sacchi N. (1987). Single-step method of RNA isolation by acid guanidinium thiocyanate-phenol-chloroform extraction. Anal Biochem. 162:156-159.

Chung T. D., Yu J. J., Kong T. A., Spiotto M. T., Lin J. M. (2000). Interleukin-6 activates phosphotidylonositol-3 kinase, which inhibits apoptosis in human prostate cancer cells. Prostate. 42:1-7.

Cogoni C., Macino G. (2000). Post-transcriptional gene silencing across kingdoms. Review. Curr Opin Genet Dev. 10:638-643.

Combs A. P., Yue E. W., Bower M., Wayland B., Douty B., Takvorian A., Polam P., Wasserman Z., Zhu W., Crawley M. L., Pruitt J., Sparks R., Glass B., Modi D., McLaughlin E., Bostrom L., Li M., Galya L., Blom K., Hillman M., Gonneville L., Reid B. G., Wei M., Becker-Pasha M., Klabe R., Huber R., Li Y., Hollis G., Burn T. C., Wynn R., Liu P., Metcalf B. (2005). Structure-based design and discovery of protein tyrosine phosphatase inhibitors incorporating novel isothiazolidinone heterocyclic phosphotyrosine mimetics. J Med Chem. 48:6544-6548. 
Cunnick J. M., Mei L., Doupnik C. A., Wu J. (2001). Phosphotyrosine 627 und 659 of Gab1 constitute a bisphosphoryl tyrosine-based activation motif (BTAM) conferring binding and activation of SHP2. J Bio Chem. 276:24380-24387.

Cunnick J.M., Meng S., Ren Y., Desponts C., Wang H.G., et al. (2002). Regulation of the mitogen-activated protein kinase signaling pathway by SHP2. J Bio Chem. 277:9498-9504.

Dent C. L., Smith M. D., Latchman D. S. (1993). The DNA mobility shift assay, in Latchman (Ed.) Transcriptional factors: A practical Approach, $2^{\text {nd }}$ Edition, Oxford Universitiy Press, Oxford, UL, 1999:1-5.

De Wet J. R., Wood K. V., Helinski D. R., Deluca M. (1986). Cloning firefly luciferase. Meth Enzymol. 133:3-14.

Digilio M. C., Conti E., Sarkozy A., Mingarelli R., Dottorini T., Marino B., Pizzuti A., Dalla piccola B (2002). Grouping of multiple-lentigines/LEOPARD and Noonan syndromes on the PTPN11 gene. Am J Hum Genet. 2:389-94.

Elbashir S. M., Harborth J., Lendeckel W., Yalcin A., Weber K., Tuschl T. (2001). Duplexes of 21-nucleotide RNAs mediate RNA interference in cultured mammalian cells. Nature. 411:494-498.

Endo T. A., Masuhara M., Yokouchi M., Suzuki R., Sakamoto H., Mitsui K., Matsumoto A., Tanimura S., Ohtsubo M., Misawa H., Miyazaki T., Leonor N., Taniguchi T., Fujita T., Kanakura Y., Komiya S., and Yoshimura A. (1997). A new protein containing an SH2 domain that inhibits JAK kinases. Nature. 387:921-924.

Erdmann J., Hassefeld S. Kallisch H., Fleck E., Regitz-Zagrosek V. (1998). Cloning and characterization of the 5'-flanking region of the human Cardiotrophin-1 gene. Biochem and Biophys Res Comm. 244:494-497.

Fan Q. W., Zhang C., Shikat K. M., Weiss W. A. (2002). Chemical genetic blockade of transformation reveals dependence on aberrant oncogenic signalling. Curr Biol. 12:13861394. 
Feinberg A. P., Vogelstein B. (1983). A technique for radiolabeling DNA restriction endonuclease fragments to high specific activity. Anal Biochem. 132:6-13.

Fentzke R. C., Korcarz C. E., Schroff S. G., Lin H., Leiden J. M., Lang R. M. (2001). The left ventricular stress-velocity relation in transgenic mice expressing a dominant negative CREB transgene in the heart. J Am Soc Echocardiogr. 14:209-218.

Fimia G. M., Morlon A., Macho B., De Cesare D., and Sassone-Corsi P. (2001). Transcriptional cascades during spermatogenesis: pivotal role of CREM and ACT. Mol Cel Endocrinol. 179:17-23.

Fragale A., Tartaglia M., Wu J., Gelb BD. (2004). Noonan syndrome-associated SHP2/PTPN11 mutants cause EGF-dependent prolonged Gab1 binding and sustained ERK2/MAPK1 activation. Hum Mutat. 23:267-77.

Fryer A.E., Holt P.J., Hughes H.E. (1991). The cardio-facio-cutaneous (CFC) syndrome and Noonan syndrome: Are they the same? Am J Med. 38:548-51.

Fukada T., Tonks N (2003). Identification of YB-1 as a regulator of PTP1B expression: implications for regulation of insulin and cytokine signaling. EMBO. 22:479-493.

Fukuda S., Kato F., Tozuka Y., Yamaguchi M., Miyamoto Y., Hisatsume T. (2003). Two distinct subpopulations of nestin-positive cells in adult mouse dentate gyrus. $J$ Neurosci. 23:9357-9366.

Fulton R., Van Ness B. (1993). Luminescent reporter gene assay for luciferase and betagalactosidase using a liquid scintillation counter. Biotechniques. 14:762-763.

Gershoni J. M., Palade G. E. (1982). Electrophoretic transfer of proteins from sodium dodecyl sulfate-polyacrylamide gels to a positively charged membrane filter. Anal Biochem. 124:396-405.

Gershoni J. M., Palade G. E. (1983). Protein blotting: principles and applications. Review.Anal Biochem. 131:1-15. 
Haan C., Hermanns H. M., Heinrich P. C., Behrmann, I. (2000). A single amino acid substitution (Trp (666)-->Ala) in the interbox1/2 region of theinterleukin-6 signal transducer gp130 abrogates binding of JAK1, and dominantly impairs signal transduction. Biochem J. 349:261-266.

Haan C., Heinrich P. C., Behrmann I. (2002). Structural requirements of the interleukin-6 signal transducer gp130 for its interaction with Janus kinase 1: the receptor is crucial for kinase activation. Biochem J. 361:105-111.

Hammond S. M., Boettcher S., Caudy A. A., Kobayashi R., Hannon G. J. (2001a). Argonaute2, a link between genetic and biochemical analyses of RNAi. Science. 293:11461150

Hammond S. M., Caudy A. A., Hannon G. J. (2001b). Post-transcriptional gene silencing by double-stranded RNA. Nature Rev Genet. 2:110-119.

Hanafusa H., Torii S., Yasunaga T., Matsumoto K., Nishida E. (2004). SHP2, an SH2containing Protein-tyrosine phosphatase positively regulates receptor tyrosine kinase signaling by dephosphorylating and inactivating the inhibitor Sprouty. J Biol Chem. 279:22992-22995.

Hanahan D. (1983). Studies of transformation of E. coli with plasmids. J Mol Biol. 166:557580.

Hannon G. J. (2002). RNA interference. Review. Nature. 418:244-251.

Heinrich P. C., Behrmann I., Müller-Newen G., Schaper F., Graeve L. (1998). Interleukin-6-type cytokine signalling through the gp130/Jak/STAT pathway. Biochem. J. 334:297-314.

Heinrich P. C., Behrmann, Haan S., Hermanns H. M., Müller-Newen I., Schaper, F. (2003). Principles of Interleukin (IL)-6-type cytokine signalling and its regulation. Biochem J. 374:1-20. 
Hemmann U., Gerhartz C., Heesel B., Sasse J., Kurapkat G., Grotzinger J., Wollmer A., Zhong Z., Darnell J. E. Jr., Graeve L., Heinrich P. C., Horn F. (1996). Differential activation of acute phase response factor/Stat3 and Stat1 via the cytoplasmic domain of the interleukin 6 signal transducer gp130. II. Src homology SH2 domains define the specificity of stat factor activation. J Biol Chem. 271:12999-13007.

Herrington J., Smith L. S., Schwartz J., Carter-Su C. (2000). The role of STAT proteins in growth hormone signaling. Oncogene. 19:2858-2597.

Hilton D. J., Richardson R. T., Alexander W. S., Viney E. M., Willson T. A., Sprigg N. S., Starr R., Nicholson S. E., Metcalf D., Nicola N. A. (1998). Twenty proteins containing a C-terminal SOCS box form five structural classes. Proc Natl Acad Sci USA. 95:114-119.

Hof P., Pluskey S., Dhe-Paganon S., Eck M. J., Schoelson S. E. (1998). Crystal structure of the tyrosine phosphatase SHP2. Cell. 92:441-450.

Hogan B., Beddington R., Costantini F., Lacy E (1986). Manipulating the mouse embryo: a laboratory manual. Cold Spring Harbour, NY, USA: Cold Spring Harbour Press.

Horvath C. M., Darnell J. E. (1997). The state of STATs: recent development in the study of signal transduction to the nucleus. Curr Opin Cell. Biol. 9:233-39.

Hutvagner G., Zamore P. D. (2002). RNAi: nature habors a double-strand. Curr Opin Genet Dev. 12:225-232.

Ion A., Tartaglia M., Song X., Kalidas K., Van der Burgt I. et al. (2002). Absence of PTPN11 mutations in 28 cases of cardiofaciocutaneous (CFC) syndrome. Hum Genet. 111:421-27.

Ishihara K., Hirano T. (2002). Molecular basis of the cell specifity of cytokine action. Biochim Biophys Acta. 1592:281-296. 
Jain V. K., Magrath I. T. (1991). A chemiluminescent assay for quantitation of betagalactosidase in the femtogram range: application to quantitation of beta-galactosidase in lacZ-transfected cells. Anal Biochem. 199:119-124.

Jamieson C. R., van der Burgt I., Brady A. F., van Reen M., Elsawi M. M., Hol F., Jeffery S., Patton M. A., Mariman E. (1994). Mapping a gene for Noonan syndrome to the long arm of chormosome 12. Nat Genet. 8:857-60.

Jin X., Yue S., Wells K. S., Singer V. L. (1994). SYBR Green I: a new fluorescent dye optimized for detection of picogram amounts of DNA in gels. Biophys J. 66:A159.

Kavamura M. I., Pomponi M. G., Zollino M. Leece R., Murdolo M. Brusoni D., Alchome M. M., Opitz J. M., Neri G. (2003). PTPN11 mutations are not responsible for the cardiofaciocutaneous (CFC) symndrome. Eur J Hum Genet. 11:64-68.

Kent J. W. (2002). BLAT - The BLAST-Like Alignment Tool. Genome Res. 12:656-664.

Klaman L. D., Boss O., Peroni O. D., Kim J. K., Martino J. L., Zabolotny J. M., Moghal N., Lubkin M., Kim Y. B., Sharep B. B. (2000). Increased energy expenditure, decreased adipositiy and tissue-specific insulin sensitivity in protein-tyrosine phosphatase 1b-deficient mice. Mol Cell Biol. 20:5479-5489.

Koga T., Suico M. A., Nakamura H., Taura M., Lu Z., Shuto T., Okiyoneda T., Kai H. (2005). Sp1 dependent regulation of Myeloid Elf-1 like factor in human epithelial cells. FEBS Letters 579:2811-2816.

Kosaki K., Suzuki T., Muroya K., Hasegawa T., Sato S., Matsuo N., Kosaki R., Nagai T., Hasegawa Y., Ogata T. (2002). PTPN11 (protein-tyrosine phosphatase, nonreceptor-type 11) mutations in seven Japanese patients with Noonan syndrome. J Clin Endocrinol Metab. 87:2539-33.

Laird P., Zijderwald A., Linders K., Rudnicki M. A., Jaenisch R., Berns A. (1991). Simplified mammalian DNA isolation procedure. Nucleic Acids Res. 19:4293. 
Lee I., Kim M. K., Choi E. Y., Mehl A., Jung K. C., Gil M. C., Rowe M., Park S. H. (2001). CD99 expression is positively regulated by SP1 and is negatively regulated by Epstein-Barr virus latent membrane protein 1 through nuclear factor- ${ }_{k} B$. Blood. 97:35963604.

Lee J. S., Tartaglia M., Gelb B. D., Fridrich K., Sachs S., Stratakis C. A., Muenke M., Robey P. G., Collins M. T., Slavotinek A. (2005). Phenotypic and genotypic characterisation of Noonan-like/multiple giant cell lesion syndrome. J Med Genet. 42: e11.

Lee W-H., Raas-Rotschild A., Miteva M. A., Bolasco G., Rein A., Gillis D., Vidaud D., Vidaud M., Villoutreix B. O., Parfait B. (2005). Noonan syndrome type I with PTPN11 3 bp deletion: structure-function implications. Proteins. 58:7-13.

Legius E., Schollen E., Matthijs G., Fryns J.P. (1998). Fine mapping of Noonan/cardiofacio cutaneous syndrome in a large family. Eur J Hum Genet. 6:32-37.

Leichtman L. G. (1996). Are cardio-facio-cutaneous syndrome and Noonan syndrome distinct? A case of CFC offspring of a mother with Noonan syndrome. Clin Dysmorphol. 5:61-64.

Lewin B. (2000). Genes. Oxford University press.

Lienhardt A., Garabedian M., Bai M., Sinding C., Zhang Z., Lagarde J. P., Boulesteix J., Rigaud M., Brown E. M., Kottler M. L. (2000). A large homozygous or heterozygous in-frame deletion within the calcium-sensing receptor's carboxyterminal cytoplasmatic tail that causes autosomal dominant hypocalcemia. A Clin Endocr Meteb. 85:1695-1702.

Loh E. Y., Elliott J. F., Cwirla S., Laniert L. L., Davis M. M. (1989). Polymerase chain reaction with single-sided specificity: analysis of $\mathrm{T}$ cell receptor delta chain. Science. 243:217-220. 
Loh M. L., Reynolds M. G., Vattikuti S., Gerbing R. B. Alonzo T.A., Carlson E., Cheng J. W., Lee C. M., Lange B. J., Meshinchi S; Children's Cancer Group. (2004). PTPN11 mutations in pedriatric patients with acute myeloid leukaemia: results from the Children's Cancer Group. Leukemia. 18:1831-1834.

Loh M. L., Martinelli S., Cordeddu V., Reynolds M. G., Vattikuti S., Vattikuti S., Lee C. M., Wulfert M., Germing U., Haas P., Niemeyer C., Beran M. E., Strom S., Lubbert M., Sorcini M., Estey E. H., Gattermann N., Tartaglia M. (2005). Acquired PTPN11 mutations occur rarely in adult patients with myelodysplastic syndromes and chronic myelomonocytic leukemia. Leukemia Res. 29:459-462.

Look D. C., Pelletier M. R., Tidwell R. M., Roswit W. T., Holtzman M. J. (1995). Stat1 depends on transcriptional synergy with SP1. J Bio Chem 270:30264-30267.

Mantamadiotis T., Lemberger T., Bleckmann S. C., Kern H., Kretz O., Martin Villalba A., Tronche F., Kellendonk C., Gau D., Kapfhammer J., Otto C., Schmid W., Schutz G. (2002). Disruption of CREB function in brain leads to neurodegeneration. Nat Genet. 1:4757.

Maroun C. R., Naujokas M. A., Holgado-Madruga M., Wong A. J., Park M. (2000). The tyrosine phosphatase SHP2 is required for sustained activation of extracellular signalregulated kinase and epithelial morphogenesis downstream form the met receptor tyrosine kinase. Mol Cell Biol. 20:8513-8525.

McGovern S. L., Caselli E., Grigorieff N., Shoichet B. K. (2002). A common mechanism underlying promiscuous inhibitors form virtual and high-throughput screening. J Med Chem. 45:1712-1722.

Morbach S., Tebbe S., Schneider E. (1993). The ATP-binding cassette (ABC) transporter for maltose/maltodectrins of Salmonella typhimurium. Characterization of the ATPase activity associated with the purified MalK subunit. J Biol Chem. 25:18617-18621 
Morrison T. B., Weis, J. J., Wittwer, C. T. (1998). Quantification of low-copy transcripts by continuous SYBR Green I monitoring during amplification. Biotechniques. 24:954-958, 960, 962.

Murakami M., Narazaki M., Hibi M., Yawata H., Yasukawa K., Hamaguchi M., Taga T., Kishimoto T. (1991). Critical cytoplasmic region of the interleukin 6 signal transducer gp130 is conserved in the cytokine receptor family. Proc Natl Acad Sci U S A. 88:1134911353.

Naka T., Narazaki M., Hirata M., Matsumoto T., Minamoto S., Aono A., Nishimoto N., Kajita T., Taga T., Yoshizaki K., Akira S., Kishimoto T. (1997). Structure and function of a new STAT-induced STAT inhibitor. Nature. 387:924-929.

Negoro S., Oh H., Tone E., Kunisada K., Fujio Y., Walsch K., Kishimoto T., YamauchiTakihara K (2000). Glycoprotein 130 regulates cardiac myocyte survival in doxorubicininduced apoptosis through phophatidylinositol 3-kinase/Akt phosphorylation and Bclxl/caspase-3 interaction. Circulation. 103:555-561.

Neri G., Zollino M. (1996). More on the Noonan-CFC-controversy. Am J Med Genet. 54:100.

Nicholson S. E., De Souza D., Fabri L. J., Corbin J., Willson T. A., Zhang J. G., Silva A., Asimakis M., Farley A., Nash A. D., Metcalf D., Hilton D. J., Nicola N. A., Baca M. (2000). Suppressor of cytokine signaling-3 preferentially binds to the SHP-2-binding site on the shared cytokine receptor subunit gp130. Proc Natl Acad Sci U S A. 97:6493-6498.

Noonan J. A., Ehmke, D. A. (1963). Associated noncardiac malformations in children with congenital heart disease. J Pediat. 63:468-470.

Olivier M., Hsiung C. A., Chuang L. M., Ho L. T., Ting C. T., Bustos V. I., Lee T. M., Witte A. Chen Y. I., Olshen R., Rodriguez B., Wen C. C. Cox D. R. (2004). Single nucleotide polymorphisms in protein tyrosine phosphatase $1 \beta$ (PTPN1) are associated with essencial hypertension and obesity. Hum Mol Genet. 13:1885-1892. 
Pellegrini S., Dusanter-Fourt I. (1997). The structure, regulation and function of the Janus kinases (JAKs) and the signal transducers and activators of transcription (STATs). Eur $J$ Biochem. 248:615-633.

Qu C. K., Shi Z. Q., Shen R., Tsai F. Y., Orkin S. H., Feng G. S. (1997). A deletion mutation in the SHP2-N domain of SHP2 severely suppresses hemaopoietic cell development. Mol Cell Biol. 17:5499-5507.

Ren Y., Meng S., Mei L., Zhao Z. J., Jove R., Wu J. (2004). Role of Gab1 and SHP2 in Paxillin tyrosine phosphorylation and Src activation in response to epidermal growth factor. $J$ Biol Chem. 279:8497-8505.

Saiki R. K., Gelfand D. H., Stoffel S., Scharf S. J., Higuchi R., Horn G. T., Mullis K. B., Erlich H. A. (1985). Primer-directed enzymatic amplification of DNA with a thermostable DNA polymerase. Science. 239:487-491.

Sambrook J., Fritsch E. F. and Maniatis T. (1989). Molecular cloning: a laboratory manual. 2. Auflage, Cold Spring Harbor, New York, USA.

Sanger F., Nicklen S., Coulson A. R. (1977). DNA sequencing with chain-terminating inhibitors. Proc Natl Acad Sci USA. 74:5463-5467.

Sasaki A., Yasukawa H., Suzuki A., Kamizono S., Syoda T., Kinjyo I., Sasaki M., Johnston J. A., and Yoshimura A. (1999). Cytokine-inducible SH2 protein-3 (CIS3/SOCS3) inhibits Janus tyrosine kinase by binding through the $\mathrm{N}$-terminal kinase inhibitory region as well as SH2 domain. Genes Cells. 4:339-351.

Saxton T. M., Henkemeyer M., Gasca S., Shen R., Rossi D. J., Shalaby F., Feng G. S., Pawson T. (1997). Abnormal mesoderm patterning in mouse embryos mutant for the SH2 tyrosine phosphatase SHP2. EMBO. 16:2352-2364.

Saxton T. M., Ciruna B. G., Holmyard D., Kulkarni S., Harpal K., Rossant J., Pawson T. (2000). The SH2 tyrosine phosphatase SHP2 is require for mammalian limb development. Nat Genet. 24:420-423. 
Scanga D. R., Schwinn D. A. (1998). Transcriptional regulation of alpha-1 adrenergic receptors. Front Biosc. 3:348-353.

Schlessinger J. (2000). Cell signalling by receptor tyrosine kinases. Cell. 103:211-255.

Schlüter G., Boinska D., et al. (2000). Evidence for translational repression of the SOCS-1 major open reading frame by an upstream open reading frame. Biochem Biophys Res Commun. 268:255-261.

Schlüter G., Rossius M., Wessel A., Zoll B. (2003). Das Noonan-Syndrom. Deutsches Ärtzeblatt. 100: 1192-1997.

Schmitz J., Dahmen H., Grimm C., Gendo C., Müller-Newen G., Heinrich P.C. Schaper F. (2000). The cytoplasmic tyrosine motifs in full-length glycoprotein 130 have different roles in IL-6 signal transduction. J Immunol. 164:848-854.

Schmitz J., Weissenbach M., Haan S., Heinrich P. C., Schaper F. (2000). SOCS3 exerts its inhibitory function on interleukin-6 signal transduction through the SHP2 recruitment site of gp130. J Biol Chem 275:12848-12856.

Senaldi G., Varnum B. C., Sarmiento U., Starnes C., Lile J., Scully S., Guo, J., Elliott G., McNinch J., Shaklee C. L., Freeman D., Manu F., Simonet W. S., Boone T., Chang M. S. (1999). Novel neurotrophin-1/B cell-stimulating factor-3: a cytokine of the IL-6 family. Proc Natl Acad Sci USA. 96:11458-11463.

Sharp P. A. (2001). RNA interference-2001. Genes Dev. 15:485-490.

Shi Z. Q., Yu D. H., Park M., Marshall M., Feng G. S. (2000). Molecular mechanism for the SHP2 tyrosine phosphatase function in promoting growth factor stimulation of ERK activity. Mol Cell Biol. 20:1526-1536.

Shi Y., Hsu J. H., Hu L., Gera J, Lichtensetin A. (2002). Signal pathways involved in activation of p70S6K and phosphorylation of 4E-BP1 following exposure of multiple myeloma tumor cells to interleukin-6. J Biol Chem. 277:15712-15720. 
Shuai K., Liu B. (2003). Regulation of JAK-STAT signalling in the immune system. Nat Rev Immunol. 3:900-911.

Singer V. L., Jin X., Ryan D., Yue S. (1994). SYBR Green dyes: ultrasensitive stains for detection of DNA and RNA in electrophoretic gels. Biomed Products. 19: 86-72.

Skarke C., Grosch S., Geisslinger G., Lotsch J. (2004). Single-step identification of all lenght polymorphism in the UGT1A1 gene promoter. Int J Clin Pharmacol Ther. 42:133-138.

Smale S. T. (2001). Core promoters: active contributors combinatorial gene regulation. Genes Dev. 15:2503-2508.

Southern E. M. (1975). Detection of specific sequences among DNA fragments separated by gel electrophoresis. J Mol Biol. 98:503-517.

Stahl N., Farruggella T. J., Boulton T. G., Zhong Z., Darnell J. E. Jr., Yancopoulos G. D. (1995). Choice of STATs and other substrates specified by modular tyrosine-based motifs in cytokine receptors. Science. 267:1349-1353.

Starr R., Willson T. A., Viney E. M., Murray L. J., Rayner J. R., Jenkins B. J., Gonda T. J., Alexander W. S., Metcalf D., Nicola N. A., Hilton D. J. (1997). A family of cytokineinducible inhibitors of signalling. Nature. 387:917-921.

Tanner J. W., Chen W., Young R. L., Longmore G. D., Shaw A. S. (1995). The conserved box 1 motif of cytokine receptors is required for association with JAK kinases. J Biol Chem. 270:6523-6530.

Tanuma N., Nakamura K., Kikuchi K. (1999). Distinct promoter control transmembrane and cytosolic protein tyrosine phoshpatase $\varepsilon$ expression during macrophage differentiation. Eur J Biochem. 259:36-53.

Tanuma N., Nakamura K., Shima H, Kikuchi K. (2000). Protein tyrosine phosphatase PTP\&C inhibits Jak. STAT signalling and differentiation induced by interleukin-6 and leukemia inhibitory factor in M1 leukemia cells. J Bio Chem. 275:28216-28221. 
Tanuma N., Nakamura K., Shima H. and Kikuchi K. (2001). Protein tyrosine phosphatase $\varepsilon C$ selectively inhibits interleukin-6-and interleukin-10-induced JAK-STAT signaling. Blood. 98:3030-3034.

Tartaglia M., Mehler E. L., Goldberg R., Zampino G., Brunner H. G. (2001). Mutations in PTPN11, encoding the protein tyrosine phosphatase SHP-2, cause Noonan syndrome. Nat Genet. 29:465-468.

Tartaglia M., Kalidas K., Shaw A., Song X., Musat D.L. (2002). PTPN11 mutations in Noonan syndrome: molecular spectrum, genotype-phenotype correlation, and phenotypic heterogeneity. Am J Hum Genet. 70:1555-1563.

Tartaglia M., Niemeyer C. M., Fragale A., Song X., Buechner J., Jung A., Hahlen K., Hasle H., Licht J. D., Gelb B. D. (2003). Somatic mutations in PTPN11 in juvenile myelomonocytic leukemia, myelodysplastic sydnormes and acute myeloid leukemia. Nat Genet 34:148-150.

Tartaglia M., Gelb B D. (2005). Noonan Syndrome and related disorders: genetics and pathogenesis. Annu Rev Genomics Hum Genet. 6:45-68.

Tartaglia M., Gelb B. D. (2005). Germ-line and somatic PTPN11 mutations in human disease. Eur J Med Genet. 48: 81-96.

Traxler P. M. (1997). Protein tyrosine inhibitors in cancer treatment. Expert Opin Ther Pat. 7:571-588.

Troger B., Kutsche K., Bolz H., Luttgen S., Gal A., Almassy Z., Caliebe A., Freisinger P., Hobbiebrunken E., Morlot M., Stefanova M., Streubel B., Wieczorek D., Meinecke P. (2003). No mutation in the gene for Noonan syndrome, PTPN11, in 18 patients with Costello syndrome. Am J Med Genet. 121:82-84.

Tuschl T. (2001). RNA Interference and Small Interfering RNAs. Chembiochem Europ $J$ Chem Biol. 2:239-245. 
Van der Burgt I., Brunner H. (2000). Genetic heterogeneity in Noonan syndrome: evidence for an autosomal recessive form. Am J Med Genet. 94:46-51.

Vogelstein B., Gillespie D. (1979). Preparative and analytical purification of DNA from agarose. Proc Natl Acad Sci USA. 76:615-619.

Wain H. M., Bruford E. A., Loverung R. C., Lush M. J., Wirght M. W., Povey S. (2002). Guidlines for human gene nomenclatur. Genomics. 79:464-470.

Wang H., Shimizu E., Tang Y. P., Chi M., Kyin M., Zuo W., Robonson D.A., Alaimo P. J. (2003). Inducible protein knockout reveals temporal requirement of CaMKII reactivation for memory consolidation in the brain. Proc Natl Acad Sci. 100:4287-4292.

Wang Y., Liu Y., Buhl K., Rowe D. W. (2005). Comparision of the action transient and continuous PTH on primary osteoclasts cultures expressing differentiation stage-specific GFP. J Bone Miner Res. 20:5-14.

Ward K. A., Moss C., Mckeown C. (1994). The cardio-facio-cutaneous syndrome: a manifestation of the Noonan syndrome? Br J Dermatol. 131:270-74.

Wieczorek D., Majewski F., Gillessenkaesbach G. (1997). Cardio-facio-cutaneous (CFC) syndrome-a distinct entity? Report of three patients demonstrating the diagnostic difficulties in delineation of CFC syndrome. Clin Genet. 52:37-46.

Wilhelm J. (2003). Inauguraldissertation: Entwicklung real-time-PCR basierter Methoden für die moderne DNA-Analytik. Justus-Liebig-Universität, Gießen. S.6.

Wollina U., Frenkl A., Knöll B., Hipler U. C. Wetzker R. (2003). Inhibition of signal transduction in EGF-dependent epithelial cell lines. Int J Mol Med. 12:673-677.

Wu C. J., O’Rourke D. M., Feng G. S., Johnson G. R., Wang Q., Greene M. I. (2001). The tyrosine phosphatase SHP2 is required for mediating phosphatidylinositol 3-kinase/Akt activation by growth factors. Oncogene. 20:6018-6025. 
Wu L., Kobayashi K., Sun T., Gao P., Liu J., Nakamura M., Weisberg E., Mukhopadhyay N. K., Griffin J. D. (2004). Cloning and functional characterization of the murine mastermind-like 1 (Maml1) gene. Gene. 328:153-165.

Yang Q., Sanbe A., Osinska H., Hewett T. E., Klevitsky R., Robbins J. (1998). A mouse model of myosin binding protein C human familial hypertrophic cardiomyopathy. J Clin Invest. 102:1292-1300.

Yang Q., Sanbe A., Osinska H., Hewett T. E., Klevitsky R., Robbins J. (1999). In vivo modeling of myosin binding protein $\mathrm{C}$ familial hypertrophic cardiomyopathy. Circ Res. 85:841-847.

Yasukawa H., Misawa H., Sakamoto H., Masuhara M., Sasaki A., Wakioka T., Ohtsuka S., Imaizumi T., Matsuda T., Ihle J. N., Yoshimura, A. (1999). The JAK-binding protein $\mathrm{JAB}$ inhibits Janus tyrosine kinase activity through binding in the activation loop. EMBO J. 18:1309-1320.

Yoshida R., Miyata M., Nagai T., Yamazaki T., Ogata T. (2004). A 3 bp Deletion Mutation of PTPN11 in an infant with severe Noonan syndrome including hydrops fetalis and juvenile myelomonocytic leukemia. Am J Med Genet. 128:63-66.

You M., Flick L. M., Yu D., Feng G. S. (2001). Modulation of the nuclear factor kappa B pathway by SHP2 tyrosine phosphatase in mediating the induction of interleukin (IL)-6 by IL1 or tumor necrosis factor. $J$ Exp Med. 193:101-10.

Zhang S. Q., Tsiaras W. G., Araki T., Wen G., Minichiello L. (2002). Receptor-specific regulation of phosphatidylinositol 3'-kinase activation by the protein tyrosine phosphatase SHP2. Mol Cell Biol. 22:4062-4072.

Zhang S. Q., Yang W., Kontaridis M. I., Bivona T. G., Wen G. (2004). SHP2 regulates SRC family kinase activity and Ras/Erk activation by controlling Csk recruitment. Mol Cell. 13:341-355. 
Zhou T., Chiang C. M. (2001). The intronless and TATA-less human TAF $\mathrm{F}_{\mathrm{II}} 55$ gene contains a functional initiator and a downstream promoter element. J Biol Chem 276:25503-25511.

Zinker B. A., Rondinone C. M., Trevillyan J. M., Gum R. J., Clampit J. E., Waring J. F., Xie N., Wilcox D., Jacobson P., Frost L., Kroeger P. E., Reilly R. M., Kotersi S., Opgenorth T. J., Ulrich R. G., Crosby S., Butler M., Murray S. F., McKay R. A., Bahnot S., Monia B. P., Jirousek M. R. (2002). PTP1B antisense oligonucleotide lowers ptp1b protein, normalizes blood glucose, and improves insulin sensitivity in diabetic mice. Proc Natl Acad Sci USA. 99:11357-11362. 


\section{Danksagungen}

Herrn Prof. Dr. W. Engel danke ich für die Betreuung meiner Arbeit, seine hilfreichen Anregungen und Vorschläge, sowie die gründliche Durchsicht meiner Manuskripte.

Frau PD Dr. S. Hoyer-Fender danke ich für die freundliche Übernahme des Korreferats.

Meinen Betreuern Herrn Dr. G. Schlüter und Herrn L. Wehner danke ich für die vielfältigen Anregungen, Diskussionen, Vorschläge und Hilfen, und natürlich für die Durchsicht und Korrektur meines Manuskriptes.

Besonders möchte ich mich bei Silke Kaulfuß bedanken, die immer eine weit über das kollegiale Verhältnis hinausgehende Hilfsbereitschaft gezeigt hat, mir mit Rat und Tat zur Seite stand, vor allem in der Phase des Zusammenschreibens, ebenso wie ihr Betreuer Herr PD Dr. P. Burfeind.

Dass meine Zeit im Humangenetischen Institut so angenehm war, ich viele schöne Momente erlebt habe und mich dort wohlfühlen konnte, verdanke ich vor allem Maren, Conny, Silke, Anna und Peter.

Für meine Eltern: Els hi dono les gràcies per l'ajuda i el suport que sempre m'han donat i els ànims per fer el pas a fer el Doctorat a Göttingen.

Bei meiner WG bedanke ich mich für die schöne Zeit neben der Arbeit.

Mein besonderer Dank gilt Simon Dubbert, der immer für mich da war und mich sehr unterstützt hat. 


\section{Lebenslauf}

Persönliche Daten: Roser Ufartes Mas

Geboren am 21. Januar 1979 in Barcelona

\section{Bildungsweg:}

1984-1993

1993-1997

1997-2002

2003
Besuch der Grundschule Monatgut in Vilafranca del Penedès

Besuch des Gymnasiums Eugeni d'Ors in Vilafranca del Penedès Biologiestudium an der Facultat de Biología de la Universitat de Barcelona in Barcelona

Experimentelle Arbeiten zur Dissertation am Institut für Humangenetik in Göttingen 